ZASPiL Nr. 47 - April 2007

Studies in Complement Control

Barbara Stiebels (ed.) 


\section{Preface}

This volume represents a collection of papers that present some of the results of two projects on control: on the one hand, the project Typology of complement control directed by Barbara Stiebels and funded by the German Research Foundation (DFG STI 151/2-2), and on the other hand the project Variation in control structures directed by Maria Polinsky and Eric Potsdam and funded by the US National Science Foundation (NSF grants BCS-0131946, BCS-0131993; website http://accent.ucsd.edu/). Whereas the first project pursued a lexical approach to control with a semantic definition of obligatory control, the second project has mainly pursued a syntactic approach to control - with special emphasis on less studied control structures (such as adjunct control, backward control, finite control, etc.). Both projects have aimed at extending the research on complement control to structures that differ from the prototypical cases of infinitival complements with empty subjects found in many Indo-European languages; their common interest was to bring in new empirical data, both primary and experimental.

Stiebels discusses the dual lexical-syntactic nature of complement control and proposes a semantic definition of obligatory control. She distinguishes between control-inducing vs. control-neutral structures of sentential complementation. On the basis of this distinction she divides SOA-argument-taking predicates into three major groups: inherent control predicates (showing control readings in all types of clausal complements), structural control predicates (showing control only with control-inducing structures) and non-control predicates. Her paper also includes a questionnaire on complement control in its appendix. The papers by Gamerschlag and Słodowicz are based on Stiebels' definition of control and the proposed classes of control predicates.

This volume includes two papers on control structures in Korean (by Gamerschlag and Polinsky). Gamerschlag gives a general overview of complement control in Korean; he shows that Korean mainly displays control-neutral structures (nominalized complements or finite complements with complementizer suffixes) with SOA-argument-taking predicates. He identifies a class of inherent control predicates (mainly directive predicates and implicative predicates like 'regret') and proposes a lexical-semantic account of the control readings. In addition, he shows that control readings may also be triggered by markers of sentence mood: Utterance predicates, which do not instantiate any control reading, may select a complement clause headed by the quotative suffix and marked in terms of declarative, imperative, volitional or propositive mood. Depending on the modal marker, the structure is coerced into a subject (volitional), object (imperative) or split control reading (propositive). 
Polinsky discusses in detail two alternative structures of Korean object control verbs with accusative objects. She shows that these two structures, which differ in word order, also have interpretative differences and are not derivationally related. Whereas the structure with the object controller preceding the embedded clause is an instance of obligatory control, the structure with the object controller following the embedded clause is an instance of non-obligatory control (in the usual syntactic sense).

Słodowicz provides an overview of complement control in Turkish, which almost exclusively displays nominalized clausal complements: those with possessor agreement and those without (='infinitival complements'). The latter show a strong, though not absolute tendency to behave like control-inducing structures. However, as Słodowicz shows, there are some mismatches between the matrix predicate's control properties (being an inherent or a non-control predicate) and the selected clausal complement: On the one hand, there are inherent control predicates that select possessor-marked nominalized clauses, which are control-neutral, on the other hand there are predicates without disposition for control that select the 'nominalized infinitive'.

Fukuda reconsiders the cross-linguistically common ambiguity of certain (aspectual) clause-embedding predicates as raising and control verbs. He argues that the potential ambiguity is not of a lexical nature but results from different positions in which the respective predicate is inserted: It is a raising predicate if it is inserted above $v \mathrm{P}$, thus scoping over the external argument, and it is a control predicate if it is inserted below $v \mathrm{P}$ and, hence, in the scope of the external argument. Fukuda extends his analysis to Indonesian 'want'-verbs, which are likewise ambiguous between control and raising. 


\section{Table of contents}

Barbara Stiebels (ZAS Berlin)

Towards a typology of complement control

Thomas Gamerschlag (Heinrich-Heine-Universität Düsseldorf)

Semantic and structural aspects of complement control in Korean

Szymon Stodowicz (Christan-Albrechts-Universität Kiel)

Complement control in Turkish

Shin Fukuda (University of California, San Diego)

On the control/raising ambiguity with aspectual verbs:

a structural account

Maria Polinsky (Harvard University)

Object control in Korean: Obligatory vs. non-obligatory control 


\section{Addresses of contributors}

\section{Shin Fukuda}

Department of Linguistics

UC San Diego

9500 Gilman Drive \#108

La Jolla, CA 92093-0108

USA

Email: fukuda@ling.ucsd.edu

\section{Thomas Gamerschlag}

Institut für Sprache und Information

Heinrich-Heine-Universität

Universitätsstr. 1

40225 Düsseldorf

Germany

Email: gamer@phil-fak.uni-duesseldorf.de

\section{Maria Polinsky}

Department of Linguistics

Harvard University

Boylston Hall, 3rd floor

Cambridge, MA 02138

USA

Email: polinsky@fas.harvard.edu

\section{Szymon Słodowicz}

Seminar für Allgemeine u. Vergleichende Sprachwissenschaft

Christian-Albrechts-Universität zu Kiel

Olshausenstraße 40

24098 Kiel

Germany

Email: slodowicz@linguistik.uni-kiel.de

\section{Barbara Stiebels}

Zentrum für Allgemeine Sprachwissenschaft (ZAS)

Schützenstr. 18

10117 Berlin

Germany

Email: stiebels@zas.gwz-berlin.de 


\section{Towards a typology of complement control}

\section{Barbara Stiebels}

ZAS Berlin

\section{Introduction*}

The analysis of complement control has been largely influenced by the properties of control structures in Indo-European languages, mainly Germanic and Romance languages. Complement control occurs with verbs that take a state of affairs (SOA) argument and in which identification of an argument of the matrix predicate with an argument of the embedded predicate takes place:

(1) a. John $n_{i}$ tried [ _ i to bake a cake].

b. Mary ${ }_{i}$ persuaded $\mathrm{John}_{\mathrm{j}}\left[{ }_{-}{ }^{\mathrm{j}} *_{\mathrm{i}}\right.$ to bake a cake $]$.

c. Mary ${ }_{i}$ promised $\mathrm{John}_{\mathrm{j}}\left[{ }_{-}{ }^{\mathrm{i} / *_{\mathrm{j}}}\right.$ to bake a cake $]$.

In (1a) and (1c) the subject of the matrix verb is identified with the covert subject of the embedded verb (subject control), whereas in (1b) the object of the matrix verb is identified with the covert subject (object control). The English examples suggest that, in general, the matrix argument is overt (the 'controller' in the following), whereas the relevant argument in the embedded clause is covert (the 'controllee' in the following, indicated by ' ','). The embedded predicate occurs in an infinite verb form, which does not show any agreement with the covert subject. From these data, the conclusion has been drawn that the typical instance of complement control obligatorily involves a covert argument in the complement clause; neither free nor bound pronouns are assumed to be possible, an assumption that led to the early analyses of 'Equi NP deletion' (Rosenbaum 1967). The gap in the complement clause regarding the controllee is generally attributed to the lack of projections that license the structural case of the respective argument or the failure of the embedded (infinite) predicate to assign that structural case.

Cross-linguistic research, however, has revealed that this picture is too simple. First of all, not all languages make use of infinite complement clauses (e.g. Chinese as an isolating language, Classical Nahuatl as a polysynthetic language). This, then, raises the question of whether complement control should be ruled out in these languages in principle. Secondly, not all languages leave the controllee covert; pronominal controllees are possible, as I will show below.

* The research on control verbs was funded by the German Science Foundation (STI 151/22). I would like to thank Ingo Feldhausen, Thomas Gamerschlag, Edmund Pohl, Szymon Słodowicz, and Dieter Wunderlich for helpful comments. 
Thirdly and related to the previous point, obligatory argument identification may also be required with finite SOA-arguments, which has already been pointed out by various linguists (see Landau 2004 and the references therein). And fourthly, deviating from the majority of languages and structures, the position of overt controller and covert controllee can be reversed: In structures of 'backward control' (Polinsky \& Potsdam 2002a), the controller is realized in the complement clause.

It is the aim of this paper to evaluate the various types of sentential complementation available in terms of complement control cross-linguistically . I will propose a lexical classification of control classes on the basis of the instantiated subordination patterns. I want to focus on an important distinction, namely that of structural vs. inherent control. Structural control is found with predicates that select a clausal complement whose structure requires argument identification and thus 'induces' control. Infinitival complements are prototypical cases for this kind of control because in most languages infinitival complements can only 'survive' in structures of control or raising. The interesting question is which predicates license structural control and which cross-linguistic differences emerge between potential licensors. Inherent control is found with predicates that require control readings independent of the instantiated structure of sentential complementation (e.g. a directive predicate such as zwingen 'force'). In addition, I will recapitulate and add arguments for the dual lexical-syntactic nature of complement control.

The paper is organized as follows: In section 2, I will give a brief summary of the properties of complement control, which then will allow to define obligatory control in section 3. Section 4 discusses the interplay of lexicon and syntax in complement control, highlighting the dominant role of syntax for the controllee and the dominant role of the lexicon for the controller. In section 5, I will illustrate the distinction of structures that I consider to require control and those that are neutral with respect to control. This distinction is relevant for the discussion of the various lexical classes of control predicates in section 6, which are defined on the basis of their control properties in dependence of the pattern of sentential complementation. Finally, in section 7, I will briefly discuss backward control and control in embedded questions. I add a general questionnaire on complement control in the appendix.

\section{Properties of complement control}

In order to define obligatory control (see section 3), it is necessary to consider the phenomena that may fall under complement control. In this section I will deal with variable control and control shift, the potential control readings (exhaustive vs. non-exhaustive), implicit control, and control in subject clauses. 


\subsection{Variable control and control shift}

The distinction of subject vs. object control is one of the earliest in the research on complement control. Predicates that have only one individual argument besides the SOA-argument only qualify for subject control. Polyadic predicates represent the interesting case because they may show either subject or object control. Many syntactic approaches (since Rosenbaum 1967) have assumed that polyvalent control verbs should exhibit object control (see Rosenbaum's Minimal Distance Principle or the Minimal Link Condition between controller and controllee used by Hornstein 1999); subject control verbs such as promise are considered to be highly marked exceptions, an assumption that ignores the systematicity of the class of commissive predicates such as promise.

Verbs with a causative semantic structure have been identified as the typical instances of object control predicates. Predicates that express a request or predicates that denote that the object referent is made responsible for something (e.g. ankreiden 'fault s.o.', anlasten 'blame', anzeigen 'bring charge against') are likewise object control predicates. Commissive predicates and verbs of communication with an implied addressee (e.g. verkünden 'announce') are typical subject control predicates. Besides the systematic control classes there are also more or less isolated predicates with a specific control reading (e.g. beneiden 'envy', object control).

Quite a number of verbs do not show a preference for subject or object control; they allow control with either argument, thus exhibiting 'variable control'. Typically, these are verbs of joint intentions/plans/ arrangements, e.g. vorschlagen 'propose'.

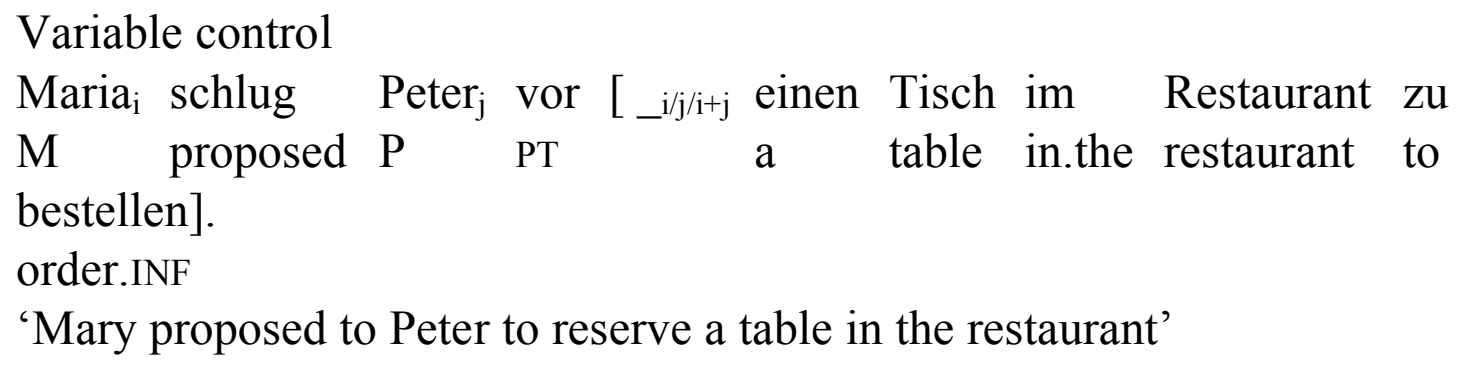

'Mary proposed to Peter to reserve a table in the restaurant'

Usually, the context triggers a preferred reading; but other markers may delimit the set of possible readings as well. The Chinese particle le has two uses (perfective marker and marker of 'currently relevant state', see Li \& Thompson 1981) that both reduce the potential readings of variable control predicates because they trigger a factive reading of the SOA-argument, which renders the subject the more plausible controller (see (3b/c)). 
(3)

Chinese (Yi-Chun Yang p.c.)

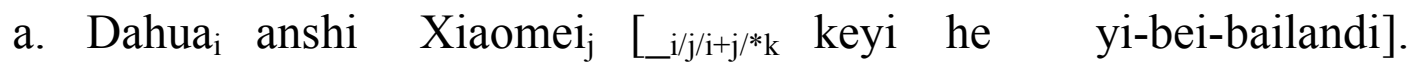
$\mathrm{D}$ signal $\mathrm{X}$ can drink one-CL-brandy

'Dahua signaled Xiaomei that he/she/they can drink a glass of brandy'

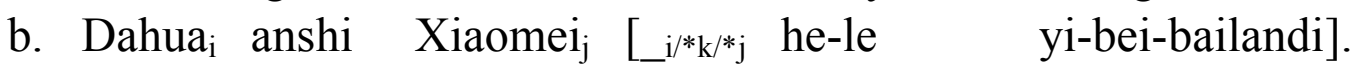
D signal $\mathrm{X}$ drink-PERF one-CL-brandy

'Dahua signaled Xiaomei that he has drunk a glass of brandy'

c. Dahua $a_{i}$ anshi Xiaomei $i_{j}\left[{ }_{i} / *^{*} / *_{j}\right.$ he yi-bei-bailandi le].

D signal $\mathrm{X}$ drink one-CL-brandy CRS

'Dahua signaled Xiaomei that he has drunk a glass of brandy'

Related to the phenomenon of variable control is the phenomenon of 'control shift' (Růžiččka 1983, 1999, Comrie 1984, 1985, Farkas 1988, Wegener 1989, Sag \& Pollard 1991, Panther 1993, Petter 1998): the controller of polyvalent control predicates shifts from subject to object control (e.g. with versprechen 'promise') or vice versa (e.g. bitten 'ask'). Unlike variable control, control shift is generally triggered in marked environments, i.e. the shift is typically induced by modal predicates such as 'be allowed', by passivization of the embedded verb or by the embedding of non-agentive, i.e. recipient-oriented verbs. In (4a) the shift from object to subject control is triggered by passive, in (4b) by the context which renders the subject referent the more likely candidate for control. In German the modal dürfen 'be allowed to' is the strongest trigger for control shift. (4c) shows that bitten 'ask' may shift, whereas this shift is not plausible for raten 'advise' (see (4d)).

(4) Control shift

a. Mary ${ }_{i}$ asked Peter ${ }_{j}\left[{ }_{i} \mathrm{i}\right.$ to be invited to the party].

b. The pupil ${ }_{i}$ asked the teacher ${ }_{j}\left[{ }_{-} \mathrm{i}\right.$ to leave early].

c. Maria $a_{i}$ bat Peter ${ }_{j}$ [_i zur Party gehen zu dürfen]. $\mathrm{M}$ asked $\mathrm{P}$ to.the party go.INF to be.allowed.INF 'Mary asked Peter to be allowed to go to the party'

d. ? Maria $_{\mathrm{i}}$ riet Peter $_{\mathrm{j}}\left[_{-} \mathrm{i} / \mathrm{j}\right.$ zur Party gehen zu $M$ advised $P$ to.the party go.INF to dürfen]. be.allowed.INF

'Mary advised Peter to be allowed to go to the party.'

The 'shift' is actually a shift on the syntactic surface; in semantic terms, the controller does not shift: Farkas (1988), Sag \& Pollard (1991), Pollard \& Sag (1994) and Jackendoff \& Culicover (2003) have assumed a semantic coercion of the embedded predicate such that it is enriched with a causative-like component. The controller is identified with the implicit causer of the coerced predicate. Let me show this with a control shift in directive verbs based on the trigger dürfen. 
These predicates have the simplified representation in (5a), ignoring potential non-exhaustive readings. The embedded predicate $\mathrm{P}$ may be extended as in (5b). Semantic composition will then yield (5c).
a. $\lambda \mathrm{P} \lambda \mathrm{y} \lambda \mathrm{x} \mathrm{V}(\mathrm{x}, \mathrm{y}, \mathrm{P}(\mathrm{y}))$
b. $\lambda \mathrm{u} P(\mathrm{u}) \rightarrow \lambda v \exists \mathrm{u}$ ALLOW $(\mathrm{v}, \mathrm{u}, \mathrm{P}(\mathrm{u}))$
c. $\lambda P \quad \lambda y \lambda x \exists u$ V(x,y,ALLOW $(y, u, P(u)))$ with $u=x$

That P's highest argument $\mathrm{u}$ is identified with $\mathrm{x}$ and not projected independently yields a reading in which $\mathrm{x}$ benefits from the situation denoted by the embedded predicate.

The availability of control shift is language-specific, as has been already pointed out by Růžička (1983) and Comrie $(1984,1985) .{ }^{1}$ Germanic languages seem to be more prone to control shift than other languages. That English displays less control shift than German has been observed by Comrie (1985) and studied by Panther (1993), who tested several control predicates with native speakers of English and German and found out that German control predicates are more likely to shift than their English equivalents. Słodowicz (2006) has shown that control shift is not available in Polish.

Since control shift seems to depend on the sketched implicit coercion mechanisms, languages that avoid these implicit operations are expected to avoid control shift as well.

\subsection{Control readings}

Orthogonally to the simple contrast of subject vs. object control, other dimensions of control relations have to be taken into account. Whereas in the simple case, controller and controllee overlap completely in terms of their reference (= 'exhaustive control'), other control readings occur as well, namely 'split control' and 'partial control'. Split control occurs if the two individual arguments of a polyvalent matrix predicate jointly control the controllee, which is indicated by '+':

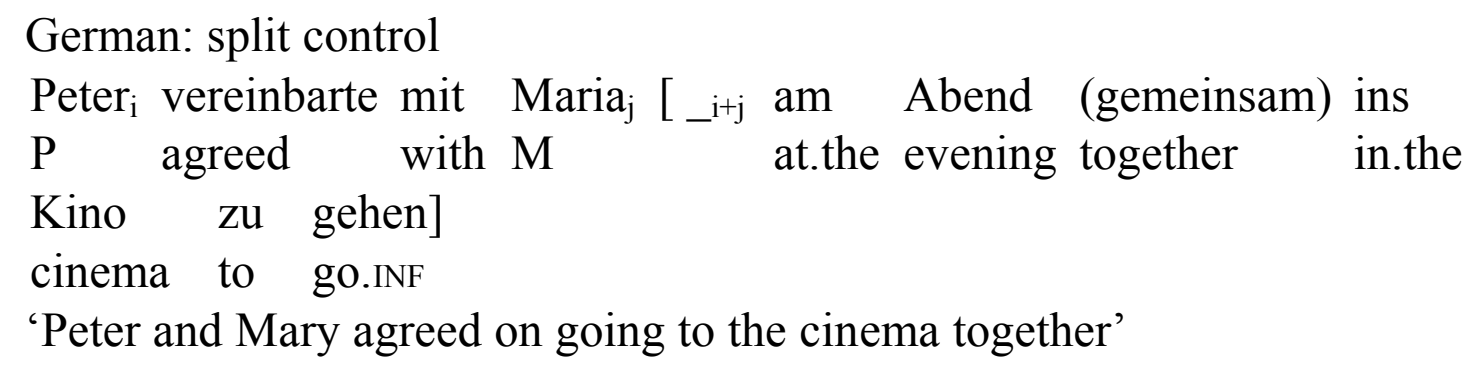

1 There are even control predicates that require a control shift context. The German verb ver-hindern 'prevent', derived from the object control verb hindern 'prevent s.o. from', can only take an infinitival complement with a control shift context that renders the subject referent a possible controller; the internal argument present in hindern is no longer available in verhindern. 
Predicates that denote a cooperative behavior typically allow split control, but other predicates may do as well, especially if modifiers such as together support the split control reading. In general, split control is not the only reading available with the respective matrix predicate, although it may be the preferred reading. In Mandarin Chinese (Yi-Chun Yang p.c.) there are some predicates that obligatorily require split control, namely bang(mang) 'help', qing 'invite', yao 'invite/ask' and yue 'ask'.

(7) Chinese: obligatory split control (Yi-Chun Yang p.c.)

a. Dahua ${ }_{\mathrm{i}}$ yue $\mathrm{Xiaomei}_{\mathrm{j}}\left[{ }_{-}{ }^{\mathrm{i}+\mathrm{j} / *_{\mathrm{k}}}\right.$ zai tushuguan $\mathrm{kan}$ shu]. $\mathrm{D}$ ask $\mathrm{X}$ at library see book 'Dahua asked Xiaomei to study together with him in the library.'

b. * Dahua $a_{i}$ yue Xiaomei ${ }_{j} L_{j}$ lai $\mathrm{ta}_{\mathrm{i}}$ jia $]$. $\mathrm{D}$ ask $\mathrm{X}$ come 3SG home

'Dahua asked Xiaomei to come to his home.'

Another control pattern, which has been put into focus by Landau (2000), is the so-called 'partial control', in which the controllee refers to an entity that includes the referent of an argument of the matrix verb and a further participant $(i+v)$ not included in the referents of the arguments of the matrix predicate. As the examples in (8) show, the admissibility of partial control is a lexical property of the matrix verb: manage excludes it, want allows it. According to Landau (2000) factive, propositional, desiderative, and interrogative predicates allow partial control in English.

(8e) Partial control

a. ${ }^{*} J_{o h n} n_{i}$ managed [ _ _ ${ }^{i+v}$ to meet at six].

b. John ${ }_{i}$ wanted [ _ ${ }^{i+v}$ to meet at six] .

Partial control involves a semantic plural in the controllee, which is enforced by the embedding of a collective predicate. Split control, in contrast, involves a syntactic plural in the controllee, as has been pointed out by Landau (2000). Collective predicates typically come in two patterns: they either select a plural subject (they meet at six) or a comitative structure (John met with Mary). In order to test the availability of partial control, one has to look for collective predicates that do not allow the comitative NP/DP to remain implicit; otherwise, the test for the complex reference of the controllee $(\mathrm{i}+\mathrm{v})$ fails to be conclusive. Partial control is less common in German than in English. The German correspondences of meet and gather (sich treffen and sich versammeln) are inherently reflexive verbs. Since German reflexives bear phi-features (person and number), feature clashes, as triggered by the partial control reading, are not tolerated by many speakers. The German equivalent of (8b) is not really acceptable: A sentence with the third person reflexive, which is underspecified in terms of num- 
ber, is already hardly acceptable (see (9a)); in case of a person/number clash as in $(9 b)$ it is completely ungrammatical.

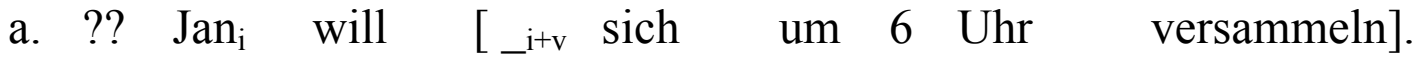 John wants 3.REFL at 6 o'clock gather.INF 'John wants to gather at six'.
b. * Ich will ${ }_{-}$mich/uns/sich um $6 \mathrm{Uhr}$ I want 1SG.REFL/1PL.REFL/3.REFL at 6 o'clock versammeln]. gather.INF

The class of German predicates that allow partial control seems to be restricted to propositional attitude predicates such as befürworten 'approve', ablehnen 'decline', dagegen/dafür sein 'to be against/for it'. The common interpretation of (10a) and similar examples is that the subject referent of the embedded predicate includes the subject referent of the matrix predicates and other referents. A reading with the exclusion of the matrix subject referent is not available, as is demonstrated in (10b): If the embedded object pronoun is interpreted as coreferential with the controller, the controllee must have a partial reading; a generic reading (indicated as 'gen') is impossible.

(10) German

a. Die $\mathrm{IHK}_{\mathrm{i}}$ befürwortet, $\left[\mathrm{i}_{\mathrm{i}+\mathrm{v}}\right.$ an den Standorten im Osten the board.of.trade approves at the locations in.the east Deutschlands Lehrstellen zu schaffen]. [IDS-corpus] Germany.GEN apprentice.position to create.INF 'The board of Trade approves of creating new positions for apprentices in East Germany'

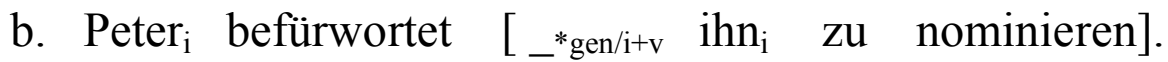
$\mathrm{P}$ approves him to nominate.INF

'Peter approves of nominating him'

Whereas ablehnen may occur with exhaustive control readings, befürworten and dagegen/dafür sein preferentially occur with partial control readings. Usually, there are hardly any predicates that are restricted to a partial control reading. According to Yang (p.c.), Chinese shandong 'abet' is a predicate that requires partial control readings. In Polish and Turkish (Słodowicz 2006, this volume), partial control is not available. ${ }^{2}$

As already mentioned in the context of (10b), 'generic control' represents a further reading - besides 'arbitrary control', both of which are sometimes not

2 Although Słodowicz (this volume) excludes partial control for Turkish, propositional attitude predicates, similiar to those discussed for German, seem to be potential candidates for partial control. This, however, has to be checked systematically. 
clearly distinguished. I will distinguish these two notions: Generic control is control by a generically understood argument, whereas arbitrary control is the label for non-control; the referent of the controllee must be determined otherwise. I will return to these notions in the context of implicit control (2.3) and control in subject clauses (2.4).

Generally, exhaustive control readings allow a simple semantic analysis, e.g. the single abstraction over multiple occurrences of a variable in the Semantic Form (SF) of the control predicate, as shown in (11a) for an intransitive subject control predicate and in (11b) for a transitive object control predicate.

(11) Representation of exhaustive control

a. $\lambda \mathrm{P} \lambda \mathrm{x} \lambda \mathrm{s} \mathrm{V}(\mathrm{x}, \mathrm{P}(\mathrm{x}))(\mathrm{s})$

b. $\lambda \mathrm{P} \lambda \mathrm{y} \lambda \mathrm{x} \lambda \mathrm{s} \mathrm{V}(\mathrm{x}, \mathrm{y}, \mathrm{P}(\mathrm{y}))(\mathrm{s})$

In all the other cases, additional mechanisms are required. In case of nonexhaustive control I will make use of the following representation, in which the controllee is represented as the variable z. Argument identification between $\mathrm{z}$ and the controller is subject to further interpretational mechanisms.

(12) Representation of non-exhaustive control ${ }^{3}$

a. $\lambda \mathrm{P} \lambda \mathrm{x} \lambda \mathrm{s} \mathrm{V}(\mathrm{x}, \lambda z \mathrm{P}(\mathrm{z}))(\mathrm{s})$

b. $\lambda \mathrm{P} \lambda \mathrm{y} \lambda \mathrm{x} \lambda \mathrm{s} \mathrm{V}(\mathrm{x}, \mathrm{y}, \lambda \mathrm{z} \mathrm{P}(\mathrm{z}))(\mathrm{s})$

\subsection{Implicit control}

Another aspect that has to be considered is the fact that the controller does not necessarily have to be overt; in some cases it can remain implicit. Generally, the

3 Note that the representation in (12) suggests an analysis of control complements as properties, not as propositions. The issue whether control predicates embed properties (e.g. Chierchia 1983, 1985, Dowty 1985, Asudeh 2005) or propositions (e.g. Higginbotham 1992, Landau 2000, 2004, most syntacticians) has not been settled yet because there is no completely conclusive evidence for either case. Both groups mainly argue on the basis of syntactic arguments (propositional analyses: e.g. the syntactic integration of PRO, finite control; property analysis: sloppy identity under ellipsis). The basic assumption seems to be that all control complements either have to be properties or propositions, not regarding the alternative that some predicates presumably select a proposition (e.g. factive predicates) and some a property (e.g. predicates like get used to etc., which select for event types, not event tokens). I would like to argue that the issue has to be decided on semantic grounds, testing the compatibility of sentence adverbs such as probably with infinitival complements, which, for instance, are grammatical with SOAarguments of factive predicates:

(i) weil sie bedauert, wahrscheinlich eine Fehlentscheidung getroffen zu haben. because she regrets probably a wrong.decision made to have 'because she regrets to have made a wrong decision' 
control relation is not affected if the potential controller is left implicit (see $(13 \mathrm{a} / \mathrm{b})$ ). However, some predicates show a control shift if the potential controller argument is left implicit, as Jackendoff \& Culicover (2003) have shown for $\operatorname{ask}($ see $(13 \mathrm{c} / \mathrm{d}))$.

(13) a. $\mathrm{John}_{\mathrm{i}}$ shouted to $\operatorname{Sally}_{\mathrm{j}}\left[{ }_{-} \mathrm{j}^{*}\right.$ i to take care of herself. $]$

b. John $\mathrm{J}_{\mathrm{i}}$ just shouted [ $\__{\mathrm{j}} / *_{\mathrm{i}}$ to look out for him $\left.\mathrm{h}_{\mathrm{i}}\right]$.

c. $\mathrm{John}_{\mathrm{i}}$ asked Sally $\mathrm{j}_{\mathrm{j}}\left[{ }_{\mathrm{j}} *_{\mathrm{i}}\right.$ to take care of herself $\left.\mathrm{f}_{\mathrm{j}}\right]$.

d. $\mathrm{John}_{\mathrm{i}}$ asked [ _ i $_{\mathrm{i}}$ to take care of himself $\left.\mathrm{i} / * \mathrm{him}_{\mathrm{i}}\right]$.

Jackendoff \& Culicover attribute the difference between these two verbs to the admissibility of a 'bring about coercion', which is compatible with ask, but not with shout.

There are even cases of obligatory implicit control. The German particle verb an-ordnen 'order' does not allow the addressee of the order to be mentioned explicitly. However, the implicit argument obligatorily controls the controllee. ${ }^{4}$

(14) Obligatorily implicit control

$\mathrm{Sie}_{\mathrm{i}}$ ordnete $\left(*\right.$ den Mitarbeitern $\left._{\mathrm{j}}\right)$ an, $\mathrm{L}_{\mathrm{j}}$ die Eingangstüren um she ordered the.DAT employees PT the entrance.doors at 20 Uhr zu schließen].

8 o'clock to close.INF

'she ordered (her employees) to close the entrance doors at 8 p.m.'

Implicit control has often been mistaken as generic or arbitrary control (see also Landau 2000). Superficially, (15a) seems to involve arbitrary control, i.e. noncontrol (indicated by the index 'arb') due to the lack of a controller. (15b), however, reveals that the predicate has an implicit controller that may surface as PP.
a. Es ist leicht [_arb das Fahrrad-fahren zu er-lernen]. it is easy the bicycle-ride.INF to PX-learn.INF 'it is easy to learn to ride a bike'

b. Es ist leicht für Kinder ${ }_{i}$, [_i das Fahrrad-fahren zu er-lernen]. it is easy for children the bicycle-ride.INF to PX-learn.INF 'it is easy for children to learn to ride a bike'

Therefore, (15a) has to be interpreted as to involve an implicit generic controller (i.e. Es ist leicht_ _j=gen [_ _das Fahrradfahren zu erlernen $]$ ).

Another pattern of implicit control can be found with passivized control predicates in German and other languages, in which the external argument is existentially bound and not realized. Since German has impersonal passives, subject control verbs can be passivized, as shown in (16a). Subject control verbs

4 The nominalized form Anordn-ung allows the controller to be realized within an oblique phrase (headed by the preposition an 'at'). 
with an overt internal argument (e.g. versprechen 'promise') show a specific behavior when they are passivized: they have to undergo a control shift (compare $(16 \mathrm{~b} / \mathrm{c}))$. This is not necessary if the internal argument is left implicit as in (16d).

(16) a. Es wurde versucht, $\left[{ }_{-}\right.$das Auto $\mathrm{zu}$ reparieren $]$.
it we car to repair.INF

'it was tried to repair the car'

b. ?? $\mathrm{Ihm}_{\mathrm{i}}$ wurde versprochen, [_ _ das Auto $\mathrm{zu}$ reparieren]. he.DAT was promised the car to repair.INF

lit. 'he was promised to repair the car'

c. $\mathrm{Ihm}_{\mathrm{i}}$ wurde versprochen [_ $\mathrm{i}$ das Auto reparieren $\mathrm{zu}$

he.DAT was promised the car repair.INF to

dürfen].

be.allowed.INF

'he was promised to be allowed to repair the car'

d. Es wurde versprochen, [ _ das Auto zu reparieren].

it was promised the car to repair.INF

'it was promised to repair the car'

Since the patterns of implicit control do not differ from those of overt control, there is no reason to exclude implicit control from the core domain of complement control.

\subsection{Control in subject clauses}

Control readings also occur in case of SOA-'subjects'. ${ }^{5}$ Many linguists who have dealt with control in subject clauses (e.g. Williams 1980, Manzini 1983) have assumed that there is no true control in subject clauses, which, however, is false as a general claim. One can find predicates that impose a control reading on a SOA-subject. Typically, these are predicates of Belletti \& Rizzi's (1988) preoccupare-class or Levin's (1993) amuse-class, which denote the causation of an experience, hence, exhibit an internal experiencer argument; the higher SOAargument denotes the stimulus. As $(17 \mathrm{a} / \mathrm{b})$ show, thrill requires its internal argument to be identified with the controllee in the subject clause, independent of the position of the subject clause.

5 There are two possibilities to define SOA-arguments as subjects: a) Pronominalization of the SOA-Argument yields the typical subject properties, e.g. 'subject case'. b) Alternatively, a SOA-argument that is the highest argument in the argument structure - apart from the referential event argument - is analyzed as subject (= logical subject). I will use the latter criterion. 
(17) Control in subject clauses

a. [ ${ }_{-} \mathrm{i} /{ }^{*} \mathrm{j}$ to win the prize] would thrill $\mathrm{me}_{\mathrm{i}}$.

b. It would thrill $\mathrm{me}_{\mathrm{i}}\left[{ }_{-} \mathrm{i} / \mathrm{j}_{\mathrm{j}}\right.$ to win the prize $]$.

The same applies to German ärgern 'annoy, make angry'. Its internal argument must control the covert subject of the subject clause, shown in (18a). It is not possible to interpret the controllee generically, as shown in (18b). ${ }^{6}$

a. [ _ i bei der Stellen-planung nicht berücksichtigt worden zu sein] at the job-planning not consider.PTC AUX.PTC to be.INF ärgert Peter ${ }_{\mathrm{i}}$. annoy.3SG not 'it annoys Peter not to have been considered in the staff planning'

b. * [ _arb=gen die Wände mit Graffiti zu besprühen] ärgert Peter. the walls with graffiti to spray.INF annoy.3SG $\mathrm{P}$ intended reading: 'it annoys Peter that people spray graffiti on the walls'

In general terms, these predicates have the simplified Semantic Form in (19): Regarding the experiencer argument $\mathrm{x}$, the SOA-stimulus argument is both higher - in terms of CAUSE - and lower - in terms of the EXPERIENCE-relation.

$$
\lambda x \lambda p \operatorname{CAUSE}(p, \operatorname{EXPERIENCE}(x, p))
$$

That the SOA-argument is lower than the experiencer argument in terms of the EXPERIENCE relation may explain the unexpected obligatory control because this is the semantic structure found with SOA-objects. So far, no systematic studies have been carried out to exhaustively determine the class of predicates that show obligatory control in subject clauses.

\section{The notion of obligatory control}

An important prerequisite for the analysis of complement control is the characterization of obligatory vs. non-obligatory control. Generally, different mechanisms are assumed for these two types of control. One can observe the general tendency to analyze obligatory control as control proper, whereas non-obligatory control is resorted to 'elsewhere strategies'. The various definitions take control relations as well as structural properties into account. There are different notions of obligatory control in the literature, depending on the perspective taken by the authors. The most influential characterization has been provided by Williams

6 Generic readings can be either induced by a generic controller or by a generic interpretation in case of arbitrary control, especially if there is no indication that the infinitival clause refers to a specific event as in [_arb=gen smoking in the presence of babies $\left._{\mathrm{i}}\right]$ is dangerous for them . $_{\mathrm{i}}$ 
(1980); his rather strict characterization of obligatory control has been taken over by most syntacticians:

(20) Williams' (1980:211f.) characterization of obligatory control

a. A lexical NP cannot replace PRO.

b. The controller must c-command the controlled structure.

c. The controller must precede the controlled structure.

d. The controller must be thematically or grammatically unique.

e. The controller must be overt.

In general, obligatory control encompasses structures in which control is exhaustive and invariant and the controller is overt; moreover, the controllee must be covert. Thus, Williams excludes partial and split control as well as variable and implicit control from the notion of obligatory control. In addition, subject clauses are exempted from exhibiting obligatory control because the controller cannot c-command the controlled structure. Note that Williams' precedence requirement cannot be maintained; it is not even valid in English. The conditions in (20) do not apply in non-obligatory control.

Hornstein (1999) adds the following properties to the characterization of obligatory control: a) the controller must be local (i.e. an argument of the matrix predicate), b) the controllee (PRO) receives a sloppy reading under ellipsis of the verb complement as in (21), and c) the controllee receives a de se interpretation.

(21) $\mathrm{John}_{\mathrm{i}}$ expects [ _ $\mathrm{i}$ to win $]$ and Bill $\mathrm{j}_{\mathrm{j}}$ does too. (= expects [ ${ }_{\mathrm{j}}$ to win $\left.]\right)$

Hornstein, who aims at a unification of control and raising in terms of syntactic movement, needs this rather strict notion of obligatory control because he wants to reduce obligatory control to structures that can be conceived of as movement of the control argument in various $\theta$-positions. All non-exhaustive control readings could not be accounted for, i.e. could not be derived under standard assumptions of movement. For all cases of non-obligatory control Hornstein assumes pro in the position of the controllee. This analysis, however, fails to explain the lack of disjoint readings in the relevant examples: partial or split control cannot be replaced by non-control readings. ${ }^{7}$

Jackendoff \& Culicover (2003) deviate from the dichotomy of obligatory/non-obligatory control. They distinguish between free, nearly free and

7 Hornstein's approach has been extensively criticized (Culicover \& Jackendoff 2001, Jackendoff \& Culicover 2003, Landau 2003, Kiss 2005). An argument that I would like to add is the following: The unification of raising and control under movement is not plausible for German; here, raising verbs show obligatory clause union, whereas control verbs only optionally allow clause union. Some control verbs do not allow clause union at all. A movement approach would predict that there should not be such structural differences. 
unique (= obligatory) control: In contrast to unique control, free and nearly free control allow generic and split control. Free control includes non-local control and control by discourse or speech act participants, which is not allowed in nearly free control.

Landau (2000) analyzes all instances of local control as obligatory control, thus including partial and split as well as implicit control. I will follow his notion of obligatory control as local control and define complement control as follows:

(22) Definition of obligatory control (OC)

OC applies to structures in which a predicate $\mathrm{P}_{1}$ selects an SOA-argument and requires one of its (individual) arguments to be (improperly) included in the set of referents of an argument of the embedded predicate $\mathrm{P}_{2}$ heading the SOA-argument.

$\left[\mathbf{X}_{\mathrm{i}} \mathbf{P}_{1}\left(\mathbf{Y}_{\mathrm{j}}\right)\left[\mathbf{Z}_{\mathrm{k}} \mathbf{P}_{2} \ldots\right]_{\text {SOA }}\right]$ with $\mathrm{k} \cap\{\mathrm{i}, \mathrm{j}\} \neq \varnothing$

The controllee $\mathrm{Z}$ may have $\mathrm{X}$ or $\mathrm{Y}$ as its controller - with the referential indices $i, j, i+j, i+v, j+v$ or $i+j+v$. The definition in (22) is open as to how the control reading is obtained: either structurally or semantically/lexically. A verb like hoffen 'hope' requires a control reading with an infinitival complement; this, however, is not necessary with a finite complement. Therefore, (23a) is a case of structural control, i.e. control is induced by the structure of the clausal complement. I will discuss this more thoroughly in section 5. A predicate like ermutigen 'encourage' invariantly requires a control reading, being, thus, a predicate of inherent control. There is a strong preference for infinitival complements; the finite complement is hardly acceptable. In any case, the only possible reading is a control reading, as indicated in (23d). Nominalized complements, which are not barred from realizing all arguments within the PP (Peters Teilnahme am Rennen 'Peter's participation in the race'), likewise only admit control readings, as shown in (23e).

(23) German: structural vs. lexical/inherent control

a. Maria ${ }_{i}$ hofft, [ $\__{i}{ }^{*}{ }_{j}$ im Lotto $\mathrm{zu}$ gewinnen].

Mary hopes in.the lottery to win.INF

'Mary hopes to win in the lottery'

b. Maria hofft, [daß ihr Sohn im Lotto gewinnt].

Mary hopes that her son in.the lottery wins

'Mary hopes that her son will win in the lottery'

c. Maria ${ }_{i}$ ermutigt ihren $\operatorname{Sohn}_{j}\left[{ }_{-}{ }^{\prime} *_{i} / *_{k}\right.$ am Rennen teilzunehmen]. Mary encourages her son at.the race participate.INF

'Mary encourages her son to participate in the race' 
d. ?? $M^{2}$ aria $a_{i}$ ermutigt ihren $\operatorname{Sohn}_{\mathrm{j}}(\mathrm{da}-\mathrm{zu})\left[\mathrm{da} ß \mathrm{er}_{\mathrm{j} / * \mathrm{k}}\right.$ am Rennen Mary encourages her son there-to that he at.the race teilnimmt]. participates 'Mary encourages her son to participate in the race'

e. Maria $a_{i}$ ermutigt ihren $\operatorname{Sohn}_{j}$ [zur ${ }_{-j}{ }^{j / *_{i} / *_{k}}$ Teilnahme am Mary encourages her son to.the participation at.the Rennen]. race

'Mary encourages her son to participate in the race'

Another, though far less common pattern of instantiating a control reading can be found in Korean (see Gamerschlag, this volume). Here, utterance predicates select a finite clause marked by the complementizer suffix $-k o$. This suffix does not block modal markers on the embedded predicate. With a complement in the declarative mood, the utterance predicate does not restrict the reading of the embedded subject, as shown in (24a). Certain modal markers, however, only allow control readings. The volitional marker, for instance, only allows subject control readings, as indicated in $(24 b)$.

(24) Korean: control reading induced by modal marker

(Gamerschlag, this volume)

a. Chelswu-nun ${ }_{i}$ Yenghi-eykey $_{j}\left[{ }_{-}{ }_{j} / i_{i k}\right.$ caknyen-ey safari-yehayng-ul C.-TOP Y.-DAT last.year-in safari-trip-ACC hay-ss-ta-ko] malhay-ss-ta. do-PAST-DECL-COMP say-PAST-DECL

'Chelswu told Yenghi that he/she/s.o. did a safari trip last year'

b. Chelswu-nun ${ }_{i}$ Yenghi-eykey ${ }_{j}\left[{ }_{-}{ }^{i} *_{j} / *_{k}\right.$ naynyen-ey safari-yehayng-ul C.-TOP Y.-DAT next.year-in safari-trip-ACC ha-keyss-ta-ko] malhay-ss-ta. do-VOL-DECL-COMP say-PAST-DECL

'Chelswu told Yenghi that he wants to go on a safari next year'

The control reading is determined by aspects of semantic compatibility between the matrix predicate and the modalized embedded predicate.

The definition in (22) does not preclude pronominal controllees (as long as their reference is restricted in the indicated sense) - either as free or bound pronouns, as illustrated in (25) for bound pronouns in the Mayan language Jakaltek and in the Oceanic language Mangap-Mbula. 
(25)

a. Jakaltek (Grinevald Craig 1977:312)

xc-ach w-iptze [ $\quad$ ha-munlayi $]$

ASP-2.N 1.E-force 2.E-work

'I forced you to work'

b. Mangap-Mbula (Bugenhagen 1995:273)

$\begin{array}{llll}\text { ay-manga }\left[{ }_{-} \text {be }\right. & \text { an-po } & \text { ruumu }] \\ \text { 1sG-stand.up NONFACT } & \text { 1SG-tie } & \text { house } \\ \text { 'I started to build the house' } & & \end{array}$

Likewise, (22) does not exclude control into subject clauses. This semantic definition enhances cross-linguistic comparison of complement control. It aims at two goals: a) to determine the structures that induce local control ('controlinducing structures'), and $b$ ) to determine the class of predicates that invariantly require control independent of the instantiated subordination structure ('inherent control'). In languages such as German or English, in which many SOAA-taking predicates may select a control-inducing structure, there is a big class of predicates that exhibit control only in control-inducing structures.

\section{Syntax vs. lexicon}

Complement control underlies an intricate interaction of lexicon and syntax. Whereas some approaches have emphasized the syntactic nature of complement control (e.g. Rosenbaum 1967, Williams 1980, Manzini 1983, Hornstein 1999), others have focused on the semantic influence of the various control predicates on the actual control relation (e.g. Comrie 1984, 1985, Foley \& van Valin 1984, Farkas 1988, Panther 1993, van Valin 1993, Růžička 1999, Jackendoff \& Culicover 2003). The interesting question is to which extent complement control is determined by syntax and to which extent by the lexical properties of the predicates involved. Cross-linguistic data suggest that in the unmarked case, the controller is determined by semantic/lexical properties of the control predicate, whereas the selection of the controllee is determined by syntax. In the marked case, however, the controller may be determined by syntax and the lexicon may influence the selection of the controllee. Both scenarios are sketched in (26).

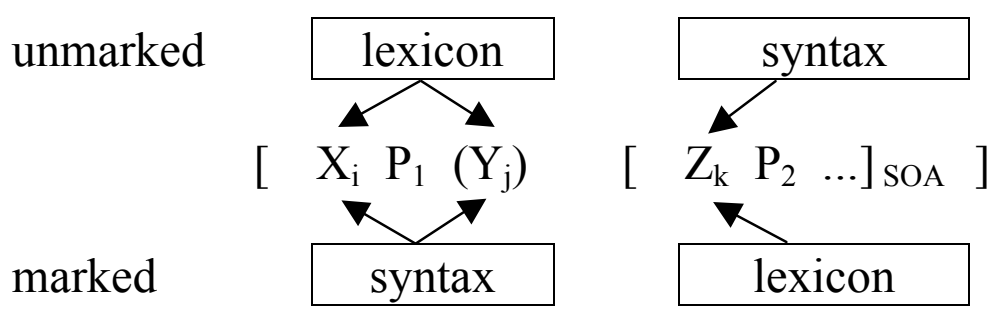

The lexical nature of complement control is already evident in view of the fact that the potential control readings (exhaustive/partial/split control; subject vs. 
object control) are a specific property of the respective predicate or its lexical class. Likewise, the admissibility of control shift is lexically determined: only a subclass of the control predicates may license control shift.

In the next two subsections I will discuss the role of lexicon and syntax for controller and controllee and deal with the scenarios displayed in (26). Though backward control and WH-control provide further evidence for the dual nature of control, I will postpone their discussion to section 7.

In this section I also want to take up the issue of the consequences of an exclusive syntactic account of control: If complement control were determined exclusively or to a very large extent by syntax, one would expect structural properties such as argument realization to play a crucial role for controller choice. I will show in 4.3 with examples from German that no strict correlations between argument realization and control can be established (see also Jackendoff \& Culicover 2003 for arguments against a syntactic/configurational approach to control).

\subsection{The controllee}

Since Keenan's (1976) seminal paper on subject properties, controllee choice has been taken as one of the central subject properties, i.e. the argument that is controlled in complement control is considered to be the subject. Languages mainly follow two patterns: the controllee corresponds to the highest-ranked argument of the embedded predicate ('logical subject') or to the argument that would receive the default linker (usually nominative/absolutive). This distinction does not play such an important role in languages in which all highestranked arguments receive the default linker. However, languages that exhibit quirky case either show sensitivity to the argument role of the embedded predicate or to its linking pattern. Whereas German only allows arguments to be controlled that would receive the default linker (NOM), Icelandic (Andrews 1990) seems to allow quirky subjects to be controlled. (27b) shows that it is impossible in German to embed a dative-subject verb such as grauen 'dread' (see (27a)) under a control verb. Note that hoffen 'hope' does not require the embedded verb to be agentive; therefore, semantic inconsistencies between matrix and embedded predicate are ruled out as the explanation for the unacceptability of the example.

(27) German

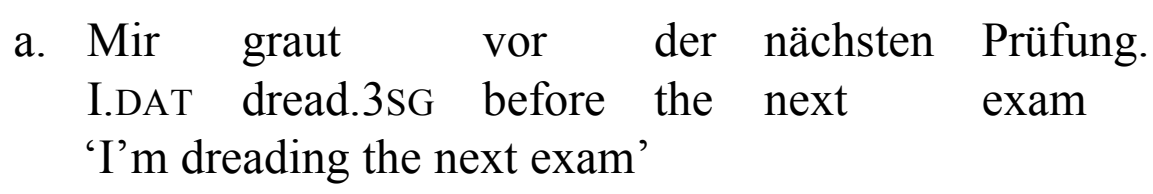



b. * Ich hoffe [ ${ }_{-}$nicht vor der nächsten Prüfung $\mathrm{zu}$ I hope.1SG Ø.DAT not before the next exam to grauen]. dread.INF 'I hope not to be dreading the next exam'

(28b) shows that an Icelandic verb with an ACC-subject can be embedded under a control verb; it is the ACC-subject that is controlled.

(28) Icelandic (Andrews 1990:198)

a. stelpuna vantar efni í ritgerðina girl.DEF.ACC lacks material in paper.DEF 'the girl lacks material for the paper'

b. stelpun/ *stelpuna vonast [til að _ vanta ekki girl.DEF.NOM/ girl.DEF.ACC hopes toward to Ø.ACC lack not efni í ritgerðina] material in paper.DEF 'the girl hopes not to lack material for the paper'

The syntactic selection of the controllee argument is not strictly parameterized such that languages either only select the highest argument or the default linker argument. In a few languages, e.g. Tagalog (Kroeger 1993), both options are available in principle. Usually the highest (actor) argument is controlled independent of the verbal voice morphology. Thus, the actor argument may be controlled in the actor voice (AV) as in (29a), corresponding to an overt NOMargument, or it may be controlled in the instrumental (IV) or dative voice (DV) as in $(29 b) /(29 c)$, corresponding to an overt GEN-argument. Note that the various voice markers render a specific verbal argument as most prominent; this argument receives the default linker: in (29a) the actor, in (29b) the theme and in (29c) the recipient.

(29) Tagalog (Kroeger 1993:39)
a. binalak
niya $=$ ng
[mag-bigay ng=pera
PERF.plan.OV
3SG.GEN=COMP AV-give
$\mathrm{GEN}=$ money
$\mathrm{sa}=$ Nanay _ $]$
DAT $=$ mother $\quad$ Ø.NOM
'he planned to give money to Mother'
b. binalak niya $=$ ng [i-bigay $-\quad s a=$ Nanay
PERF.plan.OV 3SG.GEN=COMP IV-give $\quad \bar{\emptyset}$.GEN DAT=mother
ang=pera]
$\mathrm{NOM}=$ money
'he planned to give money to Mother'



c. binalak
niya $=$ ng
3sG.GEN $=$ COMP
[bigy-an
ng=pera
PERF.plan.OV
give-DV
$\bar{\emptyset} . \mathrm{GEN}$
$\mathrm{GEN}=$ money
ang $=$ Nanay $]$
$\mathrm{NOM}=$ mother
'he planned to give money to Mother'

Control of the NOM-argument is obligatory in the non-volitive mood, marked by ma-:

(30) Tagalog: control in non-volitive mood (Kroeger 1993:95)
a. * in-utus-an ko si=Maria $=$ ng [ma-halik-an PERF-order-DV 1SG.GEN NOM=M=COMP NONVOL-kiss-DV $\bar{\varnothing}$.GEN $\mathrm{si}=$ Pedro]
$\mathrm{NOM}=\mathrm{P}$

'I ordered Maria to kiss Pedro'
b. in-utus-an ko si=Maria $=$ ng $\quad[$ ma-halik-an
PERF-order-DV 1SG.GEN $\quad$ NOM $=\mathrm{M}=\mathrm{COMP} \quad$ NONVOL-kiss-DV
ni $=$ Pedro _ $]$
$\mathrm{GEN}=\mathrm{P} \quad$ Ø.NOM

'I ordered Maria (to allow herself) to be kissed by Pedro'

As (30a) shows, it is not possible in the non-volitive mood to control a genitive argument; only control of NOM-arguments as in $(30 \mathrm{~b})$ is possible; the dative voice renders the patient argument accessible to the default linker. Balinese, another Austronesian language, shows consistent NOM control (Wechsler \& Arka 1998), whereas Madurese (Davies 2004) instantiates both actor and NOM control.

Tagalog also provides evidence that the selection of the controllee may be influenced lexically, which is strongly marked and which has to do with its two options for controllee choice. As mentioned above, Tagalog has a pattern of actor control (in the general case) and of Nom control if the embedded verb is realized in the non-volitive mood. Interestingly, some verbs allow both NOM and actor control, the former even in volitive mood (NOM control in (31a), actor control in (31b)):

(31) Tagalog: verbs allowing actor and NOM control (Kroeger 1993:97/98)

a. nagpilit $\mathrm{si}=$ Maria $=\mathrm{ng} \quad$ [bigy-an $\mathrm{ng}=$ pera

PERF.AV.insist.on $\quad \mathrm{NOM}=$ maria $=\mathrm{COMP}$ give-DV $\quad$ GEN $=$ money

$\mathrm{ni}=\mathrm{Ben} \quad$ _ $]$

GEN=Ben $\quad$ Ø.NOM

'Maria insisted on being given money by Ben' 


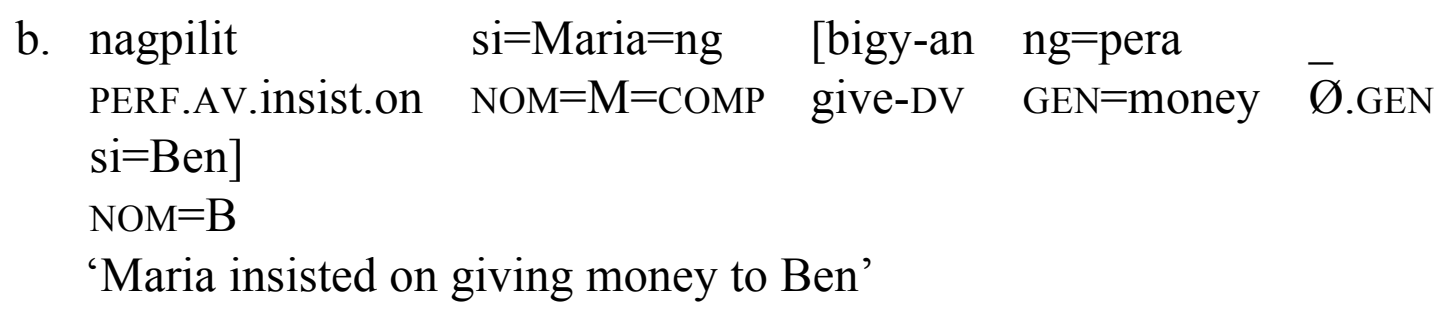

Kroeger characterizes the verbs that allow both types of control as 'orientation' verbs in the sense of Sag \& Pollard (1991), with himukin 'persuade' being the only exception. The potential selection of the controllee is thus lexically influenced to some extent, a phenomenon that needs further cross-linguistic study.

In languages that lack quirky or lexical case, voice operations may reveal the nature of the controllee: Does passivization, for instance, shift the controllee (the argument that would be realized with the default linker) or does it leave the controllee unchanged (e.g. the agent argument)? In the first case, there is NOM control, in the second actor control. The second option also implies that an oblique argument (or an argument that would surface obliquely) may be controlled. The Mayan language Tojolabal provides a case in question. Here, only intransitive verbs can be embedded under control verbs. Therefore, transitive verbs must be passivized in order to be embedded under a control verb. However, passivization does not change the control relation as it would, for instance, in English and most other languages; it is still the (implicit) agent that is controlled.

(32) Tojolabal (Robertson 1980:226)
a. h-moh-t-ay-a
1SG.E-accompany-TR-TH-2SG.N
$\left[\begin{array}{ll}\text { way-el }] \\ \text { sleep-NOML }\end{array}\right.$
'I accompanied you to sleep'
b. ha-kol-t-ay-on [ $\quad$ y-ahn-a-he-el $]$
2SG.E-help-TR-TH-1 SG.N 3SG.E-cure-TH-PASS-NOML
'you helped me cure him'

McCloskey \& Sells (1988) discuss instances of control of oblique arguments in Irish. In contrast to the examples considered so far, the controllee is overt in Irish.

\subsection{The controller}

The fact that controllers may be oblique or implicit, which affects the syntactic representation of the respective argument but not its semantic representation, suggests that the controller is determined semantically/lexically, given that cross-linguistically, semantically equivalent predicates show equivalent control patterns. Differences in the syntactic realization of the controller do not show strong effects (see also Jackendoff \& Culicover 2003). 
Further evidence for a semantic basis of control comes from control predicates in which the controller is a possessor argument; possessors do not ccommand the controllees. Therefore, the control relation can be ruled out on syntactic grounds. The Mayan language Q'eqchi', for instance, exhibits complex predicates with body-part expressions in which the possessor (of the body part) functions as controller; it is marked by ergative agreement (E; see (33)). Similar expressions can be found in other Mayan as well as non-Mayan languages.

$$
\begin{aligned}
& \text { Q'eqchi' Maya: possessor controller (Kockelman 2003:30) } \\
& \text { X-naq sa' in-ch'ool chalk } \\
& \text { PERF-drop inside 1SG.E-heart come } \\
& \text { 'I remembered to come' (lit. 'it has dropped into my heart to come') }
\end{aligned}
$$

These data imply that at least in some languages a purely syntactic account of control cannot be maintained.

The fact that many languages have lexically/semantically determined structures of complement control does not rule out languages in which control is determined exclusively in syntactic terms. There is sparse evidence for a syntactic organization of control. Syntactic controller choice has been claimed for the Austronesian language Kavalan and some closely related languages (Chang \& Tsai 2001). Here, the controller must always be the actor subject, which implies that directive verbs cannot surface as object control verbs. According to Chang \& Tsai, Kavalan chooses a strategy of causativization of the embedded predicate to maintain actor subject control. (34a) shows the respective pattern, in which the actor subject is identified with the newly added causer argument in the embedded clause; (34b) shows the pattern that would correspond to the familiar pattern of object control.

(34) Kavalan (Chang \& Tsai 2001:3)
a. pawRat a tina-na tu suni [ force NOM mother-3SG.P ACC child CAUS.AV-sleep 'his mother forces her child such that she causes him/her to sleep'
b. ?? pawRat a tina-na tu suni [_ m-aynəp]. force NOM mother-3SG.P ACC child AV-sleep 'his mother forces her child to sleep'

(34a) suggests that the structure of directive control structures must be that of (35a); directive predicates cannot instantiate a structure such as (35b), evidenced by (34b).
a. $\lambda P \lambda y \lambda x[\operatorname{FoRce}(x, y) \& \operatorname{Cause}(x, P(y))]$
b. $\lambda \mathrm{P} \lambda \mathrm{y} \lambda \mathrm{x}$ FORCE $(\mathrm{x}, \mathrm{y}, \mathrm{P}(\mathrm{y}))$ 
Unfortunately, the authors do not discuss cases in which causativization of the embedded predicate would be semantically inadequate: a) with negation of the matrix predicate, b) with non-implicative directive verbs such as 'ask'. In these cases, Kavalan should resort to some other strategy.

A further case for a syntactic restriction on controllers is attested in the Mayan language Mam (England 1989): Here, control is restricted to controllers in the absolutive (= nominative) case if the matrix predicate selects an infinitival complement; this restriction does not apply to finite clausal complements. In (36a) the controller is an internal argument, indexed by $\mathrm{N}(\mathrm{OM})$-agreement. With a controller indexed by $\mathrm{E}(\mathrm{RG})$-agreement, only a finite clausal complement is possible; an infinitival complement is excluded (compare (36b/c)).

(36) Mam (England 1989:291f.)
a. ma tz'-ok t-laj-o-'n Kyel [tx'eem-al sii'] REC.PAST 3SG.N-DIR 3SG.E-oblige-TH-DIR Miguel cut-INF wood 'Miguel obliged him to cut wood'
b. w-ajb'el-a [chin aq'n-a-an-a]
1SG.E-want-1SG 1SG.NOM work-THV- ANTIPASS-1SG
'I want to work'
$\begin{array}{lll}\text { c. } & \text { * w-ajb'el-a } & \text { [aq'n-a-al] } \\ & \text { 1sG.E-want-1SG } & \text { work-TH-INF }\end{array}$

For a certain type of sentential complementation, Mam thus shows a correlation between argument linking and controller choice.

The literature on complement control does not reveal how wide-spread syntactic restrictions on controllers may be. There is no systematic evidence for such a pattern. The Kavalan case, however, already indicates the 'expenses' of syntactic control: In order to maintain certain structural configurations for control, lexical predicates have to be accommodated in order to exhibit the adequate syntactic potential. It is also likely that in languages with a purely syntactic control pattern, lexical control predicates are more homogeneous than in languages with semantically based control because in the latter no syntactic requirements restrict possible control predicate classes.

\subsection{Control and argument realization}

Unlike Mam, German (and other languages) do not show any strict correlation between argument linking and controller choice, which would be expected under a purely syntactic regulation of control. In order to understand the linking patterns of control predicates, it is helpful to distinguish between canonical and non-canonical linking patterns. According to the assumptions of Lexical Decomposition Grammar (Joppen \& Wunderlich 1995, Wunderlich 1997, Stiebels 2002), canonical linking in German encompasses the linking patterns in 
(37) with predicates that do not take an SOA-argument. The order of the case markers from left to right refers to the argument hierarchy lowest-medial-highest argument.

(37) Canonical linking in German

\begin{tabular}{|lllll|}
\hline intransitive & & & $\lambda \mathrm{x}$ & $\mathrm{V}(\mathrm{x})$ \\
& & & $\mathrm{NOM}$ & \\
transitive & & $\lambda \mathrm{y}$ & $\lambda \mathrm{x}$ & $\mathrm{V}(\mathrm{x}, \mathrm{y})$ \\
& & ACC & NOM & \\
ditransitive & $\lambda \mathrm{z}$ & $\lambda \mathrm{y}$ & $\lambda \mathrm{x}$ & $\mathrm{V}(\mathrm{x}, \mathrm{y}, \mathrm{z})$ \\
& ACC & DAT & NOM & \\
\hline
\end{tabular}

If the lowest argument is an SOA-argument, one expects a STRUCT-NOM or STRUCT-DAT-NOM pattern in the canonical case, with STRUCT representing the structural, hence non-oblique, realization of the SOA-argument. If one of the arguments is realized obliquely, the pattern is non-canonical; the same is true for lexical case marking, e.g. DAT (like gefallen 'like') or ACC (like reuen 'regret') on the highest argument. (38) shows the canonical and some non-canonical patterns in German.

(38) Canonical vs. non-canonical linking patterns in German SOAA-taking predicates

a. bivalent

\begin{tabular}{|lccl|}
\hline & $\lambda \mathrm{P}$ & $\lambda \mathrm{x}$ & $\mathrm{V}(\mathrm{x}, \lambda \mathrm{z} \mathrm{P}(\mathrm{z})))$ \\
canonical & STRUCT & NOM & \\
non-canonical & OBL & NOM & \\
& N.STRUCT & ACC & \\
& N.STRUCT & DAT & \\
\hline
\end{tabular}

b. trivalent

\begin{tabular}{|lcccl|}
\hline & $\lambda \mathrm{P}$ & $\lambda \mathrm{y}$ & $\lambda \mathrm{x}$ & $\mathrm{V}(\mathrm{x}, \mathrm{y}, \lambda \mathrm{z} \mathrm{P}(\mathrm{z}))$ \\
canonical & STRUCT & DAT & NOM & \\
non-canonical & N.STRUCT & ACC & NOM & \\
& N.STRUCT & OBL & NOM & \\
& OBL & ACC & NOM & \\
\hline
\end{tabular}

I distinguish between three types of linking of SOA-arguments: structural, nonstructural (N.STRUCT) and oblique. Non-structural SOA-arguments differ from oblique SOA-arguments in that the latter show an oblique marking in terms of an oblique correlative pronoun in the matrix clause (a compound of the deictic adverb $d a$ and a preposition) or of a correlative expletive in the matrix clause. German SOA-arguments are not case-marked directly because they are verbal projections. 
(39) shows corpus examples of oblique SOA-arguments: (dar-auf) achten 'pay attention to', (da-nach) streben 'strive for', (da-vor) bewahren 'protect from', (es) aushalten 'stand'. Bewahren is an object control verb, the others are subject control verbs.

(39) Oblique SOA-arguments [IDS-corpus] ${ }^{8}$

a. ... die Kultur $_{i} \quad m u ß$ dar-auf $f_{j}$ achten, [ _ ${ }_{i}$ sich nicht the culture must there-on pay.attention REFL not allzu unbedacht in die Arme der Wirtschaft zu too.much thoughtlessly in the arms of commerce to werfen $]_{j}$. throw

'Culture must pay attention not to throw itself into the arms of commerce that thoughtlessly'

b. der Außenseiter, der ${ }_{i}$ immer da-nach $_{j}$ strebte, [ _ i der Größte zu the outsider who always there-after strived the greatest to werden $]_{\mathrm{j}} \ldots$

become

'the outsider who always strived to become the greatest'

c. Wie die $\mathrm{Frau}_{\mathrm{i}} \mathrm{es}_{\mathrm{j}}$ aus-hält, [_i stundenlang im warmen how the woman it out-hold.3sG for.hours in.the warm Kostüm in glühender Sonne $\mathrm{zu}$ agieren $]_{\mathrm{j}} \ldots$ costume in heating sun to act

'how does the woman stand acting for hours in the burning sun in her warm suit'

d. Wir wollen die Welt $t_{i}$ doch nur da-vor ${ }_{j}$ bewahren, [ _ ${ }_{i}$ we want the world but only there-in.front.of keep.from $\mathrm{zu}$ einem einzigen großen 'Bush' $\mathrm{zu}$ werden]. [Google] to one unique great Bush to become

'we want to protect the world from becoming one unique great Bush'

Non-structural SOA-arguments do not exhibit oblique marking, but show another non-structural property: Non-structural SOA arguments cannot undergo restructuring (see also Sabel 1996, who has already discussed some aspects of argument linking and restructuring), which is also true for oblique SOA-arguments. ${ }^{9}$

German - as well as other languages - exhibits numerous predicates that take an oblique controller. Oblique controllers usually surface as PPs, as shown for

8 'IDS-corpus' refers to the morphosyntactically annotated corpus (TAGGED) of the Institut für Deutsche Sprache in Mannheim.

9 In languages that exhibit object agreement, lack of agreement with an SOA-object may also be an indication for its non-structural character (besides clause union). 
the verbs (an jemanden) appellieren 'appeal at' in (40a), (auf jemanden) einwirken: 'have an effect on' in (40b) and (von jemandem) er-warten 'expect from' in (40c). So far there is no evidence that a control reading is blocked by an oblique realization of the respective argument.

(40) Oblique controllers [examples from IDS-corpus]

a. Er $_{\mathrm{i}}$ appellierte an die Länder ${ }_{j}$, ${ }_{\_} \_$mit den Forderungen maßvoll $\mathrm{zu}$ he appealed at the states with the demands modest to bleiben].

remain

'He appealed to the states to remain modest with their demands.'

b. Die $U_{S A}$ wollen auf den $\operatorname{Irak}_{j}$ ein-wirken, $L_{j}$ seine Grenzen the USA want on the Iraq in-effect its borders im Norden des Landes zu öffnen]. in.the north the.GEN country.GEN to open.INF

'The US want to influence Iraq to open its borders in the north of the country.'

c. Erwartet $\operatorname{man}_{\mathrm{i}}$ von uns $\mathrm{j}_{\mathrm{j}}, \quad\left[\mathrm{L}_{\mathrm{j}}\right.$ gesünder $\mathrm{zu}$ leben]? expect.3SG one from us.DAT healthier to live

'Does one expect from us to live healthier?'

Regarding the control properties, almost no strict correlations between linking pattern and control can be observed. Among the polyadic verbs with the canonical STRUCT-DAT-NOM linking pattern, one can find subject control verbs with an optional DAT argument (e.g. versprechen 'promise') as well as object control verbs (e.g. an-kreiden 'accuse of', ab-verlangen 'demand', an-lasten 'make responsible for', be-scheinigen 'certify', auf-tragen 'instruct', bei-bringen 'teach', ein-schärfen 'impress', vor-werfen 'reproach'). Therefore, the canonical pattern does not induce any preferred control pattern. Among the non-canonical patterns there is a strong preference for object control in the N.STRUCT-ACC-NOM pattern. However, if the SOA-argument is oblique, one can also find predicates with subject control (OBL-ACC-NOM: (da-mit) abtun 'dismiss', (dar-aus) beziehen 'draw from', (da-mit) bedrohen 'threaten', (dar-an) setzen 'put energy into').

Moreover, there is no correlation between the control reading and the structural or oblique status of the controller argument or the SOA-argument in German. The scattered data from other languages point into the same direction. The only correlation to be observed has to do with another syntactic property, namely clause union (restructuring): oblique SOA-arguments block restructuring, which also does not correlate with any control property because some control predicates allow restructuring, others do not (see Bech 1955/57, Sabel 1996, Wurmbrand 2001, Reis \& Sternefeld 2004). 


\section{Control-inducing vs. control-neutral structures}

If one takes into account the various possible types of subordination crosslinguistically available, one has to distinguish structures that 'induce' control (due to their need of argument identification) from those that do not. The need for argument identification is either motivated structurally, due to the deficiencies of argument linking (e.g. with infinitival or other infinite complements), i.e. not all arguments may be realized within the linking domain of the SOA-head, or semantically, due to the requirement of denoting coherent events; situational coherence is commonly established by shared participants in the various subevents of a complex event (e.g. with serial verbs). In the case of structurally motivated argument identification, argument raising is an alternative to control. The predicate want, for instance, may instantiate subject control as well as 'object raising' (another label being ACI or ECM construction). Generally, infinitival/infinite complements, serial verb constructions, and verb incorporation are structures of argument identification. In contrast, nominalizations and finite clauses do not require argument identification in most languages; all arguments may be realized overtly within the linking domain of the nominalized or finite head. I will call structures that require argument identification 'controlinducing' structures. The other structures of sentential complementation will be called 'control-neutral'.

Cross-linguistically there is no strict correlation between the semantic class of the SOAA-taking predicate and its sentential complementation pattern. This is due to the fact that languages make use of different structures of sentential complementation. There are some tendencies which have been pointed out in the typological literature: Givón (1990), van Valin (1993), and Cristofaro (2003) among others - have already proposed some correlations concerning the semantic coherence of SOA-arguments with their matrix predicate and the corresponding syntactic realization. Givón (1990) predicts that finite SOAcomplements are less likely in case of argument sharing:

(41) Referential cohesion and event integration (Givón 1990:527)

The more the two events coded in the main and complement clauses share their referents, the more likely they are to be semantically integrated as a single event; and the less likely is the complement clause to be coded as an independent finite clause.

Givón ranks the syntactic realization of SOA-arguments according to their syntactic coherence as in (42). Predicate raising (i.e. co-lexicalization such as verb incorporation) is assumed to exhibit the strongest syntactic coherence. 
(42) Syntactic scale of SOA-arguments (Givón 1990:519)

Predicate raising $>$ bare stem $>$ infinitive $>$ for-to $>$ Subjunctive $>$ indirect quote $>$ direct quote

Givón assumes the following hierarchy of predicate classes, starting with predicates of 'successful intended causation' on top. The predicates high in the hierarchy are predicted to show co-lexicalization or higher syntactic coherence along (42).

(43) Scale from manipulation to cognition (Givón 1990:530)

successful intended causation $>$ attempted manipulation $>$ preference/aversion $>$ epistemic anxiety $>$ epistemic certainty/uncertainty $>$ utterance

Van Valin (1993) distinguishes structures of co-subordination, subordination and coordination for all three levels of nuclear, core, and clausal juncture, with structures of nuclear co-subordination exhibiting the strongest syntactic coherence and clausal coordination the weakest. He likewise aligns the hierarchy of syntactic coherence with a hierarchy of predicate classes, given in (44).

(44) van Valin's (1993:112) hierarchy of predicates in terms of semantic coherence

causative $>$ aspectual $>$ psych-action $>$ purposive $>$ jussive $>$ direct perception $>$ propositional attitude $>$ cognition $>$ indirect discourse $\ldots$

Like in Givón's account, predicates high in the hierarchy are expected to show the strongest syntactic coherence. There are differences in the terminology and the ranking of the predicate classes. Cristofaro (2003) assumes the hierarchy of argument 'deranking' in (45), in which modals and phasals are ranked higher than causatives/manipulatives; 'deranking' refers to structural asymmetries found in comparison to independent clauses. Predicates high in the hierarchy are likely to make use of non-deranking means (verb incorporation, verb cluster etc.).

(45) The Complement deranking-argument hierarchy (Cristofaro 2003) Modals, Phasals $>$ Manipulatives, Desideratives $>$ Perception $>$ Knowledge, Propositional attitude, Utterance

According to Cristofaro, this hierarchy also accounts for the presence/absence of tense/aspect/mood and agreement markers and the overt coding of arguments. The various approaches do not deal with complement control per se and in detail.

In this section I will discuss the various structures of sentential complementation in terms of their possible structural influence on control. I will first discuss the potential control-inducing structures (infinite/infinitival complements, verb 
incorporation and serial verb constructions) and then the potential controlneutral structures (nominalization and finite complements). Finally, I will deal with switch-reference systems.

\subsection{Infinite/infinitival complements}

In many languages, infinitives/infinite verb forms are not able to license the realization of all arguments. Typically, the unmarked structural linker (nominative/absolutive) cannot be assigned in an infinitival complement, although there are well-known counter-examples from Romance: These languages show an intricate variation concerning lexical subjects with infinitives: In Portuguese, lexical subjects are possible with inflected infinitives (Raposo 1987, Mensching 2000; see (46a)), whereas in Spanish adverbial PPs and subject clauses may show lexical subjects with infinitival heads. The intricacy of the phenomenon is displayed by the fact that subject clauses only allow postverbal lexical subjects (compare (46b/c)); this restriction does not apply with adverbial PPs (see (46d). Mensching (2000) gives a good overview for the major Romance varieties.

(46) Portuguese/Spanisch: lexical subjects in infinitival clauses

(Mensching 2000:6f.)

a. Portuguese

a. para as mulheres chegar-*(em)

for the women arrive.INF-3PL

'for the women to arrive'

b. Spanish

[Haber $=$ se Julia presentado a las elecciones] fue un error. have.INF=REFL $J$ present.PTC at the elections] was a mistake 'the fact that Julia presented herself at the elections was a mistake'

c. * [Yo presentar $=$ me a las elecciones] fue un error $1 \mathrm{SG}$ present.INF $=1 \mathrm{SG} . \mathrm{REFL}$ at the elections] was a mistake 'the fact that I presented myself at the elections was a mistake'

c. [Para yo presentar $=\mathrm{me}$ a las elecciones] sería for $1 \mathrm{SG}$ present=1SG.REFL at the elections] be.COND.3SG necesario mucho dinero necessary much money

'to present myself at the elections, a lot of money would be necessary'

The Romance data indicate that structural aspects of the syntactic context may influence the admissibility of lexical subjects in infinitival clauses.

Besides the infinitive there are other types of infinite complements, e.g. supine complements, which do not allow the use of the default linker in their linking domain. In Kolma Yukaghir, some predicates select supine complements. According to Maslova (2003), this pattern is restricted to structures of 
subject control (including split control) and to cases in which the situation denoted by the SOA-argument is not implied (Maslova 2003). The controllee has to be covert. (47) is an example for split control.

(47) Kolma Yukaghir: supine complement (Maslova 2003:415)

titte es'ie-nin ${ }_{i}$ qamie-d'ā-nu-l'el-ni $i_{j} \quad\left[{ }_{i}{ }^{i+j}\right.$ kereke-n'e

their father-DAT help-DETR-IMPF-INFER-3PL.ITR Koryak-COM kimd'î-din]

fight-SUP

'they helped their father to fight with the Koryaks'

\subsection{Languages without a finite-infinite distinction}

Languages that lack a finite-infinite distinction on the morphological level typically lack control-inducing structures such as infinitival complements. However, they may exhibit verb incorporation or verbal compounding (see below). Among this type of language one can find isolating languages such as Chinese, but also polysynthetic languages such as Nahuatl. In Nahuatl, the embedded verb is inflected for tense/modality and agreement; therefore, the controllee is overtly expressed by subject agreement markers; however, there is generally no overt marker for $3 \mathrm{SG}$ subject agreement. In $(48 \mathrm{a} / \mathrm{c})$ the embedded predicate is marked with future tense, in (48b) with optative mood. Note that Nahuatl is a pro-drop language.

(48) Nahuatl
a. $\quad \bar{o}-\mathrm{k}-\mathrm{ilk} \overline{\mathrm{a}} \mathrm{w}$
[ki-čīwa-s]
ANT-3SG.A-forget.SST 3SG.A-make-FUT
'he forgot to do it'
b. ni-mits-KāKawtia [in mā ši-k-čīwa]
1SG.N-2SG.A-ask DET OPT 2.IMP-3SG.A-do
'I ask you to do it'
c. ayāk mo-Kāpaloā-ya [in oksē om-m-īš-ketsa-s] nobody REFL-dare-IMPF DET another DIR-REFL-eye-stand-FUT 'nobody dared to propose a substitute'

Some control predicates in Nahuatl may instantiate verb incorporation (see below); however, this pattern is not available as a general option for all control predicates.

In Chinese, control structures are distinguished from non-control structures by the lack of overt pronouns. Chinese is a pro-drop language as well. (49a) can only have the indicated control reading, whereas an overt pronoun as in (49b) is free in its reference. An inherent control predicate such as $b i$ 'force' does not allow the controllee to be overt (see $(49 \mathrm{c} / \mathrm{d})$ ). 
(49) Mandarin Chinese (Yi-Chun Yang p.c.)

a. Dahua $a_{i}$ biaoshi $\left[{ }_{i}{ }^{*} *_{j}\right.$ wufa canjia zhe-ge-huodong $]$. D mean cannot participate this-CL-activity

'Dahua meant not to be able to take part in this activity'

b. Dahua ${ }_{i}$ biaoshi $\left[\mathrm{ta}_{\mathrm{i} j \mathrm{j}}\right.$ wufa canjia zhe-ge-huodong].

D mean 3SG cannot participate this-CL-activity

'Dahua meant that he cannot participate in this activity'

c. Zhangsan ${ }_{i}$ bi $\operatorname{Lisi}_{j}\left[L_{j} / *_{i}\right.$ xie gongke].

$\mathrm{Z}$ force $\mathrm{L}$ write homework

'Zhangsan forced Lisi to do the homework'

d. * Zhangsan ${ }_{i}$ bi Lisi $_{j}$ [ta xie gongke].

$\mathrm{Z}$ force L $3 \mathrm{SG}$ write homework

Note that careful studies are necessary in languages without finite-infinite distinction in order to find out which predicates that take SOA-arguments only allow control readings.

\subsection{Verb incorporation}

In structures of verb incorporation a verb is morphologically integrated into another verb. The incorporated verb must share at least one argument with the incorporating verb, either semantically and/or structurally. In the following example from the Uto-Aztecan language Sonora Yaqui, the object control verb su'utoja 'allow' incorporates a transitive verb whose highest argument is identified with the internal argument of the higher predicate.

(50) Sonora Yaqui: verb incorporation - control (Guerrero 2004)

$\mathrm{U}$ tata\#paare ili uusi-ta teopo-ta tu'ute-ne-su'utoja-k.

the priest.NOM little child-ACC church-ACC fix-EXPE-allow-PERF

'the priest allowed the child to clean the church.'

The only alternative to control in case of verb incorporation is raising, as shown in the following example from Sonora Yaqui:

(51) Sonora Yaqui: raising (Guerrero 2004)

a. Joan tuuka Tibu-ta siim-maachia

J yesterday T-ACC go-believe.PRES

'Juan believes Tibu to have left yesterday'

b. Tibu tuuka siim-maachia-wa

$\mathrm{T}$ yesterday go-believe-PASS.PRES

'Tibu was believed to have left yesterday'

The accusative DP in (51a) is a semantic argument of siim 'go', but not of the matrix verb maachia 'believe'. However, due to Functional Composition, it 
becomes a structural argument of the resulting complex verb. If the complex is passivized as in (51b), the semantic argument of siim is realized as subject.

Since verb incorporation (or verbal compounding) involves the 'fusion' of argument structures of the respective predicates, it can be structurally restricted if the resulting argument structure exhausts the linking resources of the language. However, Sonora Yaqui allows rather complex patterns of verb incorporation. In (52) the desiderative subject control verb incorporates a directive object control verb, which in turn incorporates a causativized transitive verb. Note that two internal arguments are left implicit. (52b) shows the simplified representation of (52a).

(52) Sonora Yaqui (Dedrick \& Casad 1999:285)
a. 'ám bít-tá'aa-tua-tebo-bae-n
them see-know-CAUS-order-want-PAST
'he wanted to give a command to cause (others) to know them by sight'
b. $\lambda y \lambda x \lambda u v_{v} \lambda s^{\prime} \exists s_{\operatorname{NaNT}}[v, \operatorname{ORDER}(v, u, \operatorname{ACT}(u, \operatorname{KNOW}(\mathrm{x}, \mathrm{y})(\mathrm{s})))]\left(\mathrm{s}^{\prime}\right)$

Sonora Yaqui exhibits other patterns of sentential complementation as well, even with control predicates. Generally, polysynthetic languages are not confined to verb incorporation in case of complement control. Some predicates, however, are typical candidates for verb incorporation, especially aspectual and desiderative predicates. In Classical Nahuatl the verb neki 'want' may be used as an incorporating verb; in contrast, the desiderative predicate elêwia 'want' selects finite complements.

Nahuatl
a. ni-k-čīwa-s-neki
1SG.N-3SG.A-make-FUT-want
'I want to do it'
b. ni-k-elēwia [in mā ni-pa?ti]
1SG.N-3SG.A-want DET OPT 1SG.N-recover
'I want to recover'

In Yupik and other Eskimo languages some suffixal verbs act like control verbs. These structures are specific instances of verb incorporation because the heads are bound forms that have to incorporate another predicate, typically a verb.

(54) Yupik (de Reusse 1994:60/62)
a. yug-m anengagh-mnun
negh-sqe-aa kayu
man-ERG older.brother-TERM.1SG/SG eat-ask.to-3SG/3SG fish
'the man asked my brother to eat the fish' 
$\begin{array}{lll}\text { b. esghagh-na-luku } & \text { qinuyug-lghii } & \text { yug } \\ \text { see-want-3SG/3SG } & \text { be.sick-PTC.ITR } & \text { person } \\ \text { 'he wants to see the sick person' } & \end{array}$

\subsection{Serial verb constructions}

Among the various patterns of serial verb constructions (SVC) one can also find structures of complement control - at least in some languages. Besides the typical SVC patterns such as resultatives (e.g. hit-die, hit-kill), directionals (e.g. Vgo), argument-extending SVCs (e.g. instrumental take-V, beneficiary V-give), one also finds types in which an SOAA-taking predicate is the main functor of a SVC. Generally, SVCs require argument sharing between the predicates involved due to situational coherence of the subevents denoted by the predicates of the SVC. Argument sharing may affect the subject, or both subject and object, or the object of one verb and the subject of the other. ${ }^{10}$ The required argument identification qualifies SVCs as control-inducing structures. Let me show this with data from the Amazonian language Tariana (Aikhenvald 2003), which exhibits a great variety of SVCs: Like regular SVCs, structures of complement control are monoclausal; the predicates exhibit the same subject agreement, even if the object of the first verb and not its subject is the shared argument as in $(55 \mathrm{c})$; here, the subject of the control verb is third person non-female, whereas the subject of the embedded predicate is first person, which is not reflected in verbal agreement.

(55) Tariana: SVC (Aikhenvald 2003:432/433/439) then-REP 3SG.NF.grab 3SG.NF-meet DET knife-DIM-TOP 'then he managed to grab the little knife'
a. nese-pida [dhipa di-keta] diha malie-tiki-nuku
b. [di-ni di-mataRa-pidana] diha
3SG.NF-do 3SG.NF-leave-REM.PAST.REP he 'he stopped doing (this)'
c. emite-tiki nu-na [dihpani di-adeta-naka] child-DIM 1SG-OBJ 3SG.NF.work 3SG.NF-prevent-PRES.VIS 'the little boy is preventing me from working'

Languages differ as to which predicates may instantiate SVCs and whether they include SOAA-taking predicates.

10 In case of 'ambient serialization' (Crowley 1987) the situational variables of the predicates are shared. This pattern does not play a role for complement control. 


\subsection{Nominalization}

Nominalization is a major means of subordination in many languages or at least an important structural alternative to other structures of complementation (Noonan 1985, Comrie \& Thompson 1985, Koptjevskaja-Tamm 1993). Depending on the linking potential of nominalized verbs, all arguments may be realized in the domain of the nominalized head. Therefore, argument identification is not required, at least in those languages without restrictions on the linking of the arguments of the nominalized verb. Note that the nominalization of intransitive verbs does not pose problems for nominal linking because the resulting nominal has the complexity of an inherently relational noun; polyadic predicates, however, may be problematic (see Stiebels 2006).

Turkish SOA-arguments are realized as noun clauses, i.e. clauses based on deverbal nouns. Argument linking is that of a 'mixed category', i.e. the highest argument is realized nominally (marked by genitive), the other arguments are realized verbally (marked by the usual verbal cases). Therefore, argument identification is not required. Turkish distinguishes three types of nominals: 'factive' nominals $(-d I K)$ as in (56a), event nominals with possessor agreement $(-m E)$ as in $(56 \mathrm{~b})$, and event nominals without possessor agreement $(-m E K)$ as in $(56 \mathrm{c} / \mathrm{d})$, the latter also being called 'infinitive'.

$$
\begin{aligned}
& \text { Turkish (Kornfilt 1997:50/51/53) } \\
& \text { a. (ben) [Ahmed-in öl-düğ-ün]-ü duy-du-m } \\
& \text { I A-GEN die-NOML-3SG.P-ACC hear-PAST-1SG } \\
& \text { 'I heard that Ahmet died' } \\
& \text { b. (ben) [Ahmed-in öl-me-sin]-den kork-uyor-du-m } \\
& \text { I A-GEN die-NOML-3SG.P-ABL fear-PROG-PAST-1SG } \\
& \text { 'I was afraid that Ahmet would die' }
\end{aligned}
$$

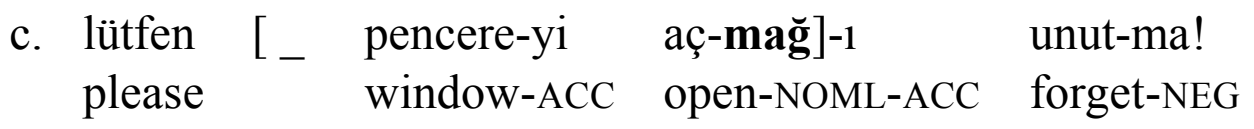

$$
\begin{aligned}
& \text { 'please don't forget to open the window' } \\
& \text { d. (ben) Ahmed-i [ } \\
& \text { 1SG A-ACC flee-NOML-DAT force-PAST-1SG }
\end{aligned}
$$

Control predicates typically instantiate the 'infinitival' construction as in (56c/d). SOA-arguments realized with agreeing deverbal nouns as in (56b) as well as factive nominals as in (56a) do not induce control readings (see also Słodowicz this volume). Gamerschlag (this volume) demonstrates the controlneutral character of Korean nominalized complements.

Whereas in most languages, structures of nominalization follow the controlneutral pattern of Turkish and Korean, Q'eqchi' and possibly other Mayan languages exhibit nominalized clausal complements that do not allow all 
inherited verbal arguments to be overtly realized because structural linking is restricted here to possessor (ergative) agreement; hence, they are controlinducing in case of polyadic predicates. In the following example, the ergative possessor agreement (E) indexes the lower argument, i.e. the theme li kabl 'the house'; the higher argument has to be controlled.

(57) Q'eqchi': infinite transitive complements (Kockelman 2003:32)

n-in-lub [chi $\quad x-m e s u n k-i l \quad$ li kabl]

PRES-1SG.N-tire OBL.COMP 3SG.E-sweep-NOML the house

'I'm tired of sweeping the house'

\subsection{Finite complements}

Finite complements are generally control-neutral, although there may be exceptions (see below). They do not require argument identification in structural or semantic terms. A rather common finite structure instantiated by control verbs are so-called subjunctive complements, already discussed by Noonan (1985). The notion 'subjunctive' is rather heterogeneous; it may apply to non-indicative verbal categories (e.g. in Spanish or Hungarian) or to specific complementizer forms (e.g. in some Balkan languages, where the verbs do not display a distinct subjunctive mood).

Generally, subjunctive complements do not induce control, which I will show with data from the Balkan languages; in these languages the subjunctive has replaced the infinitive partially or completely. If one compares desiderative predicates, which do not require control, with directive predicates, which show inherent control, one can see that subjunctives may occur with non-control readings if they are compatible with the matrix predicate. This is illustrated with data from Albanian, in which the subjunctive has replaced the infinitive completely: a desiderative predicates and its readings are given in (58a), a directive verb is given in (58b).

Albanian (Noonan 1985:67)
a. Njeriu $\mathrm{i}_{\mathrm{i}}$ deshi [ta $\_\mathrm{i} / \mathrm{j}$ vjedhë man wanted.3SG COMP steal.3SG.SUBJ chicken
'the man wanted to steal the chicken'/ 'the man wanted him to steal the chicken'
b. Gruaja $a_{i}$ e detyroi njeriun $n_{j}$ [ta _j vjedhë woman PRO forced man.ACC COMP steal.3SG.SUBJ pulën] chicken 'the woman forced the man to steal the chicken'

Serbian and Croatian differ with respect to the use of the subjunctive. Both share the preference for subjunctive complements with directive (object control) 
verbs, as shown in (59a). Whereas Croatian favors the infinitival structure in (59b) in case of subject control, Serbian favors the subjunctive structure in (59c).

(59) Serbo-Croatian (Stojanović \& Marelj 2004:445f.)
a. Jovan je naredio Mariji [da _ dodē/
J AUX ordered.PART M.DAT SUBJ.COMP come.3SG/
*doći]
come.INF
'Jovan has ordered Marija to come'
b. Marija $a_{i}$ hoće [ ${\text { _i } /{ }^{*} \mathrm{j}}$ spavati $]$
M want.3SG sleep.INF
'Marija wants to sleep'
c. $\mathrm{Marija}_{\mathrm{i}}$ hoće [da $\quad \_\mathrm{i} / \mathrm{j}$ spava $]$
M want.3sG SUBJ.COMP sleep.3.SG
'Marija wants (someone) to sleep'

The two languages likewise differ regarding their preferences with subject control verbs such as 'try'. In Serbian (see (60a)), again the subjunctive is used.

(60) a. Serbian (Stojanović \& Marelj 2004:446)

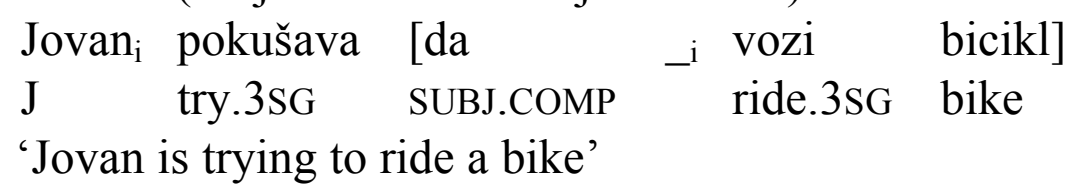

b. Croatian

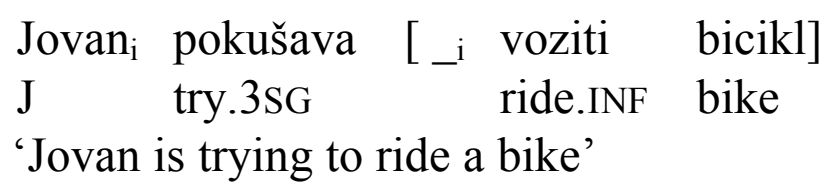

If a language displays a control-inducing as well as a control-neutral structure, there may be a division of labor between the two structures - at least with some predicate classes. In these cases the control-neutral structure encompasses readings not subsumed by the control-inducing structure, namely the disjoint reference readings (see Comorovsky 1985, Kempchinsky 1987, Zec 1987, Ruwet 1991, Farkas 1992, Landau 2004). In Spanish as well as most other Romance languages, control readings are realized with infinitival complements as in (61a). The control reading is blocked in the subjunctive, which, then, has the disjoint reference reading only as in (61b).

(61) Spanish
a. quiero [ $_{i}$ ivenir $]$
want.1SG come.INF
'I want to come' 


\section{b. * quiero [que venga yo] want.1SG COMP come.1SG.SUBJ $1 \mathrm{SG}$ \\ lit. 'I want that I come'}

Of course, this division of labor only makes sense for predicates that are not inherently bound to control readings; inherent control predicates are incompatible with disjoint reference readings. ${ }^{11}$

The predicate classes that are most likely to occur with subjunctives (or irrealis finite complements) are desideratives and directives, although the former do not belong to the inherent control predicates, whereas the latter do. The languagespecific inventory of sentential complementation structures, however, may influence the selection of complementation structures. In the Oceanic language North-East Ambae (Hyslop 2001) directive predicates are very small in number and instantiate SVCs. Here, implicative verbs like 'try' select irrealis complements:

(62) North-East Ambae (Hyslop 2001:404)

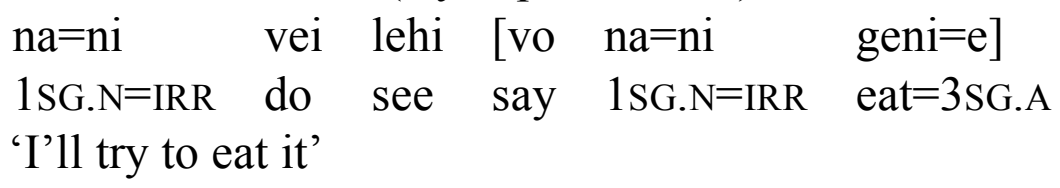

In Mangap-Mbula, an Oceanic language of Papua New Guinea, both directive and implicative predicates select non-factual complements, as shown in (63). Here, SVCs, although being present, do not include the typical classes of control predicates.

(63) Mangap-Mbula (Bugenhagen 1995:272f.)
a. ti-ruutu yo be ay-la som
3PL-prevent 1SG.ACC NON.FACT 1SG-go NEG
'they prevented me from going'
b. i-toombo be i-kot mbun kini
3SG-try NON.FACT 3SG-cover debt 3SG.LOC
'he tried to repay his debt'

That finite clauses are not control-neutral per se is evidenced by Q'eqchi' and some other Mayan languages. The non-control reading is triggered by the complementizer naq, which may be regarded a switch-reference marker. ${ }^{12}$ (64a) shows a desiderative predicate with a finite clause in control reading. The disjoint reading requires the complementizer $n a q$, as shown in (64b). Note that

11 The disjoint reference effect does not occur with epistemic verbs such as doubt etc.

12 The difference between (64a) and (64b) seems to be one of IP vs. CP (pointed out by Aissen p.c.). Lacking further evidence, it is not clear to me whether these domains could be characterized as control-inducing vs. control-neutral. 
the matrix predicate may also select an infinitival complement as in (64c), which only allows the control reading.

(64) Q'eqchi' (Kockelman 2003:28/30; Berinstein 1985:257)
a. n-inw-aj [t-in-xik sa' li k'ayil] PRES-1SG.E-want FUT-1SG.N-go inside the market 'I want to go to the market'
b. ta-cu-aj [naq t-at-xik]
TMP-1.E-want COMP.DS FUT-2.N-go
'I want you to go'
c. n-inw-aj [xik sa' li k'ayil] PRES-1SG.E-want go into the market 'I want to go to the market'

\subsection{Switch-reference}

Switch-reference systems are orthogonal to the dichotomy of control-inducing vs. control-neutral structures because the respective markers - as important means of reference-tracking in verbal chains/sequences or in the integration of verbal adjuncts - establish referential readings. Usually, they indicate whether the subject of the respective predicate is co-referential with the subject of some higher predicate. This property immediately raises the question as to what extent switch-reference markers are used in complements of control verbs in order to encode control relations. Subject control verbs should instantiate complements with same-subject markers (SS), object control verbs complements with different-subject markers (DS). Quite interestingly, switch-reference markers are rarely attested cross-linguistically in structures of complement control.

Hale (1992) has shown that two relatively related languages may differ as to whether they instantiate switch-reference in complement control. In Hopi, switch-reference markers may occur in complement control. (65a) is an instance of subject control, (65b) an instance of 'object raising', (65c) an instance of object control and (65d) an instance of clause sequencing with identical subjects.

(65) Hopi: switch-reference system (Hale 1992:51/53/67/53)
a. $\mathrm{Nu}^{\prime}$ 'as [ ${ }_{-}$kweewa-t tu'i-ni-qa-y] naawakna 1SG PRT belt-ACC buy-FUT-NC-ACC.SS want 'I want to buy a belt'
b. Nu' ['i-pava 'inu-ngam kweewa-t yuku-ni-qa-t] $1 \mathrm{SG}$ my-brother me-for belt-ACC make-FUT-NC-ACC.DS naawakna want 'I want my brother to make me a belt'



c. Taaqa tiyo-t [ $\quad$ _ kaway-mu-y 'oyato-ni-qa-t $]$ 'ayata man boy-ACC horse-PL-ACC put-FUT-NC-ACC.DS send 'the man sent the boy to put the horses back'
d. Pam wu'ti noes-q (puu') mi taaqa pitu that woman eat-DS then that man arrive 'the woman ate and (then) the man arrived'

In the related language Miskitu, the switch-reference markers are not used with control verbs. Instead, infinitival complements are chosen.

(66) Miskitu (Hale 1992:54/ibid./65/66)
a. yang [witin nani aisi-n] wal-ri
$1 \mathrm{SG}$ they PL speak-DS.3 hear-PAST.1
'I heard them speak'
$\begin{array}{lllll}\text { b. yang } & \text { sula } & \text { kum } & \text { kaik-ri } & \text { plap-an } \\ \text { 1SG } & \text { deer } & \text { a } & \text { see-DS.1 } & \text { run-PAST.3 }\end{array}$
'I saw a deer and it ran'
c. yang [ _ Ulwa lan tak-aia $]$ trai kaik-ri
1SG Ulwa learn become-INF try see-PAST.1
'I tried to learn Ulwa'

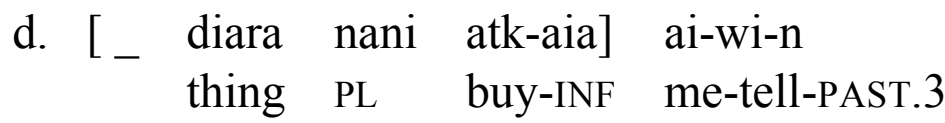
'he told me to buy things'

The switch-reference markers are used in 'object raising' as in (66a) and in clause sequencing as in (66b), but not in subject control as in (66c) or object control as in (66d). ${ }^{13}$

In Imbabura Quechua control verbs select structures marked with switchreference markers. Example (67a) shows that the subject control verb muna 'want' selects a complement marked with the same-subject marker -ngapaj. If the verb ayuda 'help' is used as a control verb as in (67b), it embeds a complement with the different-subject marker -chun because it behaves as an object control verb. ${ }^{14}$

(67) Imbabura Quechua (Jake 1985:178/181)

a. [ can [nuca-ta ayuda-wa-ngapaj] muna-na-ta] cri-n 2SG 1SG-ACC help-1SG.A-SS want-FUT-ACC think-3 'he thinks that you want to help me'

13 Hale provides an example from Miskitu in which the verb for 'begin' is used with a switch-reference marker on its complement. Hale leaves the question open whether this verb is a raising or a control verb.

14 Note that the structure in (67b) seems to be an instance of backward control: the controller is realized within the complement clause of ayuda. 

b. [[ can yachachi-wa-chun] ayuda-ngapaj] muna-n 2SG teach-1sG.A-DS help-SS want-3 'he wants to help you teach me'

Scattered instances of switch-reference can also be found in Kolma Yukaghir, as Maslova (2003) has shown: It is restricted to patterns of subject control (hence, it occurs only with ss markers).

(68) Kolma Yukaghir: switch-reference (Maslova 2003: 414)

[čomōlben qayī-nu-t] kis'ie-l'el-ni

elk pursue-IMPF-SS.IMPF learn-INFER-3PL.ITR

'they learnt how to pursue elk'

The fact that many languages with elaborated devices of switch-reference marking do not use these structures systematically in case of complement control suggests that switch-reference marking seems to be redundant and that the control reading is already determined lexically to some extent. Switchreference markers could, however, be relevant in encoding control shifts, i.e. marked control readings. So far, I have found evidence for the encoding of control shifts by means of a switch-reference marker only in Tukang Besi, for which Donohue (1999) provides a few examples. Further research is needed to check whether other languages allow similar patterns.

\section{Lexical classes}

The classes of control predicates proposed in the literature serve various functions. The classification by Sag \& Pollard (1991) and Pollard \& Sag (1994) mainly distinguishes between predicates of subject control and predicates of object control: influence-verbs (object control, e.g. persuade, appeal), commitment-verbs (subject control, e.g. promise, try) and orientation-verbs (subject control, e.g. want, hate). The controller corresponds to a class-specific thematic role (INFLUENCED, COMMITTOR, EXPERIENCER).
a. try:
[COMMITTOR, SOA-ARG]
b. persuade:
[INFLUENCE, INFLUENCED, SOA-ARG]
c. want:
[EXPERIENCER, SOA-ARG]

Petter (1998) distinguishes between obligatory subject and obligatory object control and intransitive and transitive verbs of variable control. Landau (2000) aims at a classification that singles out predicates of potential partial control - in contrast to predicates that are restricted to exhaustive control.

All these classifications do not take into account whether the control predicates select structures that induce control or whether they also allow for control-neutral structures. A classification of control predicates should aim at a 
distinction of predicates that invariably trigger control readings irrespective of the type of sentential complementation, those that only license structures that induce control, and those that do not allow neither inherent nor structural control.

Verbs/predicates are usually not restricted to one pattern of subordination but may allow for various subordination patterns (e.g. allowing a control-inducing structure such as an infinitival clause and a control-neutral structure such as a nominalized complement). Regarding the clausal selection pattern one may distinguish three types, ignoring differences between the various types of control-inducing or control-neutral structures. First, there may be predicates that only select control-inducing structures. Secondly, there may be predicates that allow control-inducing as well as control-neutral structures. Thirdly, there may be predicates that are restricted to control-neutral clausal complements. Controlneutral structures present the test case regarding the lexical control property of the matrix predicate: If a control reading is obligatory even in this case, the matrix predicate must be an inherent control predicate. If there is no obligatory control reading but free reference of the embedded subject, the matrix predicate does not show any inherent control. The types of sentential complementation and their control readings yield five lexical predicate classes.

(70) summarizes the interesting classes of predicates. ' $V$ ' indicates that the relevant structure is selected by the predicate. [+control] and [-control] denote whether a control reading is required despite the control-neutral character of the SOA-argument.

(70) SOAA-taking predicates

\begin{tabular}{|l|c|c|}
\hline & control-inducing & control-neutral \\
\hline Strong inherent control & $\sqrt{ }$ & $*$ \\
\hline Weak inherent control & $\sqrt{ }$ & $\sqrt{ }[+$ control $]$ \\
\hline Structural control & $\sqrt{ }$ & $\sqrt{ }[$-control $]$ \\
\hline Marked inherent control & $*$ & $\sqrt{ }[+$ control $]$ \\
\hline Non-control & $*$ & $\sqrt{ }[$-control $]$ \\
\hline
\end{tabular}

Hence, a weak inherent control predicate is one that allows control-inducing as well as control-neutral clausal complements, but instantiates a control reading in any case. Marked inherent control occurs if the matrix predicates only selects a control-neutral clausal complement despite its inherent control property. I will discuss the various classes more thoroughly below.

Note that the class of structural control predicates could be further differentiated: It may be the case that the readings available in the controlneutral structure have to be complementary to the readings in the controlinducing structure, hence disjoint ([+disjoint $]$ ), which has been described as 
'obviation' effect (Farkas 1992 and the references cited above), or the controlneutral structure is not subject to the disjoint reference effect.

A more fine-grained analysis of control predicate classes could further distinguish between predicates that take SOA-'objects' and those that take SOA'subjects'. And although the status of the SOA-argument as structural or nonstructural/oblique does not seem to play a role for control, but possibly could, one could in addition distinguish between canonical and oblique SOAarguments. The distinction between subject/object/variable control and between exhaustive/partial/ split control would yield further classes, which, however, would result in a rather complex lexical cross-classification. Therefore, I will confine myself to the classes in (70).

Languages that lack control-inducing structures only distinguish between inherent control predicates and non-control predicates.

\subsection{Strong inherent control}

The class of predicates that only select control-inducing structures is often rather small; many inherent control predicates often allow at least a nominalized SOAcomplement as control-neutral structure. Typical instances of this class are phasal and modal verbs, although it has to be shown that they are true control verbs, not just raising verbs. Likewise, implicative verbs like 'dare', 'manage' or 'try' are among the predicates that most likely exhibit strong inherent control.

Among the Polish control verbs that only select infinitival complements are przestać 'quit', śmieć 'dare', spróbować 'try', zdolać 'manage', zwyknqć 'use to' (see Słodowicz 2006). In German, sich weigern 'refuse', sich erdreisten/ erkühnen 'have the audacity to do/dare' are among the few predicates that are restricted to infinitival complements and do not allow nominalized complements; fort-fahren 'continue', an-fangen 'start', wagen 'dare', sich an-gewöhnen 'get used to', leicht sein 'be easy', schwierig sein 'be difficult', ver-lernen 'unlearn', for instance, all allow a nominalized complement instead of an infinitival complement and, thus, belong to the following class of weak inherent control predicates.

In Q'eqchi' (Kockelman 2003), aspectuals (e.g. choyok 'finish', yoobank 'begin'), implicatives like yalok 'try' or kanabank 'desist from', movement verbs, some psych-predicates (e.g. lubk 'tire of', jiq'e'k 'choke on', xutaanak 'be ashamed'), and manipulative predicates constitute the class of strong inherent control predicates, licensing only infinitival or nominalized complements, the latter being control-inducing structures unexpectedly.

\subsection{Weak inherent control}

If nominalized complements are taken into consideration, many inherent control predicates fall into the class of weak inherent control predicates because they 
license nominalized complements. This is shown in (71a) for auffordern 'ask/request' and überreden 'persuade'. Non-control readings are not available, as shown in $(71 b)$.

(71) a. Sie haben ihn zum Verzicht auf das Mandat aufgefordert/ they have him to.the renunciation on the mandate ask.PTC/ überredet.

persuade.PTC

'they have asked/persuaded him to renounce his mandate'

b. * Sie haben ihn zu Marias Verzicht auf das Mandat they have him to Mary's renunciation on the mandate aufgefordert/ überredet. ask.PTC/ persuade.PTC

'they have asked/persuaded him that Mary renounces her mandate'

However, there is a difference between nominalized complements and finite complements; the latter are often excluded with inherent control predicates. Polish has inherent control verbs that may take a nominalized complement, but not a finite complement (e.g. obiecać 'promise', zdażyć 'manage', nakazać 'order', zakazać 'forbid'; see Słodowicz 2006).

In German, one only finds scattered instances of finite complements with inherent control predicates such as directive verbs. (72) is an example for überreden 'persuade' (the only instance in the TAGGED corpus of the IDS).

(72) Nachdem Mathias Stätter die angeschlossenen Fahrer der Taxi-

Vereinigung überredet hatte, daß doch jeder mit 1000 Mark zur

Anschaffung des Datenfunk-Systems beitragen solle...

'After Matthias Stätter had persuaded the drivers of the taxi organization that everybody should contribute 1000 German marks to the purchase of the radio system'

Note that one has to check carefully if the predicate that occurs with a finite complement has the meaning related to the control variant. German control predicates such as versprechen 'promise' or überzeugen 'convince' have additional meanings that do not require control. Versprechen can have an epistemic reading in which the subject referent has strong evidence for a certain state of affairs (versprechen = 'know for sure'; see (73)); überzeugen can also mean that the subject referent tries to invoke a certain mental state in the object referent. In contrast, überreden 'persuade' can only mean 'talk someone into doing something'; there is no meaning shift available that might license noncontrol readings. 
(73) Natürlich kann niemand versprechen, daß die Ex-DDR in diesem oder im nächsten Jahr einen rasanten wirtschaftlichen Aufschwung nimmt.

[IDS-corpus]

'Of course, no one can promise (= know for sure) that there will be a rapid boom in the former GDR in this or the following year.'

In Spanish (and some other Romance languages), directive verbs allow infinitival as well as subjunctive complements, which are far more common than finite clauses with inherent control predicates in German. The subjunctive complements of these predicates can only occur with a control reading.

(74) Spanish
a. te
prohíbo
[que entres]
2SG.ACC forbid.1SG COMP enter.2SG.SUBJ
'I forbid you that you come in'
b. te $_{\mathrm{i}}$
prohíbo [ _i $_{i}$ entrar$]$
2SG.ACC forbid.1SG
enter.INF
'I forbid you to come in'

\subsection{Marked inherent control}

In some languages directive verbs with an inherent control reading show an unexpected selection pattern: they select a subjunctive complement even though the respective language has a control-inducing structure (e.g. infinitive). This can be observed, for instance, in Hungarian. Most directive verbs (e.g. meg-kér 'ask', kényszerit 'force', meg-gyöz 'convince') select a subjunctive; the infinitive is impossible.

(75) Hungarian (Farkas 1988:91, Beata Gyuris, p.c.)
a. János ${ }_{i}$ meg-gyöz-te Mariá- $t_{j}$ [hogy _j/****k men-jen/
J PV-convince-PAST.3SG M-ACC COMP go-3SG.SUBJ/
*men-ni vel-e]
go-INF with-3sG

'János convinced Mary to go with him'

b. Péter ${ }_{i}$ meg-kér-te Mariá-t $\mathrm{j}_{\mathrm{j}}\left[\right.$ hogy $_{-} \mathrm{j}^{\mathrm{j} / \mathrm{*}_{\mathrm{i}} / *_{\mathrm{k}}}$ vegye meg

P PV-ask-PAST.3SG M-ACC COMP buy.SUBJ.3SG PV

az ennivaló-t]

the food-ACC

'Peter asked Mary to buy the food'

The Nilotic language Lango shows the same pattern: infinitival complements occur in case of subject control, subjunctive complements in case of object control verbs as in (76b). 
(76)

Lango (Noonan 1985:67)

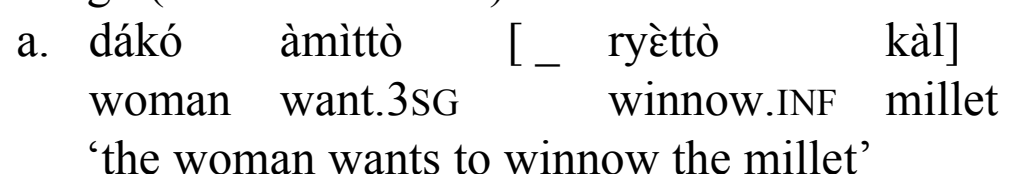

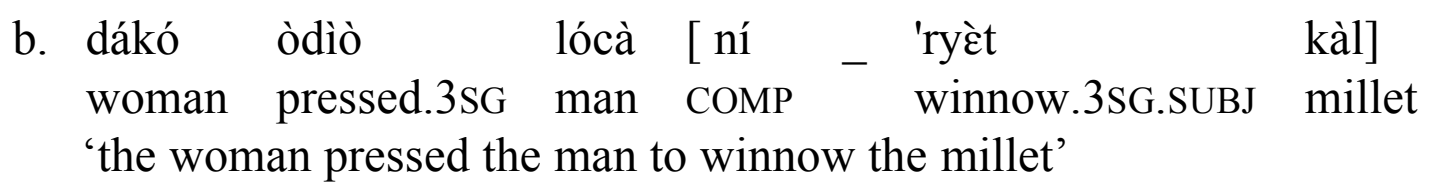

Why do these languages show this marked pattern to encode inherent control? Recall that the same class of predicates may select a subjunctive in Spanish and other Romance languages as well; there, however, the infinitival complement is possible. The first speculation might be that the subjunctive encodes some kind of unrealized event, which is one of the characteristics of the complements of these predicates. However, this raises immediately the question why desiderative predicates do not show the same strong preference for subjunctive complements in these languages.

There are two observations that may provide an alternative explanation. The first observation concerns the fact that Korean utterance predicates are coerced into directive predicates if the complement clause is marked by imperative (see Gamerschlag, this volume), as the following example illustrates. Without the additional modal morphology, the predicate does not necessarily instantiate a control reading (see (77a)); the imperative requires an object control reading, as shown in (77b).

(77) Korean (Gamerschlag, this volume)

a. Chelswu-nun $n_{i}$ Yenghi-eykey $_{j}\left[{ }_{-} \mathrm{i} / j \mathrm{k}\right.$ caknyen-ey safari-yehayng-ul C.-TOP Y.-DAT last.year-in safari-trip-ACC hay-ss-ta-ko] malhay-ss-ta.

do-PAST-DECL-CMP say-PAST-DECL

'Chelswu told Yenghi that he/she/s.o. did a safari trip last year.'

b. Chelswu-nun ${ }_{i}$ Yenghi-eykey ${ }_{j}\left[\__{j} / *_{i} / *_{k}\right.$ naynyen-ey safari-yehayng-ul C.-TOP Y.-DAT next.year-in safari-trip-ACC

ha-la-ko] malhay-ss-ta. do-IMP-CMP say-PAST-DECL

'Chelswu told Yenghi to go on a safari trip next year.'

The second observation concerns the interesting fact that the subjunctive in Hungarian and Lango shows a strong overlap with the imperative: In Hungarian, they form a common verbal paradigm, the example (78a) represents a subjunctive (with complementizer) and an imperative (without complementizer). In Lango the imperative corresponds to the subjunctive stem (leaving out 
agreement morphology). ${ }^{15}$ And in Spanish and other Romance languages, the polite imperative and the negated imperative actually take the subjunctive form, yielding a partial overlap.

(78) Subjunctive/imperative syncretism

a. Hungarian

$\begin{array}{lll}\text { (hogy) olvas-d } & \text { el } & \text { ez-t! } \\ \text { (COMP) read-2SG.IMP/SUBJ } & \text { PV } & \text { DEM-ACC } \\ \text { '(that you) read this!' } & & \end{array}$

b. Lango (Noonan 1992:93)

$\begin{array}{ll}\text { ì-kwánó } & \text { 2SG-read.PERF } \\ \text { ì-kwân } & \text { 2SG-read.SUBJ } \\ \text { kwăn } & \text { read.IMP.SG }\end{array}$

c. Spanish

ven come.2SG.IMP

venga come.3SG.SUBJ/come.3SG.IMP

no vengas NEG come.2sG.SUBJ 'don't come!'

Although the subjunctive in these languages covers a spectrum of meanings that cannot be equated with the imperative, one may ask whether the overlap of imperative and subjunctive is accidental and without any relevance for the emergence of the subjunctive preference in directive control predicates. I do not take this syncretism to be an accident and the subjunctive only a marker for unrealized events. ${ }^{16}$ I assume that directive verbs could have evolved from predicates that introduce reported speech, which at a previous stage might have been direct speech. There are still languages that avoid indirect speech and, thus, do not show the respective matrix predicates. Therefore, subjunctive complements may represent a late stage of grammaticalization, in which the directive force of the imperative has been integrated into the matrix predicate without giving up completely the imperative morphology on the embedded predicate. (79) sketches a possible path of grammaticalization, in which first reported speech is changed to indirect speech, then the directive force is added to the meaning of the matrix predicate. Finally, imperative morphology in the complement clause becomes superfluous. Hungarian and Lango may thus represent stage $(79 \mathrm{c})$.

15 In Lango, subjunctive/imperative show a specific underlying tonal pattern, which deviates from that of indicative forms. Due to tone sandhi, the imperative stem in (78b) is not completely identical to the subjunctive stem.

16 Note that there is no difference in Hungarian between directive verbs that entail the embedded situation (with predicates such as 'force') and those that do not (with predicates of request). 
(79)

Grammaticalization

a. I say to him: "you must go"/"go!"

b. I say to him, he must go.

c. I tell him he must go

d. I tell him to go.

Further typological research must reveal how widespread the syncretism of subjunctive and imperative is in cases in which directive predicates instantiate marked inherent control. ${ }^{17}$ In view of the typological literature it is remarkable that directive verbs, which are considered to be rather likely candidates for syntactically coherent structures (see Givón's (1990) and Cristofaro's (2003) hierarchies in (43) and (77)), may deviate from the expected pattern. ${ }^{18}$ For theoretical approaches such as Hornstein's (1999), the fact that excellent candidates for obligatory control do not instantiate a structure that is used in subject control and in raising is likewise unexpected.

There may also be other instances of marked inherent control. Słodowicz (2006) reports that Polish odmówić 'refuse' and some other predicates only select a nominalized instead of an infinitival complement. Since this pattern seems less systematic, it should be regarded a lexical idiosyncrasy, perhaps a relic of a previous diachronic stage.

\subsection{Structural control}

Unlike the predicate classes of inherent control, the predicate classes that license structural control show more cross-linguistic variation. Since there is no inherent preference for a control-inducing structure because a co-referent reading is only one alternative among various options, other properties of the control-inducing structure may determine whether it will be selected by the respective predicate. Utterance predicates, for instance, which do not trigger any time or world dependence regarding their SOA-argument may select a control-inducing structure according to its potential to encode various temporal and modal relations. The latter aspect will also be relevant for factive predicates (see below).

17 According to Isac \& Jacob (2004) the subjunctive in Balkan languages has imperative force as well.

18 Note that Cristofaro's hierarchy and her predictions regarding sentential complementation are not valid for Hungarian: Here, perception verbs, which are lower on the hierarchy than directive/manipulative verbs, may take an infinitival complement (see (i)), which is not possible with most directive predicates; they take the syntactically less coherent subjunctive.
(i) Lát-tam a nap-ot fel-kel-ni
see-1SG.PAST.DEF the sun-ACC PT-rise-INF
'I saw the sun rise' [Kiss 2002:200] 
For a language such as German, structural control predicates are numerous compared to inherent control predicates. German seems to be a 'control-happy' language, i.e. almost all predicates that take an SOA-argument (with the systematic exception of interrogative predicates) may select an infinitival complement - though with a varying degree of frequency. Apart from very general utterance predicates such as sagen 'say', most utterance predicates or predicates of sound emission may take an infinitival complement if they are coerced into a meaning of a transfer of content by means of the utterance or sound omission, as the examples in (80) illustrate. These forms are not very frequent because they belong to a formal register.
a. Wir können nicht immer nur jammern, [am Rande we can not always only wail at.the edge Baden-Württembergs $\mathrm{zu}$ liegen]. B-W to lie 'we cannot always wail over being located at the edge of Baden- Württemberg' [IDS-corpus]
b. Er zischte, keine gebratene Blutwurst essen zu wollen. he hissed no fried blood.sausage eat to want 'he hissed not to want to eat fried blood sausage'

Whereas utterance predicates in German may occur with infinitival complements, other languages exclude utterance predicates from controlinducing structures (e.g. Q'eqchi', Kockelman 2003).

Factive predicates are also subject to cross-linguistic variation. Whereas Polish factive predicates (Słodowicz 2006) do not allow infinitival complements, German factive predicates may take infinitival complements, especially if the embedded predicates are modalized, as shown in the examples for bedauern 'regret' in (81a-c). The modals function as stativizers, thus yielding event types which seem to be more in line with the factivity requirement of the matrix predicate. Likewise, the use of the aspectual auxiliary haben enhances the embedding of infinitival complements under factive predicates.

(81) German: infinitival complements of bedauern 'regret' [IDS-corpus]

a. Er bedauerte, aufgrund des Steuergeheimnisses keine weiteren he regretted because.of the tax.privacy no further Angaben $\mathrm{zu}$ dem Fall machen $\mathrm{zu}$ dürfen statements to the case make to be.allowed 'he regretted not to be allowed to make further statements concerning the case because of tax privacy' 
b. Unter den 26, die schriftlich bedauerten, nicht dabeisein $\mathrm{zu}$ among the 26 who in.writing regretted not participate to können ...

be.able

'among the 26 who regretted in writing not to be able to participate'

c. Die tschechischen Ermittler bedauern sehr, mitteilen zu müssen ... the Czech detectives regret very inform to have

'the Czech detectives regret honestly, to have to inform'

d. ... sie bedauert es, nicht schon viel früher den Schritt zu einem she regrets it not already much earlier the step to a Neuanfang gewagt $\mathrm{zu}$ haben ... new.beginning dared to have 'she regrets not to have dared earlier the move to a new beginning'

A factive predicate like bereuen, which roughly corresponds to 'repent' (although in a less religious sense) and which is a predicate of inherent control because one can only show or feel contriteness for one's own actions, shows a slight preference for infinitival complements over finite complements. That some factive predicates require a control reading, whereas others do not, shows that factivity and control are independent from each other.

Structural control is also typically found with predicates that take SOA'subjects'. The fact that one can observe the disjoint reference effect with subjunctive SOA-'subjects' as in (82) shows both that here control is not inherent but structural and that there is control into SOA-'subjects'. Recall that I define SOA-'subjects' as SOA-arguments in highest argument position.

(82) Spanish: obviative effect in subject clauses
a. $\mathrm{Me}_{\mathrm{i}}$ molesta $\left[\mathrm{L}_{\mathrm{i}}\right.$ venir tan tarde] 1SG.ACC disturb.3SG come.INF so late
'it disturbs me to come so late'
b. Me molesta [que Juan/*yo haya venido tan 1sG.ACC disturb.3SG COMP J/1sG AUX.SUBJ come.PTC so tarde]
late
'it disturbs me that Juan/*I has/have come so late'

\section{Further evidence for the dual nature of complement control}

In the previous sections I have already shown the relevance of the lexicon for complement control. In this section I will discuss two further constructions that 
reveal the dual lexical-syntactic nature of control: backward control and control in embedded questions.

\subsection{Backward control}

Another interesting evidence for the double lexical-syntactic nature of complement control is the structure of backward control: Here, the controller is realized in the embedded clause, whereas the unrealized controllee can be postulated for the matrix clause. ${ }^{19}$ Backward control has been claimed for Japanese ('counter-equi', see Harada 1973), Jakaltek (Grinevald Craig 1977), Brazilian Portuguese (Farrell 1995), Tsez and related Daghestanian languages (Polinsky \& Potsdam 2002a), Malagassy (Polinsky \& Potsdam 2002b), Korean (Monahan 2003). ${ }^{20}$ The Na-Dene language Haida (Enrico 2003) exhibits patterns of backward control as well.

Backward control is per definition only possible in structures of sentential complementation in which the argument to be identified with an argument of the matrix predicate is realized overtly. Hence, the structures are not controlinducing, which is also true for the matrix clause. This, however, means that backward control should be restricted to inherent control predicates; otherwise, the notion of control would not make sense.

The lexical character of backward control is documented in the class of verbs that trigger backward control; only a small subset of control predicates license structures of backward control. With the majority of verbs, all respective languages display forward control, which reflects the marked character of backward control. Cross-linguistically, the respective class of control predicates is not homogeneous. In Tsez and other Daghestan languages as well as Malagassy, backward control can be found with aspectual verbs such as 'begin', 'continue', 'stop'. Korean exhibits backward control with directive verbs such as 'persuade'. In Jakaltek, movement verbs optionally seem to trigger backward control.

The following example from Korean illustrates backward object control. (83a) shows the typical pattern of forward control: the controller is realized in the matrix clause as accusative object of the verb seltukhata 'persuade'. In (83b) the controller is realized in the complement clause; here, it receives the subject

19 The notion of 'backward control' is rather unfortunate because it covers, in linear terms, backward as well as forward control. 'Upward control' would be more adequate. However, since the notion of backward control has been established in the literature, I will use it in the following.

20 As far as I can see, Brazilian Portuguese is misanalyzed. The evidence provided by Farrell (1995) is not striking. I assume that the two verbs mandar 'send' and fazer 'do' are potential ECM-verbs in which the subject of the embedded verb is not raised into the matrix clause. 
linker nominative. Monahan (2003) provides ample evidence (case marking, scrambling, temporal adverbs) that the controller is realized within the subordinate clause.

(83) Korean: Backward control vs. forward control (Monahan 2003:357)

a. Chelswu-nun Yenghi-lul ${ }_{i}{ }_{-}$i kakey-ey ka-tolok $]$ Ch-TOP Y-ACC store-LOC go-COMP seltukha-ess-ta persuade-PAST-DECL

'Chelswu persuaded Yenghi to go to the store'

b. Chelswu-nun _ ${ }^{i}$ [Yenghi-ka ${ }_{i}$ kakey-ey ka-tolok] Ch-TOP Y-NOM store-LOC go-COMP seltukha-ess-ta persuade-PAST-DECL

'Chelswu persuaded Yenghi to go to the store'

Haida shows an interesting case of 'case transfer' in backward control: The matrix verb selects an inactive subject, whereas the embedded verb selects an active subject. However, in the embedded clause the inactive pronominal marker (INACT) is used. Word order facts - the controller stands between embedded object and embedded verb - and especially the interpretation of the clitic = Pisan 'too' - provide evidence for backward control.

(84) Haida: backward control (Enrico 2003:888)

$\begin{array}{lllll}\text { ['laa-Caa } & \text { dii=?isan } & \text { guusuw-ee-rii] } & \text { /*dii } & \text { kilsda-ang } \\ \text { 3-OBL } & \text { 1SG.INACT=too talk-INF-OBL } & \text { /1SG } & \text { be.tired.of-PRES } \\ \text { 'I am tired of talking to him too' } / * \text { 'I too am tired of talking to him' }\end{array}$

'I am tired of talking to him too'/ *'I too am tired of talking to him'

The following properties of backward control have to be taken into account: a) The admissibility of backward control is cross-linguistically parameterized. So far, backward control has only been reported for a small number of languages. b) Backward control seems only to allow a reduced range of control readings (compared to forward control). Up to now, only exhaustive readings have been documented. $^{21}$ c) Backward control can be found in verb-final (e.g. Korean, Tsez) as well as verb-initial languages (e.g. Malagassy). In verb-final languages, backward control could be characterized as a kataphoric relation between con-

21 The restriction to exhaustive readings allows movement analyses as those proposed by Polinsky \& Potsdam (2002a/b).

In semantic terms, the restriction to exhaustive readings corresponds to the simplified semantic representation of control (see page 8), illustrated here for a control verb such as force: $\lambda \mathrm{P} \lambda \mathrm{x} \lambda \mathrm{y}$ FORCE $(\mathrm{x}, \mathrm{y}, \mathrm{P}(\mathrm{y}))$. The specific effect of backward control would thus be a systematic syntax-semantics mismatch. The saturation of the arguments must be bound to the embedded clause, indicated by bracketing on the theta-grid:

$[\lambda \mathrm{P} \lambda \mathrm{y}]_{\mathrm{IP}} \lambda \mathrm{x} \operatorname{FORCE}(\mathrm{x}, \mathrm{y}, \mathrm{P}(\mathrm{y}))$. 
troller (filler) and controllee (gap), whereas in verb-initial languages this could be characterized as an anaphoric relation:
a. $\left[{ }_{i}\left[\mathrm{NP}_{\mathrm{i}} \mathrm{V}\right] \mathrm{V}\right]$
[verb-final $=$ 'kataphoric']
b. $\left[\mathrm{V}\left[\mathrm{V} \mathrm{NP}_{\mathrm{i}}\right]_{-} \mathrm{i}\right]$
c. $\left[{ }_{\mathrm{i}} \mathrm{V}\left[\mathrm{NP}_{\mathrm{i}} \mathrm{V}\right]\right]$
[verb-initial $=$ 'anaphoric']
[mixed structures]

d) Backward control occurs preferentially in languages with surface orders that are potentially ambiguous between forward and backward control (see also Potsdam \& Polinsky 2002a). If no matrix clause element (e.g. an adverb) intervenes between the controller/controllee and the embedded clause, forward and backward control cannot be distinguished in terms of word order, although they may be distinguished in terms of case marking.

$\begin{array}{llll}\text { Control type } & \text { verb-initial } & \text { verb-final } & \text { mixed } \\ \mathrm{BC} & {\left[\mathrm{V}\left[\mathrm{V} \mathrm{NP}_{\mathrm{i}}\right]_{\mathrm{i}}\right]} & {\left[{ }_{-}\left[\mathrm{NP}_{\mathrm{i}} \mathrm{V}\right] \mathrm{V}\right]} & {\left[{ }_{\mathrm{i}} \mathrm{V}\left[\mathrm{NP}_{\mathrm{i}} \mathrm{V}\right]\right]} \\ \mathrm{FC} & {\left[\mathrm{V}\left[\mathrm{V} \_\mathrm{i}\right] \mathrm{NP}_{\mathrm{i}}\right]} & {\left[\mathrm{NP}_{\mathrm{i}}\left[{ }_{i} \mathrm{~V}\right] \mathrm{V}\right]} & {\left[\mathrm{NP}_{\mathrm{i}} \mathrm{V}\left[\_\mathrm{i}\right]\right]}\end{array}$

e) The presence of backward control does not necessarily correlate with the presence of other deep-embedding structures (e.g. internally headed relative clauses, which occur in Korean, Japanese and Haida, but not in Tsez, Jakaltek or Malagassy).

f) Backward control preferentially occurs in languages in which the matrix predicate does not need to agree with the control argument (with the exception of Tsez and its close relatives). Tsez is peculiar in that it allows non-local agreement in other structures as well (see Polinsky \& Potsdam 2001, Polinsky 2003).

Structures that remind of backward control can also be found in German. In contrast to zwingen 'force', the derived variant er-zwingen 'force' preferentially selects a clausal structure in which the person put under pressure is realized as an overt argument of the embedded predicate (see (87b)).

(87) German

a. Gerhard zwang Joschka, [ _ das Training wieder auf-zu-nehmen]. $\mathrm{G}$ forced $\mathrm{J}$ the training again up-to-take.INF 'Gerhard forced Joschka to take up his training again'

b. Gerhard er-zwang, [dass Joschka das Training wieder auf-nimmt]. G PX-forced COMP $J$ the training again up-take.3SG 'Gerhard forced from Joschka to take up his training again'

The 'backward control' structure is used if the manipulation is of a more indirect nature, involving possibly an intervening authority. ${ }^{22}$

22 Cross-linguistically, directive verbs often comprise two classes: a class that only allows readings of direct manipulation (e.g. force, persuade) usually instantiated by structures 


\subsection{Control in embedded questions}

Since in some languages interrogative predicates select control-inducing structures besides finite clauses, the question arises which control patterns emerge. The syntactic aspect of control in embedded questions is the general admissibility of control-inducing structures, which is language-specific. Whereas English interrogative predicates allow control-inducing structures, i.e. WH-infinitives, Standard German does not: $(88 \mathrm{a} / \mathrm{b})$ shows extensional and intensional interrogatives in English, (88c/d) their German translations, which are ungrammatical. Since the controllee has to be covert in English, subject questions are ungrammatical as in (88e).
a. She cabled Helen [when _to send the package].
b. He wondered [how to reach the summit].
c. *Sie telegraphierte Helen [wann_das Paket zu schicken].
d. *Er fragte sich [wie _ den Gipfel zu erreichen].
e. *I don't know [who to go first].

Sabel (1996) attributes the admissibility of WH-infinitives to the option of filling the infinitival C-system with a base-generated overt element (e.g. for in English); Standard German lacks this option. Gärtner (2006) observes that there is a strong correlation between the admissibility of WH-infinitives and the uniqueness of the WH-pronoun in the respective language: If there is an overlap between the WH-pronoun and an indefinite/unspecific pronoun and, thus, potential ambiguity between a declarative and interrogative reading, WHinfinitives are ruled out. Since the overlap often does not affect the whole set of interrogative pronouns, further research is needed to establish the basis of the observed correlation.

According to Kornfilt (1997) Turkish does not allow structures of embedded questions that would resemble WH-infinitives; only factive nominals such as (89) are possible, no 'infinitival' structures, which would be nominalized verb forms without possessor agreement (see also (56)):

Turkish (Kornfilt 1997:52f.)
a. (sen) ban-a [Ahmed-in öl-üp öl-me-diğ-in]-i 2SG 1SG-DAT A-GEN die-and die-NEG-NOML-3SG.P-ACC sor-ma! ask-NEG 'don't ask me whether Ahmet has died (or not)'

such as $\left[\ldots \mathrm{DP}_{\mathrm{i}} \mathrm{V}_{1} \mathrm{DP}_{\mathrm{j}}\left[\__{\mathrm{j}} \mathrm{V}_{2} \ldots\right]\right]$ and a class that allows readings of indirect/mediated manipulation as well (e.g. order), often instantiated in structures such as $\left[\ldots \mathrm{DP}_{\mathrm{i}} \mathrm{V}_{1}\left[\mathrm{DP}_{\mathrm{j}}\right.\right.$ $\left.\left.\mathrm{V}_{2} \ldots\right]\right]$. The latter structures remind of backward control (see Tomić 2006 for examples in Balkan languages). 

b. Hasan ban-a [kim-in öl-düğ-ün]-ü sor-du $\mathrm{H}$ 1SG-DAT who-GEN die-NOML-3SG.P-ACC ask-PAST 'Hasan asked me who had died'

Besides the fact that the general admissibility of embedded questions with control-inducing structures is language-specific, there is also evidence for a lexical factor in WH-infinitives. In English the set of predicates that license WH-infinitives seems to be a subset of the predicates that select finite embedded questions, as the following data show; among Huddleston's (2002) ten classes of interrogative predicates, four do not allow WH-infinitives, namely predicates that express disbelief, surprise, dependence, or significance:

(90) English: unacceptable WH-infinitives; Huddleston (2002a:985)

a. I doubt [whether I should accept].

a'. *I doubt [whether_to accept].

b. It was amazing [what they offered].

b'. *It was amazing [what to offer].

c. It depends on [how much I must pay].

c'. *It depends on [how much _ to pay].

d. I don't care [whether I go or not].

d'. *I don't care [whether_to go or not].

Another potential lexical factor has not been studied thoroughly, namely the question of whether there are predicate-specific control readings. There is no consensus in the literature regarding the potential control readings in $\mathrm{WH}$ infinitives. In the syntactic literature, WH-infinitives have been assumed to show arbitrary control, typically illustrated by examples like the following, in which the anaphor oneself is taken as indication for arbitrary control.

(91) $\mathrm{John}_{\mathrm{i}}$ asked [how_j to behave oneself $\mathrm{f}_{\mathrm{j}}$.

In contrast, Landau (2000) assumes partial control for WH-infinitives because arbitrary control should render the following example grammatical; here, the controller is co-referential with the pronominal object of the embedded predicate. The blocking of pronominal binding can only be explained if the subject referent of the embedded clause is a potential binder of the object pronoun.

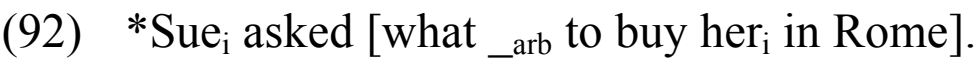

Jackendoff \& Culicover (2003) show that generic readings are excluded for embedded infinitival polar questions:

(93) Harry ${ }_{\mathrm{i}}$ asked Sally $\mathrm{j}_{\mathrm{j}}\left[\right.$ whether $\_\mathrm{i} / *^{*} \operatorname{gen} / *_{\mathrm{j}}$ to take care of himself $/{ }^{*}$ oneself/ *herself]. 
One can also find instances of split control, for instance in Spanish WHinfinitives:

(94) Spanish: split control in WH-infinitives

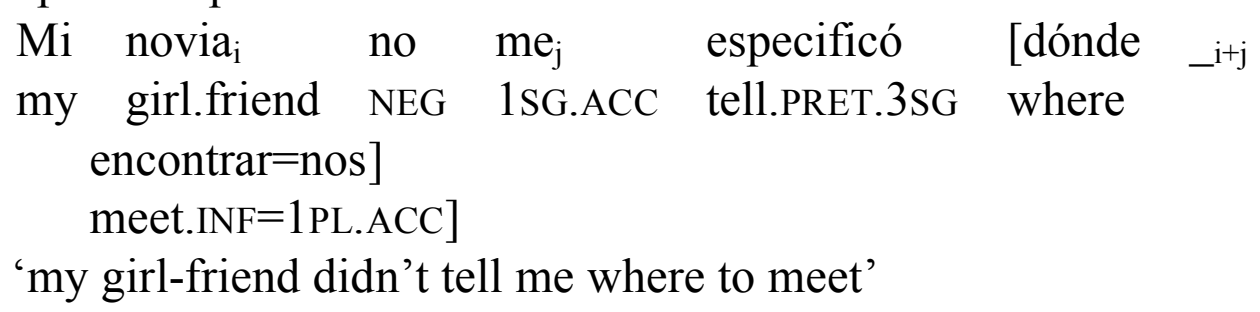

The unclear status of the potential referential readings in WH-infinitives is due to the fact that an exhaustive study of all interrogative predicates and their admissible readings regarding WH-infinitives still has to be carried out. One might speculate that there may be predicate-specific control readings as in the case of embedded declaratives. Nevertheless, restrictions on potential readings of the controllee seem to be loosened compared to control declaratives.

So far there is no attested case of an interrogative predicate with inherent control, which suggests that interrogative predicates are either structural control predicates or non-control predicates, the latter being predicates that exclude WH-infinitivals (see (90)). It is very difficult to think of an interrogative predicate with inherent control, at least with an inherent subject control reading. A potential candidate would be a predicate with a meaning such as 'wonder about one's own perspectives in life' with the SOA-argument denoting the question regarding a specific aspect, e.g. regarding 'when winning the lottery'. An interrogative predicate with inherent object control could, for instance, be a predicate such as 'interrogate someone regarding SOA' in which the predicate only refers to situations of interrogation in which the interrogated person can only be someone accused of something, not a person having witnessed something. So far, no such predicates have been highlighted in the discussion of interrogative predicates.

\section{Summary}

In this paper I have shown the complex interplay of lexicon and syntax in complement control. The lexicon mainly determines the control readings (especially the selection of the controller and the referential readings), whereas the syntax determines the syntactic complementation pattern (the structure of subordination, the admissibility of backward control and control in embedded questions) and in most languages the selection of the controllee.

An important distinction in complement control is that of structural vs. inherent control. Due to the focus on languages with infinitival complements, no strong attention has been paid to the question whether the control is induced by 
the structure or by the lexical meaning of the matrix predicates. Only research on languages with different complement patterns or on the structural alternatives of predicates that may show control will reveal whether the control reading is due to structural requirements of argument identification or due to semantic requirements in terms of the situation denoted by the matrix predicate.

Inherent control predicates are more homogeneous cross-linguistically than structural control predicates because their control property is determined by their meaning. Therefore, equivalent predicates in languages should show equivalent control properties. This, however, does not imply that they should have the same sentential complementation pattern, which is especially evident in terms of directive predicates, which in some languages constitute a separate class of marked inherent control, i.e. they select a control-neutral structure although a control-inducing structure is available in the respective language. Inherent control predicates include directive predicates, (agentive) phasal predicates and implicative predicates. These predicates share the property that the event denoted by the SOA-argument is in some way dependent on the event denoted by the control predicate (being, for instance, a bring-about relation or a implicative relation). This kind of event dependency seems to require argument sharing (as in the case of event coherence in serial verb constructions).

Regarding structural control, more emphasis and cross-linguistic research is needed with respect to the question of which predicates may select a controlinducing structure. Moreover, one may wonder why arbitrary control is hardly possible with SOAA-taking predicates in the context of control-inducing structures. The potential exceptions are SOA-subjects, though not generally. The avoidance of arbitrary control may be due to locality, i.e. a local controller is preferred over a non-local controller. Therefore, there is the strong tendency in non-inherent control predicates to select one of its arguments as controller in case of control-inducing structures.

Since most grammatical descriptions do not acknowledge the role of the lexicon in sentential complementation, there are no exhaustive lists of predicates including their syntactic properties. Therefore, an exhaustive lexical typology of control predicates is far from being achieved in the near future. Since the lexicons of languages differ (partly from environmental and cultural factors), a language may lack certain predicate classes. It can be observed that Australian and Oceanic languages do not exhibit the richness of directive predicates found in European languages (confirmed by Peter Austin p.c.). They often only exhibit a few causative-like verbs that do not encode the manner of manipulation. These languages, however, do not lack inherent control predicates in principle. 


\section{Abbreviations}

\begin{tabular}{|c|c|c|c|}
\hline$=$ & clitic boundary & $\mathrm{NF}$ & non-feminine gender \\
\hline A & 'accusative' agreement & NOM & nominative/default linker \\
\hline ABL & ablative & NOML & nominalization \\
\hline ACC & accusative & NONFACT & non-factual \\
\hline ANT & anteriority & NONVOL & non-volitive \\
\hline ANTIPASS & antipassive & NONSTRUCT & non-structural realization \\
\hline AUX & auxiliary & OBL & oblique \\
\hline AV & actor voice & OBJ & object case \\
\hline CAUS & causative & OPT & optative \\
\hline $\mathrm{CL}$ & classifier & OV & object voice \\
\hline $\mathrm{COM}$ & comitative & $\mathrm{P}$ & possessor agreement \\
\hline COMP & complementizer & PASS & passive \\
\hline CRS & 'current relevant state'marker & PAST & past tense \\
\hline DAT & dative & PERF & perfective \\
\hline DECL & declarative & PL & plural \\
\hline DEF & definite & PRES & present \\
\hline DET & determiner & PRET & preterite \\
\hline DETR & detransitivizer & PRO & pronominal form \\
\hline DIM & diminutive & PROG & progressive \\
\hline DIR & directional & PRT & not explained by Hale (1992) \\
\hline DS & different subject & $\mathrm{PT}$ & particle \\
\hline DV & dative voice & PTC & participle \\
\hline $\mathrm{E}$ & 'ergative' agreement & PX & prefix \\
\hline ERG & ergative & REFL & reflexive \\
\hline EXPE & expected & REM.PAST & remote past \\
\hline FUT & future & REP & reported evidential \\
\hline GEN & genitive & SG & singular \\
\hline IMP & imperative & SS & same subject \\
\hline IMPF & imperfective & SST & short stem \\
\hline INACT & inactive & STRUCT & structural realization \\
\hline INF & infinitive & SUBJ & subjunctive \\
\hline INFER & inferential & SUP & supine \\
\hline IRR & irrealis & TERM & terminative case \\
\hline ITR & intransitive & $\mathrm{TH}$ & thematic element \\
\hline IV & instrumental voice & TMP & tense marker \\
\hline LOC & locative & TOP & topic \\
\hline $\mathrm{N}$ & 'nominative' agreement & TR & transitive \\
\hline $\mathrm{NC}$ & not explained by Hale (1992) & VIS & visual (evidential) \\
\hline NEG & negation & VOL & volitional \\
\hline
\end{tabular}




\section{References}

Aikhenvald, Alexandra Y. (2003). A grammar of Tariana, from Northwest Amazonia. Cambridge: Cambridge University Press.

Andrews, Avery (1990). Case structures and control in Modern Icelandic. Joan Maling \& Annie Zaenen (eds.), Modern Icelandic Syntax. Syntax and Semantics 24. San Diego: Academic Press, 187-234.

Asudeh, Ash (2005). Control and semantic resource sensitivity. Journal of Linguistics 41, 465-511.

Bech, Gunnar (1955/57). Studien über das deutsche verbum infinitum, 2 vols. Copenhagen: Munksgaard.

Bech, Gunnar. 1983². Studien über das deutsche Verbum infinitum. Tübingen: Niemeyer.

Belletti, Adriana \& Luigi Rizzi (1988). Psych-verbs and $\theta$-theory. Natural Language and Linguistic Theory 6, 291-352.

Berinstein, Anne (1985). Evidence for multiattachment in K'ekchi Mayan. New York: Garland.

Bugenhagen, Robert D. (1995). A grammar of Mangap-Mbula: an Austronesian language of Papua New Guinea. Canberra: Pacific Linguistics.

Chang, Yung-Li \& Wei-tien DylanTsai (2001). Actor-sensitivity and obligatory control in Kavala and some other Formosan languages. Language and Linguistics 2, 1-20.

Chierchia, Gennaro (1983). Outline of a semantic theory of (obligatory) control. Proceedings of the West Coast Conference on Formal Linguistics 2, 19-31

Chierchia, Gennaro (1985). Formal semantics and the grammar of predication. Linguistic Inquiry, 16, 417-433.

Comorovsky, Ileana (1985). Control and obviation in Romanian. ESCOL 2, 47-56.

Comrie, Bernard (1984). Subject and object control: syntax, semantics, pragmatics. Proc. Berkeley Linguistics Society 10, 450-64.

Comrie, Bernard (1985). Reflections on subject and object control. Journal of semantics 4, 47 -65 .

Comrie, Bernard \& Sandra A. Thompson (1985). Lexical nominalization. In: Timothy Shopen (ed.), Language typology and syntactic description: Grammatical theories and the lexicon (Vol. III.). Cambridge: Cambridge University Press, 349-398.

Cristofaro, Sonia (2003). Subordination. Oxford: Oxford University Press.

Crowley, Terry (1987). Serial verbs in Paamese. Studies in Language 11, 35-84.

Culicover, Peter W. \& Ray Jackendoff (2001). Control is not movement. Linguistic Inquiry, 32, 493-512.

Davies, William (2004). Madurese control constructions. Paper presented at the workshop Control verbs in cross-linguistic perspective, April 2004, ZAS Berlin.

Dedrick, John M. \& Eugene H. Casad (1999). Sonora Yaqui language structures. Tucson: University of Arizona Press.

Donohue, Mark (1999). A grammar of Tukang Besi. Berlin: Mouton de Gruyter.

Dowty, David R. (1985). On recent analyses of the semantics of control. Linguistics and Philosophy 8, 291-331.

England, Nora C. (1989). Comparing Mam (Mayan) clause structures: subordinate vs. main clauses. International Journal of American Linguistics 55, 283-308. 
Enrico, John (2003). Haida syntax. Vol. I/II. Lincoln: University of Nebraska Press.

Farkas, Donka F. (1988). On obligatory control. Linguistics and Philosophy 11, 27-58.

Farkas, Donka F. (1992). On obviation. In: Ivan A. Sag \& Anna Szabolcsi (eds.), Lexical matters. Stanford: CSLI Publications, 85-110.

Farrell, Patrick (1995). Backward control in Brasilian Portuguese. Proceedings of ESCOL 11, Cornell University, 116-127.

Foley, William A. \& Robert D. van Valin Jr. (1984). Functional syntax and Universal Grammar. Cambridge: Cambridge University Press.

Gärtner, Hans-Martin (2006). From German quirk to universal tendency: a speculation on (the absence of) WH-infinitives. Ms., ZAS Berlin.

Gamerschlag, Thomas (this volume). Semantic and structural aspects of complement control in Korean.

Givón, Talmy (1984/1990). Syntax: a functional-typological introduction. Vol. I/II. Amsterdam: Benjamins.

Grinevald Craig, Colette (1977). The structure of Jacaltec. Austin: University of Texas Press.

Guerrero, Lilian (2004). Complement-taking predicates in Yaqui. Paper presented at SWL 1 (Syntax of the world's languages), Leipzig, August 2004.

Hale, Ken (1992). Subject obviation, switch reference, and control. In Richard K. Larson, Sabine Iatridou, Utpal Lahiri \& James Higginbotham (eds.), Control and grammar. Dordrecht: Kluwer, 51-77.

Harada, S. I. (1973). Counter equi NP deletion. Annual Bulletin of the Research Institute of Logopedics and Phoniatrics, 113-147. University of Tokyo.

Higginbotham, James (1992). Reference and control. In: Richard K. Larson, Sabine Iatridou, Utpal Lahiri \& James Higginbotham (eds.). Control and grammar. Dordrecht: Kluwer, 79-108.

Hornstein, Norbert (1999). Movement and control. Linguistic Inquiry 30, 69-96.

Huddleston, Rodney (2002a). Content clauses and reported speech. In: Rodney Huddleston \& Geoffrey K. Pullum (eds.), The Cambridge grammar of the English language. Cambridge University Press, 947-1030.

Hyslop, Catriona (2001). The Lolovoli dialect of the North-East Ambae language, Vanuatu. Canberra: Pacific Linguistics.

Isac, Daniela \& Edit Jakab (2004). Mood and force features in the languages of the Balkan. In: Olga Mišeska Tomić (ed.), Balkan syntax and semantics. Amsterdam: Benjamins, 315338.

Jackendoff, Ray \& Peter W. Culicover (2003). The semantic basis of control in English. Language $79,517-56$

Jake, Janice Lynn (1985). Grammatical relations in Imbabura Quechua. New York: Garland.

Joppen, Sandra \& Dieter Wunderlich (1995). Argument linking in Basque. Lingua 97, 123169.

Keenan, Edward L. (1976). Towards a universal definition of 'subject'. In: Charles N. Li (ed.), Subject and topic. New York: Academic Press, 303-33.

Kempchinsky, Paula (1987). The Subjunctive Disjoint Reference Effect. In: Carol Neidle \& Rafael. A. Nuñez-Cedeño (eds.), Studies in Romance Languages. Foris: Dordrecht, 123140.

Kiss, Katalin É. (2002). The syntax of Hungarian. Cambridge: Cambridge University Press. 
Kiss, Tibor (1995). Infinite Komplementation: Neue Studien zum deutschen Verbum infinitum. Tübingen: Niemeyer.

Kiss, Tibor (2005). On the empirical viability of the movement theory of control. Ms., University of Bochum.

Kockelman, Paul (2003). The interclausal relations hierarchy in Q'eqchi' Maya. International Journal of American Linguistics 69, 25-48.

Koptjevskaja-Tamm, Maria (1993). Nominalizations. London: Routledge.

Kornfilt, Jaklin (1997). Turkish. London: Routledge.

Kroeger, Paul (1993). Phrase structure and grammatical relations in Tagalog. Stanford: CSLI publications.

Landau, Idan (2000). Elements of Control: Structure and Meaning in Infinitival Constructions. Dordrecht: Kluwer.

Landau, Idan (2003). Movement out of control. Linguistic Inquiry 34, 471-498.

Landau, Idan (2004). The scale of finiteness and the calculus of control. Natural Language and Linguistic Theory 22, 811-877.

Levin, Beth (1993). English verb classes and alternations: a preliminary investigation. Chicaco: The University of Chicago Press.

Li, Charles \& Sandra A. Thompson (1981). Mandarin Chinese: A Functional Reference Grammar. Berkeley: University of California Press.

Manzini, Rita (1983). On control and control theory. Linguistic Inquiry 14, 421-446.

Maslova, Elena (2003). A Grammar of Kolyma Yukaghir. Berlin: Mouton de Gruyter.

McCloskey, James \& Peter Sells (1988). Control and a-chains in Modern Irish. Natural Language and Linguistic Theory 6, 143-189.

Mensching, Guido (2000). Infinitive constructions with specified subjects: a syntactic analysis of the Romance languages. Oxford: Oxford University Press.

Monahan, Philip J. (2003). Backward object control in Korean. Proceedings of WCCFL 22, 356-369.

Noonan, Michael (1985). Complementation. In: Timothy Shopen (ed.). Language typology and syntactic description: Complex constructions (Vol. II). Cambridge: Cambridge University Press, 42-140.

Noonan, Michael (1992). A grammar of Lango. Berlin: Mouton de Gruyter.

Panther, Klaus-Uwe (1993). Kontrollphänomene im Englischen und Deutschen aus semantisch-pragmatischer Perspektive. Tübingen: Narr.

Petter, Marga (1998). Getting PRO under control. The Hague: Holland Academic Graphics.

Polinsky, Maria (2003). Non-canonical agreement is canonical. Transactions of the Philological Society 101, 279-312.

Polinsky, Maria \& Eric Potsdam (2001). Long distance agreement and topic in Tsez. Natural Language and Linguistic Theory 19, 583-646.

Polinsky, Maria \& Eric Potsdam (2002a). Backward Control. Linguistic Inquiry 33, 245-282.

Polinsky, Maria \& Eric Potsdam (2002b). Backward Control: Evidence from Malagasy. Proceedings of AFLA 8, MIT Working Papers in Linguistics 44, 257-272.

Pollard, Carl \& Ivan Sag (1994). Head-driven Phrase Structure Grammar. The University of Chicago Press.

Raposo, Eduardo (1987). Case theory and Infl-to-Comp: the inflected infinitive in European Portuguese. Linguistic Inquiry 18, 85-109. 
Reis, Marga \& Wolfgang Sternefeld (2004). Review of Susanne Wurmbrand (2001), Infinitives: Restructuring and clause structure, Berlin, Mouton de Gruyter. Linguistics 42, 469508.

Reuse, Willem Joseph de (1994). Siberian Yupik Eskimo: the language and its contacts with Chukchi. Salt Lake City: University of Utah Press.

Robertson, John S. (1980). The structure of pronoun incorporation in the Mayan verbal complex. New York: Garland.

Rosenbaum, Peter (1967). The grammar of English predicate complement constructions. Cambridge, Ma.: MIT Press.

Ruwet, Nicolas (1991). Je veux partir/*Je veux que je parte: On the distribution of finite complements and infinitival complements in French. In Nicolas Ruwet, Syntax and Human Experience. The University of Chicago Press.

Růžička, Rudolf (1983). Remarks on control. Linguistic Inquiry 18, 309-324.

Růžička, Rudolf (1999). Control in grammar and pragmatics: a cross-linguistic study. Amsterdam: Benjamins.

Sabel, Joachim (1996). Restrukturierung und Lokalität: universelle Beschränkungen für Wortstellungsvarianten. Berlin: Akademie Verlag.

Sag, Ivan A. \& Carl Pollard (1991). An integrated theory of complement control. Language 67, 63-113.

Słodowicz, Szymon (2006). Control in Polish complement clauses. Unpublished Ph.D. dissertation, University of Kiel.

Słodowicz, Szymon (this volume). Complement control in Turkish.

Stojanović, Danijela \& Marijana Marelj (2004). Interpreting empty subjects in nontensed complement clauses: child and adult strategies. In: Olga Mišeska Tomić (ed.), Balkan Syntax and Semantics: Amsterdam: Benjamins, 439-459.

Stiebels, Barbara (2002). Typologie des Argumentlinkings: Ökonomie und Expressivität. Berlin: Akademie Verlag.

Stiebels, Barbara (2006). From rags to riches. Nominal linking in contrast to verbal linking. To appear in: Dieter Wunderlich (ed.), Advances in the theory of the lexicon. Berlin: Mouton de Gruyter, 167-234.

Tomić, Olga Mišeska (2006). Balkan Sprachbund morpho-syntactic features. Dordrecht: Springer.

van Valin, Robert D. Jr. (1993). A synopsis of Role and Reference Grammar. In: Robert D. van Valin Jr. (ed.), Advances in Role and Reference Grammar. Amsterdam: Benjamins, 1164.

Wechsler, Stephen \& I Wayan Arka (1998). Syntactic ergativity in Balinese: an argument structure based theory. Natural Language and Linguistic Theory 16, 387-441.

Wegener, Heide (1989). Kontrolle - semantisch gesehen. Deutsche Sprache 3, 206-228.

Williams, Edwin (1980). Predication. Linguistic Inquiry 11, 203-238.

Wunderlich, Dieter (1997). Cause and the structure of verbs. Linguistic Inquiry 28, 27-68.

Wurmbrand, Susanne (2001). Infinitives: restructuring and clause structure. Berlin: Mouton de Gruyter.

Zec, Draga (1987). On obligatory control in clausal complements. In: Masayo Iida, Stephen Wechsler \& Draga Zec (eds.), Working papers in grammatical theory and discourse structure. Stanford: CSLI Publications, 139-168. 


\section{Appendix: Questionnaire for complement control and control predicates ${ }^{\#}$}

\section{Introduction}

This questionnaire focuses on control structures that are instantiated by predicates that take a state of affairs (SOA) argument. Noonan (1985) has called these predicates 'complement-taking predicates'; I will use the notion of SOAAtaking predicates (SOAA $=$ state of affairs argument).

Prototypically, complement control is instantiated by certain classes of verbs; however, adjectives (be eager to) and nouns (e.g. nominalizations such as promise) may function as control predicates as well. 'Control' refers to the pattern of argument identification between an argument of the SOAA-taking predicate and an argument of the SOAA-head. In the literature the notion of 'equi deletion' or 'equi-NP deletion' has been used (following Rosenbaum 1967), which refers to structures in which an overt argument of the matrix predicate is identified with a covert argument of the embedded predicate. This questionnaire aims at a crosslinguistic application of the notion of control and thus uses a semantic definition of complement control. It extends the notion of control to other patterns of referential dependency between arguments of a SOAA-taking predicate and of the embedded predicate.

The questionnaire is based on the following definition of obligatory control:

Definition of obligatory control

Obligatory control applies to structures in which a predicate $\mathrm{P}_{1}$ selects a SOA-argument and requires one of its (individual) arguments to be (improperly) included in the set of referents of an argument of the embedded predicate $\mathrm{P}_{2}$ heading the SOA-argument.

$$
\left[\mathrm{X}_{\mathrm{i}} \mathrm{P}_{1}\left(\mathrm{Y}_{\mathrm{j}}\right)\left[\mathrm{Z}_{\mathrm{k}} \mathrm{P}_{2} \ldots\right]_{\text {SOA }}\right] \text { with } \mathrm{k} \cap\{\mathrm{i}, \mathrm{j}\} \neq \varnothing
$$

From this viewpoint, a selectional restriction between a predicate and a SOAargument and the referential dependency between an argument of the matrix predicate and an argument of the dependent predicate are the prerequisites for complement control.

Following the general terminology I will call the argument that establishes the referential reading the controller and the argument whose referential interpretation is dependent on some other argument the controllee. The controllee

\# This questionnaire replaces the one that has been used in the project Typology of control verbs, funded by the German Science Foundation (DFG; STI 151/2-2) and directed by myself. 
may be covert or a pronominal element. In forward control, which represents the prototypical case, the controller is in the matrix clause (i.e. the arguments $\mathrm{X}$ or $\mathrm{Y}$ in (1)) and the controllee in the embedded clause (argument Z). In backward control, the relation is reversed, i.e. the controller is in the embedded clause and the controllee in the matrix clause.

(1) subsumes the following control readings, whereby $\mathrm{k}, \mathrm{i}$, and $\mathrm{j}$ refer to the referential indices of $\mathrm{Z}, \mathrm{X}$ and $\mathrm{Y}$ and $\mathrm{v}$ to some disjoint referent:

(2) Control readings of (1)

$\begin{array}{lcc} & \text { Subject control } & \text { Object control } \\ \mathrm{k}=\mathrm{j} \\ \text { exhaustive } & \mathrm{k}=\mathrm{i} & \mathrm{k}=\mathrm{j}+\mathrm{v} \\ \text { Partial } & \mathrm{k}=\mathrm{i}+\mathrm{v} & \mathrm{k}=\mathrm{i}+\mathrm{j}\end{array}$

The definition of obligatory control in (1) takes finite SOA-arguments, overt pronominal controllees, control in subject clauses, and non-exhaustive control readings into consideration, thus deviating from many syntactic approaches.

Complement control is a core phenomenon of the lexicon-syntax interface. General syntactic properties of the language (e.g. the general structure of sentential complementation in the respective language) interact with the lexical properties of the particular SOAA-taking predicate. The degree to which syntax and lexicon/semantics play a role is language-specific. This questionnaire aims to target both general syntactic properties and predicate-specific properties. Therefore, some questions deal with the syntax of the respective language and its control structures and some with the specific properties of the SOAA-taking predicates. The questions are based on insights into control predicates of well-studied languages.

Given that raising verbs are also instances of complex predicates, it is important to distinguish control predicates from raising predicates (e.g. seem). Raising occurs if an argument of the embedded predicate is realized as a complement/the subject of the matrix predicate, yielding a semantics-syntax mismatch: semantically, the argument belongs exclusively to the embedded predicate, syntactically to the matrix predicate.

Besides the well-known cases of subject raising (Peter seems to be hungry) and object raising (also ACI verbs or ECM verbs: she believes him to be a liar), there are structures that have been analyzed as object-to-subject raising (generally dubbed tough-movement: John is easy to please) or object-to-object raising. However, these structures seem to preclude the raising of expletive arguments; therefore, these structures cannot be analyzed as raising structures proper.

One distinctive feature of raising predicates is that they allow the raising of expletives, whereas control predicates cannot embed predicates whose control- 
lee would be an expletive. Therefore, the admissibility of 'weather verbs' or other impersonal verbs is an indication of a raising structure.
a. It seems [to rain].
b. *John wants [_ to rain].
c. John wants [it to rain].

[raising verb]

[control verb variant]

[raising verb variant]

Furthermore, the truth conditions of sentences containing raising verbs do not change if the embedded verb is passivized.

a. She seems [to prefer red roses].

b. Red roses seem [to be preferred by her].

In contrast, control relations are affected by passivization of the embedded predicate, as different buletic situations are characterized by the following sentences:
a. I want [ _ to praise them].
[wish to praise]
b. I want [ _ to be praised].
[wish to be praised]

Often languages display a number of predicates that have both a raising and a control variant.'want' is a typical example (cf. (6a/b)); other verbs may have such a double function as well (cf. (6c-e)):

a. Mary wants [ _ to sing].

b. Mary wants [him to sing].

[subject control]

c. Peter droht ${ }_{-}$die [object raising] $P$ threatens the door in-to-smash.INF 'Peter threatens to smash the door'

d. Peter droht [in den Keller zu fallen]. $\mathrm{P}$ threatens in the cellar to fall.INF 'Peter threatens to fall into the cellar'

e. Es droht [zu regnen]. it threatens to rain.INF 'it threatens to rain'

[subject raising]

Not all criteria that may distinguish raising from control are applicable in all languages. In German, for instance, subject control predicates are distinguished from subject raising predicates by their potential to be passivized. (6c) can thus be passivized, (6d) cannot.

Raising of DPs/NPs should be differentiated from long scrambling or similar movement processes in terms of the observable effect in argument linking: the raised DP/NP receives a linker by the matrix verb, not by the embedded verb. There is one systematic exception to the general pattern: In most languages, DPs/NPs that are lexically marked by the embedded predicate do not allow this 
linker to be overridden by the matrix predicate; hence, the linking effect should not occur with lexically marked arguments.

\section{The language profile}

Some background information is needed in order to capture all relevant aspects of complement control. The following questions help to highlight the relevant structural properties of the respective language.

2.1 Unrealized arguments: Does the language allow pro-drop, i.e. the dropping of unemphatic personal pronouns (as subjects or objects)? Does the language allow topic drop?

In order to avoid that structures of pro-drop or topic drop in embedded clauses are mistaken as instances of complement control, it is important to check the potential referents of the unrealized argument: If there is no requirement that the referent of the unrealized argument (improperly) includes the referent of one of the arguments of the matrix verb, the respective structure should not be analyzed as an instance of complement control.

\subsection{Argument linking}

Argument linking may influence control; for instance, a language may exclude oblique arguments from being controlled, which affects the selection of the controllee. With respect to controller choice, there is no strict evidence that the selection of the controller correlates with a certain pattern of argument realization. However, there may be languages in which argument linking does play a role in terms of the controller.

2.2.1 Does the language exhibit morphological case? If so, which kind of linker inventory does it have (e.g. accusative/nominative, ergative/nominative, ergative/ accusative/nominative)?

2.2.2 Does the language have oblique linkers (morphological case or adpositions)?

2.2.3 Does the language exhibit predicates with lexically induced argument linking?

In lexically induced argument linking certain predicates deviate from the canonical linking pattern, e.g. the following German transitive predicates that do not realize their object with accusative (ACC) and their subject with nominative (NOM) but instead with dative (DAT) or genitive (GEN).
a. helfen 'help' DAT-NOM/*ACC-NOM
b. gefallen 'like'NOM-DAT/*ACC-NOM
c. gedenken 'commemorate' GEN-NOM/*ACC-NOM 
2.2.4 Does the language exhibit verbal agreement? If the language has object agreement: Does the verb agree with a SOA-argument?

2.2.5 If the language lacks morphological case and/or agreement: Does it exhibit a positional linking system, i.e. are arguments identified by their position?

2.2.6 Does the language exhibit a linking system that does not operate in terms of structural case, i.e. does the language make use of an

- active/inactive system,

- inverse system (as in the Algonquian languages),

- Philippine-style voice system,

- another system?

\subsection{Voice system}

2.3.1 Does the language have passive and/or antipassive? What are its properties? Is an oblique realization of the demoted argument possible? Is the demoted argument excluded from being overtly realized?

Voices such as passive may affect control, changing the control relation. It may be the case that some control predicates cannot be passivized or only under certain conditions. Moreover, passivization of the embedded predicate may lead to a shift of the controllee, yielding control of the theme argument.

2.3.2 Does the language make use of diathesis operations that introduce new arguments (causative, applicative)?

Since argument-extending diathesis operations affect the argument structure of predicates, they may affect control relations as well.

2.4 Phrasal constituency: Which tests are applicable in the respective language to determine phrasal constituency (movement processes, pronominalization, special-position clitics etc.)?

These tests may help to distinguish forward control from backward control (see 3.6).

\subsection{Sentential complementation}

2.5.1 Which types of sentential complementation are attested in the respective language?

- parataxis

- finite complement clauses

- infinitival complement clauses 
- participial or other types of infinite complement clauses

- nominalization

Please indicate their range of use and frequency. Indicate whether the various types may occur with or without a complementizer.

2.5.2 Does any of the attested types of sentential complementation exhibit restrictions on the realization of the arguments of the embedded head, i.e. does one argument have to remain covert (e.g. as often is the case, e.g. with infinitives)?

This is an important aspect of the study of complement control. Structures that require one argument to remain covert can only be licensed by raising or control predicates. ${ }^{1}$ These structures will be termed 'control-inducing' in the following. Structures that allow all arguments to be realized within the domain of their functor are called 'control-neutral'.

2.5.3 Do these types of sentential complementation show the same structural potential as matrix clauses, i.e. do they allow

- the same patterns of agreement,

- the same tense/aspect/mood markers,

- the same polarity markers,

- the same voice distinctions?

Differences in the structural potential may motivate differences in the class of the licensing matrix predicates. Factive predicates or utterance predicates preferentially occur with sentential complementation structures that allow the full range of tense/aspect/mood marking.

2.5.4 Do dependent clauses differ from matrix clauses in terms of word order?

2.5.5 Does the language make use of complex predicates? Especially, does it show

- verb incorporation or verb-verb compounds,

- affixal verbs (as in Greenlandic),

- serial verb constructions?

Complex predicates generally require argument sharing/identification unless they trigger raising. Please indicate the types of argument sharing, i.e. which arguments of the head predicate are shared with which arguments of the non-head predicate.

1 In some cases, e.g. with nominalized sentential complements, restrictions on argument realization may only show up with polyvalent embedded predicates. Likewise, in some types of sentential complementation the realization of the respective argument may be excluded only in certain structural contexts. 
2.5.6 Which of the attested complementation types are used with SOAarguments (including subject clauses), i.e. clauses that are semantically selected by the matrix predicate?

2.5.7 Which of the attested types are used with SOA-adjuncts, especially with purpose clauses (he came to see the exhibition, he called her in order to learn about her new friend)?

This question aims at the potential parallels between structures of complement control and purpose clauses because they latter often also show control.

2.5.8 Does the language have a switch-reference system? Please list the markers for same subject (SS) and different subject (DS). What is their distribution in terms of the structures they may occur in?

Although switch-reference markers are not attested systematically for structures of complement control, there may be languages that may use a switch-reference system in complement control.

2.5.9 Does the language distinguish between structural and oblique sentential complementation?

A SOA-argument may be realized obliquely by direct oblique case marking (e.g. with nominalized complements) or indirect oblique case marking (correlative pronouns in the matrix clause). Although languages may lack oblique markings on SOA-arguments, the SOA-arguments may still be non-structural, which may be indicated by the lack of object agreement or the failure to undergo clause union/restructuring. The Mayan language Q'eqchi' exhibits both oblique and structural SOA-arguments. Oblique SOA-arguments have an oblique complementizer (chi) as in (8a) and lack object agreement; they only have an N-agreement marker (nominative/absolutive), indexing the subject. With structural SOAarguments the oblique complementizer is not present as in (8b), and the subject is indexed by ergative agreement (E-marker), whereas the SOA-argument is indexed by the non-overt 3SG.N-marker.

Q'eqchi' (Kockelman 2003:30)
a. X-in-lub [chi k'anjelak $]$ PERF-1SG.N-tire COMP.OBL work 'I got tired of working'
b. n-inw-aj [xik sa' li k'ayil] PRES-1SG.E-want Go into the market 'I want to go to the market'




\section{General properties of the language's control structures}

This section deals with the general properties of complement control, i.e. the type of instantiated sentential complementation, the admissibility of backward control, WH-control and control in subject clauses. The predicate-specific properties are dealt with in 9.

3.1 Which structures of sentential complementation that require argument identification with some argument of the matrix predicate (= 'controlinducing' structures) are used with SOAA-taking predicates?

Typically, structures with infinite heads are potential candidates for this type of sentential complementation. In languages that do not have control-inducing structures control is confined to certain predicates that require a control reading independent of the type of sentential complementation (see question 3.3). If the language exhibits several types of control-inducing structures, please indicate the differences between these structures in terms of control and non-control properties.

3.2 Which structures of complex predicates are used with SOAA-taking predicates?

Not all languages that have complex predicates use them in complement control. A language may have, for instance, serial verb constructions, but exclude them for SOAA-taking predicates. Likewise, a language may limit verb incorporation to raising predicates.

3.3 Are there instances in which a SOAA-taking predicate selects a controlneutral structure and requires a control reading even in this type of sentential complementation?

Recall that control-neutral structures are those structures that do not require argument identification with some argument of the matrix clause and may link all arguments of the head predicate within its linking domain. Predicates that require a control reading with these types of sentential complementation are inherent control predicates.

3.4 Do structures of complement control differ from purpose clauses?

Purpose clauses may instantiate control-inducing structures as well. Therefore, it is worthwhile to compare these clause types (he came in order to hear about the latest news) with structures of complement control. The question is whether the status as SOA-adjunct (purpose clause) vs. SOA-argument (complement control) has any consequences.

3.5 Are there structural restrictions regarding the embedded predicate? 
Given that languages may restrict structures of sentential complementation to intransitive predicates (e.g. in some Mayan languages) one should check whether there are structural restrictions with some or all of the types of sentential complementation.

\subsection{Backward control}

As mentioned above, backward control reverses the relation of controller and controllee: the controller is in the embedded clause, the (covert) controllee in the matrix clause , indicated by '_, (see Polinsky \& Potsdam 2002a, 2002b):

$$
\left[{ }_{\mathrm{i}} \mathrm{P}_{1}\left(\mathrm{DP}_{\mathrm{j}}\right)\left[\mathrm{DP}_{\mathrm{i}} \mathrm{P}_{2} \ldots\right]_{\mathrm{SOA}}\right]
$$

3.6.1 Does the language allow backward control?

Please indicate which structural properties suggest that the controller is realized within the embedded clause (e.g. scrambling of the complement clause), the position and interpretation of adverbials, ellipsis, agreement patterns).

3.6.2 Which predicates license backward control? Is forward control also possible with these predicates?

Usually, the set of licensing predicates is rather small (e.g. certain phasal predicates, certain directive predicates).

3.6.3 Is there a semantic difference between forward and backward control?

Maria Polinsky (p.c.) has pointed out that the difference between forward and backward control tends to be one of implicative vs. non-implicative readings regarding the SOA-argument. There may also be scopal differences in interpretation.

3.6.4 Which kinds of quantificational controllers are possible in backward control?

Quantifiers are usually in a structurally higher position than the variables bound by them. Backward control thus poses a structural challenge to quantificational controllers because the quantificational controller is lower than the variable (i.e. the controllee). The Caucasian language Tsez, for instance, excludes quantificational controllers in backward control.

\subsection{Control in embedded questions (WH-control)}

In some languages control structures can also be found with embedded questions. Typically, these are languages in which control-inducing structures are compatible with interrogative predicates.

3.7.1 Does the language allow control-inducing structures with interrogative predicates? 
3.7.2 Which interrogative predicates select control-inducing structures?

Not all interrogatives that select, for instance, finite embedded questions also select embedded questions with control-inducing structures. Besides interrogative predicates (wonder, ask), which instantiate intensional embedded questions (he wondered [how _to reach the summit]), one can also find non-interrogative predicates with embedded questions, which are cases of extensional embedded questions (she cabled Helen [when _to send the package]):

3.7.2 Are there non-interrogative predicates that license embedded questions with control-inducing structures?

3.7.3 Are there interrogative predicates that require a control reading independent of the instantiated complementation structure?

Even languages that do not exhibit control-inducing structures or that do not allow interrogative predicates with control-inducing structures could have interrogative predicates that require a control reading, independent of the type of sentential complementation. So far, no cases have been attested, but the existence of these predicates cannot be ruled out completely.

Regarding the control readings in WH-control, I refer to question 6.4.

\subsection{Control in subject clauses}

Many SOAA-taking predicates select a SOA-argument as internal (lowest) argument, hence as object. There are some predicates in which the SOA-argument is analyzed as subject. Depending on the characterization of subject, a subject clause is one in which the SOA-argument corresponds to the highest argument in the argument structure (highest-argument subject clause) or one in which a pronominalization of the clause would yield the default linker (NOM-linker subject clause). The agreement pattern (3SG on the matrix predicate) is another superficial morphosyntactic criterion that points into the direction of the second criterion. Under the second view, intransitive SOAA-taking predicates with an implicit argument, which may be realized obliquely, are assumed to take subject clauses. The interesting case, however, is a SOA-argument being higher in the argument hierarchy than any potential controller. Therefore, the two notions of subject clauses should be distinguished.

3.8.1 Are there instances of obligatory control with highest-argument subject clauses?

Potential candidates are (causative) experiencer-object verbs such as disturb, amuse, thrill ..., in which the higher stimulus may be a SOA-argument. It is important to check whether these verbs truly behave as control verbs (requiring (improper) inclusion between controllee and controller). 
3.8.2 Are there instances of obligatory control with NOM-linker subject clauses?

If the predicate has an implicit argument, it is expected to be the controller. If the SOA-argument is the single argument, there cannot be any local controller. In order to identify the potential control readings, it is important to check whether one can enforce a reading in which the non-SOA-argument of the matrix predicate is excluded as controller as in (10a). ${ }^{2}$

(10) a. [ _arb:gen to smoke around babies $\mathrm{j}_{\mathrm{j}}$ is dangerous for them $\mathrm{j}_{\mathrm{j}}$.

b. [ _ _i/??gen to smoke around babies $\left.\mathrm{j}_{\mathrm{j}}\right]$ is dangerous for Peter ${ }_{\mathrm{i}}$.

\section{The controllee}

Since Keenan (1976) the control pattern in terms of the controllee has been taken as a subject criterion. The selection of the argument to be controlled is generally not predicate-specific but determined by the grammar of the respective language. However, there may be exceptions such as Tagalog, in which certain modal contexts or certain predicates are not confined to one pattern of controllee choice. This section deals with the language-specific restrictions on controllees. Recall that controllees tend to be covert, but can be pronominal as well.

4.1 Which argument is selected as controllee in the unmarked case?

a) the semantically highest argument irrespective of its case marking (= actor control)

b) the argument that would receive the default linker (nominative/ absolutive) (= NOM control)

Usually, languages choose one option (e.g. actor control in Icelandic, NOM control in German). However, there are languages that allow the other option in certain contexts (see 4.3).

4.2 Does the language allow the controllee to be a lexically designated argument (i.e. an argument that would surface with a lexical/oblique case in non-control structures)?

Languages with actor control should allow lexically designated controllees unless they require the lexical/oblique case to be visible, which is in conflict with covert controllees. Languages with NOM control should exclude lexically designated controllees.

2 The index 'arb' indicates arbitrary control, which is actually non-control. 'gen' indicates a generic reading. See section 6 . 


\subsection{Controllee shift}

4.3.1 Languages with unmarked actor control: Does the language allow NOM control in certain contexts? If so, what are the contexts (e.g. certain tense/aspect/mood configurations, certain matrix predicates)?

4.3.2 Languages with unmarked NOM control: Does the language allow actor control in certain contexts? If so, what are the contexts (e.g. certain tense/aspect/mood configurations, certain matrix predicates)?

These two patterns of controllee shift are principled shifts in terms of actor or NOM control. Another potential shift is one that does not affect the general controllee selection strategy but shifts the controllee within the NOM or actor control paradigm:

4.3.3 Is the control relation affected by voice or diathesis operations on the embedded predicate such that the controllee is shifted?

Passivization of the embedded predicate, for instance, yields a controllee shift in NOM control:

(11) a. John wants [ _ to invite Mary].

controllee $=$ agent

b. John wants [ _ to be invited].

controllee $=$ patient

Actor control is incompatible with such a shift; in actor control, controllees can only be shifted if the highest argument is no longer semantically accessible; then, the next-to-highest argument should become controllee.

Other diathesis operations can affect the control relation as well. In languages with NOM control, control of a NOM object is possible if the highest argument is linked by a non-default linker. An applicative that introduces a new object and renders the base object oblique should turn the new object into the controllee.

\section{The controller}

The central question regarding the controller is whether its selection is mainly predicate-specific (or specific for a semantic class of predicates), which crosslinguistic data suggest, or whether it is determined or influenced syntactically a cross-linguistically rare option.

5.1 Does the language impose syntactic constraints on the selection of the controller?

The only attested case so far for a strict syntactic selection of the controller are the Austronesian language Kavalan and its closest relatives (Chang \& Tsai 2001) and the Mayan language Mam (concerning cases of infinitival comple- 
ments, see England 1989), both discussed in the preceding paper. A syntactically determined controller choice is bound to certain syntactic configurations. Please indicate the admissible syntactic configurations for controllers.

5.2 In languages with syntactic controller choice: Does the language apply repair strategies in order make certain arguments accessible as controllers or to establish a control relation at all?

Kavalan shows one kind of repair strategy: the causativization of the embedded predicate in order to preserve actor subject control. Diathesis operations on the matrix predicate or on the embedded predicate represent the expected repair strategies.

5.3 Does the language allow oblique controllers (e.g. agent phrases in passive, oblique objects)?

5.4 Does the language allow implicit control (e.g. Mary signalled $(X)$ L_X $_{\text {to }}$ follow her])? Are there predicates with obligatorily implicit control?

Please indicate whether there is a specific linking pattern for implicit arguments/controllers in case they are overtly realized. If there is no specific linking pattern for implicit arguments, this may be taken as indication that the control relation is established on semantic grounds and not on configurational grounds.

5.5 For languages that instantiate a switch-reference system in complement control: Indicate the use of switch-reference markers with cases of subject and object control.

\section{Referential dependencies between controller and controllee}

The various control verbs differ in their potential referential dependencies between controller and controllee. One can find:

- exhaustive control: the referents of controller and controllee overlap completely,

- partial control: the referent of the controller is (properly) included in the referents of the controllee ( Peter $_{i}$ wants $\left[{ }_{-}{ }^{i+v}\right.$ to meet at six]),

- split control: two arguments of the control predicate jointly control the controllee,

- generic control: the controller is generically bound (it is easy (for $\mathrm{X}_{\mathrm{gen}}$ ) [_ gen to manipulate the data]), 
- arbitrary control: there is no local controller ([_arb to smoke around babies is $_{i}$ dangerous for them ${ }_{i}$. $^{3}$

This section deals only with the general properties. The predicate-specific readings are dealt with in section 9.

6.1 Are there instances of partial control?

Partial control may be tested with collective predicates such as meet or gather, which require plural actants (in semantic terms).

6.2 Are there instances of split control?

6.3 Are there instances of arbitrary control?

Usually, arbitrary control does not occur with SOA-objects; however, some SOA-subjects may exhibit arbitrary control with certain predicates. It is unclear whether there are languages that have predicates which instantiate arbitrary control with SOA-objects.

6.4 Which control readings are possible in WH-control if the language exhibits WH-control?

Often, control readings seem to be loosened compared to control in declarative SOA-arguments. It is therefore important to check whether WH-control may occur with exhaustive, partial, split or abitrary control.

\section{Control shift}

As has been observed in the literature (e.g. Růžička 1983, 1999, Comrie 1984), some (transitive) control verbs may shift the controller (from subject to object control or vice versa) under certain circumstances. It is helpful to determine first which structures may trigger control shift - if the language allows control shift. In the second step, the lexical predicates that allow control shift should be determined (see 9.4). It is important to keep in mind that there is a gradual difference between predicates of variable control (e.g. propose) and predicates that may shift. The latter generally require a strong trigger for a control shift, whereas the former at most need contextual support for a certain control reading.

7.1 May a control shift be induced by non-active voice (e.g. passive) on the embedded predicate or on the matrix predicate?

Passive has been attested as a weak trigger for control shift. Besides the wellknown cases of control shift with passivized embedded verbs, passivization of

3 Arbitrary control can be interpreted generically. Generic readings may arise from generically bound implicit controllers in the matrix predicate and from generic interpretations of non-controlled (= arbitrary) arguments. 
the matrix predicate may also require a control shift: polyadic subject control verbs may have to undergo control shift if they are passivized, as the following German example illustrates.

(12) a. ?? $\operatorname{Ihm}_{\mathrm{i}}$ wurde versprochen, [ _ j das Auto zu reparieren]. he.DAT was promised the car to repair.INF lit. 'he was promised to repair the car'

b. $\operatorname{Ihm}_{\mathrm{i}}$ wurde versprochen [ ${ }_{\mathrm{i}}$ das Auto reparieren $\mathrm{zu}$ dürfen]. he.DAT was promised the car repair.INF to be.allowed.INF 'he was promised to be allowed to repair the car'

7.2 Are there instances of control shift if the dependent verb is embedded under a modality operator (e.g. deontic mood) or a modal expression (e.g. to be allowed to) - either explicitly or implicitly?

7.3 Are there instances of control shift if the embedded predicate is nonagentive?

Recipient-oriented predicates such as bekommen 'get' may trigger a control shift with some predicates.

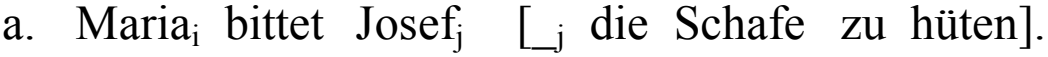 $\mathrm{M}$ asks $\mathrm{J}$ the sheep to tend.INF
'Mary asks Joseph to tend the sheep' [object control]
b. Maria ${ }_{i}$ bittet Josef $f_{j}[i$ ein neues Auto $z$ bu bekommen]. $M$ asks $J$ a new Car to get.INF
'Mary asks Joseph to get a new car' [subject control]

7.4 Do object control verbs shift to subject control if their internal argument is left implicit (compare English shout vs. ask)?

7.5 For languages that instantiate a switch-reference system in control structures: Can a change in the switch-reference marker trigger a control shift?

7.6 Does the language show other patterns of control shift?

\section{Control and clause union}

Provided that the respective language allows clause union (restructuring), the question arises whether there is any correlation between control and clause union. Data from the literature have already revealed that the various control verbs do not behave homogeneously regarding clause union and that there is no neat correlation between control reading and clause union. Nevertheless, there may be languages that show some kind of correlation between control and clause union. It is, however, important to check whether any observed correlation is one 
that relates the control property to clause union and not some other property of the control predicate (e.g. its linking pattern).

8.1 Which clause union effects show up in the respective language?

Here is a list of some clause union effects observed in the literature:

- movement of a constituent out of the embedded clause into the matrix clause (including elements such as argumental or adverbial clitics; see (14))

- agreement of the control verb with an argument of the embedded verb; see (15)

- linking effects due to some trigger on the control verb; see (16)

In Hungarian, some control verbs attract the preverb of an embedded verb if they do not have a preverb on their own and nothing else appears in the preverbal focus position.

(14) Hungarian

a. Anna el-akar-ja [olvas-ni a könyv-et]

A. PV-want-3SG.DEF read-INF the book-ACC

'Anna wants to read the book'

b. * Anna el-szeret-i [olvas-ni a könyv-et]

A. PV-love-3SG.DEF read-INF the book-ACC

'Anna loves to read the book'

c. Anna szereti [ el-olsvasni a könyvet]

In Basque, the two subject control verbs nahiago 'want more, prefer' and nahi 'want' differ in their clause union patterns; the former excludes clause union (agreement with the embedded DAT-argument), the latter requires it.

(15) Basque (Hualde \& de Urbina 2003:697/695)

a. Amaiak [niri liburu bat erosi] nahiago

A.ERG 1SG.DAT Book one buy.PTC want.more

$\mathrm{du} / \quad *$ dit

AUX.3SG.E/3SG.N/ AUX.3SG.E/1SG.D/3SG.N

'A. prefers to buy me a book'

b. [gurasoei Bilbon etxe bat erosi] nahi

parents.DAT Bilbao.LOC house one buy.PTC want

diet/ *dut

AUX.3N/3PL.D/1sG.E/ AUX.3N/1SG.E

'I want to buy my parents a house in Bilbao'

In Polish, negation of the control verbs triggers genitive on the object of the embedded verb. 
(16) Polish

$\begin{array}{llll}\text { a. Jan kazal Piotrowi } \quad \text { [zamknąc } & \text { okno] } \\ \text { J. ordered } & \text { Peter.DAT close.PERF.INF } & \text { window.ACC } \\ \text { 'Jan ordered Peter to close the window' } & \end{array}$

b. Jan nie kazał Piotrowi [zamykać okna]

J. not ordered Peter.DAT close.IMPERF.INF window.GEN

'Jan didn't order Peter to close the window'

8.2 To what extent do control verbs allow/require clause union with the embedded verb? Please check whether the control verbs behave homogeneously, i.e. whether each control verb allows the same clause union properties.

8.3 Is there any interaction between clause union and the referential dependencies (e.g. such that clause union excludes partial control with verbs that would allow partial control otherwise)?

\section{Lexical classes}

Since the control properties are predicate-specific or predicate-class-specific, careful studies are necessary to determine the various control predicate classes. The lexical classes can be established on a multi-dimensional basis, which includes the controller argument, the distinction of inherent vs. structural control, the referential readings, control shift, and the semantic selection of embedded predicates.

\subsection{Inherent vs. structural control}

A very important class is the class of inherent control predicates, i.e. predicates that require a control reading independent of the syntactic realization of the SOA-argument. One can distinguish three types of inherent control, depending on the types of sentential complementation in the respective language. If the language distinguishes control-inducing and control-neutral structures, there may be inherent control predicates that

- only select control-inducing structures (strong inherent control)

- select control-inducing as well as control-neutral structures without a change in the control readings (weak inherent control)

- only select control-neutral structures, but are restricted to control readings (marked inherent control).

Languages that do not distinguish control-inducing and control-neutral structures only exhibit one class of inherent control predicates without further subclassifications. 
Predicates that only exhibit control readings with control-inducing structures are structural control predicates. Their specific lexical property is their potential to license a control-inducing structure, which may not be possible for all predicates that select a SOA-argument.

9.1.1 Which predicates belong to the class of inherent control predicates? If the language distinguishes control-inducing and controlneutral structure, please differentiate in terms of the following classification:

a) list the predicates of strong inherent control.

b) list the predicates of weak inherent control.

c) list the predicates of marked inherent control.

9.1.2 Which predicates license structural control in languages that exhibit control-inducing structures?

9.1.3 Which SOAA-taking predicates do not license structural control in languages that exhibit control-inducing structures?

\subsection{Classes in terms of the controller argument}

9.2.1 Which predicates function as subject control predicates, which as object control verbs in the unmarked case?

The unmarked case is represented by a SOA-argument headed by an agentive predicate in active voice.

9.2.2 Which predicates do not show any preference regarding subject or object control (= variable control)?

A predicate of variable control should at most require pragmatic or contextual reinforcement in order to trigger all potential control readings.

\subsection{Referential readings}

9.3.1 Which control predicates are restricted to readings of exhaustive control?

9.3.2 Which control predicates allow partial control? Are there predicates that require a partial control reading?

9.3.3 Which control predicates allow split control? Are there predicates that require a split control reading?

\subsection{Control shift}

On the basis of the general properties of control shift dealt with in 7 , it is possible to determine the predicate-specific admissibility of control shift. 
9.4.1 Which polyadic subject control predicates allow a control shift? Does this shift occur in all triggering contexts?

9.4.1 Which object control predicates allow a control shift? Does this shift occur in all triggering contexts?

\subsection{Semantic selection}

The predicate-specific control behavior might also correlate with the semantic selection of the embedded predicate. Jackendoff \& Culicover (2003) suggest that the class of exhaustive control predicates coincides with the class of SOAAtaking predicates that only select agentive predicates ('Action predicates' in their terminology). The following questions highlight dimensions of semantic selection that may correlate with other structural or control properties.

9.5.1 Does the control predicate show any thematic restrictions with respect to the embedded verb (e.g. only agentive verbs or verbs that allow an agentive reinterpretation)?

Directive verbs such as überreden 'persuade' usually only select agentive predicates; non-agentive predicates have to be coerced into an agentive reading. Predicates such as hoffen 'hope' preferentially select non-agentive predicates (??ich hoffe zu tanzen 'I hope to dance' vs. ich hoffe tanzen zu können 'I hope to be able to dance').

9.5.2 Does the control verb show any restrictions with respect to the aspectual class of the embedded verb? Does it allow activity verbs (run), state verbs (know), accomplishment verbs (draw a circle) and achievement verbs (arrive)?

9.5.3 Does the control verb show any restrictions with respect to aspectual, temporal or modal categories on the embedded verb taking the general restrictions for these categories in complementation into account? Which control verbs allow independent time reference in the embedded clause?

Control predicates that do not impose any time dependence on the embedded predicates are believed to show a wider spectrum of control readings, e.g. partial control readings (Landau 2000, Wurmbrand 2001).

\subsection{Evaluation of classes}

The evaluation of the lexical classes should include a cross-classification of the various dimensions mentioned in this section, i.e. which predicates share certain properties in terms of inherent vs. structural control, in terms of the controller argument, the referential readings, the control shift, and the semantic selection. 
A cross-classification along these lines is purely structural and thus independent of traditional nations of semantic/lexical fields.

\section{List of SOAA-taking predicates}

This is an exemplary list of SOAA-taking predicates; this list is not meant to be exhaustive; it is suggested as a starting point for the investigation of possible control predicates. Note that languages may display control predicates that are not covered by the following classes. Moreover, the proposed verb classes are not meant as structural classes. See also Noonan (1985) for complement-taking predicates, Pollard \& Sag (1994) and Landau (2000) for control verbs.

10.1 desiderative predicates: want, prefer, yearn, arrange, hope, be afraid, refuse, agree, plan, aspire, decide, mean, intend, wish, need, long, expect, resolve, strive, demand, choose, offer, be eager, be ready,

Note that Noonan distinguishes three classes of desideratives: 'hope class', 'wish class', 'want class'.

10.2 directive/manipulative predicates: cause, force, make, persuade, tell, threaten, let, cajole, command, order, request, ask, press, charge, command, induce, compel, signal, forbid, prevent (from), enable ...

10.3 implicative predicates/achievement predicates: manage, chance, dare, remember to, happen to, get to, try, forget to, fail, avoid, refrain, decline, neglect, ...

10.4 factive/commentative predicates/experiencer-subject verbs: regret, hate, be sorry, be glad, like, dislike, loath, be surprised, be shocked, ...

10.5 experiencer-object verbs: thrill, amuse, cheer, satisfy, sadden, ...

The following predicate classes mainly function as raising predicates. However, some of them may have a usage as control predicate as well, which needs to be checked carefully.

10.6 phasal predicates/aspectual verbs: begin, start, continue, keep on, finish, stop, cease ...

10.7 modal predicates: can, be able, ought, should, may, be obliged, must, ...

10.8 perception predicates: see, hear, watch, feel, sense, smell ...

The following predicates are generally not predicates of inherent control. Some languages, however, may allow structural control with these predicates. 
10.9 propositional (attitude) predicates: claim, believe, think, suppose, assume, doubt, deny, ...

10.10 utterance predicates/verbs of communication: tell, say, report, promise, ask, ...

Depending on whether the language exhibits WH-control, interrogatives have to be studied in terms of their control behavior.

10.11 interrogative predicates: wonder, ask, find out, interrogate, inquire, contemplate, deliberate, guess, grasp, understand, know, be unclear, ... 


\title{
Semantic and structural aspects of complement control in Korean
}

\author{
Thomas Gamerschlag
}

Heinrich-Heine-Universität Düsseldorf

\begin{abstract}
In this article, I will present a survey of control structures in Korean. The survey is based on a sample of seventy SOA-argument-taking predicates, which are classified with respect to their complementation patterns and control properties. As a result, Korean is characterized as a language in which semantically determined control is predominant, whereas constructionally induced control is only marginal. In the discussion of the sample, I will show that there are two major classes of verbs exhibiting semantic control: the first class consists of matrix verbs such as hwuhoyhata 'regret' or kangyohata 'force', which require obligatory coreference between a matrix argument and the embedded subject due to their lexical meaning. The verbs of the second class are utterance verbs such as malhata 'tell', which select clauses headed by the quotative complementizer ko. With these verbs, subject, object, or split control arises if specific modal suffixes are attached to the verb heading the complement clause. In the second part of the paper, I will provide a lexical analysis of control in Korean, which adopts the Principle of Controller Choice proposed by Farkas (1988) as well as additional constraints which have to be assumed independently.
\end{abstract}

\section{Introduction*}

The phenomenon of control has been a central topic to all major theories of language. For several decades, however, the study of control phenomena has been confined to a few languages, mainly English. It is only recently that the empirical base has been extended to cover a wider range of languages. This development is accompanied by novel approaches to control in formal theory: while Williams (1980) and Hornstein (1999), among others, assume a highly restricted notion of control, excluding e.g. non-exhaustive control, Landau (2000, 2004)

* This paper grew out of my work in the ZAS-project "Typology of control verbs" which was funded by the German Science Foundation (STI 151/2-2). I am grateful to my informants for providing me with examples and grammaticality judgments. I would also like to thank Hans-Martin Gärtner, Nayoung Kwon, Maria Polinsky, Szymon Słodowicz, Barbara Stiebels, Ilse Zimmermann, and the members of the project "Variation in control structures" at UCSD for valuable discussion. Moreover, the audiences of my talks at the ZAS-Semantikzirkel, the Universities of Potsdam and Tübingen, and a ZAS-workshop on imperatives gave many helpful comments. 
presents an analysis which covers partial and split control as well as control into finite (subjunctive) complements.

The aim of this paper is to contribute the profile of Korean to a typology of control. Therefore, a sample of SOA-argument-taking predicates is examined in the first part of the paper. As a result of this survey, Korean is characterized as a language that does not possess a designated control construction. Rather, control is determined semantically by the matrix predicate's meaning or certain modal suffixes on the embedded verb.

Presently, Korean is in the focus of some theoretical approaches to control because object control verbs like seltukhata 'persuade' are assumed to exhibit so-called 'backward control' with the controller being deeper in syntactic structure than the controllee. Cormack \& Smith (2004) analyze seltukhata as an instance of control which is determined entirely semantically. In contrast, Monahan (2003) offers a syntactic approach where backward as well as forward control are analyzed as instances of movement into various $\theta$-positions.

Without making any concession to Cormack \& Smith's syntactic assumptions, the results of the present study are in line with their characterization of Korean object control verbs. As will be shown, semantically determined control is not restricted to object control but is predominant in subject control as well, while constructionally induced control is only marginal in Korean. Therefore, an approach that neglects the semantic nature of control in Korean misses an important feature of this language.

After a discussion of the sample in section 3, I will first focus on verbs that determine control solely due to their lexical meaning in section 4 . As will be shown, subject control verbs belong to various verb classes whereas object control verbs uniformly pertain to the class of manipulative verbs. In section 5, I will focus on control triggered by modal affixes attached to the embedded verb. In section 6, I will present a semantic approach to control in Korean. Finally, some of the theoretical consequences will be discussed in the last section.

\section{Definition of control}

The notion of 'obligatory control' assumed in this paper is given in (1). It is defined for constructions with a matrix predicate selecting an SOA-argument (= state-of-affairs-argument):

(1) Definition of obligatory control (Stiebels, this volume)

Obligatory control applies to structures in which a predicate $\mathrm{P}_{1}$ selects a SOA-argument and requires one of its (individual) arguments to be (improperly) included in the set of referents of an argument of the embedded predicate $\mathrm{P}_{2}$ heading the SOA-argument. 
Since the definition is aimed at typological research, it does not exclude control structures with pronominal controllees or control into finite complement clauses, both of which are attested for Korean (see below). Moreover, the definition is not restricted to cases of exhaustive control but also permits partial and split control. The possible control relations are shown in (2) $\left(\mathrm{P}_{1}\right.$ and $\mathrm{P}_{2}$ are variables for the matrix and the embedded predicate, respectively. $\mathrm{X}$ and $\mathrm{Y}$ stand for the subject and object argument of the matrix verb; $\mathrm{Z}$ is the subject of the embedded verb, i.e., the controllee).

(2) Possible control relation in $\left[\mathbf{X}_{i} \mathbf{P}_{\mathbf{1}}\left(\mathbf{Y}_{j}\right)\left[\mathbf{Z}_{k} \mathbf{P}_{\mathbf{2}} \ldots\right]\right]$ with $k \cap\{i, j\} \neq \varnothing$ :

\begin{tabular}{|l|c|c|}
\hline & Subject control & Object control \\
\hline exhaustive & $\mathrm{k}=\mathrm{i}$ & $\mathrm{k}=\mathrm{j}$ \\
\hline partial & $\mathrm{k} \supset \mathrm{i}$ & $\mathrm{k} \supset \mathrm{j}$ \\
\hline split & \multicolumn{2}{|c|}{$\mathrm{k}=\mathrm{i}+\mathrm{j}$} \\
\hline
\end{tabular}

Exhaustive control is given if the embedded verb's subject and one of the matrix arguments are referentially identical $(\mathrm{k}=\mathrm{i}$ or $\mathrm{k}=\mathrm{j})$. Examples of verbs exhibiting exhaustive control are verbs such as try in $\mathrm{He}_{\mathrm{i}}$ tried [ _ $\mathrm{i}$ to open the gate] or forbid in Peter forbad his son $_{\mathrm{j}}$ L $_{\mathrm{j}}$ to see the movie]. In partial control, the controllee is only partially identical with one of the matrix arguments $(\mathrm{k}=\mathrm{i}+\mathrm{v}$ or $\mathrm{k}$ $=\mathrm{j}+\mathrm{v}$ ). Predicates permitting partial control are want as in John $n_{\mathrm{i}}\left[\mathrm{i}_{\mathrm{i}+\mathrm{v}}\right.$ wanted to meet at six] or afraid as in The chair ${ }_{\mathrm{i}}$ was afraid [ ${ }_{\mathrm{i}+\mathrm{v}}$ to gather during the strike]. All verbs with partial control also exhibit exhaustive control. Finally, in split control, two arguments of the control verb jointly control the controllee (i.e., $\mathrm{k}=\mathrm{i}+\mathrm{j}$ ). Verbs that allow for split control (besides exhaustive control) are talk about as in John $n_{\mathrm{i}}$ talked to Sarah $\mathrm{j}_{\mathrm{j}}$ about $\left[\mathrm{i}_{\mathrm{i}+\mathrm{j}}\right.$ meeting each other at 6] or discuss as in Amy $y_{\mathrm{i}}$ figured that John $n_{\mathrm{j}}$ would discuss $\left[_{\mathrm{i}} \mathrm{i}+\mathrm{j}\right.$ protecting themselves during the strike] (examples for partial and split control taken from Jackendoff \& Culicover 2003).

As I will show below, split control arises in Korean if the embedded verb is followed by the propositive suffix - $c a$. Additionally, I will discuss instances of split and partial control with overtly realized controllees.

Since the definition of control given above is semantic in nature, the survey and analysis presented in the following stand in the tradition of approaches to control that focus on the importance of semantic factors (Jackendoff 1972, 1974, Růžička 1983, 1999, Dowty 1985, Farkas 1988, Chierchia 1988, Pollard and Sag 1994, and Jackendoff \& Culicover 2003). For reasons of space, I will not discuss the majority of these proposals with respect to the data and my analysis. Moreover, some of the theoretical devices of these approaches such as theta-roles do not play any role in my analysis. I will, however, adopt the proposal made by 
Farkas in my analysis in section 6 . Finally, some of the shortcomings of syntactic analyses will be addressed in section 7 .

\section{SOA-argument-taking predicates in Korean}

As a starting point, a list of approximately seventy SOA-argument-taking predicates was compiled. The predicates of the resulting sample were characterized with respect to the types of complement they license. Additionally, the specific combinations of matrix predicate and complement were subdivided into control and non-control structures in dependence of the definition of complement control given above. Before presenting the statistical distribution of complement types and control in section 3.2, the different types of complementation and their relation to control/non-control are introduced in section 3.1. If not otherwise mentioned, all examples presented in this paper were provided by my informants.

\subsection{Types of complements and control}

The types of complements found in the sample are nominalizations (via the verbal suffixes -ki and -um or the dummy noun kes), complements with the quotative particle $k o$ and complements with the resultative suffix -tolok. In addition, a number of matrix predicates in the sample are nouns to which the embedded verb is connected by relativization. Finally, there are miscellaneous strategies where a verb selects a specific base form of the dependent verb or is part of a complex idiomatic sequence.

\subsubsection{Nominalization}

There are at least three sentential nominalizers in Korean: $-k i$ and -um are suffixes which attach to the verb stem. According to the view generally held in literature, $-k i$ and -um are in complementary distribution: - $u m$ is found with complements of factive verbs, whereas - $k i$ appears with complements of non-factive verbs (Lee 1983, Sohn 1994, 1999, Yoon 1991 among others). Though this generalization is not uncontroversial and not without exceptions, I will keep with it since the distribution of $-k i$ and $-u m$ is not central to the following discussion. Kes 'thing' is a defective noun. Formally, the nominalized clause in a kesnominalization is a relative clause with kes being the head of the clause and the dependent verb exhibiting inflection specific to heads of relative clauses.

\section{Distribution of nominalizers}

The distribution of $-k i,-u m$, and kes is illustrated by the following examples. Independent of the nominalizer chosen, all of the verb's arguments can be realized inside the nominalization and get marked by verbal case. As (3) shows, 
only -um- and kes-complements are compatible with the factive verb alta 'know'. Since -um-nominalizations sound formal, they are often replaced by a kes-nominalization in colloquial speech (Sohn 1999:322).

a. Na-nun [ku-ka cohun salam i-m-ul/*i-ki-lul]

I-TOP he-NOM good man COP-NML-ACC/COP-NML-ACC al-ko\#iss-ta.

know-PROG-DECL

'I know that he is a good man.' (Lee 1983:96)

b. Na-nun [ku-ka cohun salam i-n kes-ul]

I-TOP he-NOM good man COP-PRES.REL ${ }^{1}$ NML-ACC

al-ko\#iss-ta.

knOw-PROG-DECL

'I know that he is a good man.'

On the other hand, $k i$-nominalizations are selected by a non-factive verb such as palata 'want' in (4a) while um-nominalizations are excluded. To some speakers, the use of kes in (4b) sounds rather unusual, which indicates that $k i$ nominalizations are preferred over kes-nominalizations as complements of nonfactive verbs.

(4) a. Yenghi-nun [Chelswu-ka cohun salam *i-m-ul/i-ki-lul]

Yenghi-TOP Chelswu-NOM good man COP-NML-ACC/COP-NML-ACC pala-n-ta.

want-PRES-DECL

'Yenghi wants Chelswu to be a good man.' (Lee 1983:96)

b. (?) Yenghi-nun [Chelswu-ka cohun salam i-1

Yenghi-TOP Chelswu-NOM good man COP-FUT.REL

kes-ul] pala-n-ta.

NML-ACC want-PRES-DECL

'Yenghi wants Chelswu to be a good man.'

\section{Tense marking}

Yoon (1991) notes that the three nominal constructions also differ with respect to the realization of tense. According to him, and others, - $k i$ does not permit tense inflection on the verb it attaches to, while such a restriction does not apply to $-u m$ and $k e s$. Yoon gives the examples in $(5 \mathrm{~b} / \mathrm{c})$ to show that $-k i$ cannot follow

1 For the sake of simplicity, the suffixes $-(u) n$, $-n u n$, and $-(u) l$ are glossed as relativizers also indicating past, present or future tense, respectively (cf. Sells 1995). It is a subtle question if the information carried by these affixes is of a modal, temporal, or aspectual nature. Sohn (1999), e.g., analyzes $-(u) n$ as a mere relative marker, which incorporates past tense after a verb stem. In addition, he segments - nun into the indicative suffix - $n u$ and the relativizer $-n$ while $-(u) l$ is characterized as a prospective suffix. 
a verb with the past tense marker -ess/-ass or the future marker $-l k e s i^{2}$, but is only allowed to be suffixed to a verb which is unmarked for tense as in (5a).

a. John-un [Mary-ka mwusahi o-ki-lul] pala-n-ta.

John-TOP Mary-NOM without.accident come-NML-ACC want-PRES-DECL 'John wants Mary to come without accident.'

b. ??? John-un [Mary-ka mwusahi o-ass-ki-lul]

J.-TOP M.-NOM w/o.accid. come-PAST-NML-ACC

pala-n-ta.

want-PRES-DECL

intended: 'John wants Mary to have come without accident.'

c. *John-un [Mary-ka mwusahi o-lkesi-ki-lul] pala-n-ta.

J.-TOP M.-NOM w/o.accid. come-FUT-NML-ACC want-PRES-DECL intended: 'John wants Mary to come without accident.'

(Yoon 1991:119)

However, if the embedded verb ota 'come' in (5b) is replaced with tochakhata 'arrive' as in (6), the sentence becomes perfect in spite of the past tense suffix.

(6) John-un [Mary-ka mwusahi tochakhay-ss-ki-lul] pala-n-ta. ${ }^{3}$

J.-TOP M.-NOM w/o.accident arrive-PAST-NML-ACC want-PRES-DECL

'John wants Mary to have arrived without accident.'

The contrast between (5b) and (6) can be explained in the following way: desiderative matrix verbs such as palata 'want' can only be combined with the past form of the embedded verb if the referent of the matrix subject is uncertain that the event denoted by the embedded verb has come about. This is the case in (6): John can be waiting at home while he expects Mary to have arrived somewhere. However, in (5b) the embedded verb ota 'come' is a deictic verb denoting a movement towards a deictic center, which is the referent of the matrix subject John. Therefore, John must know if Mary has come without accident. Consequently, the desiderative palata 'want' cannot be combined with the past form of ota 'come'.

The contrast between (5b) and (6) shows that the suffixation of -ki to tensemarked stems is not ruled out categorically. Moreover, the restriction on the use of $-k i$ does not hold when a nominalization functions as adjunct. In (7) the $k i$ nominalization is marked by the adverbial postpostion -ey. As can be seen by examples (7b) and (7c), $-k i$ is compatible with the past or future form of the verb.

2 -lkesi is a complex form, which can be analyzed into the future (prospective) relativizer -l, the nominalizer kes 'thing' and the copula $i(t a)$ 'be'. Following Yoon (1991), among others, I simply gloss it as a marker of future tense.

3 I owe this example to Nayoung Kwon (p.c.). 
a. [Cikum yoksil-ul swuliha-ki]-ey cip-i maywu telep-ta. now bathroom-ACC renovate-NML-at house-NOM very dirty-DECL 'Since they are renovating the bathroom now, the house is very dirty.'

b. [Nwun-i w-ass-ki]-ey sukhi tha-le ka-ss-e. snow-NOM come-PAST-NML-at ski ride-to go-PAST-INT 'Since it had snowed, (I) went skiing.' (Sohn 1999:320)

c. [Onul-cenyek sonnim-i o-lkesi-ki]-ey na-nun cangpole today-evening guest-NOM come-FUT-NML-at I-TOP shopping ka-n-ta.

go-PRES-DECL

'Since we will have guests this evening, I go shopping.'

The data in (7) strongly suggest that the prohibition of tense markers is not inherent to the $k i$-nominalization but is determined by the meaning of the matrix verb.

The prohibition of past and future tense markers does not apply to -um and kes since they are selected by factive verbs. As (8b) and (8c) show, -um is compatible with the past and future form of the verb.

$\begin{array}{llll}\text { a. Yeyswu-nun } & \text { salamtul-eykey } & \text { [chenkwuk-i } & \text { kakkai } \\ \text { J.-TOP } & \text { people-DAT } & \text { kingdom.of.h.-NOM } & \text { near } \\ \text { o-m-ul] } & \text { cenphahay-ss-ta. } & \\ \text { come-NML-ACC } & \text { announce-PAST-DECL } & \end{array}$

'Jesus announced to the people that the kingdom of heaven is near (literally: comes near).'

b. Pawul-un uli-eykey [Yeyswu-kkeyse uli-lul-wihay cwuk-ess-um-ul]

P.-TOP we-DAT J.-NOM.HON we-ACC-for die-PAST-NML-ACC

cenphahay-ss-ta.

announce-PAST-DECL

'Paul announced to us that Jesus had died for us.'

c. Peytulo-nun salamtul-eykey [Yeyswu-kkeyse tasi i ttang-ey

P.-TOP people-DAT J.-NOM.HON again this earth-to

o-lkesi-m-ul] cenphahay-ss-ta.

come-FUT-NML-ACC announce-PAST-DECL

'Peter announced to the people that Jesus will come back to earth.'

Finally, the nominalizer kes is also compatible with the full range of tense markers. This is illustrated by the examples in (9) below.

a. John-un [Mary-ka ecey o-n kes-ul] al-ass-ta.

John-TOP Mary-NOMyesterd. come-PAST.REL NML-ACC know-PAST-DECL 'John knew that Mary came yesterday.' 
b. John-un [Mary-ka o-nun kes-ul] po-n-ta.

John-TOP Mary-NOM come-PRES.REL NML-ACC See-PRES-DECL

'John sees Mary coming.'

c. John-un [Mary-ka nayil o-1 kes-ul] kitayha-n-ta.

John-TOP Mary-NOM tomor. come-FUT.REL NML-ACC expect-PRES-DECL

'John expects Mary to come tomorrow.'

The tense marking found with nominalizations used as complements is shown in (10). As can be seen, only the combination of $k i$-nominalizer and future tense is ruled out.

(10) Tense Markers and Nominalized Complements

\begin{tabular}{|l|c|c|c|}
\hline & Past & Present & Future \\
\hline$-(u) m$ & -ess/-ass & $\varnothing$ & $-(u)$ lkesi \\
\hline- -ki & -ess/-ass & $\varnothing$ & $*-(u)$ lkesi \\
\hline kes & $-(u) n$ & $-n u n$ & $-(u) l$ \\
\hline
\end{tabular}

\section{Nominalization and control}

All of the matrix verbs discussed above do not exhibit control if combined with a nominalization: alta 'know' in (3), palata 'want' in (5), cenphahata 'announce' in (8), pota 'see' in (9b), and kitayhata 'expect' in (9c) allow the subject inside the argument to be referentially independent from the matrix subject or object. Therefore, it is evident that the choice of a nominalized complement does not trigger control, i.e., a nominalized complement cannot be utilized to induce control and can therefore be considered as 'control-neutral'.

Control into nominalized complements only shows up if the matrix verb determines control by its meaning. This is the case in the following example. In (11), the verb hwuhoyhata 'regret' triggers subject control: the unrealized subject argument inside the nominalization in (11a) is obligatorily coreferential with the matrix subject. An embedded subject with independent reference such as atul 'son' in (11b) renders the sentence ungrammatical.

\footnotetext{
a. Chelswu-nun ${ }_{i}\left[\perp_{i} /{ }_{j} k u\right.$ il-ul ha-n kes-ul] hwuhoyhay-ss-ta. C.-TOP that thing-ACC do-PAST.REL NML-ACC regret-PAST-DECL 'Chelswu regretted doing that.'

b. *Chelswu-nun [ku-uy atul-i ku il-ul ha-n kes-ul] C.-TOP he-GEN son-NOM that thing-ACC do-PAST.REL NML-ACC hwuhoyhay-ss-ta. regret-PAST-DECL intended: 'Chelswu regretted that his son did that.'
} 
Here, control is simply an effect of the lexical meaning of hwuhoyhata 'regret': one can only regret actions one has done on its own. Following Stiebels (this volume), I will call this type of control 'inherent control' as opposed to 'constructional control' (or 'syntactic control' in Cormack \& Smith's 2004 terminology).

Kangyohata 'force' in (12) is an instance of semantically determined object control: since kangyohata means something like 'act upon a person in order to make him/her do the action expressed by the embedded verb', the coreferentiality of the matrix object and the embedded subject is fixed lexically.
a. Theylelisuthu-nun $n_{i}$ terrorist-TOP
incil-tul-eykey $_{j}$ hostage-PL-DAT
$\left[{ }_{-}^{\mathrm{j} / *_{\mathrm{i}} / *_{\mathrm{k}}}\right.$
nwup-ki-lul]
kangyohay-ss-ta.
lie.down-NML-ACC
force-PAST-DECL
'The terrorists forced the hostages to lie down.'
b. * Theylelisuthu-nun phaillet-eykey [incil-tul-eykey terrorist-TOP pilot-DAT hostage-PL-DAT
nwup-ki-lul] kangyohay-ss-ta.
lie.down-NML-ACC force-PAST-DECL
intended: 'The terrorists forced the pilot that the hostages lie down.'

So far, we have come to the conclusion that control with nominalizations results only if triggered by the matrix verb's meaning. In the next section, I will discuss an exception to this generalization.

\section{Nominalization and two-place adjectives}

There is a class of two place predicates that mark both of their arguments with nominative. The lexical category of these predicates has been a controversial issue: while some authors regard them as adjectives (Han 1991, Sohn 1994, 1999), others such as Yang (1994) consider them as static verbs since they can hardly be distinguished from verbs morphologically. For the sake of simplicity, I will follow Sohn and others and refer to this class of predicates as adjectives. Semantically, these adjectives are experiencer/psych-predicates with an experiencer and a stimulus argument. This type of predicate is illustrated by twulyepta 'fear, be afraid' in (13).

a. Chelswu-nun ${ }_{i}\left[{ }_{-}{ }_{j} /\right.$ Yenghi-lul tasi manna-nun kes-i] twulyep-ta. C.-TOP Y.-ACC again meet-PRES.REL NML-NOM fear-DECL 'Chelswu fears that he/s.o. meets Yenghi again.' 
b. Chelswu-nun ${ }_{i}$ [Mina-ka Yenghi-lul tasi manna-nun kes-i] C.-TOP M.-NOM Y.-ACC again meet-PRES.REL NML-NOM twulyep-ta.

fear-DECL

'Chelswu fears that Mina meets Yenghi again.'

As the admissibility of the disjoint embedded subject Mina in (13b) shows, the $k e s$-nominalization does not involve control. However, if the $k i$-nominalization is chosen instead, subject control results, as has already been mentioned by Kim (1990). This is shown by the pair of examples in (14), which is identical to the previous pair with the exception of the use of $-k i$ instead of kes. (14a) is an instance of control with the unrealized subject of the subordinate verb being obligatorily coreferential with the matrix subject Chelswu. As (14b) illustrates, the realization of an independent embedded subject renders the sentence ungrammatical.
a. Chelswu-nun ${ }_{i}\left[{ }_{-}{ }^{i} / *_{j}\right.$ Yenghi-lul tasi manna-ki-ka $]$ twulyep-ta. C.-TOP Y.-ACC again meet-NML-NOM fear-DECL 'Chelswu fears to meet Yenghi again.'
b. * Chelswu-nun [Mina-ka Yenghi-lul tasi manna-ki-ka] twulyep-ta. C.-TOP M.-NOM Y.-ACC again meet-NML-NOM fear-DECL intended: 'Chelswu fears that Mina meets Yenghi again.'

As already shown above, the use of the ki-nominalization with nominativeaccusative-verbs such as palata 'want' in (4) does not trigger control. Therefore, the control effect cannot be tied simply to the use of -ki instead of kes.

Yang (1994) argues convincingly that psych-predicates like twulyepta in (14) are stative. It is a well-known fact for Korean as well as Japanese that there is a close relation between statitivity and the double nominative case pattern. Yet, to my knowledge, the relation between stativity and control has neither been discussed nor analyzed yet.

\subsubsection{Quotative clauses}

The complementizer $k o$ is called a 'quotative particle' by Sohn $(1994,1999)$. Ko-complements are licensed by verbs that involve some utterance such as potohata 'report' in (15). Clauses headed by $k o$ are also attested as complements of verbs like mitta 'believe' in (16). For Sells (1995:297) ko is "basically a marker of someone's words or thoughts." As the examples show, ko follows sentencetype markers such as the declarative - $t a$. In Sells' (1995) analysis of the Korean verb morphology ko occupies the outer slot of the four slots he assumes for verbal suffixes. Therefore, the verbs in ko-complements can bear the full range of verbal affixes found also with verbs in matrix clauses. 
(15) Cenellisuthu-nun [Sadam-i cap-hi-ess-ta-ko] potohay-ss-ta. Journalist-TOP S.-NOM capture-PASS-PAST-DECL-CMP report-PAST-DECL 'The journalist reported that Saddam was captured.'

(16) Ai-tul-un [Santa-Halapeci-ka issta-ko] mit-nun-ta. child-PL-TOP Santa-Claus-NOM exist-CMP believe-PRES-DECL 'The children believe that Santa Claus exists.'

Both examples above demonstrate that ko-complements do not induce control. However, if a modal affix such as the imperative -la is attached to the embedded verb, obligatory control arises. This is shown by the contrast between (17a) and (b): whereas (17a) without a modal affix does not show control, (17b) exhibits object control since the imperative suffix -la follows the verbal base $h a-$ 'do'.

a. Chelswu-nun ${ }_{i}$ Yenghi-eykey $_{j}\left[{ }_{-}{ }_{i j / k}\right.$ caknyen-ey safari-yehayng-ul C.-TOP Y.-DAT last.year-in safari-trip-ACC hay-ss-ta-ko] malhay-ss-ta. do-PAST-DECL-CMP say-PAST-DECL 'Chelswu told Yenghi that he/she/s.o. did a safari trip last year.'

b. Chelswu-nun ${ }_{i}$ Yenghi-eykey $_{j}\left[{ }_{-j} / *_{i} / *_{k}\right.$ naynyen-ey C.-TOP Y.-DAT next.year-in safari-yehayng-ul ha-la-ko] malhay-ss-ta. safari-trip-ACC do-IMP-CMP say-PAST-DECL

'Chelswu told Yenghi to go on a safari trip next year.'

To my knowledge, the control effect of modal affixes such as the imperative has not been analyzed systematically in the literature. I will focus on control triggered by modal affixes in section 5 .

\subsubsection{Result clauses}

According to Sohn (1994:75) -tolok is a resultative suffix meaning 'to the extent that, so that'. It can be attached to a verbal stem to form result clauses like the one in (18a) (Lee \& Lee 2003). With the exception of the subject honorific -si, no other affix can precede -tolok. Consequently, if -tolok is attached to a verb, neither tense nor modal markers can appear. Tolok-clauses are also attested as complements of object control verbs such as kangyohata 'force' in (18b).

$$
\begin{aligned}
& \text { a. Minca-nun [phal-i aphu-tolok] ilhay-ss-ta. } \\
& \text { Minca-TOP arm-NOM hurt-CMP work-PAST-DECL } \\
& \text { 'Minca worked so hard that her arms hurt.' (Sohn 1994:75) }
\end{aligned}
$$




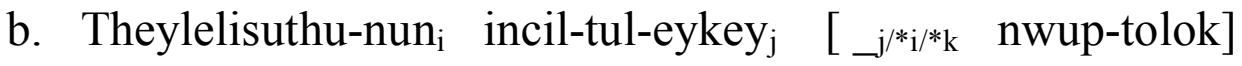
terrorist-TOP hostage-PL-DAT lie.d.-CMP kangyohay-ss-ta. force-PAST-DECL

'The terrorists forced the hostages to lie down.'

As (18a) shows, tolok-clauses do not suppress the external argument of the embedded verb. Therefore, the object control in (18b) cannot be regarded as a structural effect of the tolok-complement. Moreover, the use of a tolok-result clause such as the one in (18a) seems to be fairly unrestricted. (18a) suggests that a part-whole relation as between phal 'arm' and Minca may have to exist in order for a result clause to be licensed. However, such a relation cannot be found in the following example.

[Os-i humppek cec-tolok] pi-ka ssotacye-ss-ta.
clothes-NOM entirely wet-CMP rain-NOM pour.down-PAST-DECL
'The rain poured down so that my clothes got soaking wet.'

Therefore, it seems plausible that the only restriction on tolok-result clauses seems to be that the event denoted by the tolok-clause can be brought about by the event referred to by the matrix verb.

\subsubsection{Complements of matrix nouns}

Some English control verbs are translated most naturally into Korean by a construction in which the matrix predicate is a noun followed by an auxiliary or auxiliarized verb such as the copula ita 'be', the verb issta 'exist' or toyta 'become'. In this case, the embedded verb is connected to the matrix noun by relativization. The sentences in (20) illustrate this construction with the nouns kyeyhoyk 'plan' and cwunpi 'readiness'. Though superficially identical, the sentences in (20) are semantically different from an ordinary relative clause since the head noun kyeyhoyk 'plan' or cwunpi 'readiness' cannot be postulated to be coreferential with an unrealized argument or adjunct in the embedded clause.
a. Yenghi-nun ${ }_{i}\left[{ }_{-} \mathrm{i} /{ } \mathrm{j}\right.$ onul pwuekh-ul chyengsoha-1] kyeyhoyk $\mathrm{i}$-ta. Yenghi-TOP today kitchen-ACC clean-FUT.REL plan COP-DECL 'Yenghi has planed to clean the kitchen today.'

b. Na-nun ${ }_{i}\left[{ }_{-}{ }^{i} * j\right.$ tokil-ul ttena-1] cwunpi-ka toy-e\#iss-ta. I-TOP Germany-ACC leave-FUT.REL readin.-NOM bec.-RES-DECL 'I am ready to leave Germany.' 
All instances of matrix nouns in the sample involve subject control (besides raising in some cases ${ }^{4}$ ).

\subsubsection{Miscellaneous strategies}

Besides clausal complementation, there are also closer combinations where the matrix verb subcategorizes for a specific base form of the dependent verb. All of these combinations, which can be regarded as instances of clause union, exhibit subject control (in addition to raising in some cases) but never object control. In (21a) pota 'try' requires a form which is yielded by attaching $-e /-a$ to the stem. This form is sometimes referred to as 'infinitive' in the literature (Martin 1992, Sohn 1994, 1999 among others). Less frequently, matrix verbs such as siphta 'wish' in (21b) combine with the ko-form of the verb", which is called 'gerundive' by Martin (1992) and Sohn $(1994,1999)$.

$$
\begin{aligned}
& \text { a. John-un } n_{i} \quad\left[{ }_{i}{ }^{*}{ }_{j} \text { i nonmwun-ul ilk-e] po-ass-ta. }{ }^{6}\right. \\
& \text { J.-TOP this paper-ACC read-INF try-PAST-DECL } \\
& \text { 'John tried to read this paper.' }
\end{aligned}
$$

b. Na-nun ${ }_{i}\left[{ }_{-} i^{*}{ }^{j}\right.$ ttena-ko $]$ siph-ta.

I-TOP leave-GER wish-DECL

'I wish to go.'

Typically, the matrix verb develops a special meaning in such combinations. For example, pota, which means 'try' in (21a), means 'see' in isolation, and siphta 'wish' in (21b) is not attested as an independent verb without a ko-complement. In addition to such formations, there are also more complex idiomatized sequences such as ka-lyeko hata (go-VOL.CONJ do) 'intend to go' comprising the so-called 'intentive conjunctive' -(u)lyeko and the light verb hata 'do' or ka-yaman hata (go-if-only do) 'must go', which consists of the conditional form of the base verb, the particle man 'only' and hata.

The formations introduced in this section are instances of constructionally induced control, i.e. the type of complement always involves control. For exam-

4 An instance of a matrix noun exhibiting raising is philyo 'neccessity':
(i) Pi-ka o-l
philyo-ka iss-ta.
rain-NOM come-FUT.REL necc.-NOM exist-DECL
'It is neccessary that it rains.'

5 The gerundive suffix $-k o$ is not identical to the quotative particle $k o$. The gerundive $-k o$ can only be preceded by the verb stem or verb stem plus subject honorific $-(u) s i$, while the quotative $k o$ can follow the full array of verbal suffixes. Consequently, in Sells' (1995) analysis the quotative $k o$ occupies the outer verbal slot 4 , whereas the gerundive $-k o$ can only appear in slot 2.

6 Verb-Verb-Sequences with the first verb being in the infinitive form have been analyzed as serial verb constructions (Lee 1992, Suh 2000). For reasons of space, I will not discuss these analyses. In principle, a characterization as a control structure and a characterization as a serial verb construction do not exclude each other. 
ple, there are no instances of ko-complement plus siphta that permit the dependent verb to realize a referentially independent subject. Although such formations are frequent in language use since they refer to highly frequent concepts such as 'wish' or 'must', they are attested only for a handful of matrix verbs and almost always involve reanalysis or idiomatization. Therefore, they can be considered as marginal compared to the types of complementation introduced in the preceding sections.

\subsection{Distribution of complementation patterns in the sample}

The matrix predicates in the sample are either verbs, adjectives, or nouns. Their distribution is given in (22).

(22) Matrix predicates: distribution of lexical classes in sample

\begin{tabular}{|l|l|}
\hline lexical category of matrix predicate & number (percentage) \\
\hline verbs & $58(83 \%)$ \\
\hline adjectives (stative verbs) & $5(7 \%)$ \\
\hline nouns & $7(10 \%)$ \\
\hline
\end{tabular}

\section{Matrix verbs}

The table in (23) shows the distribution of control types and complement types that appear with the matrix verbs in the sample. The roman numbers in the last column refer to the classes which are constituted by verbs exhibiting identical complementation patterns.

(23) Matrix verbs: complement types and control

\begin{tabular}{|c|c|c|c|c|c|c|c|}
\hline & & & \multirow{2}{*}{$\begin{array}{l}\text { control- } \\
\text { inducing }\end{array}$} & \multicolumn{3}{|c|}{ control-neutral } & \\
\hline & & & & NML & QUOT $(k o)$ & RESULT (-tolok) & \\
\hline \multirow{2}{*}{$\begin{array}{l}\text { structural } \\
\text { control }\end{array}$} & subj & 4 & \multirow{2}{*}{$\sqrt{ }$} & \multirow{2}{*}{$*$} & \multirow{2}{*}{$*$} & \multirow{2}{*}{$*$} & \multirow{2}{*}{ I } \\
\hline & obj & 0 & & & & & \\
\hline \multirow{3}{*}{$\begin{array}{l}\text { inherent } \\
\text { control }\end{array}$} & \multirow{2}{*}{ subj } & 8 & * & $\sqrt{ }$ & $*$ & $*$ & II \\
\hline & & 1 & $*$ & $\sqrt{ }$ & $\sqrt{ }$ & $*$ & III \\
\hline & obj & 10 & $*$ & $\sqrt{ }$ & $\sqrt{ }$ & $\sqrt{ }$ & $\mathrm{V}$ \\
\hline $\begin{array}{l}\text { control depen- } \\
\text { dent on modal } \\
\text { affixes }\end{array}$ & subj & 7 & $*$ & $\sqrt{ } / *$ & $\sqrt{ }$ & $*$ & IV \\
\hline \multirow{2}{*}{ non-control } & & 23 & * & $\sqrt{ }$ & $*$ & $*$ & II \\
\hline & & 5 & $*$ & $\sqrt{ }$ & $\sqrt{ }$ & $*$ & III \\
\hline
\end{tabular}

As can be seen from the table, there are only four instances of structural control, which are characterized by miscellaneous types of complementation (class I). 
The remaining matrix verbs select control-neutral complements. They can be grouped into four classes in dependence of the types of complements they occur with and the type of control they exhibit. As (23) shows, of the nine theoretically possible combinations of the three complementation types nominalization, $k o-$, and tolok-clause, only four are attested in the sample. In (23), I do not differentiate further between $k i-, u m-$, and kes-nominalization. Since all three types of complements are control-neutral, it is expected that there is no coincidence between complement type and control. However, for the classes II to V some correlation between semantic verb class, complementation patterns and control can be noted:

The verbs of class II, which can select only nominalizations, are mainly desiderative and phasal/aspectual verbs. The class III verbs allow for both quotative clauses and nominalizations. The members of this class are mostly verbs of propositional attitude such as cwucanghata 'claim' or mitta 'believe'. As can be seen from the table, both class II and class III verbs show either inherent control or non-control depending on the meaning of the specific verb chosen. The verbs of class IV are utterance verbs such as malhata 'say'. Consequently, all verbs in this class permit ko-complements. However, with respect to nominalizations class IV-verbs behave heterogeneously: while hyeppakhata 'threaten', iyakihata 'tell', malhata 'say', and potohata 'report' can combine with a kesnominalization quite naturally, native speakers only reluctantly accept kescomplements with soksakita 'whisper' and solichita 'shout'. In addition, the complex verb sinho-lul ponayta 'signal (lit. send (a) signal)' cannot select an accusative-marked nominalization at all, presumably because ponayta 'send' already combines with the accusative-marked sinho 'signal'. Since the majority of class-IV verbs exhibit the same complementation pattern as the verbs in class III, it may seem more plausible to subsume these verbs under class III. However, they should rather be regarded to constitute a class of their own. First, they can be characterized homogeneously as utterance verbs as opposed to the propositional attitude verbs of class III. Second, only with the verbs of this class control can be triggered by attaching a modal marker such as the imperative -la to the embedded verb.

Finally, the verbs of class $\mathrm{V}$, which are manipulative/directive verbs, can combine with all three types of complements. All the verbs of class V are characterized by inherent object control, which is a result of their manipulative/directive meaning. In addition, only the verbs of this class can select tolokcomplements since the selection of tolok-complements is tied to a manipulative meaning of the verb.

53 of the 58 verbs can combine with a nominalization ( $=91 \%$ of the verbs). 23 verbs $(=40 \%$ of verbs $)$ select a $k o$-complement and 10 verbs $(=17 \%$ of verbs) select a tolok-complement. Nominalization is clearly the prevalent type of 
complementation, whereas ko- and tolok-complements are used significantly less because these complementizers can be selected only by matrix verbs belonging to specific semantic classes (verbs involving some kind of utterance or thought and verbs involving manipulation/direction, respectively). A list of the complementation types attested for each predicate of the sample is given in the appendix of this paper.

The table (23) explicates the significance of semantically determined control: as argued above, all of the complement types of nominalizations, ko- and tolokclauses are control-neutral. Therefore, all cases of control exhibited by the verbs of class II to $\mathrm{V}$ are instances of semantic control, i.e. 19 verbs are inherent control verbs and 7 verbs show control if combined with a modally marked verb inside a $k o$-complement. Consequently, $45 \%$ of the verbs in the sample exhibit semantic control as opposed to $7 \%$ of verbs with constructional control (class I) and $48 \%$ verbs that never exhibit control. This ratio clearly shows the significance of semantic control, which can only become transparent in a language that lacks constructional control.

\section{Matrix adjectives and matrix nouns}

All the five adjectival matrix predicates of the sample exclusively combine with a nominalization. Unlike verbs, adjectives do not subcategorize for $k o-$ or tolok-complements. Moreover, adjectives display control in dependence of the nominalization chosen: if combined with a $k i$-complement, they exhibit subject control whereas combined with a kes-complement, they do not. The seven matrix nouns of the sample connect with the embedded verb only via relativization. All instances of matrix nouns in the sample are characterized by subject control or raising.

The adjectives and nouns constitute a significant part $(=17 \%)$ of the SOAargument-taking predicates in the sample. However, an analysis of control found with these predicates shall not be given in this paper. In the following, I will focus on verbal matrix predicates. Therefore, I proceed with a discussion of control verbs that determine control due to their lexical meaning.

\section{Inherent control verbs}

There are a number of verbs which involve control solely due to their lexical meaning, i.e. inherent control verbs. In the following, I will discuss the control relations found with these verbs. 


\subsection{Subject control}

\section{Semantic Characteristics}

Kepwuhata 'refuse' given in (24) is a subject control verb. Consequently, an unexpressed embedded subject is obligatorily coreferent with the matrix subject as in (24a). As (24b) shows, the embedded verb cannot realize an independent subject. Moreover, the complement is a ki-nominalization because kepwuhata is a non-factive verb. Since kepwuhata is not an object control verb, tolokcomplements are excluded. Likewise, $k o$-complements are not admissible.
a. Chelswu-nun ${ }_{i}\left[{ }_{-}{ }^{i} *^{j}\right.$ koki(-lul) mek-ki-lul $]$ kepwuhay-ss-ta. C.-TOP meat(-ACC) eat-NML-ACC refuse-PAST-DECL 'Chelswu refuses to eat meat.'

b. *Chelswu-nun [atul-i koki(-lul) mek-ki-lul] kepwuhay-ss-ta. C.-TOP son-NOM meat(-ACC) eat-NML-ACC refuse-PAST-DECL intended: 'Chelswu refuses that his son eat meat.'

Kepwuhata 'refuse' is a subject control verb because the referent of the matrix verb's subject can only refuse to realize the action denoted by the embedded verb if $\mathrm{s} / \mathrm{he}$ controls this action as referent of the embedded verb's subject. Hence, control results from the matrix verb's meaning. The same argumentation applies to hwuhoyhata 'regret' given in (11) above. The referent can only regret the action referred to by the embedded verb if $s /$ he has done that action. Again this entails that the subject arguments of the matrix verb and the embedded verb have to be identified.

(25) shows the subject control verbs of the sample. The roman number preceding a sequence of verbs refers to the verb class given in the table in (23) above. With the exception of the verbs in class I, which can be considered as instances of constructional control, all the remaining verbs in (25) exhibit semantic control.

Subject control verbs

class I: V-e/a pota 'try', V-e/a tayta 'go on (again and again)', V-e/a pelita 'finish', V-ko siphta 'wish';

class II: kepwuhata 'refuse', samkata 'refrain', soholhihata 'neglect', hwuhoyhata 'regret', sicakhata 'begin', kyeysokhata 'continue', kkuthmachita 'finish', memchwuta 'stop';

class III: yaksokhata 'promise'

It is evident that the subject control verbs in (25) belong to different semantic verb classes: V-e/a tayta 'go on', V-e/a pelita 'finish', sicakhata 'begin', kyeysokhata 'continue', kkuthmachita 'finish', and memchwuta 'stop' are aspectual/phasal verbs; V-ko siphta 'wish', and kepwuhata 'refuse' are desiderative verbs; V-e/a pota 'try', soholhihata 'neglect', and samkata 'refrain' are implica- 
tive verbs; hwuhoyhata 'regret' is a factive/commentative verb; yaksokhata 'promise' can be characterized as a verb of commitment.

However, taking a closer look, it becomes obvious that all the verbs share a common semantic characteristic: the verbs that are selected by the subject control verbs above all denote actions that are intentionally executed or brought about by the referent of the matrix subject. This clearly holds for 'refuse', 'try', 'neglect', 'refrain', and 'regret'. It is also valid for the phasal/aspectual verbs 'go on', 'finish', 'begin', 'continue', and 'stop': since these verbs imply that the subject referent volitionally begins, continues, finishes, or stops the event denoted by the subordinate verb, they entail the identity of the matrix subject and the embedded subject. Some of these aspectual verbs such as sicakhata 'begin' or kyeysokhata 'continue' also have a raising variant without a thematic subject. However, in their subject control reading they require that the referent of the matrix subject intentionally executes the action referred to by the embedded verb. Before presenting evidence for the assumption of a control variant for aspectual verbs, I will first summarize the considerations above as a condition on semantic subject control given in (26).

\section{Condition on Semantic Subject Control}

A matrix verb exhibits semantic subject control iff its meaning involves that the event denoted by the embedded verb is brought about by the referent of the matrix subject.

The only exception to this generalization seems to be the desiderative V-ko siphta 'wish', which does not require the event denoted by the embedded verb to be brought about by the referent of the matrix subject. On the contrary, most naturally one wishes an event to come true that one cannot bring about oneself. However, V-ko siphta, which selects the ko-form of the dependent verb, belongs to the verbs of class I, which are characterized by constructional control.

\section{Control versus raising}

Some of the verbs cited in (25) are phase/aspectual verbs which could alternatively be considered to be raising verbs since they do not pose any thematic restriction on the matrix subject. However, some of them such as V-e/a pelita 'finish' require an agentive subject thereby qualifying as control verbs. With other verbs the situation is more intricate. Sicakhata 'begin', e.g., permits inanimate subjects such as $p i$ 'rain' in the following example.
Pi-ka o-ki sicakhay-ss-ta.
rain-NOM come-NML begin-PAST-DECL
'It began to rain.'

Yet, even for sicakhata 'begin', one can assume a variant with an agentive subject which renders sicakhata ambiguous between a raising and a control reading. 
This assumption goes back to Perlmutter's (1970) analysis of the English verb begin and has been adopted, for instance, in Matsumoto's (1996) analysis of aspectual compound verbs in Japanese. As for Korean control verbs, such an assumption is backed by the following data: Sells (1998) mentions that raising predicates cannot be followed by the subject honorific suffix $-(u)$ si. This is shown by the example in (28), where - $(u)$ si can only appear on the embedded verb ilkta 'read' but not on the matrix verb pota 'seem'.

$$
\begin{array}{ll}
\text { ilk-usi-na } & \text { po(*-si)-ta } \\
\text { read-SHON-CMP } & \text { seem(-*SHON)-DECL } \\
\text { '(someone honorable) seems to read' (Sells 1998:11) }
\end{array}
$$

The ungrammaticality of such examples can be explained by a locality condition on subject honorification as assumed by Kuno (1987) for Japanese. This condition requires that subject honorification can only apply if the honorific suffix is attached to a morpheme whose argument structure contains the subject argument. Since the argument structure of a raising verb does not contain a thematic subject, (28) is ungrammatical. Sicakhata, however, can precede the subject honorific -si as in (28). The grammaticality of (28) then indicates that sicakhata can function as a control verb with a thematic (agentive) subject.

(29) Sensayngnim-kkeyse $e_{i}\left[{ }_{-} \mathrm{i} *{ }^{*} \mathrm{j}\right.$ chayk-ul ilk-ki] sicakha-si-ess-ta. teacher-NOM.HON book-ACC read-NML begin-SHON-PAST-DECL 'The teacher began to read the book.'

All of the phase/aspectual verbs cited in (25) can be followed by the subject honorific. Therefore, I characterize these verbs as subject control verbs, which have a raising variant in some cases.

\section{Overt controllees}

In addition to a null-subject, subject control verbs such as kepwuhata 'refuse' also allow an overt embedded subject such as the reflexive caki in (30a). The embedded subject can also consist of two coordinated constituents such as the reflexive and the noun atul 'son' in (30b). As a consequence, partial control arises, i.e., the referent of the matrix subject is contained in the referent of the embedded subject.

(30) a. Chelswu-nun ${ }_{i}$ [caki-ka koki(-lul) mek-ki-lul] kepwuhay-ss-ta. C.-TOP self-NOM meat(-ACC) eat-NML-ACC refuse-PAST-DECL lit.: 'Chelswu refuses that he himself eat meat.' 
b. Chelswu-nun ${ }_{\mathrm{i}}$ [caki-wa $\mathrm{i}_{\mathrm{i}}$ atul-i koki(-lul) mek-ki-lul] C.-TOP self-and son-NOM meat(-ACC) eat-NML-ACC kepwuhay-ss-ta. refuse-PAST-DECL

lit.: 'Chelswu refuses that he himself and his son eat meat.'

Overt embedded subjects are not restricted to nominalized complements. They can also appear in ko-complements. As (31) shows, the subject control verb yaksokhata 'promise' is compatible with ko-complements that contain a coordination of a reflexive and a personal pronoun. The reflexive is identified with the matrix subject while the referent of the pronoun kunye 'she' is identified with the referent of the matrix object or another person. As a consequence, split or partial control arises.

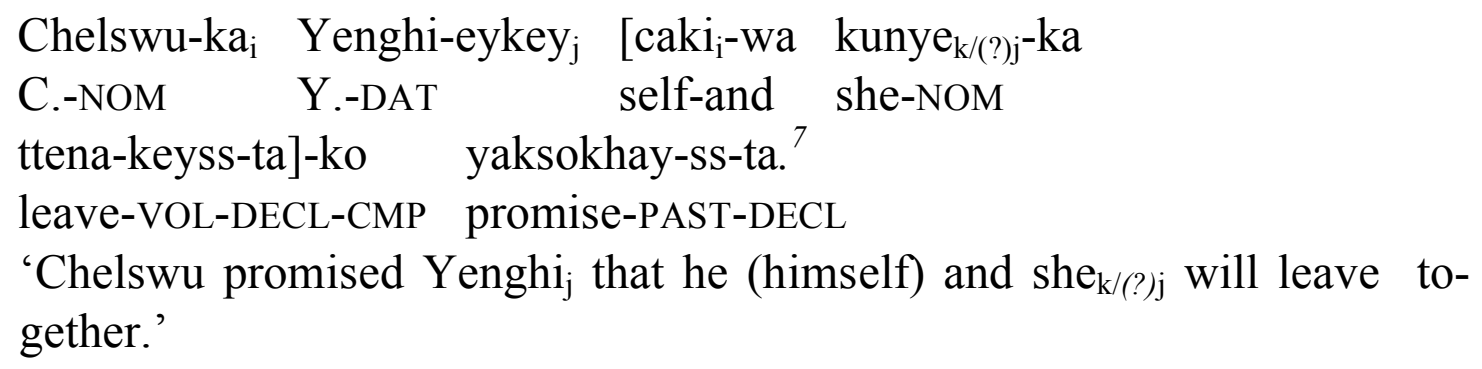

The admissibility of overt subjects shows that control is determined entirely semantically: neither the nominalization nor the ko-complements suppresses the subject of the embedded verb. Therefore, control does not result from the need of the identification of a suppressed subject argument.

In addition, the possibility of a coordinated subject constitutes an interesting typological case where split and partial control can be indicated by the conjunction of overt pronouns.

\subsection{Object control}

All of the object control verbs in the sample are directive verbs which involve manipulation of the object referent to various degrees. These verbs are given in (32).

(32) Object Control Verbs

class V: yokwuhata 'demand', kangyohata 'force', seltukhata 'persuade', myenglyenghata 'order', yochenghata 'request', pwuthakhata 'ask (as a favor)', tokchokhata 'press', pwuchwukita 'encourage', kwenyuhata 'induce', chwungkohata 'advise'

7 There seems to be some speaker variation in interpreting (31) as a case of split control. Out of eleven native speakers asked, all could accept the sentence in a partial control reading, while only six considered the sentence as grammatical with kunye 'she' and Yenghi being referentially identical. 
In contrast to subject control verbs, all object control verbs belong to the class of manipulative/directive verbs. They share the meaning that the object referent is manipulated in order to make him bring about the event denoted by the embedded verb. This meaning entails referential identity of the matrix object and the embedded subject, i.e., object control. The relation between verb meaning and object control can be captured by the condition on semantic object control in (33).

(33) Condition on Semantic Object Control

A matrix verb exhibits semantic object control if its meaning involves the manipulation of the object referent to make him/her bring about the event denoted by the embedded verb.

\section{Complement types}

All object control verbs in the sample display the same array of complement types, i.e., nominalization, $k o$ - and tolok-clauses. This is illustrated by the three sentences with the object control verb seltukhata 'persuade'.

a. Chelswu-ka $a_{i}$ Ilkyun-eykey ${ }_{j}\left[{ }_{j} j *_{i} / *_{k}\right.$ Yenghi-lul manna-l kes-ul] C.-NOM I.-DAT Y.-ACC meet-FUT.REL NML-ACC seltukhay-ss-ta. persuade-PAST-DECL 'Chelswu persuaded Ilkyun to meet Yenghi.'

b. Chelswu-ka $a_{i}$ Ilkyun-eykey ${ }_{j}\left[{ }_{-j} / *_{i} / *_{k}\right.$ Yenghi-lul manna-la-ko] C.-NOM I.-DAT Y.-ACC meet-IMP-CMP seltukhay-ss-ta. persuade-PAST-DECL 'Chelswu persuaded Ilkyun to meet Yenghi.'

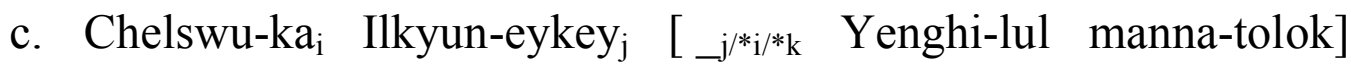
C.-NOM I.-DAT Y.-ACC meet-CMP seltukhay-ss-ta. persuade-PAST-DECL 'Chelswu persuaded Ilkyun to meet Yenghi.'

The compatibility with $k o$ - and tolok-complements can be explained straightforwardly considering the directive or manipulative character of these verbs: the object referent is manipulated in order to make him/her bring about the event referred to by the embedded verb as a result. Therefore, tolok-complements are licensed by object control verbs. In this way, tolok-complements selected by object control verbs are interpreted analogously to resultative adjuncts as in the following sentence: 
(35)
machine-ACC
well run-CMP
Chelswu-nun kikyey-lul $\mathrm{i}_{\mathrm{i}} \quad\left[{ }_{-} \mathrm{i} *_{\mathrm{j}}\right.$ cal caktongha-tolok $]$
C.-TOP
koch-yess-ta.
repair-PAST-DECL
'Chelswu repaired the machine so that it ran well.'

\section{Overt controllees}

Again, as in subject control structures, the embedded subject can be overt. In the sentences below, the embedded subject is a coordination of the personal pronoun $k u$ and the proper noun Mary. Since $k u$ is coreferential with Bill, the sentence constitutes a case of partial control.

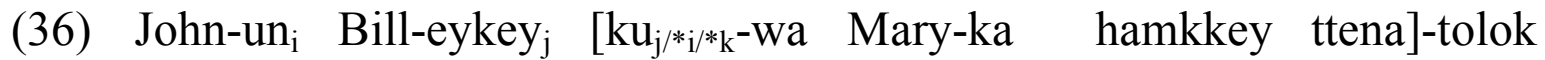 J.-TOP B.-DAT he-and Mary-NOM together leave-CMP seltukhay-ss-ta. persuade-PAST-DECL 'John persuaded Bill that he (= Bill) and Mary leave together.' (Kim 1995:208)

There are also instances of an overt embedded object found with exhaustive control. The following example is taken from Kim (1995:199).

(37) John-un Mary-eykey $\mathrm{i}_{\mathrm{i}}$ Mary-ka $\mathrm{k}_{\mathrm{i}}$ cip-ey ka-tolok] myenglyenghay-ss-ta. J.-TOP M.-DAT M.-NOM house-to go-CMP order-PAST-DECL 'John ordered Mary, that Mary go home.'

Though the example above is judged as grammatical by Kim, there seems to be a variation in grammaticality judgments. The next example is taken from Choi (1988), who regards it as marked. As the paraphrase indicates, such examples involve emphasis and contrastive focus.

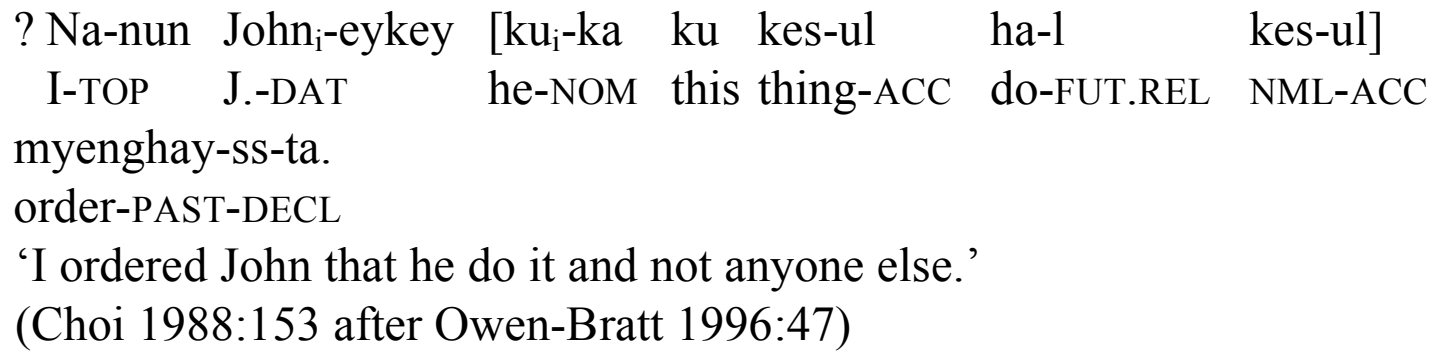

The marked or emphatic status can be motivated by the fact that the coreference of the embedded subject and the matrix subject is already fixed semantically. Therefore, the realization of the embedded subject is superfluous except for the purpose of emphasis or contrast.

In the literature, some instances of seltukhata with an overt embedded subject are cited as non-control variant. Monahan (2003:358) regards (39a) as a noncontrol version of seltukhata since the matrix object and the embedded subject 
are distinct in reference. Moreover, it seems that the non-control version is indicated by the quotative complementizer $k o$ as opposed to the control variant with tolok. However, the example in (39b) demonstrates that the tolok-variant also allows disjoint subject referents.

$$
\begin{array}{llll}
\text { a. Chelswu-nun } & \text { Yenghi-lul/eykey } & \text { [Swuyeng-i } & \text { kakey-ey } \\
\text { C.-TOP } & \text { Y.-ACC/DAT } & \text { S.-NOM } & \text { store-to } \\
\text { ka-yaha-n-ta-ko] } & \text { seltukhay-Ss-ta. } & \\
\text { go-should-PRES-DECL-CMP } & \text { persuade-PAST-DECL }
\end{array}
$$

'Chelswu persuaded Yenghi that Swuyeng should go to the store.'

b. Chelswu-nun pwumo-eykey [kakkak-uy ai-ka swukcey-lul

$$
\text { C.-TOP parents-DAT each-GEN child-NOM homework-ACC }
$$

ha-tolok] seltukhay-ss-ta.

do-CMP persuade-PAST-DECL

'Chelswu persuaded the parents to make each child do the homework.' (Cormack \& Smith 2004:68, ftn. 23)

In analyzing these examples, I will follow Cormack \& Smith (2004) who assume that they are instances of causative coercion, i.e., they are interpreted by implicitly causativizing the embedded verb. The unexpressed causer, then, is understood to be coreferential with the matrix object, which renders the examples above as special cases of object control.

\section{Backward control}

Korean has been characterized as a language with backward object control based on evidence such as in (40). (40a) shows 'forward' control with the controller expressed as matrix object and the embedded subject, i.e. the controllee, being unrealized. In contrast, in (40b) the nominative marked Yenghi is the controller whereas the unrealized matrix object is the controllee. Since the controller is realized inside the complement clause and positioned below the unexpressed controllee in the matrix clause, (40b) can be considered as backward control as opposed to 'ordinary' forward control with the controller in a syntactically higher position.

(40) a. Chelswu-nun Yenghi-lul ${ }_{i}\left[\_i\right.$ kakey-ey ka-tolok] seltukhay-ss-ta.

$$
\text { C.-TOP Y.-ACC store-to go-CMP persuade-PAST-DECL }
$$

'Chelswu persuaded Yenghi to go to the store.' (forward control)

b. Chelswu-nun _i[Yenghi-ka kakey-ey ka-tolok] seltukhay-ss-ta.

C.-TOP Y.-NOM store-to go-CMP persuade -PAST-DECL

'Chelswu persuaded Yenghi to go to the store.' (backward control) (Monahan 2003:357)

Monahan has taken backward control in Korean as evidence for a movement analysis of control in the sense of Hornstein (1999). In Monahan's approach the 
overt subject inside the tolok-clause is raised to the position of the unexpressed matrix object to receive accusative case and get theta-marked by seltukhata. Contrary to Monahan, Cormack \& Smith (2004) assume a pro as matrix object. However, in order to avoid a Condition $\mathrm{C}$ violation they have to stipulate that the tolok-clause is scrambled in front of pro. But also the raising account cannot explain instances of object control such as (36) above where both the controller and the controllee are overt. I will discuss this point in more detail in section 7 .

Since all object control verbs that show backward control are instances of semantic control, the presence of backward control seems to be closely tied to semantic control. However, this relation is neglected in Monahan's syntactic approach.

\subsection{Control shift}

Generally, a control shift can hardly be triggered in Korean. Park (2001) cites the sentence in (41) as an instance of subject control. Since seltukhata "persuade' is basically an object control verb, this can be considered as an instance of a shift from object to subject control, which is triggered by attaching the volitional suffix -keyss to the embedded verb (see next chapter for a discussion of volitional suffixes).

$$
\begin{aligned}
& \left.\mathrm{C}_{\mathrm{i}} \text {-ka } \mathrm{Y}_{\mathrm{j}} \text {-eykey [_i ttena-keyss-ta-ko }\right] \text { seltukhay-ss-ta. } \\
& \text { C-TOP Y-DAT leave-VOL-CMP persuade-PAST-DECL } \\
& \text { 'C persuaded Y that he }(=C) \text { will leave.' (Park 2001:8) }
\end{aligned}
$$

However, the example above is not easily acceptable for native speakers. Moreover, in this case seltukhata rather seems to mean something like 'make believe'.

Additionally, a control shift cannot be triggered by passivizing the embedded verb. Pwuthakhata, e.g., translates into English as 'ask to do', which permits a control shift as well as German bitten 'ask to do' when the embedded verb is passivized. As (42) shows, passivizing the embedded verb renders the sentence ungrammatical.

$$
\begin{aligned}
& \text { * Chelswu-nun }{ }_{i} Y_{\text {Yenghi-eykey }}\left[{ }_{-i j j k} \begin{array}{l}
\text { phathi-ey chotay-toy-la-ko }] \\
\text { party-to invite-PASS-IMP-CMP }
\end{array}\right. \\
& \text { C.-TOP Y.-DAT } \\
& \text { puthakhay-ss-ta. } \\
& \text { ask-PAST-DECL } \\
& \text { intended: 'Chelswu asked Yenghi to be invited to the party.' }
\end{aligned}
$$

A reading similar in meaning to 'Chelswu asked Yenghi to be invited to the party.' is yielded by adding the so-called 'reflexive benefactive' (Sohn 1999:384) -ta(l) to the embedded verb. This reflexive entails that the benefaction is intended for the speaker. In (43) this means that the referent of the matrix sub- 
ject (= the speaker) is interpreted as object argument of the embedded verb chotayhata 'invite'. Nevertheless, the example is not an instance of a shift from object to subject control but remains a case of object control.

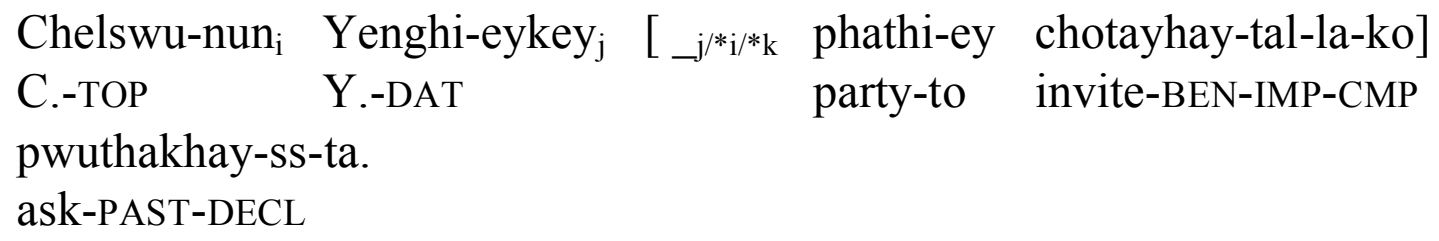

'Chelswu asked Yenghi to invite him to the party.'

Finally, it seems that a control shift is not induced by world knowledge. In (44), it is most likely that the referent of the matrix object and not the referent of the matrix subject will come out of prison. Therefore, the intended English translation involves a shift from subject to object control. However, such a shift is excluded in the example in (44). In addition, the unlikely subject control reading is not accessible, either, even under the assumption that the lawyer is a prisoner himself. Presumably this can be explained by the fact that the embedded event 'come out of jail' cannot be brought about by the referent of the matrix subject, which yields a violation of the condition for subject control given in (26) above.

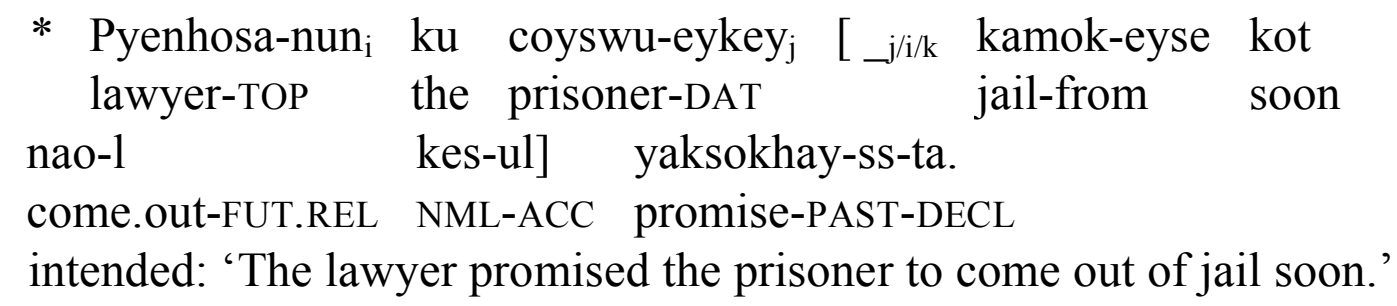

\section{Control triggered by modal affixes}

\subsection{Volitional, imperative, and propositive}

As stated above, verbs that involve some speech act can select complements marked by the quotative particle ko. The particle can follow the full range of tense and modal affixes. If a verb like malhata 'say' selects a ko-complement containing the volitional suffix -keyss, the imperative $-l a$, or the propositive $-c a$, subject control, object control, or split control result. This is illustrated by the following examples. In (45) no modal affix is attached to the subordinate verb hata 'do'. The unexpressed subject in (45a) is preferably interpreted as coreferential with the matrix subject though this is not necessarily the case. In addition, (45b) shows that the embedded verb can realize a disjoint subject. 
(45) a. Chelswu-nun ${ }_{i}$ Yenghi-eykey $_{j} \quad\left[{ }_{-} \mathrm{i} / \mathrm{j}_{\mathrm{k}}\right.$ caknyen-ey safari-yehayng-ul

C.-TOP Y.-DAT last.year-in safari-trip-ACC

hay-ss-ta-ko] malhay-ss-ta.

do-PAST-DECL-CMP SAY-PAST-DECL

'Chelswu told Yenghi that he/she/s.o. did a safari trip last year.'

b. Chelswu-nun Yenghi-eykey [Ilkyun-i caknyen-ey safari-yehayng-ul C.-TOP Y.-DAT I.-NOM last.year-in safari-trip-ACC hay-ss-ta-ko] malhay-ss-ta. do-PAST-DECL-CMP Say-PAST-DECL

'Chelswu told Yenghi that Ilkyun did a safari trip last year.'

If, however, the volitional suffix -keyss is attached to hata as in (46), subject control results. Hence, if an embedded subject is realized that is distinct in reference from the matrix subject, the resulting sentence is ungrammatical, as example (46b) illustrates.

a. Chelswu-nun ${ }_{\mathrm{i}}$ Yenghi-eykey $_{\mathrm{j}}\left[{ }_{-} \mathrm{i} / *_{\mathrm{j}} / *_{\mathrm{k}}\right.$ naynyen-ey safari-yehayng-ul

C.-TOP Y.-DAT

next.year-in safari-trip-ACC

ha-keyss-ta-ko] malhay-ss-ta.

do-VOL-DECL-CMP say-PAST-DECL

'Chelswu told Yenghi that he wants to go on a safari next year.'

b. * Chelswu-nun Yenghi-eykey [Ilkyun-i naynyen-ey
C.-TOP
Y.-DAT
I.-NOM
next.year-in

safari-yehayng-ul ha-keyss-ta-ko] malhay-ss-ta. safari-trip-ACC do-VOL-DECL-CMP say-PAST-DECL

intended: 'Chelswu told Yenghi that Ilkyun wants to go on a safari trip next year.'

Replacing -keyss with the imperative suffix -la as in (47) yields object control. Again, no independent subject is allowed to be realized inside the $\mathrm{ko}$ complement.

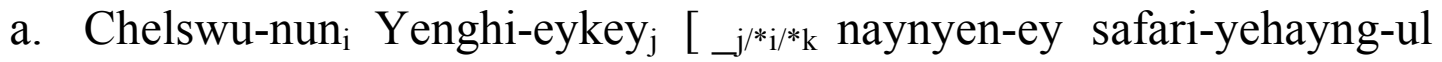

C.-TOP Y.-DAT next.year-in safari-trip-ACC

ha-la-ko] malhay-ss-ta.

do-IMP-CMP say-PAST-DECL

'Chelswu told Yenghi to go on a safari trip next year.'

b. * Chelswu-nun Yenghi-eykey [Ilkyun-i naynyen-ey
C.-TOP
Y.-DAT
I.-NOM
next.year-in

safari-yehayng-ul ha-la-ko] malhay-ss-ta.

safari-trip-ACC do-IMP-CMP say-PAST-DECL

intended: 'Chelswu told Yenghi that Ilkyun should go on a safari trip next year.' 
Finally, adding the propositive affix $-c a$ to the embedded verbs results in a split control reading as in (48).

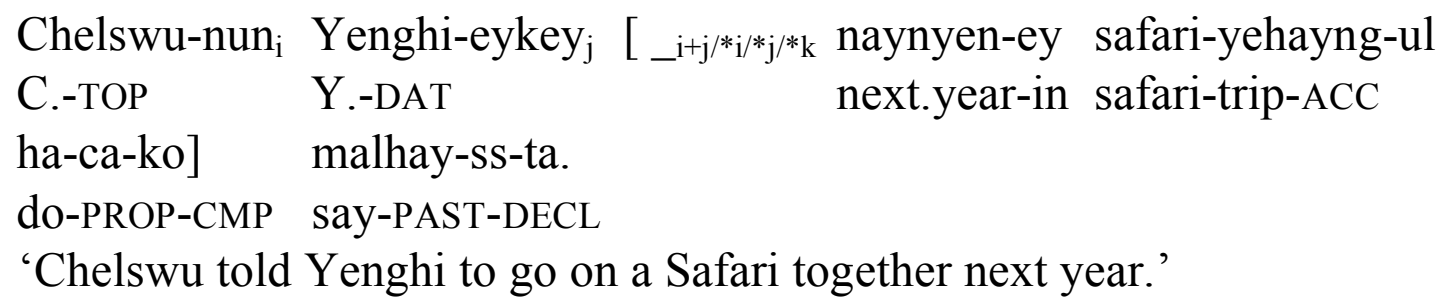

It should be mentioned that not all expressions of modality trigger control. As (49) illustrates, using the modal suffix -yaha 'must' instead of -la does not yield object control.

$\begin{array}{lll}\text { (49) Chelswu-nun } & \text { Yenghi-eykey } & \text { [Ilkyun-i safari-yehayng-ul } \\ \text { C.-TOP } \quad \text { Y.-DAT } & \text { I.-NOM safari-trip-ACC } \\ \text { hay-yaha-n-ta-ko] } & \text { malhay-ss-ta. } \\ \text { do-should-PRES-DECL-CMP } & \text { say-PAST-DECL } \\ \text { 'Chelswu told Yenghi that Ilkyun should go on a safari trip.' }\end{array}$

\subsection{Properties of the embedded imperative}

There has been some debate if -la in structures like (47a) is a "true" imperative suffix or rather a modal marker with a different meaning (cf. Han 2004 as an exponent of the pseudo-imperative hypothesis and Pak 2004 as a representative of the embedded imperative hypothesis). One argument in favor of the pseudoimperative hypothesis is that only a special neutral speech level form of the imperative can be embedded as in (50b). Embedding the formal imperative as in (50c) yields an ungrammatical sentence. Yet, in direct speech as in (50a) the formal imperative can be freely used. This contrast apparently indicates that the embedded form in (50b) is not a real imperative but something else, for example an optative or irrealis marker.

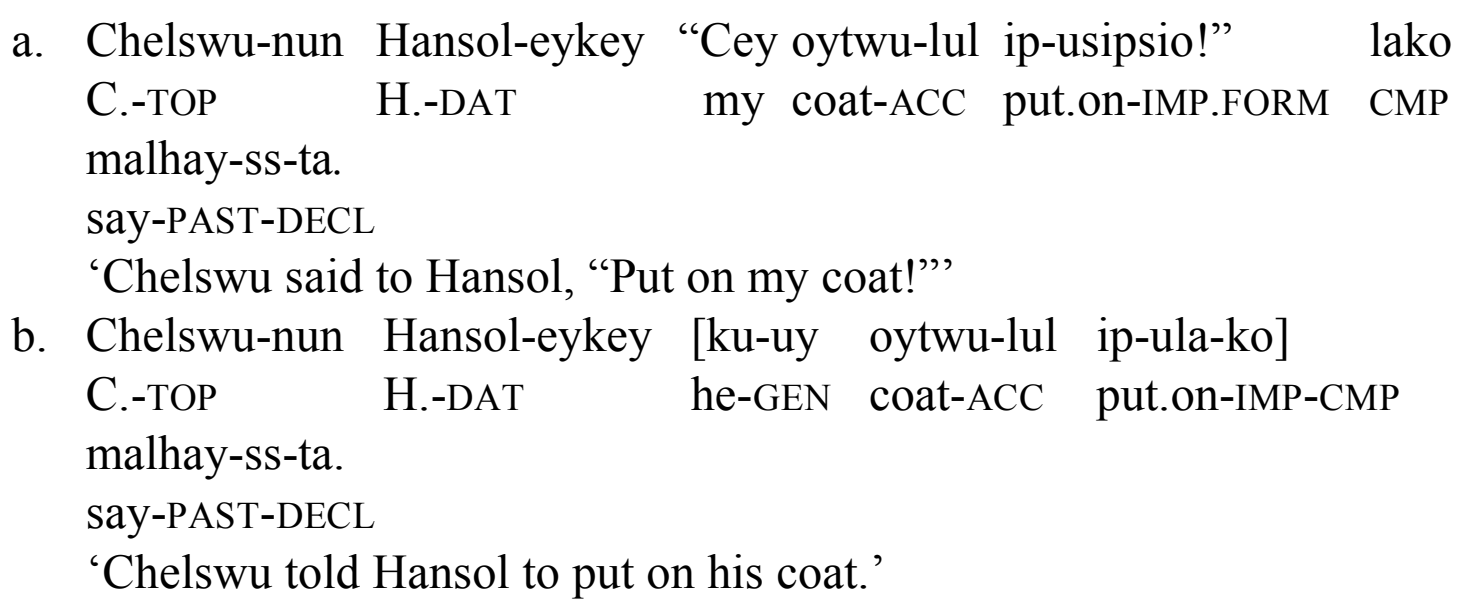


c. * Chelswu-nun Hansol-eykey [ku-uy oytwu-lul C.-TOP H.-DAT he-GEN coat-ACC ip-usipsio-ko] malhay-ss-ta. put.on-IMP.FORM-CMP say-PAST-DECL intended: 'Chelswu told Hansol to put on his coat.'

However, the same restriction also applies to the propositive and the declarative. As (51a) shows, the formal speech level form of the propositive can appear in direct speech. If the propositive is embedded as in $(51 \mathrm{~b} / \mathrm{c})$, only the neutral propositive marker - $c a$ can be used.

a. Na-nun Chelswu-eykey "Sinay-eyse Hansol-ul mana-sipsita!" lako I-TOP C.-DAT city.center-in H.-ACC meet-PROP.FORM CMP malhay-ss-ta. Say-PAST-DECL

'I said to Chelswu, "Let's meet Hansol in the city center!"'

b. Na-nun Chelswu-eykey [sinay-eyse Hansol-ul mana-ca-ko] I-TOP C.-DAT city.center-in H.-ACC meet-PROP-CMP malhay-ss-ta. say-PAST-DECL

'I told Chelswu to meet Hansol in the city center.'

c. *Na-nun Chelswu-eykey [sinay-eyse Hansol-ul mana-sipsita-ko] I-TOP C.-DAT city.c.-in H.-ACC meet-PROP.FORM-CMP malhay-ss-ta. say-PAST-DECL

intended: 'I told Chelswu to meet Hansol in the city center.'

The same picture holds with the declarative in (52). Only the neutral speech level form of the declarative can be embedded as in (52a), but not the formal speech level form as in (52b).

(52) a. Yuha-nunChelswu-eykey[sinay-eyse Hansol-ulmanna-n-ta-ko] Y.-TOP C-DAT city.center-inH.-ACC meet-PRES-DECL-CMP malhay-ss-ta. say-PAST-DECL

'Yuha told Chelswu that Yuha/s.o. will meet Hansol in the city center.'

b. * Yuha-nun Chelswu-eykey [sinay-eyse Hansol-ul Y.-TOP C-DAT city.center-in H.-ACC manna-pnita-ko] malhay-ss-ta. meet-DECL.FORM-CMP say-PAST-DECL intended: 'Yuha told Chelswu that Yuha/s.o. will meet Hansol in the city center.' 
The examples in (51) and (52) clearly show that the restriction on the embedding of speech level markers is not peculiar to the imperative. Therefore, the prohibition of speech style markers on embedded imperatives cannot be regarded as an argument in favor of the pseudo-imperative hypothesis.

A further argument in favor of the pseudo-imperative hypothesis might be that $k o$-clauses could be instances of direct speech. However, as already shown by (50a) and (51a) above, with direct speech, the particle lako (or hako) is used instead of $k o$.

Moreover, contrary to the direct speech in (53a), deictic expressions such as nayil 'tomorrow' or $i$ 'this' are adapted to the situational context of the utterance in indirect speech as in (53b):

a. Mia-nun ku ai-eykey 'ne nayil i kos uloo-nela!' hako/lako M.-TOP the kid-to you tomorrow this place to come-IMP CMP/CMP solichy-ess-ta.

shout-PAST-DECL

'Mia shouted to the kid, "Come here tomorrow!"

b. Mia-nun $\mathrm{i}_{\mathrm{k}} \mathrm{ku}$ ai-eykey [ $_{-} \mathrm{j}^{\prime *_{\mathrm{i}} / *_{\mathrm{k}}}$ taum nal ku kos-ulo o-la-ko]

M.-TOP the kid-to next day that place-to come-IMP-CMP

solichy-ess-ta.

shout-PAST-DECL

'Mia shouted to the kid to go to that place the next day.'

(Sohn 1999:324f)

In addition, ko-clauses cannot be characterized as embedded roots in the sense of Hooper and Thompson (1973). For example, a matrix verb selecting a koclause can be negated, which should not be admissible with embedded roots.

$$
\begin{aligned}
& \text { Chelswu-nun }_{i} \text { Yenghi-eykey }_{j}\left[{ }_{-j}{ }^{* *} / *_{k}\right. \text { naynyen-ey safari-yehayng-ul } \\
& \text { C.-TOP Y.-DAT next.year-in safari-trip-ACC } \\
& \text { ha-la-ko] malha-ci\#anha-ss-ta. } \\
& \text { do-IMP-CMP say-NEG-PAST-DECL } \\
& \text { 'Chelswu did not tell Yenghi to go on a safari trip next year.' }
\end{aligned}
$$

\subsection{Restrictions on the use of modal affixes in ko-complements}

Not every verb subcategorizing for a ko-complement permits the modal suffixes to be attached to the embedded verb. A verb like cwucanghata 'claim', for instance, excludes any of the three modal suffixes. This is immediately evident for -la and -ca since cwucanghata does not provide a matrix verb object, but also the subject-oriented -keyss cannot be used as shown by the example in (55). 


$$
\begin{aligned}
& \text { ??/* Chelswu-nun }{ }_{\mathrm{i}} \text { [ } \text { _i}_{\mathrm{i} j} \quad \text { Yenghi-lul top-keyss-ta-ko] } \\
& \text { C.-TOP Y.-ACC help-VOL-DECL-CMP }
\end{aligned}
$$

cwucangha-n-ta.

claim-PRES-DECL

intended: 'Chelswu claims that he wants to help Yenghi.'

Moreover, the mere presence of an object argument in the argument structure of the matrix verb is not sufficient to license the use of the imperative suffix -la as a trigger for object control. As can be seen from (56a) and (b), attaching the imperative -la to a verb embedded below hyeppakhata 'threaten' is admissible only if the embedded verb refers to a self-controllable action such as il-ul kumantwuta 'quit one's job'. Cikep-ul ilhta 'loose one's job' in (56b), on the other hand, cannot be combined with the imperative, since it denotes an event which cannot be brought about by the object referent. ${ }^{8}$

$$
\begin{aligned}
& \text { a. Sacang-un } n_{i} \text { na-eykey }{ }_{j} \quad\left[{ }_{-}{ }^{*} j_{j} / * k \text { il-ul kumantwu-la-ko }\right] \\
& \text { boss-NOM I-DAT job-ACC quit-IMP-CMP } \\
& \text { hyeppakhay-ss-ta. } \\
& \text { threaten-PAST-DECL } \\
& \text { literally: 'The boss threatened that I will quit my job.' } \\
& \text { b. * Sacang-un }{ }_{i} \text { na-eykey }{ }_{j}{ }_{[}{ }_{-}{ }_{i j j k} \text { cikep-ul ilh-ula-ko] } \\
& \text { boss-NOM I-DAT job-ACC loose-IMP-CMP } \\
& \text { hyeppakhay-ss-ta. } \\
& \text { threaten-PAST-DECL } \\
& \text { intended: 'The boss threatened that I will loose my job.' }
\end{aligned}
$$

Additionally, the propositive affix is excluded if it is incompatible with the illocution of the matrix verb. In (57), the matrix verb myenglyenghata 'order' is a highly directive verb, which is not compatible with the propositive meaning of $-c a$.

$$
\begin{array}{clll}
\text { ??Na-nun }_{i} & \text { Mary-eykey }_{j} & {\left[\begin{array}{ll}
i+j & \text { ttena-ca-ko }
\end{array}\right]} & \text { myenglyenghay-ss-ta. } \\
\text { I-TOP } & \text { M.-DAT } & \text { leave-PROP-CMP } & \text { order-PAST-DECL } \\
\text { intended: 'I ordered Mary to leave together.' } &
\end{array}
$$

Object control verbs seem to obligatorily require the imperative suffix to appear when a ko-complement is chosen. All of these verbs exhibit inherent control as discussed in the previous section. With kangyohata 'force', for instance, -la must be attached to the embedded verb if a ko-complement is chosen. This is illustrated in (58).

8 I owe this observation to Nayoung Kwon (p.c.) 

a. Theylelisuthu-nun ${ }_{i}$
incil-tul-eykey
hostage-PL-DAT
$\left[{ }_{-j} / *_{i} / * k\right.$
nwuwu-la-ko]
terrorist-TOP
lie.down -IMP-CMP
kangyohay-ss-ta.
force-PAST-DECL
'The terrorists forced the hostages to lie down.' terrorist-TOP
hostage-PL-DAT
nwuwu-ta-ko]
lie.down -DECL-CMP
b. * Theylelisuthu-nun ${ }_{i}$ incil-tul-eykey $j_{j} \quad\left[{ }_{j} j / i k\right.$
kangyohay-ss-ta.
force-PAST-DECL
intended: 'The terrorists forced the hostages to lie down.'

So far, I have shown the control effects of modal affixes when selected by utterance verbs such as malhata 'say'. Moreover, it has become evident that a specific modal affix can only appear if compatible with the meaning of the matrix verb. Additionally, verbs that exhibit semantic object control such as kangyohata 'force' obligatorily require the imperative suffix on the embedded verb. In the next section, I will present a lexical approach to the data outlined above.

\section{An approach to control in Korean}

In this section, I will first discuss a lexical treatment of control determined solely by the meaning of the matrix verb. Then I will proceed to a treatment of the control effect of modal affixes.

\subsection{Lexically determined semantic control}

The conditions on semantic subject and object control repeated below are sufficient to predict instances of control determined by the matrix verb.

(59) Condition on Semantic Subject Control

A matrix verb exhibits semantic subject control if its meaning involves that the event denoted by the embedded verb is brought about by the referent of the matrix subject.

(60) Condition on Semantic Object Control

A matrix verb exhibits semantic object control if its meaning involves the manipulation of the object referent to make him/her bring about the event denoted by the embedded verb.

Since a person who brings about an event is responsible for this event, both conditions can be captured in a more formal way by the responsibility relation RESP(i,s) proposed by Farkas (1988). According to Farkas (1988:36) the relation RESP $(i, s)$ holds "between an individual $i$ and a situation $s$ just in case $i$ brings about s". Farkas utilizes this relation to predict the controller choice in control 
structures. For control verbs, Farkas assumes that one of the matrix verb participants stands in the responsibility relation with the situation denoted by the complement verb and consequently calls these control verbs 'RESP-inducing'. This participant, called $i\left(\mathrm{~V}^{\prime} \mathrm{m}\right)$, with V'm being a projection of the matrix verb, then is chosen as controller of the infinitival complement by the Principle of Controller Choice in (61).

(61) Principle of Controller Choice (PCC, Farkas 1988:44)

For RESP-inducing V's, the controller of the infinitival complement is the argument linked to $i\left(\mathrm{~V}^{\prime} \mathrm{m}\right)$.

Farkas' principle suffices to capture the controller choice of all the Korean matrix verbs that determine control solely because of their meaning. Therefore, the Korean data can be seen as evidence for this principle. Consequently, the conditions repeated above can be substituted by the more general principle in (61).

\subsection{Control triggered by modal affixes}

The control effect of modal affixes can be understood best by considering their use in main clauses. I will begin with the volitional affix -keyss and proceed with the imperative and propositive markers $-l a$ and $-c a$.

\subsubsection{Volitional (-keyss)}

The use of -keyss in main sentences is restricted to first person subjects in declarative sentences or second person subjects in interrogative sentences as in (62a) and (b), respectively. A third person subject as in (62c) is prohibited (Sohn 1999:361).
a. Ce-nun an ka-keyss-eyo.
I-TOP NEG go-VOL-AHON
'I don't intend to go.'
b. Sensayng-nim-un ka-si-keyss-eyo?
teacher-HON-TOP go-SHON-VOL-AHON
'Do you intend to go?' (Sohn 1999:361)
c. * Chelswu-nun an ka-keyss-eyo.
C.-TOP NEG go-VOL-AHON
intended: 'Chelswu does not intend to go.'

The prohibition of third person subjects is not a peculiarity of -keyss: in general, predicates that refer to inner states, emotions or sensations such as simsimhata 'be bored' in (63) only permit first person subjects in declarative sentences. A second or third person subject is only allowed if an evidential marker as hata 'do, show signs of' is added to the main predicate as in (63c). 
(63) a. Na-nun simsimha-ta.

I-TOP bored-DECL

'I am bored.'

b. ? Chelswu-nun simsimha-ta.

C.-TOP bored-DECL

intended: 'Chelswu is bored.'

c. Chelswu-nun simsimhay ha-n-ta.

C.-TOP bored.INF do-PRES-DECL

'Chelswu seems to be bored/shows signs of being bored.'

Such a restriction can be captured tentatively by the constraint in (64).

(64) INNER STATE (tentative)

Unobservable inner states (psychological or sensory) can only be asserted about the own person.

The restriction on first person subjects does not apply if -keyss is attached to a verb embedded in a ko-complement. This is illustrated by the example repeated below.

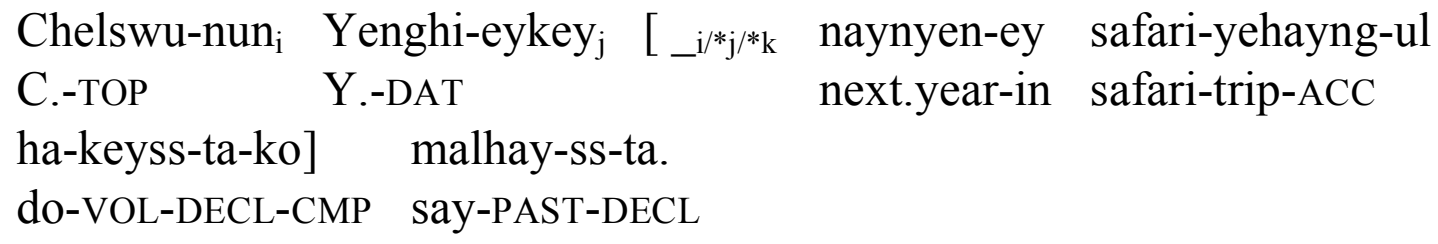

'Chelswu told Yenghi that he wants to go on a safari next year.'

The grammaticality of (65) with a third person subject can be explained if one takes into consideration that -keyss is embedded under the utterance verb malhata. As a result, the person who utters the embedded clause is the subject of the matrix sentence and not the person who utters the whole complex sentence. Therefore, the unexpressed subject of ha-keyss-ta can only be coreferential with the matrix subject. Any other reference would involve a violation of INNER STATE.

If subject control in (65) is due to INNER STATE, we expect the same effect when the embedded predicate is a psych or sensory adjective. As the examples in (66) show, this prediction is borne out. In (66) the embedded predicate is the psych adjective simsimhata 'bored'. Consequently, the unrealized subject in (66a) cannot be distinct in reference from the matrix subject. In (66b) an overt, disjoint subject is realized in the embedded clause. This yields an ungrammatical sentence due to a violation of INNER STATE.

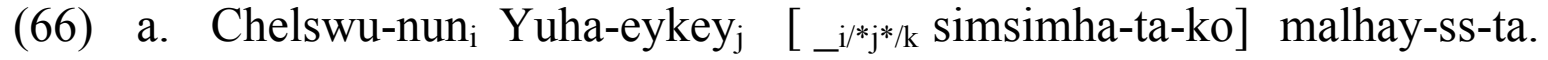
C.-TOP Y.-DAT bored-DECL-CMP tell-PAST-DECL 'Chelswu told Yuha, that he/*Yuha/*s.o. is bored.' 


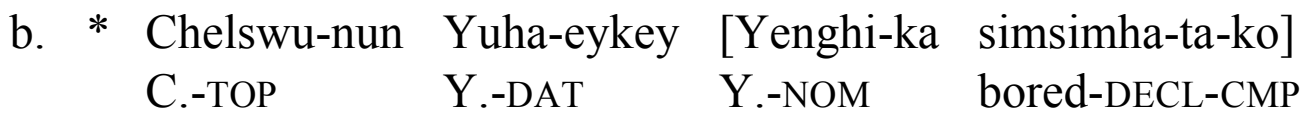
malhay-ss-ta. tell-PAST-DECL intended: 'Chelswu told Yuha that Yenghi is bored.'

Moreover, if the embedded predicate is a two-place adjective with a double nominative case frame like twulyepta 'be afraid', a nominative NP inside the koclause can only be interpreted as the non-subject argument of twulyepta. Therefore, (67b) is only acceptable with the interpretation that Chelswu told Yuha that he is afraid of Yenghi, whereas the interpretation that Chelswu told Yuha that Yenghi is afraid is not accessible.

a. Chelswu-nun ${ }_{\mathrm{i}}$ Yuha-eykey ${ }_{\mathrm{j}}\left[{ }_{-} \mathrm{i}^{*} \mathrm{j}^{\mathrm{j} / * / \mathrm{k}}\right.$ twulyep-ta-ko] malhay-ss-ta.

C.-TOP

Y.-DAT afraid-DECL-CMP tell-PAST-DECL 'Chelswu told Yuha that he/*Yuha/*s.o. is afraid.'

b. Chelswu-nun ${ }_{\mathrm{i}}$ Yuha-eykey ${ }_{\mathrm{j}}\left[{ }_{-}^{\mathrm{i} / \mathrm{j}_{\mathrm{j}} / * \mathrm{k}}\right.$ Yenghi-ka twulyep-ta-ko] C.-TOP Y.-DAT Y.-NOM afraid-DECL-CMP malhay-ss-ta. tell-PAST-DECL

'Chelswu told Yuha that he/*Yuha/*s.o. is afraid of Yenghi.' *'Chelswu told Yuha that Yenghi is afraid.'

For the control effect of the imperative and the propositive, INNER STATE does not play a role. However, as in the case of -keyss, the embedding below an utterance verb is crucial. This will be shown in the following.

\subsubsection{Imperative (-la)}

In a main clause, the imperative subject can only be a second person singular or plural as in (68). This restriction does not apply if the imperative appears on a verb in a ko-complement: in (69) the imperative subject is coreferential with the third person singular matrix object.

(Ne-nun/Nehuytul-un) ka-la!
you.SG-TOP/you.PL-TOP go-IMP
'(You) go!', '(You.pl) go!'

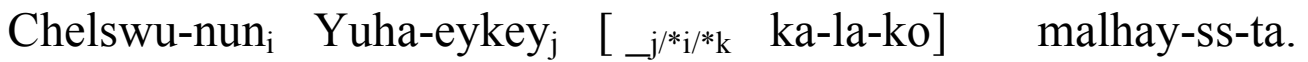
C.-TOP
Y.-DAT
go-IMP-CMP tell-PAST-DECL
'Chelswu told Yuha to go.'

Obviously, the embedding below the utterance verb malhata 'say' leads to a shift: the imperative subject is not identified with the addressee of the overall utterance but is selected out of the participants in the matrix clause. Since the referent of the indirect object is the addressee of the utterance expressed by mal- 
hata, it is identified with the imperative subject. As a consequence, object control results.

\subsubsection{Propositive (-ca)}

Like imperatives the subjects of propositives are restricted in person in main clauses. As (70) shows, the unrealized subject of a propositive is a first person plural, i.e., the referent of the propositive subject constitutes the join of speaker and addressee referent.

(70) Ka-ca!

go-PROP

'Let's go!'

Again, this restriction is lifted if the propositive is embedded as in (71). Here, the propositive subject is a third person plural.
Chelswu-nu
Yuha-eykey $_{j}$
$\left[{ }_{-}^{\mathrm{i}+\mathrm{j} / *_{\mathrm{i}} / *_{\mathrm{j}} / *_{\mathrm{k}}}\right.$ ka-ca-ko]
malhay-ss-ta.
C.-TOP
Y.-DAT
go-PROP-CMP
say-PAST-DECL

'Chelswu told Yuha that they should go together.'

In analogy to imperatives, this can be explained by the shift in the utterance context: as a result of the embedding, the speaker and the addressee are identified as the referents of the matrix subject and matrix object. Consequently, the subject referent of an embedded propositive always consists of the referents of the matrix subject and the matrix object which yields split control.

The determination of the imperative and the propositive subject in main and embedded clauses is summarized in (72).

(72) Determination of the Imperative and Propositive Subject

\begin{tabular}{|l|c|c|}
\cline { 2 - 3 } \multicolumn{1}{c|}{} & imperative & propositive \\
\hline in main clause & subject $=$ addressee & subject $=$ speaker+addressee \\
\hline in embedded clause & subject $=$ matrix object & $\begin{array}{c}\text { subject }=\text { matrix subject }+ \\
\text { matrix object }\end{array}$ \\
\hline
\end{tabular}

These regularities can be formulated as in the generalization below:

(73) Subject of Imperatives and Propositives

The imperative/propositive subject is determined out of the next-higher context. The next higher context is the situation of the utterance if the imperative/propositive appears in the main clause, and the matrix clause if the imperative/propositive appears in a clause embedded below a verb involving an utterance. 


\section{Some theoretical consequences}

I have shown above that control in Korean is not triggered by the inability of the dependent verb to realize its highest argument. On the contrary, control arises due to the meaning of the matrix predicate. Therefore, the data discussed in the preceding sections supports theories which emphasize the importance of semantics in the analysis of control phenomena. This fact, however, is not immediately evident in languages where verbs that involve control due to their meaning and verbs that do not, subcategorize for the same infinitival complement. In English, for instance, both refuse and wish select the infinitive of the dependent verb. Therefore, the subject of the dependent verb has to be identified with the matrix subject to be realized. However, only in the case of wish this is purely a structural matter. In the case of refuse the identification of the matrix verb subject and the dependent verb subject is forced not only by structure but also by meaning. Yet, this contrast is blurred by the fact that both verbs take an infinitival complement. In Korean, on the other hand, both verbs select a ki-nominalization, which does not suppress the subject of the nominalized clause, but only with kepwuhata 'refuse' the embedded subject has to be coreferential with the matrix subject. Because of the absence of structurally triggered control the semantic component of control becomes transparent in Korean.

As a consequence, all theories which tie the coreference of arguments to the suppression of the embedded subject and the resulting need to discharge the highest theta-role face problems in explaining the Korean data. Additionally, it seems questionable if control coincides with other grammatical properties assumed to be decisive in the determination of control. In his syntactic approach, Landau (2004) argues that tense plays a central role for control. As evidence, he discusses subjunctive complements in the Balkan languages. Here, certain matrix verbs such as try or forget exhibit control with a subjunctive complement while others such as persuade or ask do not. This contrast is explained by a difference in the temporal relation between matrix verb and embedded verb. Landau assumes that subjunctives selected by persuade or ask contain a tense operator since their tense can be distinct from the matrix tense operator. On the other hand, subjunctives selected by try or forget fall within the matrix tense domain and exhibit "anaphoric" tense. This apparent correlation between tense and control then is integrated as central component in Landau's "calculus of control". In contrast to tense, mood is considered "at best secondary" (Landau 2004:849) in determining control. However, the Korean data suggests that mood is a decisive factor while tense (in the sense of Landau) seems to be epiphenomenal. This is clearly shown by the example repeated in (74). 
(74)

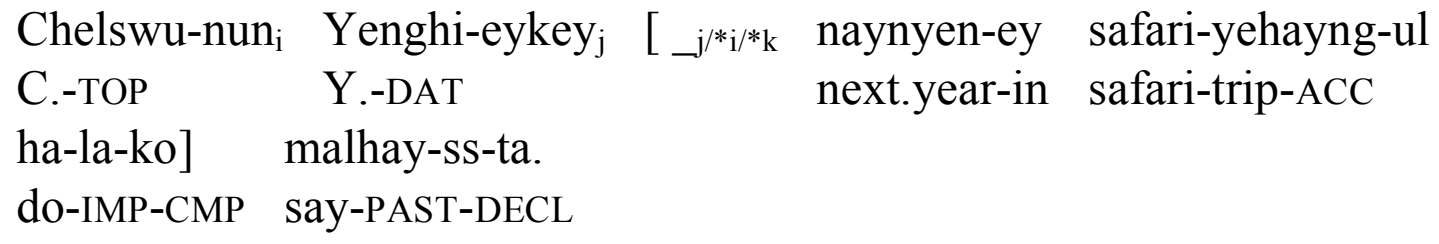

'Chelswu told Yenghi to go on a safari trip next year.'

Here, the temporal adverb modifies the embedded verb alone. According to Landau this can be regarded as an indicator of the relative temporal independence of the embedded verb. However, contrary to his prediction, the example above exhibits object control due to the presence of imperative mood. Consequently, mood can be said to be of primary importance in determining control in Korean.

A further point to be addressed concerns Monahan's (2003) analysis of backward control in Korean. As already mentioned, the absence of argument suppression in the complements of SOA-argument-taking predicates allows the embedded subject to be realized. This is illustrated by the sentence repeated in (75), which is an instance of split object control.

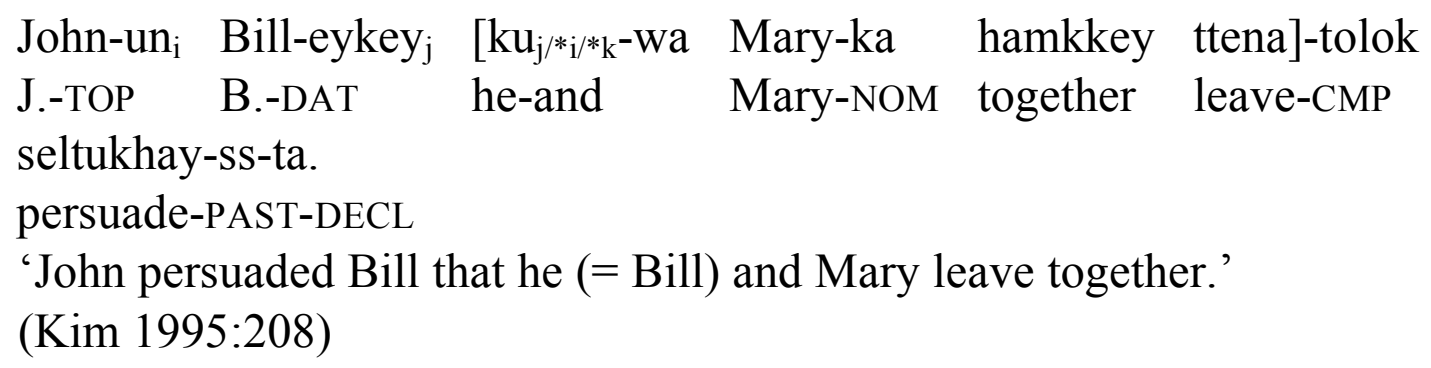

Such instances of overt controllee plus overt controller pose a problem for the control mechanism proposed by Monahan (2003). Monahan focuses on instances of so-called backward control with overt controllees and unrealized controllers. To derive both forward and backward control, he assumes that nominative marking inside the embedded clause is optional: if the controllee is marked with nominative in the embedded clause, it does not have to raise into the matrix clause for case purposes and the backward control variant arises. If nominative marking does not apply, the controllee raises into the matrix clause to receive case. However, the overt realization of both the dative-marked controller and the nominative-marked controllee such as in (75) cannot be yielded by that mechanism. Moreover, the raising analysis requires strict identity between controller and controllee which is not compatible with instances of split control such as (75).

\section{Conclusion}

The aim of the present study was to add the profile of Korean to a typology of control. Therefore, a sample of approximately seventy complement taking 
predicates was analyzed with respect to complement types and control. As a result, Korean was characterized as a language, in which semantic control, especially inherent control, is predominant. In contrast to semantic control, constructionally induced control is only peripheral in Korean. Though this characterization is based on a small sample, we expect large-scale surveys to confirm our results.

The absence of a designated type of constructional control makes it possible to easily identify inherent control verbs and verbs which exhibit control dependent on modal affixes in the complement clause. These predicates constitute $45 \%$ of the verbal predicates in the sample. Such a ratio shows the importance of the matrix predicate's meaning in the determination of control, a fact that is not evident in languages where syntactic control blurs the effects of semantic control.

The control effect of modal affixes inside $k o$-complements has been analyzed as interaction between matrix verb meaning and specific constraints on the subject choice of a verb marked by these modals. Again, control was seen to result solely from semantic properties.

The present survey of complement taking predicates in Korean has identified five different verb classes which can be distinguished by the types of complement they select. The table summarizing these classes is repeated in (76).

(76) Matrix verbs: complement types and control

\begin{tabular}{|c|c|c|c|c|c|c|c|}
\hline & & & \multirow{2}{*}{$\begin{array}{l}\text { control- } \\
\text { inducing }\end{array}$} & \multicolumn{3}{|c|}{ control-neutral } & \\
\hline & & & & NML & QUOT $(k o)$ & RESULT (-tolok) & \\
\hline \multirow{2}{*}{$\begin{array}{l}\text { structural } \\
\text { control }\end{array}$} & subj & 4 & \multirow{2}{*}{$\sqrt{ }$} & \multirow{2}{*}{$*$} & \multirow{2}{*}{$*$} & \multirow{2}{*}{$*$} & \multirow{2}{*}{ I } \\
\hline & obj & 0 & & & & & \\
\hline \multirow{3}{*}{$\begin{array}{l}\text { inherent } \\
\text { control }\end{array}$} & \multirow{2}{*}{ subj } & 8 & $*$ & $\sqrt{ }$ & $*$ & $*$ & II \\
\hline & & 1 & $*$ & $\sqrt{ }$ & $\sqrt{ }$ & $*$ & III \\
\hline & obj & 10 & $*$ & $\sqrt{ }$ & $\sqrt{ }$ & $\sqrt{ }$ & $\mathrm{V}$ \\
\hline $\begin{array}{l}\text { control depen- } \\
\text { dent on modal } \\
\text { affixes }\end{array}$ & subj & 7 & $*$ & $\sqrt{ } / *$ & $\sqrt{ }$ & $*$ & IV \\
\hline \multirow{2}{*}{ non-control } & & 23 & $*$ & $\sqrt{ }$ & $*$ & $*$ & II \\
\hline & & 5 & $*$ & $\sqrt{ }$ & $\sqrt{ }$ & $*$ & III \\
\hline
\end{tabular}

As already mentioned, out of the nine combinatorial possibilities resulting from three complement types only four are attested in the sample. This can in part be motivated semantically. Since the verbs of class V are all manipulative/directive, they allow tolok-complements. In addition, their directive meaning involves a speech act which licenses the realization of a ko-complement. As a consequence, the admissibility of a tolok-complement implies the admissibility of a kocomplement so that a verb class whose members exclusively combine with 
tolok-clauses seems to be ruled out. Nominalized complements are attested for this class, as well. This complement type, which is compatible with the verbs of four of the five classes, qualifies as the least specialized complement. As all of the verbs in class $\mathrm{V}$ are object control verbs, there is a correlation between complement selection and control type.

The remaining three classes characterized by semantic control do not exhibit a clear correlation between control and selected complement. First, all instances of control attested for class II and class III verbs are cases of inherent subject control. Yaksokhata 'promise' is the only verb in class III which exhibits control. The remaining verbs in this class are attitude verbs such as cwucanghata 'claim' or sayngkakhata 'think' which do not determine control. The verbs of class II, which can only combine with a nominalization, are mainly desiderative and phasal/aspectual verbs such as huymanghata 'hope' or sicakhata 'begin'. In this class, the verbs without control are about three times as frequent as the control verbs, which is explained by the fact that semantic control comes about only as the effect of a specific meaning such as in the case of kepwuhata 'refuse'.

Finally, the verbs in class IV, utterance verbs such as malhata 'say', combine with a ko-complement and in the majority of cases with a nominalization. They exhibit control only if the embedded verb is followed by a modal marker. The verbs of this class can be considered the most interesting ones since they allow for constructions which explicitly show the interaction between the matrix verb's meaning and the complement type in determining control. Therefore, this class especially suggests further research. 


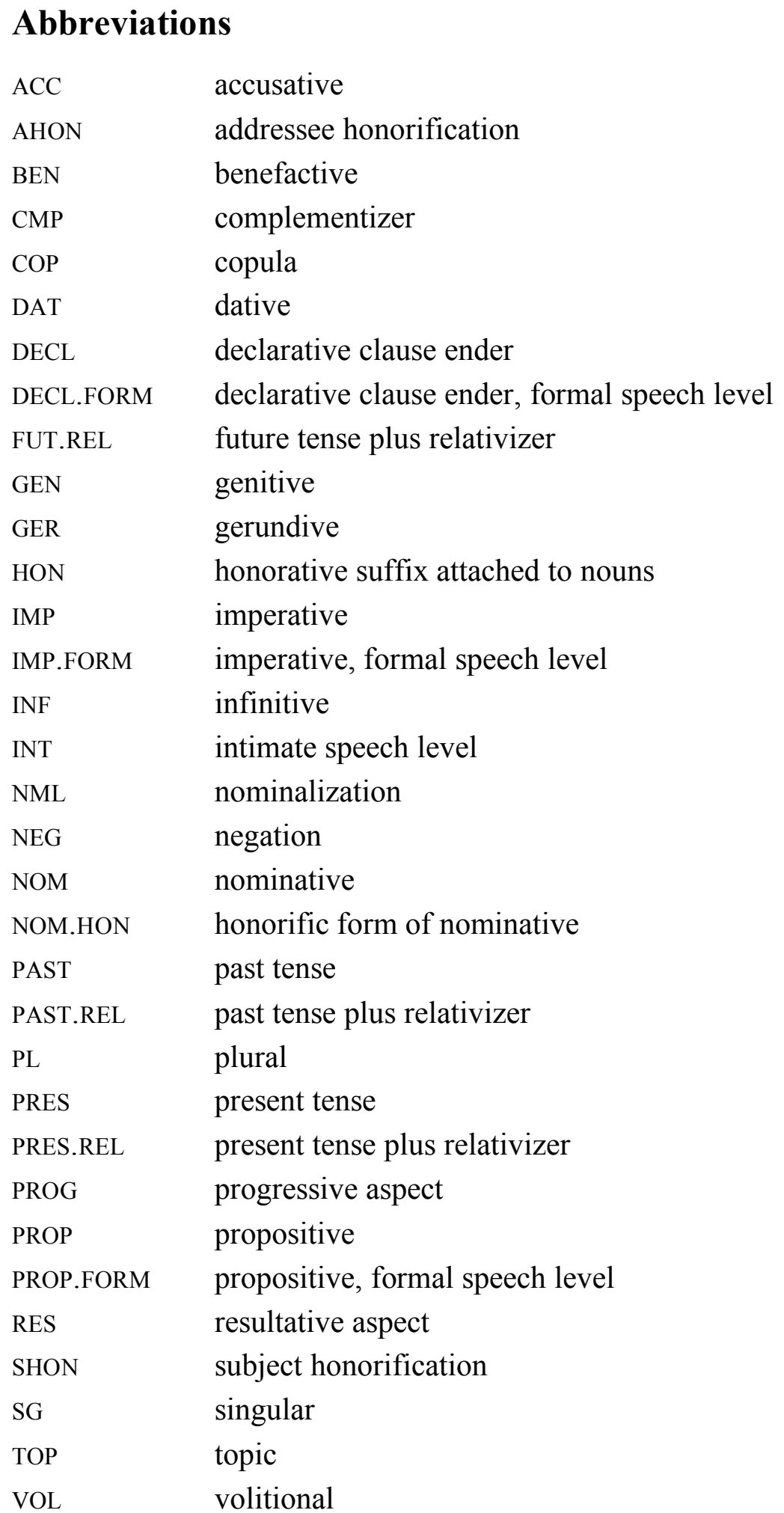

The sign '\#' connects morphemes which form a meaning/functional unit that cannot be derived compositionally by the meaning of the single morphemes. 


\section{References}

Chierchia, Gennaro (1988). Structured meanings, thematic roles, and control. In: G. Chierchia, B. Partee \& R. Turner (eds.), Properties, types, and meaning, Vol. 2. Dordrecht: Kluwer 131-166.

Choi, Young-Seok (1988). A study of ascension constructions in Korean. Ph.D. dissertation, University of Hawaii.

Cormack, A. \& N. Smith (2004). Backward control in Korean and Japanese. University College of London Working Papers in Linguistics 16.

Dowty, David (1985). On recent analyses of the semantics of control. Linguistics and Philosophy 8, 291-331.

Farkas, Donka (1988). On obligatory control. Linguistics and Philosophy 11, 27-58.

Han, C. H. (2004). The structure and interpretation of imperatives: mood and force in Universal Grammar. New York: Garland.

Han, H.-S. (1991). The Case of Korean adjectives and passive verbs. Studies in Generative Grammar 2-1, 219-249.

Hooper, Joan B. \& Sandra A. Thompson (1973). On the applicability of root transformations. Linguistic Inquiry 4, 465-497.

Hornstein, Norbert (1999). Movement and control. Linguistic Inquiry 30, 69-96.

Jackendoff, Ray (1972). Semantic interpretation in generative grammar. Cambridge, MA: MIT Press.

Jackendoff, Ray \& Peter W. Culicover (2003). The Semantic Basis of Control. Language 79, 517-556.

Kim, Kyoung-Hak (1990). Lexical Functional Grammar and control in Korean. Ms., University of Suwon.

Kim, Kyung-An (1995). Causativity in Korean - Syntactic Causative, Control and Purpose. $\mathrm{Ph} . \mathrm{D}$. dissertation, University of Southern California.

Kuno, Susumu (1987). Honorific marking in Japanese and the word formation hypothesis of causatives and passives. Studies in Language 11, 99-128.

Landau, Idan (2000). Elements of control: structure and meaning in infinitival constructions. Dordrecht: Kluwer.

Landau, Idan (2004). The scale of finiteness and the calculus of control. Natural Language and Linguistic Theory 22, 811-877.

Lee, Sookhee (1992). The syntax and semantics of serial verb constructions. Ph.D. dissertation, University of Washington.

Lee, Sun-Woo (1983). Syntax of some nominal constructions in Korean. Ph.D. dissertation, University of Wisconsin-Madison.

Lee, J. K. \& C. M. Lee (2003). Korean resultative constructions. In: Jong-Bok Kim \& Stephen Wechsler (eds.), The Proceedings of the $9^{\text {th }}$ International Conference on HPSG. Stanford: University Press, 169-186.

Martin, Samuel E. (1992). A reference grammar of Korean. Rutland: Charles E. Tuttle.

Matsumoto, Yo (1996). Complex predicates in Japanese: a syntactic and semantic study of the notion 'word'. Stanford: CSLI Publications.

Monahan, Philip J. (2003). Backward object control in Korean. In: G. Garding \& M. Tsujimura (eds.), WCCFL 22 Proceedings. Somerville: Cascadilla Press, 356-369. 
Owen Bratt, Elizabeth (1996). Argument composition and the lexicon: lexical and periphrastic causatives in Korean. PhD dissertation, Stanford University.

Pak, M. (2004). Korean particles and clause types. Ms., Georgetown University.

Park, Duk-Soo (2001). Lexical local control in Korean. Ms., The University of Sidney.

Perlmutter, David M. (1970). The two verbs 'begin'. In: Roderick A. Jacobs \& Peter S. Rosenbaum (eds.), Readings in English Transformational Grammar. Waltham, Mass.: Ginn and Co, 107-119.

Pollard, Carl \& Ivan Sag (1994) Head-driven phrase structure grammar. Chicago: University of Chicago Press.

Růžička, Rudolf (1983). Remarks on control. Linguistic Inquiry 14, 309-324.

Růžička, Rudolf (1999). Control in grammar and pragmatics: a cross-linguistic study. Amsterdam: Benjamins.

Sells, Peter (1995). Korean and Japanese Morphology from a lexical perspective. Linguistic Inquiry 26, 277-325.

Sells, Peter (1998). Structural relationships within complex predicates. In: Byung-Soo Park \& James Hye Suk Yoon (eds.), Selected papers from the 11th meeting of the International Circle of Korean Linguists (ICKL). Seoul, 115-147.

Sohn, Ho-Min (1994). Korean. London: Routledge.

Sohn, Ho-Min (1999). The Korean language. Cambridge: University Press.

Stiebels, Barbara (this volume). Towards a typology of control predicates.

Suh, Younghwan (2000). A study of the auxiliary verb construction and verb serialization in Korean. Dissertation, University of Washington.

Williams, Edwin (1980). Predication. Linguistic Inquiry 11, 203-338.

Yang, Byoeng-Seon (1994). Morphosyntactic phenomena of Korean in Role and Reference Grammar. Psych-verb constructions, inflectional verb morphemes, complex sentences, and relative clauses. Ph.D. dissertation, University of New York at Buffalo.

Yoon, Hang-Jin (1991). Functional categories and complementation: in English, Korean and Turkish. Ph.D. dissertation, University of Wisconsin. 


\section{Appendix: Verb classes distinguished by complement selection}

Control verbs are written in boldface.

Class I (subject control; infinitive (V-e), gerund (V-ko))

V-e pelita 'finish', V-e pota 'try', V-e tayta 'keep doing', V-ko siphta 'want'

Class II (subject control, nominalization)

cikhye-pota 'watch', cohahata 'prefer', culkepkye hata 'amuse', hoyphihata 'avoid', huymanghata 'hope', icepelita 'forget', hwuhoyhata 'regret', kalmanghata 'yearn', kkaytatta 'sense', kepwuhata 'refuse', kiekhata 'remember', kitayhata 'expect', kkuthmachita 'finish', kyelcenghata 'resolve', kyeyhoykhata 'plan', kyeysokhata 'continue', memchwuta 'stop', nukkita 'feel', panghayhata 'prevent', pota 'see', samkata 'refrain', pwuinhata 'deny', sicakhata 'begin', palata 'wish', soholhi hata 'neglect', sulilisskey mantulta 'thrill', sulphukey hata 'sadden', tutta 'hear', wenhata 'want', yelmanghata 'be eager', yukamulo sayngkakhata 'be sorry'

Class III (subject control, nominalization, and ko-complement) chwuchukhata 'suppose', cwucanghata 'claim', kacenghata 'assume', mitta 'believe', sayngkakhata 'think', yaksokhata 'promise; agree'

Class IV (control dependent on modal affix, ko-complement, nominalized complement possible for all verbs except for sinho-lul ponayta 'signal' but only reluctantly accepted with soksakita 'whisper', solichita 'shout')

hyeppakhata 'threaten', iyakihata 'tell', malhata 'say', potohata 'report', sinho-lul ponayta 'signal', soksakita 'whisper', solichita 'shout'

Class V (object control, nominalization, ko-complement and tolok-complement) chwungkohata 'advise', kangyohata 'force', kwenyuhata 'induce', myenglyenghata 'order', pwuchwukita 'encourage', pwuthakhata 'ask (as a favor)', seltukhata 'persuade', tokchokhata 'press', yochenghata 'request', yokwuhata 'demand' 


\title{
Complement control in Turkish
}

\section{Szymon Słodowicz}

\author{
Christian-Albrechts-Universität Kiel
}

\section{Introduction ${ }^{*}$}

Complement control is a well-known phenomenon in Turkish linguistics, and different proposals for analysing it are available. The majority of these treat control as a structural phenomenon, cf. Kerslake (1987), Özsoy $(1987 ; 2001)$ and Kural (1998). In sum, control is predicted only in sentences with complement clauses formed with the suffixes $-m E k$ and $-m E$, which can be case-marked, but the appearance of a possessive marker definitely precludes control. As far as the control relations are concerned, the research so far has attested the classical cases of subject and object control. In addition to that, variable control is discussed by Taylan (1996). The status of the controlled element is discussed by Bozşahin (in press), which concludes that the syntactic subject is appointed by this function in Turkish.

In this paper I will argue that the currently established approach to control is insufficient. The shortcomings of a strictly configurational approach become clear if a broader perspective on control is adopted. I follow the approach to control outlined by Stiebels (this volume), and show that two types of control must be distinguished. Inherent control is encoded in the lexical entry of the verb. Verbs which show inherent control either select only control-inducing structures or trigger control in environments not requiring control. Structural control, on the other hand, arises through the use of a control-inducing structure with a verb which does not inherently require control. Structural control verbs show control only with control-inducing structures. No control occurs with such verbs in other configurations. The data discussed in this paper will show that control is a 'mixed' phenomenon, since it may arise structurally or semantically. Its explanation must therefore consider the semantics of the relevant matrix verbs and the syntactic properties of complement clauses on an equal basis.

The paper is composed in the following way. Section 2 outlines the theoretical assumption guiding this analysis. Section 3 presents the relevant facts about

* This research was funded by the German Science Foundation (STI 151/2-2) as part of the research project 'Typology of control verbs'. I wish to express my gratitude to my colleagues Barbara Stiebels and Thomas Gamerschlag for the valuable comments and inspiring discussion. I would to thank Geoffrey Haig for his help on details of Turkish grammar. Bülent Suad-Engüzel, Murat Özkovalak and Ümit Demir provided the grammaticality judgments of the data discussed in this paper, for which I am very grateful. The responsibility for all mistakes is of course mine. 
complementation in Turkish, and provides a description of basic properties and the distribution of complement clauses, discusses the formation of control predicates and indicates some problems in providing exhaustive lists of control verbs in Turkish. The investigation of domain of control is carried out in section 4. In particular, the distinction between control-inducing and non-control-inducing structures in Turkish is elaborated in this section. The roles of controllee and controller are discussed in section 5. This section shows how the syntax and the lexicon interact in control constructions. The classification of control verbs is the crucial point made in this paper. A classification of inherent and structural control verbs is provided in section 6 .

\section{Theoretical assumptions}

In this paper I will distinguish between individual and state-of-affairs arguments (SOA-arguments in the following). Simplifying somewhat, the former take individuals as their referents, whereas the latter denote states of affairs, which includes activities, states, etc. I will furthermore distinguish between twoplace and three-place verbs with SOA-argument.

In this study I follow the semantic definition of control proposed by Stiebels (this volume), where control is defined as in (1).

(1) Obligatory control following Stiebels (this volume)

Obligatory control applies to structures in which a predicate $\mathrm{P}_{1}$ selects an SOA-argument and requires one of its (individual) arguments to be (improperly) included in the set of referents of an argument of the embedded predicate $\mathrm{P}_{2}$ heading the SOA-argument.

Following (1), the crucial feature of control is the obligatory co-reference of two arguments in a complex sentence. It must be noted that this definition imposes no explicit requirement with regard to the structure of the whole construction and the status of the arguments involved in this relation. Through its underspecification in these respects, it allows for the inclusion of a wider range of data not considered by other approaches. For instance, it does not narrow control only to the cases of subject and object control, as is the case in the proposals of Williams (1980) and Hornstein (1999), but also includes non-exhaustive readings, in the vein of Landau (2000) or Culicover \& Jackendoff (2005).

As defined above, control is a relation of obligatory co-reference between two arguments. The arguments involved in this relation will be called the controller and the controllee. The controller is the argument providing the reference for the controllee. In the majority of languages, the controller is an overt matrix clause argument, whereas the controllee is an implicit argument of the complement predicate. Polinsky \& Potsdam (2002) propose an analysis of a 
construction in Tsez in which the opposite seems to be the case. Since such constructions are not attested in Turkish, they are not considered here.

As will be shown in more detail below, control is a mixed phenomenon. It may arise lexically or syntactically; the notions of inherent and structural control capture this difference. Inherent control is triggered lexically. Verbs showing inherent control will require the co-reference of their arguments regardless of the realization of the SOA-argument. With these verbs, control is clearly lexically motivated. Structural control, on the other, arises only in particular syntactic configurations. Verbs with structural control do not inherently require coreference; instead they possess only a control potential which is activated by a particular type of the SOA-argument. With such verbs, control is motivated by the syntactic configuration.

There is another distinction relevant for the analysis of control, namely that between control-inducing and control-neutral structures. Control-inducing structures are those structures whose use in complementation presupposes control. Infinitive clauses, which cannot express their highest arguments, provide a well-known example of a control-inducing structure. Embedding such forms requires the identification of the highest argument with one of the matrix clause arguments, i.e. control. Stiebels (this volume) lists serial verb constructions and verb incorporation as further examples of control-inducing structures. The use of control-neutral structures, on the other hand, does not presuppose control. Such structures are not dependent on argument identification. Prominent examples of control-neutral structures are finite clauses and nominalizations.

Assuming the notions of inherent and structural control as well as the notions of control-inducing and control-neutral structures, it is possible to develop a more fine-grained approach to control than those which are concerned exclusively with control in control-inducing structures. In the following I will show on the basis of data from Turkish that a more fine-grained approach is necessary to adequately describe and analyse control constructions.

\section{Complementation in Turkish}

\subsection{Types of clauses used in complementation}

As is well-known, Turkish makes intensive use of nominalizations in subordination. ${ }^{1}$ Although Turkish has a wide range of suffixes which derive nouns from verbs, only a handful of them form verbal nouns which function as predicates in complement clauses. These forms share some features, which are listed in Haig

1 I neglect here the complement clauses introduced by $-k i$ because they are not used very extensively, cf. Kornfilt (1997:46). 
(1998:33-34). They retain the ability to bear valency-changing morphology, i.e. these verbal nouns allow for the passive or causative suffixes. The predicates in nominalized complements retain the ability to express negation. They govern the full range of arguments and allow modification by means of adverbials of manner. Finally, the internal order of the constituents in clauses headed by verbal nouns is free to a considerable extent, and may be altered for the purpose of information structure.

Following these lines, I will consider four types of clauses given in examples (4) to (7). Although the borderline between arguments and adjuncts is not satisfactorily well-defined, I assume that a distinction can be made. Consequently, clauses which do not encode arguments are not considered. ${ }^{2}$

$$
\begin{aligned}
& \text { _i [_i Çay iç-mek] isti-yor-um } \\
& \text { tea.NOM drink-INF want-PROG-1SG }
\end{aligned}
$$

Clauses formed with the suffix $-m E K$ denote, as Lewis (2000) puts it, express pure undefined action. Therefore no information about temporal identification of the SOAs denoted by the complement predicate is given. These clauses can be used as complements, but also are found in purpose clauses; this use is demonstrated in (5). In this example, the postposition icin for heads the infinitival clause, which expresses the purpose of the action denoted by the finite predicate.

$$
\begin{aligned}
& \text { Bu-nu [sen-i kurtar-mak için] yap-tı-m. } \\
& \text { this-DAT 2SG-ACC rescue-INF for do-PST-1SG } \\
& \text { 'I did it to rescue you.' }
\end{aligned}
$$

Clauses formed with the suffix $-m E$ are used in complementation to a greater extent, cf. (6). They have a similar meaning as the forms described above, and in fact a distinction between them is often difficult to motivate. The complement predicate in (6) exhibits the dative case and the 3SG possessive marking, which is optional depending on the matrix verb.

$$
\begin{array}{llll}
\text { Ben }_{\mathrm{i}} \quad \text { oo-nun }_{\mathrm{j}} \text { piyano } & \text { cal-ma-Sin]-a } & \text { bay1l-1yor-um } \\
\text { 1SG } 3 \text { SG-GEN } & \text { piano } & \text { play-INF-3SG.P-DAT } & \text { love-PROG-1SG } \\
\text { 'I like his playing the piano.' (Taylan 1996:58) } &
\end{array}
$$

Complements formed with the suffix $-E c E K$ denote SOAs that are intended to occur in the future, i.e. in (7) the act of getting the money is posterior to the time

2 The data are presented according to the following guidelines. Complement clauses are indicated by square brackets. Missing arguments are indicated by the symbol ', '. Referents of arguments are indicated by indices. Co-reference is indicated by the same index on two arguments. These guidelines do not have any theoretical implications. In particular I do not assume any covert elements active in the syntax. 
of utterance. They must be marked for the possessor agreement and case, as the example in (7) demonstrates. Complements formed with the suffix $-E c E K$ may be used attributively, but do not appear in purpose clauses, cf. (8).
Nurhan $_{i}$ Sevgi'ye $_{j}\left[{ }_{i} / \mathrm{j}\right.$ para al-acağ-1n]-1
bil-dir-di.
N. S.-DAT money get-GER-3SG.P-ACC know-CAUS-PST.3SG
'Nurhan informed Sevgi that (s)he would get the money.'

[Yap-acağ-1m] çok şey var.
do-GER-1SG much thing exist
'I've got a great deal to do.'

Predicates formed with the suffix $-D I K$ show the same properties, i.e. they must be marked for possessor agreement and case. They encode SOAs that are assumed to have taken place prior to the time of utterance, and are often called factive. The example in (9) demonstrates this. Furthermore, as nouns formed with $-E c E K$, they can be used attributively and do not appear in purpose clauses.

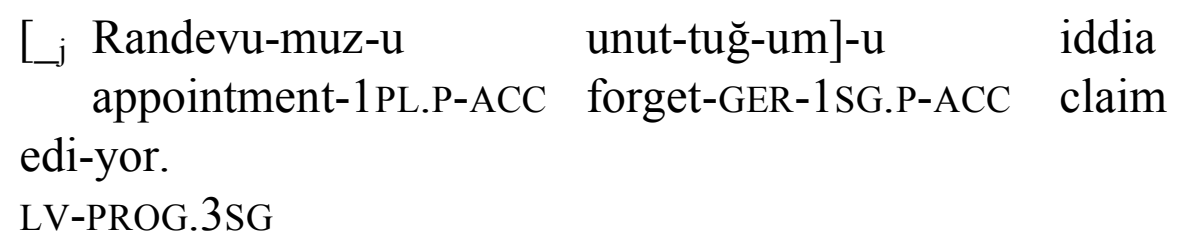

'She/he claims that I forgot our appointment.' (Göçmen et al. 1995:31)

There is some disagreement with respect to the labelling of the forms presented above. In this paper I will follow Kural (1998), and use the term infinitive for the complements formed with the suffixes $-m E K$ and $-m E$. Due to the fact that these forms receive case, I will refer to them as nominalized infinitives. Complements formed with the suffixes $-D I K$ and $-E c E K$ forms will be termed as gerunds. I treat the fact that these forms are in complementary distribution to the nominalized infinitives in purpose and relative clauses as a piece of evidence in support for these labels.

\subsection{Case marking}

Phrases that express SOA-arguments are usually case-marked. The case marking is not obligatory only with two verbs: istemek 'want' and 'bilmek' know, be able as reported by Taylan (1984:115). Otherwise, complement clauses of all types are required to take overt case. The case suffixes are given in Table 1 illustrated with the nouns $e v$ 'house' and kapl 'door'. 
Table 1: Case marking in Turkish

\begin{tabular}{|lll|}
\hline Case & Suffix & Examples \\
NOM & $\varnothing$ & ev, kap1 \\
ACC & $-y \mathrm{I}$ & ev-i, kap1-y1 \\
DAT & $-y E$ & ev-e, kap1-ya \\
LOC & -DE & ev-de, kap1-da \\
ABL & -DEn & ev-den, kap1-dan \\
GEN & $-(n)$ In & ev-in, kap1-n1n \\
\hline
\end{tabular}

Due to the case marking of SOA-arguments and the phenomenon of velar lenition (Sezer 1981), where final $/ \mathrm{k} /$ becomes $/ \varnothing /$ or a glide $/ \mathrm{j} /$, which is orthographically represented by $\breve{g}$, there are some problems with distinguishing between the complements formed with the suffixes $-m E K$ and $-m E$ if they are marked for the dative and accusative case. The judgments of my informants with respect to the written material was that the $-m E K$ forms are more formal in comparison to the $-m E$ forms. In colloquial speech, these forms seem to be interchangeable. These two suffixes can only be properly differentiated in the ablative case. However, with verbs assigning accusative or dative case to their SOAarguments, there is considerable difficulty in distinguishing between $-m E K$ and $m E$ forms. Due to these problems I will treat both forms as equal in this paper.

\subsection{Possessive marking}

Complement clauses, except for $-m E k$, can or must be marked with possessive morphology. The possessive marking is a part of the nominal paradigm and is shown in Table 2, taken from Haig (2001). The first paradigm (Type I) appears after the progressive, perfect, aorist and the copula. The second paradigm (Type II) is used with the past tense. The last on (Type III) is used in the optative, imperative and adhortative.

Table 2: The paradigm of possessive marking

\begin{tabular}{|l|c|c|c|c|}
\hline & $\begin{array}{c}\text { possessive } \\
\text { marker }\end{array}$ & $\begin{array}{c}\text { predicate } \\
\text { person marker I }\end{array}$ & $\begin{array}{c}\text { predicate } \\
\text { person marker II }\end{array}$ & $\begin{array}{c}\text { predicate } \\
\text { person marker III }\end{array}$ \\
\hline $1 \mathrm{SG}$ & $-\mathrm{Im} /-\mathrm{m}$ & $-\mathrm{Im} / \mathrm{yIm}$ & $-\mathrm{m}$ & $-\mathrm{yIm}$ \\
\hline $2 \mathrm{SG}$ & $-\mathrm{In} /-\mathrm{n}$ & $-\mathrm{sIn}$ & $-\mathrm{n}$ & $-\varnothing$ \\
\hline $3 \mathrm{SG}$ & $-\mathrm{I} / \mathrm{-sI}$ & $-\varnothing$ & $-\varnothing$ & $-\mathrm{sIn}$ \\
\hline $1 \mathrm{PL}$ & $-\mathrm{ImIz} /-\mathrm{mIz}$ & $-\mathrm{ImIz} /-\mathrm{mIz}$ & $-\mathrm{k}$ & $-\mathrm{yAlIm}$ \\
\hline $2 \mathrm{PL}$ & $-\mathrm{InIz}$ & $-\mathrm{InIz}$ & $-\mathrm{nIz}$ & $-\mathrm{In} /-\mathrm{yIn}$ \\
\hline $3 \mathrm{PL}$ & $-1 \mathrm{ArI}$ & $-1 \mathrm{Ar}$ & $-1 \mathrm{Ar}$ & -sInlAr \\
\hline
\end{tabular}


The possessor marker licenses the realization of the highest argument of the complement predicate. This argument may be realized by a genitive NP, as demonstrated in the example (6). This realization follows the regular genitive pattern found in possessive constructions, where the genitive argument denotes the possessor. If its realization is not possible, because of different processes changing the argument structure, the possessor agreement takes its default value, i.e. $3 \mathrm{SG}$, cf. (10).

$$
\begin{aligned}
& {[\mathrm{Bu} \text { ev-de otur-ul-ma-sin]-1 } \quad \text { isti-yor-um }} \\
& \text { this house-LOC live-PASS-INF-3SG.P-ACC } \\
& \text { 'I want-PROG-1SG } \\
& \text { lit: 'I want that it is lived in this house.' (Haig 1998:37) }
\end{aligned}
$$

The intransitive complement predicate in (10) is in the passive voice. Although the realization of the highest argument is impossible, the possessive morphology is present. In this case the possessor agreement takes the default value, which is 3SG.

The realization of the remaining arguments does not change with the complement predicates. Objects are realized as in verbal sentences, as the examples provided so far demonstrate.

\subsection{Formation of control predicates}

\subsubsection{Derived control predicates}

Many equivalents of English control verbs appear to be derived from non-verbal predicates, cf. Haig (2003) for the discussion of the category-changing processes in the Turkish lexicon. (11) below gives some examples of Turkish control verbs of nominal origin.

$$
\begin{array}{lll}
\text { (11) } \begin{array}{l}
\text { boş 'empty' } \\
\text { zor 'difficulty, necessity' }
\end{array} & \rightarrow & \text { boş-la-mak 'neglect' } \\
\text { çaba 'effort, work' } & \rightarrow & \text { çaba-la-mak 'try, work towards' } \\
\text { baş 'beginning, head' } & \rightarrow & \text { baş-la-mak 'begin' }
\end{array}
$$

In (11) we can see examples of nominal roots turned into verbs. In each case the original noun is still in use and its meaning is provided. In the process of derivation the selectional properties of a predicate may change, i.e. the nouns from which the verbs in (11) are derived do not have to select an SOA-argument.

Furthermore, valency-changing morphology appears inherently on some control predicates in Turkish. Some examples are given in (12).

$$
\begin{array}{lll}
\text { sık 'press' } & \rightarrow & \text { sık-ll-mak (PASS) 'be bored, aggrieved' } \\
\text { çek 'draw, pull' } & \rightarrow & \text { çek-in-mek (REFL) 'avoid' } \\
\text { kalk 'rise' } & \rightarrow & \text { kalk-ış-mak (REC/PASS) 'dare, set out to' }
\end{array}
$$


$\begin{array}{lll}\text { inan 'believe' } & \rightarrow & \text { inan-dir-mak (CAUS) 'persuade' } \\ \text { kan 'believe' } & \rightarrow \quad \text { kan-dir-mak (CAUS) 'persuade' }\end{array}$

As in the case of the category-changing morphology, the stems onto which the valency-changing morphology is applied do not have to take SOA-arguments. This is the case with çek 'draw, pull'.

We can thus see that a considerable number of control verbs in Turkish are of nominal origin, and that these nouns do not have to take SOA-arguments, since in the process of derivation the argument structure of the stems may change.

\subsubsection{Light verb constructions}

Another common way of verb formation involves the use of light verbs, such as etmek 'do' and olmak 'be'. These verbs combine with nominal elements and form complex predicates. Nominal predicates participating in such constructions are often of non-native origin. (13) shows some examples of such light verb constructions. ${ }^{3}$

(13) tercih 'preference' $\rightarrow$ tercih etmek 'to prefer'

ümit 'hope' $\rightarrow$ ümit etmek 'to hope'

$k a b u l$ 'acceptance' $\rightarrow$ kabul etmek 'to accept'

niyet 'plan' $\rightarrow$ niyet etmek 'to plan'

arz 'wish' $\rightarrow$ arz etmek 'to wish'

In contrast to derived control predicates, control verbs resulting from light verb constructions inherit the SOA-argument from the embedded noun. The data in (14) illustrate this. Thus, in light verb constructions the accommodation of a nominal element to the role of a verbal predicate takes place.

$\begin{array}{llll}\text { [Onun Istanbul-a git-me] niyet-in-i } & \text { duy-du-m. } \\ \text { 3SG-GEN Istanbul-DAT go-INF plan-3SG.P-ACC } & \text { hear-PST-1SG } \\ \text { 'I heard of his/her plan to go to Istanbul.' } & \end{array}$

Some variation in the choice of the light verb is possible in a small class of nouns appearing in light verb constructions. The predicates given in (15) may be combined with more than one light verb. Although the translations suggest that they are passive, this is not the case, but at present, no better translation for such predicates seems available.

(15) ikna etmek 'convince'

vs. ikna olmak 'be convinced'

mecbur etmek 'force' vs. mecbur olmak 'be forced'

razl etmek 'convince' vs. razl olmak 'be convinced'

3 Not all nominal predicates in light verb constructions appear independently. 
The variation in the choice of light verb obviously influences the meaning of the predicate. What is more interesting for our purposes, different light verbs apparently influence the control relation of the predicates, cf. (16).
a. Baba-mi
ben- $i_{j}$
ikna et-ti. father-1SG.P 1SG-ACC study-INF-DAT persuade LV-PST.3SG
'My father persuaded me to study.'
b. Ben_i [ _i oku-ma]-ya ikna ol-du-m.
1SG study-INF-DAT persuade LV-PST-1SG
'I am persuaded to study.'

The data above show that the noun ikna 'persuasion' may be combined with two different auxiliaries, etmek 'do', in (16a) and olmak 'be' in (16b). In both cases the complex predicate selects an SOA-argument, i.e. a nominalized infinitive marked for the dative case. The interesting piece of information concerns the choice of the controller. In (16a) the controller of the implied argument of the SOA-argument is an object, i.e. the accusative NP. In (16b), however, it is the subject, i.e. the NP in the nominative. It seems that the noun ikna changes its control properties depending on the choice of the auxiliary. In (16a) we can attest object control, whereas it is subject control in (16b). The same pattern can be observed with mecbur in (17).

$$
\begin{aligned}
& \text { a Baba-m } \left.m_{i} \text { ben- } i_{j} \quad \text { [ }{ }_{j} \text { oku-ma }\right]-y a \text { mecbur et-ti. } \\
& \text { father-1SG.P 1SG-ACC study-INF-DAT force LV-PST.3SG } \\
& \text { 'My father forced me to study.' }
\end{aligned}
$$

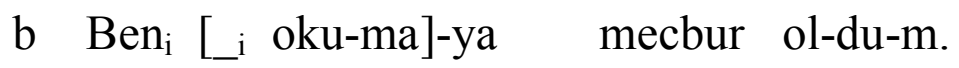

$$
\begin{aligned}
& \text { 1SG study-INF-DAT force LV-PST-1SG } \\
& \text { 'I am forced to study.' }
\end{aligned}
$$

The adverb mecbur takes an SOA-argument with two different light verbs. In (17a) with etmek it behaves like an object control verb, but in (17b) it triggers subject control. Such examples could be treated as control shift but as Barbara Stiebels (p.c.) points out, the apparent shift is only syntactic. Light verbs act differently on the argument structure of the nouns. It seems that with olmak the higher argument is existentially bound, which produces the 'passive' effect.

\section{The domain of control in Turkish}

In section $2 \mathrm{I}$ assumed the distinction between control-inducing and controlneutral structures. In this section I will investigate whether Turkish has a control-inducing structure, and if so, which of the clauses discussed above qualify as such. Furthermore I will investigate the possibility of control in non-controlinducing structures. It will be shown that the nominalized infinitive is not a con- 
trol-inducing structure, in the same sense as are infinitives in languages like German or Polish. It certainly provides a structure which facilitates control most strongly, compared to other types of complements available in this language. However it does not trigger it invariably. Furthermore, obligatory co-reference is marginally possible in non-control-inducing structures. This means that mismatches between the default readings of the complement and the meaning of the matrix verbs are possible, although not very common. The distinction between inherent and structural control proposed here allows the mismatches between the requirements of a matrix verb and the default reading of the complement clause to be explained.

\subsection{Control-inducing and control-neutral structures in Turkish}

The predominant view is that control is possible only in complement clauses with $-m E$ and $-m E K$ forms unmarked for the possessor agreement. ${ }^{4}$ Following this, complements with nominalized infinitives should be control-inducing structures in Turkish. This expectation is indeed met in the majority of cases. However, as has been noticed by Taylan (1996), there are verbs which are clear counter-examples to this prediction. An example of a sentence in which structural conditions for control are met but where no control holds is given in (18).

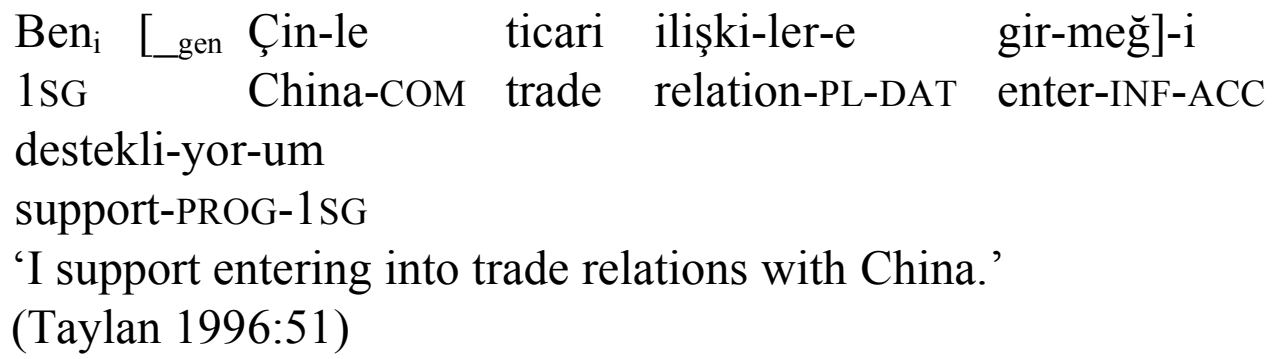

In (18), the SOA-argument is realized by means of the nominalized infinitive girmegi. According to the form of the complement predicate and its function in the sentence, (18) should be a control construction. However, this is not the case. Apparently, the speaker expresses an attitude towards an SOA which does not have to be brought about by him/her. Although the sentence meets the structural criteria for control, the meaning of the matrix predicate does not require it. The data in (18) thus demonstrates that clauses with nominalized infinitives do not provide a control-inducing structure in the strict sense. This kind of complement clause nevertheless provides the structure most appropriate for control in Turkish, and will nevertheless be treated as a control-inducing structure in the following.

4 This view is accompanied by the assumption that only sentential objects may be controlled. This assumption will be reconsidered in the following section. 
The verb desteklemek 'support' is not exceptional with regard to the interpretation of this kind of SOA-argument. Taylan (1996) gives a longer list of predicates following the same pattern. These are repeated in (19) below.

(19) Verbs not triggering control in (nominalized) infinitive complements, following Taylan (1996)

karşı olmak 'be against', desteklemek 'support', doğru bulmak 'find something right', yalnış bulmak 'find something wrong', günah 'consider something immoral', bayllmak 'love', alımak 'get accustomed to', bahsetmek 'talk about', tartışmak 'discuss'

It is interesting to observe that some regularities among the verbs listed above can be observed. There are basically two groups: one group, e.g. desteklemek 'support', günah 'consider something immoral', expresses the attitude of the speaker toward the SOA denoted by the complement predicate. The other group, e.g. bahsetmek 'talk about' and tartışmak 'discuss', refers to the manner of making utterances, and can be regarded as an utterance predicate, cf. (20).

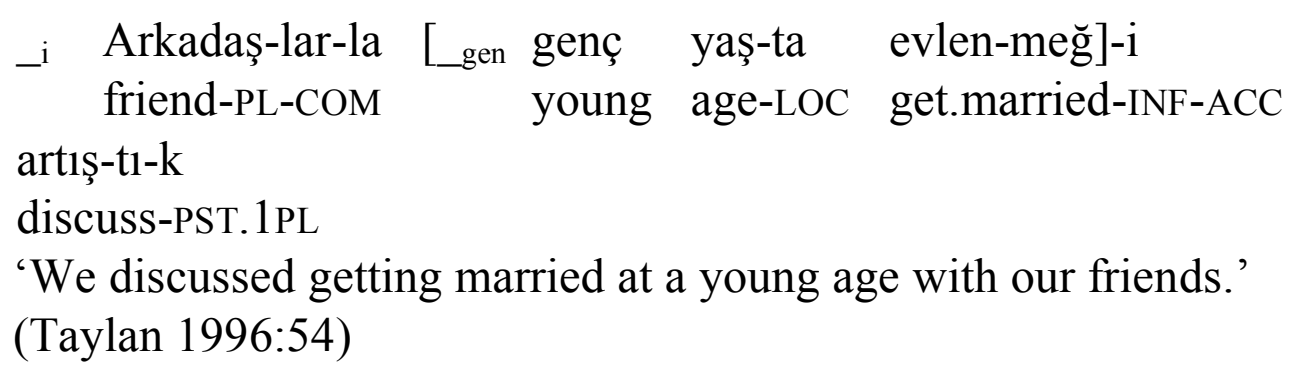

The fact that some matrix verbs do not require control with control-inducing structures is problematic for the approach to control proposed in this paper. Some solutions to this problem are possible. Nominalized infinitive may be regarded as a non-controlling structure and thus all cases of control in Turkish must be regarded as inherent control. This would however miss the fact that inherent control verbs in Polish and Turkish share some similarities. Alternatively, sentences like (18) and (20) could be treated as cases of partial control. This solution is problematic because no partial control is attested otherwise in Turkish. More research is needed to provide a satisfactory answer to this question.

\subsection{Possessor agreement and control}

As Bozşahin (in press: 6) puts it, 'embedded clauses with agreement cannot be targets of control'. This common view, that the possessive morphology on a verbal noun excludes control, is explained by the fact that the possessive agreement licenses the realization of the highest argument in the form of a genitive NP. The possessive morphology turns the embedded clause into a sentence, and the missing pronominal argument cannot bound by an argument of the higher clause. 
Although control is not predicted in such clauses, it must be noted that the interpretation of complements with possessive agreement is not uniform. Depending on the type of the suffix, either an obligatory disjoint reference or an optional co-reference is possible. Let us first consider the interpretation of missing arguments of gerund complements with $-D I K$ and $-E c E K$. As the data in (21) demonstrate, the missing argument may be co-referent with an argument of the higher clause.
a. Ahmet Ayşe-ye $_{j}\left[\_i / j / k\right.$ okul-a git-tiğ/eceğ-in]-i söyle-di.
A. A.-DAT school-DAT go-GER-3SG.P-ACC tell-PST.3SG
'Ahmet told Ayşe that he/she went/will go to school.' (Kural 1998:414)

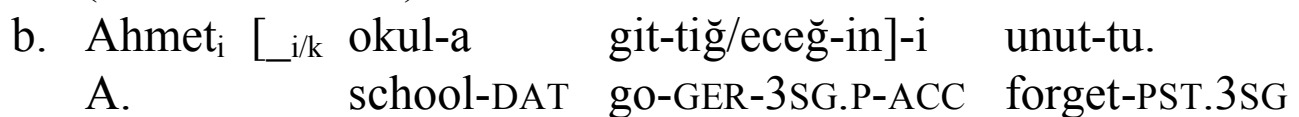

'Ahmet forgot that he/she went/will go to school.' (Kural 1998:414)

In (21a) a three-place SOA-argument-taking verb söylemek 'tell' is given. The complement is a gerund, formed with the suffixes $-D I K$ or $-E c E K$. Although the complement predicate shows the $3 \mathrm{SG}$ possessor agreement, the genitive NP is not present. The indexing shows that the unexpressed argument might be understood as a co-referent with the referent of the matrix subject or object. Although less preferred, the reference to a third participant is also possible. In (21b) with a two-place verb the same pattern can be observed. It can be seen that gerund complements generally allow for a co-reference between their implicit arguments and matrix clause arguments. This co-reference is optional, and will be excluded if the subject of the complement clause is overt.

The influence of the possessive morphology on the interpretation of the unexpressed argument of the $-m A$ complements is slightly different. The data below illustrate the pattern.

$$
\begin{aligned}
& \text { Çocuk }_{\mathrm{i}} \mathrm{k}_{\mathrm{iz}} \mathrm{a}_{\mathrm{j}} \quad\left[\mathrm{L}_{\mathrm{j} / \mathrm{k}}\right. \text { top oyna-ma-sın]-1 söyle-di. } \\
& \text { boy girl-DAT ball play-INF-3SG.P-ACC tell-PST.3SG } \\
& \text { 'The boy told the girl to play ball.' [Özsoy 1987:84] }
\end{aligned}
$$

In (22) the matrix verb söylemek 'tell' takes an SOA-argument headed by the nominalized infinitive oynamasinl, which shows the 3SG possessor agreement. As in the examples above, the genitive NP is missing. This unexpressed argument may be co-referent with the matrix clause object. Again such co-reference is possible only if the argument is implicit.

It has to be noted that the co-reference is possible only with the matrix object. The following example demonstrates that co-reference with a matrix subject is impossible. 
Ahmet $_{i}\left[*_{i} / \mathrm{j}\right.$ Sinema-ya git-me-sin]-i isti-yor.

A. Cinema-DAT go-INF-3SG.P-ACC want-PROG.3SG

'Ahmet wants (him/her) to go to the cinema.' (Kornfilt 1987:112)

In (23) the missing argument of the complement predicate must have a disjoint reference with regard to the matrix clause subject. ${ }^{5}$ It seems that disjoint reference is an invariant property of this kind of construction. This assumption is supported by the following data.
a. Ahmet ${ }_{i}$ [_?ij düş-me-sin-den] kork-uyor-du
A. fall-INF-3SG.P-ABL be.afraid-PROG-PST.3SG
'Ahmet $\mathrm{i}_{\mathrm{i}}$ was afraid that he $\mathrm{e}_{\mathrm{ji}}$ would fall.'
(Haig \& Słodowicz in press)
b. * ben i $_{\mathrm{i}}$ ij düş-me-m-den] kork-uyor-du-m
1SG fall-INF-1SG.P-ABL be.afraid-PROG-PST.1SG
int: 'I was afraid of falling.' (Haig \& Słodowicz in press)

The verb korkmak in the example (24a) may take an $-m E$ SOA-argument with the possessive morphology. Although this sentence is considered to be awkward by some informants, it is important to notice that the $3 \mathrm{SG}$ possessor agreement on the complement predicate must not refer to the matrix subject argument. This becomes even clearer in (24b) with a $1 \mathrm{SG}$ subject. In this example, the complement predicate is also in 1SG, which is supposed to mark the intended coreference. The ungrammaticality of this sentence shows that this is impossible. The data show that with two-place verb, $-m E$ complements with possessor agreement are not control-neutral structures.

The distinction between inherent and structural control postulated in this paper can be demonstrated in a convincing way with the help of this structure. The two-place verb taking an SOA-argument korkmak is a structural control verb. It may select a $-m E$ complement without possessor agreement. In this case it is a subject control verb, as demonstrated in (25).

$\begin{array}{ll}\text { Ahmet }_{i} L_{\mathrm{i}} \text { düş-mek]-ten } & \begin{array}{l}\text { kork-uyor-du. } \\ \text { A. }\end{array}\end{array}$

'Ahmet was afraid to fall.'

The co-reference, which is obligatory in (25), is not inherent to the verb korkmak. This is because this verb may appear with a control-neutral structure, as demonstrated in (24). If complement control were an inherent part of the meaning of this verb, it would either not be able to combine with a control-neutral

5 This pattern strongly resembles the pattern found in Romance languages in complex sentences with subjunctive complements, cf. Kempchinsky (1986) and Farkas (1992). This similarity makes Kornfilt (2003) label nominalized infinitive complements with possessor agreement as subjunctive. 
structure, or would adapt the structure to meet its requirements. Following this, the verb istemek is also a structural control verb, as the comparison of (23) and (26) demonstrates.

(26) Ahmet $_{i}[$ i cinema-ya git-mek] isti-yor.

A. cinema-DAT go-INF want-PROG.3SG

'Ahmet wants to go to the cinema.'

On the other hand, the verb denemek 'try' is an inherent control verb. Since it is a two-place verb taking an SOA-argument, its control properties can be well tested in the control-inducing and control-neutral structure, cf. (27).

a. Ahmet L $_{i}$ i cinema-ya git-me]-yi dene-di.

A. cinema-DAT go-INF-ACC try-PST.3SG

'Ahmet tried to go to the cinema.'

b. * Ahmet ${ }_{i}[$ _ cinema-ya git-me-sin]-i dene-di.

A. cinema-DAT go-INF.3SG.P-ACC try-PST.3SG

In (27a) the missing argument of the complement predicate gitmeyi is an obligatory co-referent with the matrix clause subject; that is to say, this sentence is a control construction. In (27b) the same matrix verb is combined with a controlneutral structure. It is important to note that this sentence is ungrammatical. Apparently the verb denemek 'try' cannot combine with a structure which requires a disjoint reference of the missing argument of the complement predicate and the matrix subject. The ungrammaticality of (27b) must be attributed to the meaning of the matrix verb. Therefore I conclude that the verb denemek 'try' is an inherent control verb, which appears only with the control-inducing structure. It must appear in an environment facilitating control. ${ }^{6}$

Becermek 'manage' is a verb which apparently tolerates such a mismatch. It may combine with the control-inducing and control-neutral structure, hence it is similar to korkmak and not to denemek in this respect. ${ }^{7}$
Ahmet $_{i} L_{-}$
bisiklet-i
tamir et-me-sin]-i
becer-di.
A. bicycle-ACC fixing LV-INF-3SG.P-ACC manage-PST.3SG
'Ahmet managed to fix the bike.' (Haig \& Słodowicz in press)

However, these two verbs are different in some important respects. Whereas korkmak is not an inherent control verb, i.e. the co-reference appears only with the control-inducing structure, becermek is an inherent control verb. Furthermore, in a control-prohibiting structure it will trigger control. The difference between these verbs is further supported by the fact that the former licenses a geni-

6 In the classification which will be elaborated below denemek 'try' will be a strong inherent control verb, cf. section 6.

7 The possessor agreement in such examples can only take the default value, i.e. 3 SG. 
tive NP with a different referent than the matrix clause subject, whereas the latter cannot license such an NP in spite of the possessor agreement, cf. (29).

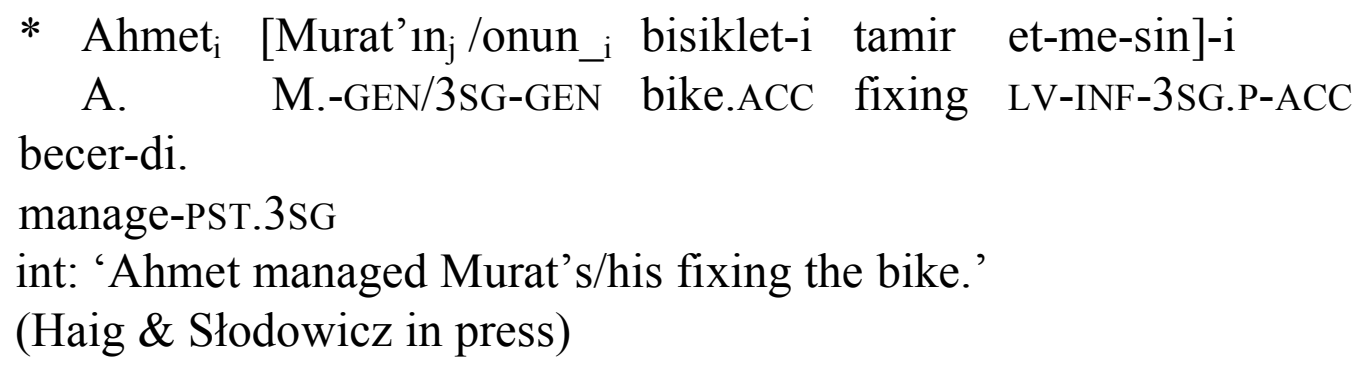

The only conclusion that the above data allows is that the verb becermek 'manage' must be an inherent control verb. In a control-neutral structure it will enforce the obligatory co-reference, but differently to other inherent control verbs like denemek, it may combine with such structures.

The distinction between inherent and structural control proposed in this paper is empirically motivated by the data provided in this section. Moreover, it can explain certain mismatches between the meaning of the verb and the readings of certain types of complement clauses. It therefore provides an improvement to the current approaches to control, for which the data would be problematic

\subsection{Control in sentential subjects}

Another assumption present in the current approach to control pertains to the function of the SOA-argument in a complex sentence. The proposal made by Manzini (1983) predicts that sentential subjects do not involve obligatory control. On the other hand, sentential objects do, when provided with the appropriate form of the complement clause. The second part of this assumption was dealt with in the preceding section. Here I will investigate the interpretation of sentential subjects and, following Stiebels (this volume), will show that sentential subjects of causative experiencer verbs must be obligatorily controlled. The same analysis can be extended to other non-causative predicates taking infinitival sentential subjects. The data will show that sentential subjects also provide a configuration in which obligatory (structural) control may hold. In the following discussion the grammatical relation 'subject' is defined in Turkish as the nominative NP.

The assumption that sentential subjects do not have to be controlled comes from examples like (30).

$$
\begin{aligned}
& \text { [_gen İstakoz-u çiğ ye-mek] sağlığ-a zararlı-dır. } \\
& \text { lobster-ACC raw eat-INF health-DAT damaging-COP.3SG } \\
& \text { 'Eating lobsters raw is a health-hazard.' (Sezer 1986:125) }
\end{aligned}
$$

In (30), the clause with the nominalized infinitive yemek functions as the subject. The missing argument is interpreted generically, which could lead to the 
conclusion that the function of the SOA-argument indeed has some influence on their interpretation. However, the situation changes if the sentence contains a dative argument, as demonstrated in (31).

$$
\begin{aligned}
& \text { [ }{ }_{i} \text { bu viski-yi içmek] hiç iyi ban- } a_{i} \text { gel-me-di } \\
& \text { this whisky-ACC drink-INF not well 1SG-DAT come-NEG-PST.3SG } \\
& \text { 'To drink this whisky was not good for me.' }
\end{aligned}
$$

The interpretation of the missing argument of the complement predicate in (31) is no longer generic. The dative NP must be co-referent with the missing subject of the SOA-argument. This sentence shows that sentential subjects can and in fact must be controlled, if an appropriate argument is present in the matrix clause. We could therefore assume that the experiencer predicates dispose of a dative argument, which is realized when its reference is specific. If this argument is not realized overtly, the argument is interpreted generically. Nevertheless this argument, overt or covert, provides the reference for the missing argument of the complement predicate. The crucial part of this assumption is that the generic interpretation of the missing argument of the complement predicate does not result from the configurational parameters, but from the referential properties of the implied argument of the matrix predicate. Obligatory co-reference holds between it and the missing argument of the complement independently of the referential status of the dative argument. Following this assumption, the example (30) could be analyzed in the following way, cf. Landau (2000) for a similar interpretation of the English data.

$$
\begin{aligned}
& \text { [_gen İstakoz-u çĭ̆ ye-mek] sağlı̆̆-a _ gen zararlı-dır. } \\
& \text { lobster-ACC raw eat-INF health-DAT damaging-COP.3SG }
\end{aligned}
$$

The analysis of control in sentential subjects outlined above could be criticized as too hypothetical. It relies on the assumption that the dative NPs are part of the argument structure of the matrix predicates. However, there is another type of construction in which the controller of sentential subjects is not assumed but motivated by the general pattern of argument linking. In Turkish some experiencer predicates are derived by means of the causative suffixes $-D I r,-I r,-t,-I t$ from predicates which do not necessarily take sentential complements. In (32), some examples of derived experiencer predicates are given.

$$
\begin{array}{ll}
\text { gülmek 'laugh' } & \rightarrow \text { gül-dür-mek 'make laugh' } \\
\text { eğe-len-mek 'amuse' } & \rightarrow \text { eğe-len-dir-mek 'make amused' } \\
\text { heyecan-lan-mak'excite' } \rightarrow \text { heyecan-lan-dır-mak'make excited' }
\end{array}
$$

The application of the causative morpheme changes the argument structure of the target predicate, cf. Comrie (1981:chapter 8) or Kroeger (2004:chapter 8). 
The result of the causative operation on the argument structure of transitive and ditransitive verbs is provided in (33).

$\begin{array}{lcc}\text { Verb } & \text { causer } & \text { causee } \\ \text { intransitive verb e.g. gülmek 'laugh' } & \text { NOM } & \text { ACC } \\ \text { transitive verb e.g. okumak 'read' } & \text { NOM } & \text { DAT } \\ \text { ditransitive verb e.g. koymak 'put' } & \text { NOM } & \text { DAT }\end{array}$

The derived experiencer verbs presented in (32) follow the same pattern of argument linking. Importantly, with these verbs, an SOA-argument can be the causer or the stimulus. In this case, the complement predicate is a nominalized infinitive, as illustrated in (34) below.

[ ${ }_{i} \mathrm{Bu}$ film-i izle-mek] ben- $i_{i}$ çok heyecanlan-dır-di. this film-ACC watch-INF 1SG-ACC much excite-CAUS-PST.3SG 'Seeing this film made me excited.'

In (34) the SOA-argument functions as a subject, i.e. it is in the nominative case (Ø-marking), and the matrix verb shows the default 3SG agreement. According to the configurational approach to control proposed by Manzini (1983), this sentence should not involve obligatory control. However, the interpretation of the arguments is in conflict with this assumption. The unexpressed argument of the complement predicate must be co-referential with the accusative argument of the matrix clause. This sentence is not obsolete. Other derived experiencer verbs in (32) follow the same pattern. The following example likewise shows obligatory control by the causee argument.

$$
\begin{aligned}
& \text { [_i } \mathrm{Bu} \text { haber-ler-i duy-mak] ben- } i_{\mathrm{i}} \text { gül-dür-du. } \\
& \text { this news-PL-ACC hear-INF 1sG-ACC laugh-CAUS-PST.3SG } \\
& \text { 'To hear this news made me laugh.' }
\end{aligned}
$$

(35) clearly shows that control in sentential subjects is possible, and following the assumptions formulated above, even obligatory. In case of the derived experiencer verbs, the missing argument of the complement predicate must be coreferential with the causee. In the case of other verbs taking sentential subjects, it must be co-referential with the dative argument, which may remain implicit if not specific. The relation between this argument and the missing argument of the verbal noun is the same (exhaustive co-reference), regardless of the implicit or explicit realization of the controller. 


\section{The arguments of the control relation}

\subsection{The controllee}

I defined the controllee above as the argument of the complement clause whose reference must be provided by at least one of the matrix clause arguments. The controllees are not overt in Turkish. Furthermore, in Turkish the arguments receiving the default linking (NOM) are controlled, i.e. this language follows the pattern found in other Nominative-Accusative languages.

The choice of the controllee is not dependent on the number of the arguments of the complement predicate. With transitive and intransitive verbs the same argument is controlled. The data in (36) illustrate this.

$$
\begin{aligned}
& \text { a. Çocuk }{ }_{i} \text { anne-sin-e } e_{j} \quad \text { [_i uyu-mağ]-a söz ver-di. } \\
& \text { child mother-3SG.P-DAT sleep.INF-DAT word give-PST.3SG } \\
& \text { 'The child promised his/her mother to sleep.' (Bozşahin in press:6) } \\
& \text { b. Çocuk } k_{i} \text { anne-sin- } i_{j} \quad\left[\_j \text { maksal kitab-1 oku-mağ }\right]-a \\
& \text { child mother-3SG.P-ACC story book-ACC read-INF-DAT } \\
& \text { ikna et-ti. } \\
& \text { persuasion LV-PST.3SG } \\
& \text { 'The child persuaded his/her mother to read a story book.' }
\end{aligned}
$$

The choice of the controllee does not depend on the voice of the complement predicate. In the active and passive voices, the argument of the complement predicate which would receive the nominative case is controlled. This is demonstrated in (37) by the passive form of the complement predicate.

$$
\begin{aligned}
& \text { Köpek }_{i} \text { [_i sev-il-mek] ist-iyor. } \\
& \text { dog pet-PASS-INF want-PROG.3SG } \\
& \text { 'The dog wants to be petted.' (Bozşahin in press:6) }
\end{aligned}
$$

The same holds of the causative morphology, although its application has some results on the control relation. Also with the causative morpheme the argument with the default linker is controlled, cf. (38).

$$
\begin{aligned}
& \text { a. Çocuk [adam-a kitab-1 oku-t-mak] ist-iyor. } \\
& \text { child man-DAT book-ACC read-CAUS-INF want-PROG.3SG } \\
& \text { (Bozşahin in press:7) } \\
& \text { b. Çocuk }{ }_{\mathrm{i}}\left[\mathrm{i}_{\mathrm{i}} \text { adam- } \mathrm{a}_{\mathrm{j}} \text { [_j }_{\mathrm{j}}\right. \text { kitab-1 oku]-t-mak] ist-iyor. } \\
& \text { 'The child }{ }_{i} \text { wants [ }{ }_{i} \text { to have the } \operatorname{man}_{j}\left[L_{j}\right. \text { read the book]]. } \\
& \text { (Bozşahin in press:7) }
\end{aligned}
$$

The data show that the choice of the controllee is constant, regardless of different factors such as transitivity and voice. Thus, the assignment of the controllee seems to be determined by the syntax. The choice of the controllee in Turkish 
presents the purely syntactic aspect of control in this language, cf. Stiebels (this volume). In the following section, the role of the lexicon in control constructions will be discussed.

\subsection{The controller}

The controller has been defined as the argument providing the reference for the controllee. I will show that apart from subject and object control, where the controller is unambiguously selected by the matrix verb, there are cases where the assignment of the controller relies on the context. Furthermore, apart from primary control relations, secondary control relations will be considered. Finally, I will show that split control is possible in Turkish, but partial control is not attested.

\subsubsection{Primary control relations}

Primary control relations do not depend on context and cannot be cancelled. In the following I treat subject, object and variable control as primary control relations. In investigating the control relations I will distinguish between two-place and three-place control verbs.

As far as subject control is concerned, the nominative argument functions as the controller with two-place control verbs. This is demonstrated below in (39) where the subject of the matrix clause, i.e. the nominative NP Ben, controls the reference of the controllee.

$$
\begin{array}{llll}
\text { Ben }_{i} \quad\left[\begin{array}{l}
\text { i } \\
\text { yüz-meğ]-e }
\end{array}\right. & \text { karar } & \text { ver-di-m } \\
\text { 1SG } & \text { swim-INF-DAT } & \text { decision } & \text { take-PST-1SG } \\
\text { 'I decided to swim.' (Taylan 1996:48) }
\end{array}
$$

Although the coding of the controller does not change, the coding of the SOAargument shows considerable variation. Among two-place verbs four different patterns of case marking can be found; these are provided in (40).

(40) Subject control verbs

$$
\text { a. } \lambda \mathrm{P} \quad \lambda \mathrm{x} \quad \mathrm{V}(\mathrm{x}, \mathrm{P}(\mathrm{x}))
$$

DAT NOM

başlamak 'begin', anlaşmak 'agree', ümit etmek 'hope', kabul etmek 'agree', niyet olm. 'plan', karar ver. 'decide', talib olm. 'hope', arzu olm. 'wish', çabalamak 'try', uğraşmak 'accomplish', hakim olm. 'be able', kalkışmak 'set out to', cesaret etmek 'dare', çallşmak 'try'

b. $\lambda \mathrm{P} \quad \lambda \mathrm{x} \quad \mathrm{V}(\mathrm{x}, \mathrm{P}(\mathrm{x}))$

ACC NOM

bitirmek 'complete', hatırlamak 'remember', düssunmek 'think about', boşlamak 'neglect', başarmak 'manage', birakmak 'stop', kesmek 'cut', hak etmek 'deserve', planlamak 'plan', tasarlamak 'consider', 
seçmek 'decide', istemek 'want', tercih etmek 'prefer', reddetmek 'refuse', kasdetmek 'intend', murad etmek 'wish', dilek etmek 'wish', temeni etmek 'wish', beklemek 'wait', halletmek 'complete' becermek 'manage', denemek 'try', unutmak 'forget', ihmal etmek 'neglect'

c. $\begin{array}{llll}\lambda \mathrm{P} & \lambda \mathrm{x} & \mathrm{V}(\mathrm{x}, \mathrm{P}(\mathrm{x}))\end{array}$

ABL NOM

hoşlanmak 'like', hazırlamak 'prepare', korkmak 'fear', sakınmak 'avoid', nefret etmek 'hate', vazgeçmek 'give up' sıkllmak 'be bored', bıkmak 'be bored', kaçmak 'avoid', çekinmek 'refrain'

d. $\lambda \mathrm{P} \quad \lambda \mathrm{x} \quad \mathrm{V}(\mathrm{x}, \mathrm{P}(\mathrm{x}))$

LOC NOM

israr etmek 'insist'

e. $\begin{array}{ccccc}\lambda \mathrm{P} & \lambda \mathrm{y} & \lambda \mathrm{x} & \mathrm{V}(\mathrm{x}, \mathrm{y}, \mathrm{P}(\mathrm{x}))\end{array}$

DAT DAT NOM

söz vermek 'promise'

We can see that the majority of verbs show ACC-NOM linking. The second largest group consists of verbs with DAT-NOM linking. The remaining linking patterns are not very widespread. The ABL-NOM pattern is found predominantly with experiencer verbs; only one verb was attested with the pattern LOC-NOM. Subject control is also possible with the three-place control verb söz vermek 'promise'. This verb exhibits DAT-DAT-NOM linking.

With three-place control verbs, the object may be chosen as the controller; that is, object control holds in this case. In (41) the referent of the matrix clause object, i.e. bana 'me', controls the interpretation of the missing argument of the complement clause.

$$
\begin{aligned}
& \__{i} \text { Ban- }_{j} \quad\left[\_j \text { geri dön-meğ] }-i \quad\right. \text { emret-ti-ler. } \\
& \text { 1SG-DAT back return-INF-ACC command-PST-3PL } \\
& \text { '(They) ordered me to return.' }
\end{aligned}
$$

Transitive verbs triggering object control show some variation in the coding of the controller. I have attested five patterns of case marking, which are given in (42).

(42) Object control verbs

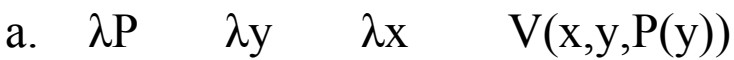

DAT ACC NOM

razl etmek 'convince', zorlamak 'force', mecbur etmek 'force', ikna etmek 'persuade', inandirmak 'persuade', kandırmak 'convince', davet etmek 'request', teşvik etmek 'encourage' müsaade etmek 'allow' 
b. $\lambda \mathrm{P} \quad \lambda \mathrm{y} \quad \lambda \mathrm{x} \quad \mathrm{V}(\mathrm{x}, \mathrm{y}, \mathrm{P}(\mathrm{y}))$

ACC DAT NOM

yardlm etmek 'help', yasaklamak 'forbid', tembih etmek 'warn', rica etmek ' ask', emretmek 'order', söylemek 'say'

$\begin{array}{lllll}\text { c. } & \lambda \mathrm{P} & \lambda \mathrm{y} & \lambda \mathrm{x} & \mathrm{V}(\mathrm{x}, \mathrm{y}, \mathrm{P}(\mathrm{y}))\end{array}$

ACC ABL NOM

taleb etmek 'request'

$\begin{array}{lllll}\text { d. } & \lambda \mathrm{P} & \lambda \mathrm{y} & \lambda \mathrm{x} & \mathrm{V}(\mathrm{x}, \mathrm{y}, \mathrm{P}(\mathrm{y}))\end{array}$

ABL DAT NOM

men etmek 'prohibit'

e. $\begin{array}{lllll}\lambda P & \lambda y & \lambda x & V(x, y, P(y))\end{array}$

ABL ACC NOM

mahrum etmek 'deprive'

Among the object control verbs, the DAT-ACC-NOM (non-canonical) linking is dominant. It is followed by the canonical ACC-DAT-NOM linking found with 7 verbs. I found only one example for the remaining types of argument linking.

So far only unique control readings have been considered. However, there are also control verbs in Turkish that exhibit variable control. As already observed by Taylan (1996) the verb önermek 'propose' is not specific as to the choice of the controller. Depending on the context, either the matrix object, or the matrix subject can be understood as controllers. The data in (43) illustrate this.
Tolga $a_{i}$ Orhan- $a_{j}\left[L_{i} / j o\right.$ binay 1 satın al-măg]-1 öner-di.
T. O.-DAT this building-ACC buy-INF-ACC propose-PST.3SG

'Tolga proposed buying that building to Orhan.' (Taylan 1996)

The missing argument of the complement predicate in (43) can be controlled either by the matrix clause subject, Tolga, or its object, Orhan. According to Taylan (1996) the choice of the controller is dependent on the context of the utterance. Variable control can be also shown with the data in (44). Here the verb tehdit etmek 'threaten' behaves like önermek 'propose' with regard to the choice of the controller.
a. _ $\_$Sen- $i_{j} \quad\left[\_i\right.$ iş-in- $i$
el-in-den
al-mak]-la 2SG-ACC work-2SG.P-ACC
hand-2SG.P-ABL take-INF-COM tehdit edi-yor.
threat LV-PROG-3SG
'She/he is threatening you that she will take away your job.'
b. $\_\mathrm{i}$ Sen- $\mathrm{i}_{\mathrm{j}}$
[ j ev-de kal-mak]-la tehdit edi-yor. 2SG-ACC house-LOC stay-INF-COM threat LV-PROG-3SG 'She/he is threatening you that you will stay at home.' 
The data show the importance of the context in the assignment of the controller with tehdit etmek 'threaten'. (44a) can only be interpreted as a subject control construction. This interpretation is reinforced by the possessive marking on the object of the complement predicate, which makes the matrix object an impossible controller. On the other hand, this verb may also trigger object control, if such an interpretation of the controller is likely. This is shown in (44b).

Not many verbs behave like önermek or tehdit etmek; I was able to attest only three verbs with variable control. These are listed in (45).

Variable control verbs

a. $\lambda \mathrm{P} \quad \lambda \mathrm{y} \quad \lambda \mathrm{x} \quad \mathrm{V}(\mathrm{x}, \mathrm{y}, \mathrm{P}(\mathrm{x} / \mathrm{y}))$

ACC DAT NOM

önermek 'propose', teklif etmek 'propose'

b. $\lambda \mathrm{P} \quad \lambda \mathrm{y} \quad \lambda \mathrm{x} \quad \mathrm{V}(\mathrm{x}, \mathrm{y}, \mathrm{P}(\mathrm{x} / \mathrm{y}))$

$\mathrm{COM}$ ACC NOM

tehdit etmek 'threaten'

\subsubsection{Secondary control relations}

Secondary control relations occur in non-neutral contexts and can be cancelled. These contexts involve, for instance, the use of collective predicates. Following this, split and partial control are secondary with respect to subject, object and variable control. The reason to treat these as secondary is that every so far predicate allowing for a secondary control relation will invariably show a primary control relation in a neutral context; in other words, I did not attest any verbs which would invariantly trigger split or partial control. In this section, I will show that Turkish seems to have split but lacks partial control.

In split control, both matrix clause arguments are understood as controllers. A regular test for this control relation involves the embedding of verbs denoting activities that can be carried out collectively, which can be additionally modified by expressions such as 'together'. The Turkish equivalents of 'meet' involve the reciprocal affix -Iş, cf. Kornfilt (1997:159). Some examples are given in (46).

$$
\begin{array}{ll}
\text { gör-mek 'see' } & \rightarrow \text { gör-üş-mek 'see each other', 'meet' } \\
\text { bul-mak'find' } & \rightarrow \text { bul-uş-mak'find each other', 'meet' } \\
\text { karşı-la-mak 'encounter' } \rightarrow \text { karşı-laş-mak 'meet' }
\end{array}
$$

The collective predicates presented above require a subject that either refers to a group of participants or an additional argument referring to a further participant involved in the SOA. The data in (47) show that buluşmak 'meet' has the required properties. 
a. Ahmet dün Ayşe-ile park-da bu-luş-tu.

A. yesterday A.-COM park-LOC find-REC-PST.3SG

'Ahmet met Ayşe yesterday in the park.'

b. Ahmet ve Ayşe park-da buluş-tuk

A. and A. park-LOC find-REFL-PST.1PL

'Ahmet and Ayşe met yesterday in the park.'

Example (47a) shows that the verb buluşmak 'meet' requires two arguments, one in the nominative, the other in the comitative. Alternatively in (47b), one argument referring to a group of participants is also possible.

Now we can turn to sentences in which such collective predicates are embedded. I will start with an analysis of three-place control verbs. The data below illustrate the behaviour of the matrix verb ikna etmek 'persuade' selecting buluşmak as its complement.
a. Ahmet ${ }_{i}$ Ayşe-yi $_{j} \quad\left[{ }_{i+j}\right.$ cinema-da bul-uş-ma $]-y a$ ikna
A. A.-DAT cinema-LOC find-REC-INF-DAT persuasion et-ti.
LV-PST.3SG

'Ahmet persuaded Ayşe to meet in the cinema.'

b. Ahmet ${ }_{i}$ Ayşe-yi $i_{j}\left[{ }_{j} / i+j\right.$ Bülent-ilek cinema-da bul-uş-ma $]$-ya
A.
A.-DAT
B.-COM
cinema-LOC find-REC-INF-DAT
ikna et-ti.
persiasion LV-PST.3SG
'Ahmet persuaded Ayşe to meet in the cinema with Bülent.'

The control verb ikna etmek 'persuade' may take the verb buluşmak 'meet' as its complement. Moreover, we can see that the complement clause in (48a) does not contain any argument in the comitative, and it has been shown that this is only possible if the subject refers to a group of participants, cf. (47b). Rejecting, for the time being, the assumption that there are further implicit arguments in the complement clause, the conclusion is that the missing argument of the complement predicate must refer to a group of participants, namely Ahmet and Ayşe, which are the referents of both arguments of the matrix clause, hence we have split control. In (48b) the second argument of the complement, the predicate is present. In this case, the primary control relation, i.e. object control, is the first choice, but the split reading is still possible. This kind of behaviour by ikna etmek 'convince' is not exceptional, and can be found with many other verbs as well. Split control therefore seems to be widely available in Turkish. ${ }^{8}$

8 I emphasize that this analysis rejects the assumption that there are additional implicit arguments in the complement clause. In Słodowicz (2006) I have shown that similar con- 
What happens if collective predicates are embedded under two-place control verbs? If such embedding were possible, we could attest partial control because the collective reading of the missing complement argument can only be maintained by inclusion of referents that are not exhaustively provided by the argument of the matrix verb, cf. Landau (2000). Consider now the data in (49).

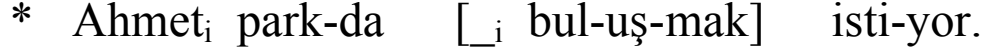

$$
\begin{aligned}
& \text { A. park-LOC find-REFL-INF want-PROG.3SG }
\end{aligned}
$$

'Ahmet wanted to meet in the park.'

It is not possible for the verb istemek 'want' to embed a collective predicate with a semantic plural subject, which clashes with the requirement of the complement predicate. ${ }^{9}$ It thus seems that Turkish does not have partial control. This assumption is supported by the data in which the verb toplanmak, another collective predicate that may be used to test for partial control in Turkish, is used, cf. $(50){ }^{10}$

$$
\begin{aligned}
& \text { a. * Ben toplan-d1-m. } \\
& \text { 1SG gather-PST-1SG } \\
& \text { '*I gathered.' }
\end{aligned}
$$

b. Biz toplan-di-k.

1PL gather-PST-1PL

'We gathered.'

The data in (50) show that this verb provides a good test for partial control. The data in (51) demonstrate the behaviour of the control verb istemek 'want', selecting toplanmak as its complement predicate. The data are representative of the rest of the two-place control verbs in the corpus.
a. * $\operatorname{Ben}_{\mathrm{i}}\left[\mathrm{i}_{\mathrm{i}+\mathrm{k}}\right.$ toplan-mak] iste-di-m. 1SG gather-INF want-PST-1SG 'I wanted to gather.'
b. Biz ${ }_{i} L_{-i}$ toplan-mak] iste-di-k.
$1 \mathrm{PL} \quad$ gather-INF want-PST-1PL
'We wanted to gather.'

The sentence (51a) shows that istemek does not allow for a partial control reading with tomplanmak as its complement. However a combination of these two predicates is possible, as shown in $(51 \mathrm{~b})$. The data shows that the ungrammati-

structions in Polish may be analyzed differently without restoring to the notion of split control.

9 It must be noted that the ungrammaticality of (49) does not result from some more general constraint on the embedding of collective predicates as is shown below.

10 The verb toplanmak has other readings, such as 'pack one's things', 'add' or 'gain on weight', which are not relevant here. 
cality of sentences like (51a) must be attributed to a general lack of partial control in Turkish, and not to some prohibition against embedding of collective predicates.

\section{Classification of control verbs}

Up to this point we have established the domain of structural control in Turkish. Additionally we have seen that there are cases, albeit not very numerous, in which control holds in control-neutral structures. In the next stage I will investigate the distribution of control verbs among the classes of inherent and structural control. First, however, I will outline the classification of control verbs as proposed by Stiebels (this volume).

\subsection{The system for classification}

Stiebels (this volume) proposes four classes of control verbs, each of which is defined by means of two features. The first feature is the sub-categorization properties of a verb. Here, a distinction between control-inducing and controlneutral structures provides three classes of verbs. Verbs selecting control-neutral structures are further divided into verbs controlling such structures and verbs which show no control. The classification of control verbs as proposed by Stiebels is given in Table 3 .

Table 3: Classification of control verbs following Stiebels (this volume)

\begin{tabular}{|l|c|cc|}
\hline & \multicolumn{2}{|c|}{ Control-inducing } & \multicolumn{2}{|c|}{ Control-neutral } \\
\hline Strong inherent control & $\sqrt{ }$ & $*$ & \\
\hline Weak inherent control & $\sqrt{ }$ & $\sqrt{ }$ & + control \\
\hline Structural control & $\sqrt{ }$ & $\sqrt{ }$ & -control \\
\hline Marked inherent control & $*$ & $\sqrt{ }$ & + control \\
\hline
\end{tabular}

Strong inherent control verbs only appear with control-inducing structures. Weak inherent control verbs combine with control-inducing and neutral structures. With both structures they require control. Structural control verbs may appear with control-inducing and neutral structures. Whereas control obtains with the former, no control reading is required with the latter. Quite exceptional are verbs which only combine with control-neutral structures but nevertheless trigger control in them, e.g. marked inherent control verbs.

To this general classification of control verbs further refinements can be added. Stiebels (this volume) suggests introducing a distinction of verbs selecting sentential subjects and those selecting sentential objects. Further modifications in the same vein are possible. Additional classes may be proposed for subject, object and variable control verbs. 


\subsection{Classes of control verbs in Turkish}

Adopting the above system of classification, a corpus of 78 verbs selecting SOA-arguments has been analysed. Although classes strong, weak inherent and structural control verbs are attested, no verb showed marked inherent control. Non-control verbs were established, but they will not be considered here. In the following, I will briefly present the classes of control verbs and provide lists of verbs falling into them.

\subsubsection{Strong inherent control}

Zorlamak 'force' is an example of a strong inherent object control verb. This verb allows for $-m E$ complements which cannot be marked for the possessor agreement. Furthermore, this verb does not select gerundial complements, cf. (52).

(52) Ahmet $_{\mathrm{i}}$ Ayşe-yi $\mathrm{i}_{\mathrm{j}}$ L $_{j}$ İstanbul'a git-me/*-sin/*eceğ-in]-e

A. A.-ACC I.-DAT go-INF $/ *^{*} 3 \mathrm{SG} . \mathrm{P} /{ }^{*}$ GER-3SG.P-DAT

zorladi.

force-PST.3SG

'Ahmet forced Ayşe to go to Istanbul.'

The data in (52) show that zorlamak 'force' is a strong inherent control verb. It allows only for the control-inducing structure, and does not tolerate any controlneutral structure. 26 verbs in my corpus show strong inherent control. Slightly more than half of them (15) show subject control, whereas 11 trigger object control. Strong inherent object control verbs in Turkish select sentential objects, i.e. no control of sentential subjects was attested. Subject and object control verbs show different argument linkings, e.g. ACC-NOM with kesmek 'cut, stop', but DAT-NOM with callşmak 'try, work toward'; in other words, no correlation can be established between the argument linking and control properties.

The strong inherent control verb zorlamak is a manipulative verb. In fact, all other object control verbs in this class express strong manipulation. As for subject control verbs, they tend to be modal, phase and implicative verbs. Some verbs cannot be definitely classified. Verbs such as reddetmek 'refuse' show a desiderative component, and are implicative at the same time. This points to serious drawbacks in the current classifications of verbs taking SOA-arguments. Notwithstanding these difficulties, strong inherent control verbs seem to constitute a homogeneous classes, if a distinction in subject and object control verbs is made. (53) provides a list of strong inherent control verbs.

(53) Verbs with strong inherent control

a. Subject control

çalışmak 'try, work towards', vazgeçmek 'give up', çekinmek 'refrain', boşlamak 'neglect', kesmek 'cut, stop', hakim olm. 'master, be 
able' reddetmek 'refuse', ihmal etmek 'neglect', sakınmak 'avoid', halletmek 'manage' çabalamak 'try', uğraşmak 'accomplish', denemek 'try', kalkışmak 'set out to' cesaret etmek 'dare'

b. Object control

mahrum etmek 'deprive', davet etmek 'request' zorlamak 'force', mecbur etmek 'force', yasaklamak 'ban', men etmek 'prohibit' ikna etmek 'persuade' emretmek 'order' teşvik etmek 'encourage' taleb etmek 'request' yardim etmek 'help'

\subsubsection{Weak inherent control}

Verbs with weak inherent control select control-inducing but also tolerate control-neutral structures. In the latter they trigger control, which shows that obligatory co-reference is an inherent part of their meaning. Becermek 'manage', already discussed above, shows such properties. (28), repeated below, illustrates this.

$\begin{array}{lllll}\text { Ahmet }_{i}[\mathrm{i} \text { bisiklet-i } & \text { tamir } & \text { et-me-sin]-i } & \text { becer-di. } \\ \text { A. } & \text { bicycle-ACC } & \text { fixing } & \text { LV-INF-3SG.P-ACC } & \text { manage-PST.3SG }\end{array}$

'Ahmet managed to fix the bike.' (Haig \& Słodowicz in press)

The matrix verb in (28) may select for a nominalized infinitive (preferably) without possessor agreement. If a possessor agreement is present, obligatory coreference holds between the matrix subject and the implied argument of the complement predicate. Other types of SOA-arguments are not possible with this verb.

The number of weak inherent control verbs in Turkish is quite small; only 6 verbs could be attested in this class. All these verbs select sentential objects and show subject control. Interestingly, the argument linking is not constant among these verbs, e.g. DAT-NOM with beçermek and ACC-NOM with başlamak, hence once again no correlation between argument linking and control properties can be established. Weak inherent control verbs show similar meanings to strong inherent ones, i.e. they are implicative and phase verbs. The list of verbs belonging to this class is given in (54).

(54) Verbs with weak inherent control

Subject control

becermek 'manage', başlamak 'begin', kaçmak 'avoid' bitirmek 'complete' başarmak 'manage' birakmak 'stop'

\subsubsection{Structural control}

The verb önermek 'propose' is a verb with structural control. The data in (55) demonstrate the control properties of this verb. 
(55) a. Ayşe $\mathrm{i}_{\mathrm{i}}$ Ahmet- $\mathrm{e}_{\mathrm{j}}\left[\mathrm{L}_{\mathrm{i} / \mathrm{j}}\right.$ alışveriş yap-mağ $]-1$ öner-di.

A. A.-DAT shopping do-INF-ACC propose-PST.3SG

'Ayşe proposed doing the shopping to Ahmet.'

b. Ayşe Ahmet-e [Murad-ın alışveriş yap-ma-sin]-1

A. A.-DAT [M.-GEN shopping do-INF-3SG.P-ACC

öner-di.

propose-PST.3SG

'Ayşe proposed to Ahmet that Murad should do the shopping.'

Clearly, the verb önermek 'propose' is not an inherent control verb. It selects a nominalized infinitive complement which may be marked with possessive morphology. In (55a) we can see a complement without possessor agreement. In this case, obligatory co-reference with one of the matrix clause arguments must obtain. In (55a) the complement bears possessor agreement. In this case a genitive NP, referring to the agent of the SOA denoted by the complement predicate, is allowed. This shows that (55b) is not a control construction.

(57) Verbs with structural control

a. Subject control

israr etmek 'insist', dilemek 'wish' sikılmak 'be bored', bıkmak 'be bored', hatırlamak 'remember', düşünmek 'think about', hak etmek 'deserve', planlamak 'plan', tasarlamak 'consider', seçmek 'decide', istemek 'want', tercih etmek 'prefer', hoşlanmak 'like', hazırlamak 'prepare', anlaşmak 'agree', ümit etmek 'hope', korkmak 'be afraid', kabul etmek 'agree', niyet etmek 'plan', karar etmek 'decide', talib olm. 'hope', unutumak 'forget', nefret etmek 'hate'

b. Object control

tembih etmek 'warn', inandirmak 'persuade', kandirmak 'convince', söylemek 'tell', müsaade etmek 'allow', heyeçanladırmak 'excite', ĕgelendirmek 'amuse', güldürmek 'make laugh' hüzün 'sadden', söz ver. 'promise', razl etmek 'convince'

c. Variable control

önermek 'propose', teklif etmek 'propose', tehdit etmek 'threaten'

\subsection{Evaluation}

The first observation concerns the linking of matrix clause arguments of control verbs and its relevance for control. The results of the analysis show that control is not dependent on any particular linking. Although canonical linkings (ACCNOM, ACC-DAT-NOM) are represented by large classes of verbs, non-canonical coding of arguments is also possible. In the corpus we find controllers and SOAarguments receiving non-canonical, semantic linking. This indicates that inherent and structural control do not depend on argument linking. 
Secondly, not all primary control relations are equally distributed among the verbs in the corpus. In particular, variable control is found only with structural control verbs. Subject and object control, on the other hand, are attested with inherent and structural control verbs. With these control relations, we observe that there are no correlations between the control relation and structural and inherent control.

Thirdly, it is important to note that although strong and weak inherent control verbs and structural control verbs are attested, no examples of marked inherent control verbs are available. Perhaps this is due to the limited size of the corpus tested. Until no further evidence becomes available, I am forced to assume that Turkish lacks this type of control verbs.

Inherent and structural control verbs show similar meanings. Inherent control verbs tend to belong to the classes of modal, phasal, implicative and (strong) manipulative verbs. On the other hand, desiderative, propositional-attitude and utterance verbs may only function as structural control verbs. This observation shows that the lexical semantics of matrix verbs is an important factor influencing the control properties.

Similar claims have been made in the past, cf. Givón (1980), Croft (2001), Cristofaro (2003) and Van Valin (2005). Approaches claiming that there is a close connection between verb semantics and its control properties rely on 'situational' classifications of such verbs. These try to predict how particular classes of verbs behave with regard to certain phenomena, control being one of them. However, there are some disadvantages to such approaches. One of them is the empirical inadequacy of the classifications they apply. Most importantly, verbs are expected to be unambiguously classified as either phasal, manipulative or propositional-attitude verbs. However, this is often not the case, as the discussion of the derived experiencer verbs in section 4.3 demonstrated. These verbs fall into (at least) two classes; they are propositional-attitude and manipulative verbs at the same time. Such multiple class membership is a central problem for the approaches mentioned above.

Another problem arises from the assumed iconicity between the meaning of the verb and the form of the SOA-argument it selects. Although Turkish seems to be a good example for this assumption, i.e. as we have seen the class of weak inherent control verbs is rather small, not all languages comply with it. In Polish, as shown in my earlier work (2006), the class of weak inherent control verbs is considerably larger, and therefore the idea of an iconic relationship has to be considered more critically.

Regardless of the problems with the current typological classifications of verbs selecting SOA-arguments, the predictions they make largely agree with the results of my analysis. Modal, phasal and implicative verbs show inherent control as expected. The same is true of strong manipulative verbs. Verbs which 
are not expected to involve inherent control cluster around the classes of propositional-attitude and utterance verbs. The difference between the classification conducted here and those proposed by Givón (1980) or Cristofaro (2003) is that the former established the classes explicitly and unambiguously, whereas the latter only assumes them and cannot classify the verbs without restoring speculations.

\section{Summary}

This paper has demonstrated that complement control in Turkish is a mixed syntactico-semantic phenomenon. The obligatory co-reference of two arguments in a complex sentence consisting of a matrix and a complement clause may arise through the lexical specifications of the matrix verb, or through the structural requirements of a particular form of the complement predicate. These two kinds of control have been termed 'inherent' and 'structural' control.

The semantic approach to control proposed here differs considerably from the currently well-established and configurationally-determined approaches to control in Turkish in some important points. Although the form of the complement predicate has been recognized as an important factor here, I have claimed that it does not fully determine control. Instead, following Stiebels (this volume), I proposed distinguishing between control-inducing and control-neutral structures. Control inducing structures are found predominantly in control constructions. As we have seen, however, exceptions are possible and control can also be found in control-neutral structures. Therefore an approach not assuming a strict connection between the form and function is superior to any approach relying on a oneto-one dependency. The approach proposed here does not restrict control to a particular form of complement clause.

In the configurational approaches, the function of the SOA-argument is expected to be relevant for control. Although sentential subjects are expected not to involve obligatory control, I have shown data which proves the opposite. Additionally, the data that has been used so far to argue for generic interpretation of the missing argument of the complement clause should receive a different analysis. The alternative analysis proposed here allows for a coherent treatment of embedded nominalized infinitives.

This paper has postulated a distinction between inherent and structural control. It has also provided a classification of control verbs which shows that such a distinction is empirically relevant. Although it is difficult to give an exhaustive list of control verbs in Turkish, partly because of the quite productive pattern of their formation, an analysis of a sample of such verbs showed that predicates are not distributed randomly between the classes of inherent and structural control. Inherent control verbs are usually found among modal, phasal, implicative and 
strongly manipulative verbs. Propositional-attitude and utterance verbs, on the other hand, tend to show structural control. These results allow predictions to be made regarding those verbs which are not included in the sample. It is expected that any verb with a meaning component denoting modality, a phase of the embedded SOA, its implication or manipulation is likely to show inherent control. Consequently, verbs denoting attitudes and acts of utterance may only function as structural control verbs.

The results presented here are in accord with the analysis of control predicates in other languages such as Polish (Słodowicz 2006). However, still more cross-linguistic evidence is needed in order to draw firm conclusions about the distribution of control verbs. Nevertheless some preliminary conclusions can be made. In comparison with Polish, Turkish is a language where little mismatch between the lexical specifications of the matrix verbs and the readings of the different types of complement clauses is allowed. There is only a small class of verbs belonging to class B. In contrast, Polish allows such mismatches on a larger scale. It is a matter of further research to explain these differences.

\begin{tabular}{ll|ll} 
Abbreviations \\
1 & first person & LOC & locative \\
2 & second person & LV & light verb \\
3 & third person & NEG & negation \\
ABL & ablative & NOM & nominative \\
ACC & accusative & P & possessive \\
CAUS & causative & PASS & passive \\
COM & comitative & PL & plural \\
COP & copula & PROG & progressive \\
DAT & dative & PST & past \\
GEN & genitive & REC & reciprocal \\
GER & gerund & REFL & reflexive \\
INF & infinitive & SG & singular \\
INST & instrumental & &
\end{tabular}

\section{References}

Boeschoten, Hendrik E. \& Ludo Th. Verhoeven (eds.)(1987). Studies in modern Turkish. Proceedings of the third conference on Turkish linguistics. Tilburg: Tilburg University Press.

Bozşahin, Cem (in press). On the Turkish controllee. Proceedings of the 12th Conference on Turkish Linguistics. 
Comrie, Bernard (1981). Language Universals and Linguistic Typology. Oxford: Blackwell.

Cristofaro, Sonia (2003). Subordination. Oxford Studies in Typology and Linguistic Theory. Oxford: Oxford University Press.

Croft, William (2001). Radical Construction Grammar. Syntactic Theory in Typological Perspective. Oxford: Oxford University Press.

Culicover, Peter W. \& Ray S. Jackendoff (2005). Simpler syntax. Oxford: Oxford University Press.

Farkas, Donka (1992). On Obviation. In: Ivan A. Sag \& Anna Szabolcsi (eds.), Lexical Matters. Stanford California: CSLI, 85-110.

Gamerschlag, Thomas (this volume). Semantic and Structural Aspects of Complement Control in Korean.

Givón, Talmy (1980). The binding hierarchy and the typology of complements. Studies in Language 4, 333-377.

Göçmen, Elvan, Onur Şehitoğlu \& Cem Bozşahin (1995). An Outline of Turkish Syntax. Ms. Department of Computer Engineering.

Haig, Geoffrey (1998). Relative Constructions in Turkish. Wiesbaden: Harrasowitz.

Haig, Geoffrey (2001). Word-class distinctions and morphological type: agglutinating and fusional languages reconsidered. Ms., University of Kiel.

Haig, Geoffrey (2003). From lexical class to syntactic function: A sketch of Turkish word structure. In: S. Özsoy et al. (eds.), Studies in Turkish Linguistics. Proceedings of the 10th International Conference on Turkish Linguistics, 2000. Istanbul: Bogaziçi Üniversitesi Press, 59-68.

Haig, Geoffrey \& Szymon Słodowicz (in press). Control in Turkish non-finite complements. In: Proceedings of the 12th International Conference on Turkish Linguistics, 2004.

Hornstein, Norbert (1999). Movement and control. Linguistic Inquiry 30, 69-96.

Kempchinsky, Paula (1986). The Subjunctive Disjoint Reference Effect. In: Carol Neidle \& Rafael A. Nuñez Cedaño (eds.), Studies on Romance Languages. Dordrecht: Foris, 123140.

Kerslake, Celia (1987). Noun phrase deletion and pronominalization in Turkish. In: Hendrik E. Boeschoten \& Ludo Th. Verhoeven (eds.), 91-104.

Kornfilt, Jaklin (1987). Beyond Binding Conditions: The Case of Turkish. In: Hendrik E. Boeschoten \& Ludo Th. Verhoeven (eds.), 105-120.

Kornfilt, Jaklin (2003). Subject Case in Turkish nominalized clauses. In: Luka Szucsich \& Uwe Junghans (eds.), Syntactic Structures and Morphological Information. Berlin: Mouton de Gruyter, 129-215.

Kornfilt, Jaklin (1997). Turkish. London: Routledge.

Kroeger, Paul R. (2004). Analyzing Syntax. A Lexical-Functional Approach. Cambridge: Cambridge University Press.

Kural, Murat (1998). Subordinate Infls and Comp in Turkish. In: Lars Johanson (ed.), The Mainz meeting: Proceedings of the 7th International Conference on Turkish Linguistics, 1994. Wiesbaden: Harrassowitz, 404-421. 
Landau, Idan (2000). Elements of control. Dordrecht: Kluwer.

Lewis, Geoffrey $\left(2000^{2}\right)$. Turkish grammar. Oxford University Press.

Manzini, Rita (1983). On control and control theory. Linguistic Inquiry 14, 421-446.

Özsoy, Sumru (1987). The null subject parameter and Turkish. In Hendrik E. Boeschoten \& Ludo Th. Verhoeven (eds.), 82-90.

Özsoy, Sumru A. (2001). On 'small' clauses, other 'bare' verbal complements and feature checking in Turkish. In: Eser Erguvanlı Taylan (ed.), The Verb in Turkish. Amsterdam: John Benjamins, 213-237.

Polinsky, Maria \& Eric Potsdam (2002). Backward Control. Linguistic Inquiry 33, 245-282.

Sezer, Engin (1986). The unmarked sentential subject constraint in Turkish. In: Dan Slobin \& Karl Zimmer (eds.), Studies in Turkish Linguistics. Amsterdam: John Benjamins, 123135.

Sezer, Erol (1981). The k/Ø alternation in Turkish. In: G. Clements (ed.), Harvard Studies in Phonology 2. Bloomington: Indiana University Linguistics Club, 354-382.

Słodowicz, Szymon (2006). Control in Polish Complement Clauses. Unpublished doctoral dissertation. CAU University of Kiel.

Stiebels, Barbara (this volume). Towards a typology of complement control.

Taylan, Eser (1984). The function of word order in Turkish grammar. Berkeley Los Angeles: University of California Press.

Taylan, Eser (1996). Aspects of control in Turkish. In: Rona Bengisu (ed.), Current issues in Turkish linguistics: Proceedings of the 5th International Conference on Turkish Linguistics, 1990. Ankara: Hitit, 46-60.

Van Valin, Robert D. (2005). Exploring the Syntax-Semantics Interface. Cambridge: Cambridge University Press.

Williams, Edwin (1980). Predication. Linguistic Inquiry 11, 203-238. 


\title{
On the control/raising ambiguity with aspectual verbs: a structural account
}

\section{Shin Fukuda}

\author{
University of California, San Diego
}

\section{Introduction*}

Since Perlmutter $(1968,1970)$ argued that English aspectual verbs are ambiguous between control and raising ${ }^{1}$, the phenomenon has been argued or assumed to exist in a number of other languages, such as French (Lamiroy 1987, Ruwet 1991), German (Wurmbrand 2001), Greek (Alexiadou \& Anagnostopoulou 1999), Hebrew (Landau 2003), Italian (Rizzi 1982, Burzio 1986), Japanese (Shibatani 1973, 1978, Kuno 1987, Nishigauchi 1993, Kageyama 1993, 1999, Matsumoto 1996, Koizumi 1998), and Spanish (Schroten 1986, Moore 1996), suggesting that it is common cross-linguistically. This paper takes up the issue of how the control/raising ambiguity with aspectual verbs should be accounted for. Two hypotheses are considered: the lexical ambiguity hypothesis and the structural ambiguity hypothesis. The lexical ambiguity hypothesis derives the differences between control and raising instances of aspectual verbs from their lexical specifications, i.e. selectional restrictions. The structural ambiguity hypothesis, on the other hand, claims that aspectual verbs may occupy different syntactic positions in a clause. The same aspectual verb is interpreted differently in different positions, creating the control/raising ambiguity. Perlmutter's influential work exemplifies the lexical ambiguity hypothesis, and a brief review of some recent analyses of control and raising also reveals that they take the lexical distinction of control and raising as a starting assumption. Under such an assumption, the control/raising ambiguity can only be lexical. In this study, I present arguments for the structural ambiguity hypothesis.

In what follows, I first briefly review Perlmutter $(1968,1970)$, in which it is argued that aspectual verbs are ambiguous between control and raising. I suggest that while the argument for the raising analysis is solid, the arguments supporting the control analysis of aspectual verbs are less so. As an alternative

* I would like to thank Peter Jenks and Laura Kertz for proofreading an earlier draft of this paper and providing me with valuable comments. Usual disclaimers apply. The work on this project was supported in part by NSF grants BCS-0131993 and BCS-0131946.

1 Perlmutter $(1968,1970)$ also discuss other ambiguous verbs, such as threaten, promise, and modals. This study focuses on aspectual verbs and extends its scope to want-type verbs, but it makes no claim about other verbs that also show the control/raising ambiguity. For recent analyses of modals and the control/raising ambiguity, see Wurmbrand (1999) and Bulter (2003). 
hypothesis to consider, I introduce the structural ambiguity hypothesis. In Section 3, I review three recent analyses of control and raising. Although there are important differences among them, they all share the basic assumption that the control/raising distinction is due to differences in selectional restrictions that the lexical items impose. Under such an assumption, the lexical ambiguity hypothesis is the only available option. In Section 4, I present evidence for the structural ambiguity hypothesis from studies concerning aspectual verbs in languages from four distinct families, German (Wurmbrand 2001), Japanese (Fukuda 2006), Romance languages (Cinque 2003), and Basque (Arregi \& Molina-Azaola 2004). These data strongly suggest that across languages aspectual verbs can appear in two different syntactic positions, either below or above $v \mathrm{P}$, or the projection with which an external argument is introduced (Kratzer 1994, 1996, Chomsky 1995). Given these findings, I argue that it is the aspectual verbs' position with respect to $v \mathrm{P}$ which creates the control/raising ambiguity. When an aspectual verb appears in a position that is lower than $v \mathrm{P}$, an external argument takes scope over the aspectual verb. Thus, it is interpreted as control. When an aspectual verb appears in a position that is higher than $v \mathrm{P}$, on the other hand, it is the aspectual verb that takes scope over an entire $v \mathrm{P}$, including the external argument. Thus, it is interpreted as raising. In section 5, I extend the scope of this study to include a discussion of want-type verbs in Indonesian, as analyzed in Polinsky \& Potsdam (2006). Polinsky \& Potsdam argue that the Indonesian want-type verbs must be raising in at least certain cases where they allow a rather peculiar interpretation. Although they assume that there are also control counterparts of the want-type verbs, I argue that applying the proposed analysis to the want-type verbs does away with the need for stipulating two distinct lexical entries for these verbs. Section 6 concludes the paper.

\section{The two verbs begin (Perlmutter 1968, 1970)}

In this section, I first briefly review the arguments for the control/raising ambiguity presented in Perlmutter $(1968,1970)$. Following that, I review past literature and discuss new evidence to suggest that the arguments for the control analysis of aspectual verbs are not as solid as those for the raising analysis. Given the questionable status of the claim that aspectual verbs are lexically ambiguous between control and raising, I introduce an alternative hypothesis, the structural ambiguity hypothesis. 


\subsection{Arguments that aspectual verbs are lexically ambiguous}

In his dissertation (Perlmutter 1968) and the influential paper, 'The two verbs begin' (Perlmutter 1970), Perlmutter argues that English aspectual verbs, such as begin, are ambiguous between control and raising. ${ }^{2}$

First, Perlmutter shows that begin can have a non-thematic subject, indicative of raising. Examples below show that begin allows sentential subjects and expletive subjects (1), exhibits active/passive synonymy (2), and permits idiom chunks to maintain their idiomatic meanings (3).

(1) a. That Bill was promoted began to annoy John.

b. It began to rain.

c. There began to be commotion.

(2) a. The noise began to annoy Joe.

b. Joe began to be annoyed by the noise.

(3) a. Heed began to be paid to urban problems.

b. Headway began to be made toward a solution.

He then presents evidence that the same verb behaving as a control verb. First, begin is compatible with the agentive nominalization with -er, unlike typical raising verbs such as seem and happen.

(4) a. Peter is a beginner.

b. *Peter is a seemer.

Also, begin can take an NP object, which can undergo passivization.

(5) a. Sam began the job.

b. The job was begun by Sam.

Moreover, begin can be embedded under a control verb, either subject control (6a) or object control (6b).

(6) a. I tried to begin to work.

b. I forced Tom to begin work.

Furthermore, he claims that begin is compatible with imperative formation, suggesting that it selects an animate subject (7).

(7) Begin to work.

Another diagnostic that Perlmutter uses is do so anaphor. Assuming that verbs that take abstract subjects cannot be replaced with this anaphor, he shows that

2 In the terminology and classification that Perlmutter used, raising verbs are intransitive verbs that take a clausal complement and control verbs are transitive verbs which require an identity between the subject and the subject of the complement, triggering Equi(valent) NP deletion. 
do so anaphor can replace begin when its subject is animate (8a), but cannot when begin's subject is inanimate, as in cases of raising (8b).

a. Warren tried to begin to work and Jerry tried to do so too.

b. *Oil began to gush from the well and water did so too.

\subsection{Arguments against the control analysis of aspectual verbs}

Although Perlmutter's arguments for analyzing begin as a raising verb remain virtually unchallenged ${ }^{3}$, his arguments for the control analysis of begin has been challenged by subsequent studies, most notably by Newmeyer (1975).

Newmeyer (1975) focuses in particular on the arguments that begin can be embedded under a control verb, as in (6). Despite Perlmutter's assumption that begin must select an animate subject in this environment in order to trigger Equi-NP deletion, Newmeyer argues that aspectual verbs are transparent in terms of selectional restrictions, even in environments like (6) (Newmeyer 1975:33-34). The example Newmeyer uses to illustrate this point involves three verbs, remember, keep, and forget. First, (9a-c) below shows that remember can embed keep (9a), and keep can embed forget (9b), but remember cannot embed forget $(9 \mathrm{c})$.
a. I remembered to keep working.
(remember $>$ keep)
b. I kept forgetting what my mother told me.
(keep $>$ forget)
c. *I remember to forget what mother told me.
$(*$ remember $>$ forget $)$

Given the assumption that selectional restrictions are local, one would expect from (9a-c) that the combination of the three verbs, 'remember $>$ keep $>$ forget', would be grammatical. However, that is not the case.

(10) *I remembered to keep forgetting what my mother told me.

Instead, (10) shows that the selectional restriction conflict between remember and forget that we witnessed in (9c) still has its effects in (10). Based on (10), Newmeyer concludes that keep is transparent with respect to selectional restrictions, even thought it is embedded under a control verb, remember. ${ }^{4}$

Newmeyer also claims that the example with do so anaphor in (8) does not necessarily show the control/raising contrast, as definiteness of the arguments appears to affect the grammaticality (Newmeyer 1975:31, fn. 7).

3 For instance, Newmeyer (1975) describes Perlmutter's arguments for the raising analysis of begin 'impeccable'. (Newmeyer 1975:27).

4 Rochette (1999) points out that the assumptions behind (6) do not carry over under the current analyses of control. Under the PRO analysis of control, for instance, (6a) can be analyzed as involving raising of PRO from the subject of the most deeply embedded complement to the subject of the complement headed by begin, where it is controlled by the matrix subject. 
(11) The oil stopped gushing from the wall and the water did so too.

In addition to Newmeyer's arguments against the control analysis of begin, I argue that the value of the -er nominalization as a support for begin selecting an agentive subject (4) is also questionable. First, the most salient interpretation of the -er form of begin, beginner, appears to be a person who is inexperienced or novice, and not a person who begins. In fact, it appears the latter interpretation is not available to some speakers. Second, the -er nominalization fails to classify continue and keep as control verbs, since they do not undergo the nominalization.

However, at least two of Perlmutter's arguments for the control analysis (or non-raising analysis) of begin still hold. The fact that begin undergoes imperative formation (7) suggests that begin must be able to select an animate subject. ${ }^{5}$ Also, the fact that aspectual verbs take an NP object (5) makes it difficult to argue that begin is always a raising verb. Cases of aspectual verbs taking a nominal object have been analyzed differently, for example the concealed complement analyses, ${ }^{6}$ which assume that such instances involve an invisible clausal complement, and a process called complement coercion, a nonsyntactic process that "converts the entity-donation object into an event description" and satisfies the selectional restrictions of aspectual verbs which otherwise require an event-denoting clausal complement (Pylkkänen \& McElree, to appear). ${ }^{7}$ As Perlmutter points out, the concealed complement analysis would have difficulties explaining why the NP object passivizes (5b), since an object of a clausal complement would not (12b). (Perlmutter 1970:fn. 11)

(12) a. Sam began to make the table.

b. *The table was begun to make.

On the other hand, complement coercion is a non-syntactic process in which the hearer accommodates by thinking up a reasonable eventive interpretation from a given NP object. As such, the assumed syntax is that of the regular transitive structure, where an aspectual verb selects a subject and an object. Thus, the raising analysis appears to be inappropriate for (5). ${ }^{8}$ However, (5) crucially does

5 Rochette (1999) argues that imperative formation does not necessarily show the control/ raising contrast, suggesting that the well-formedness of imperative formation is constrained by the aspectual nature of the verb. For instance, being a stative verb prevents seem from undergoing imperative formation (Rochette 1999:149). However, Rochette's argument only shows that a verb may fail to undergo imperative formation even when it selects an animate subject. This does not refute Perlmutter's argument that the fact that begin is compatible with imperative formation suggests that it must be capable of selecting an animate subject.

6 A similar analysis has been proposed for want (c.f. den Dikken et al. 1996).

7 Pylkkänen \& McElree (to appear) also discuss processing studies that support the coercion hypothesis.

8 However, see Rochette (1999) for an analysis of (5) as an instance of raising. 
not involve a clausal complement, and one might argue that all it shows is that begin can be a transitive verb (it is not always a raising verb). Thus, it is not as strong an argument for the control analysis for begin as imperative formation is.

In sum, a closer examination of Perlmutter's arguments reveals that not all of his arguments for the control/raising ambiguity actually hold. However, at least two of the arguments, imperative formation and NP object's would be problematic under a strict raising analysis of aspectual verbs.

\subsection{Lexical vs. structural ambiguity}

Despite the controversial nature of the control analysis of aspectual verbs, the control/raising ambiguity with aspectual verbs has been documented in a number of other languages, such as French (Ruwet 1991, Lamiroy 1986), German (Wurmbrand 2003), Greek (Alexiadou \& Anagnostopoulou 1999), Hebrew (Landau 2003), and Japanese (Shibatani 1973, 1978, Kuno 1987, Nishigauchi 1993, Kageyama 1993, 1999, Matsumoto 1996, Koizumi 1998). The ambiguity in these languages, however, is not always as carefully studied as it was for English aspectual verbs by Perlmutter. ${ }^{9}$

Assuming that the control/raising ambiguity with aspectual verbs exists, the question that I address in this study is what might be the best way to capture the ambiguity. In the rest of this paper, I consider two alternative hypotheses to account for the ambiguity. One is the position for which Perlmutter argued, that aspectual verbs are lexically ambiguous between control and raising. Under this hypothesis, each of the ambiguous aspectual verbs has two lexical entries, each of which imposes a different set of selectional restrictions. Let us call this hypothesis the lexical ambiguity hypothesis. An implicit assumption behind this hypothesis, which is important to our discussion, is that both control and raising verbs are lexical verbs, which occupy the head of VP and take a clausal complement. An alternative hypothesis suggests that the ambiguity is structural in nature. In other words, there is only one aspectual verb which means begin, and its interpretation changes depending on its syntactic position. Let us call this hypothesis the structural ambiguity hypothesis. In this study, I present arguments for the structural ambiguity hypothesis.

First, however, I review three recent analyses of control and raising, and show that the theories of control and raising currently available leave us with only one of the two hypotheses as an option: the lexical ambiguity hypothesis.

9 For instance, Rizzi (1982) simply assumes that Italian aspectual verbs are ambiguous between control and raising (i.e. Rizzi 1982ch 1, fn. 7). 


\section{Recent analysis of control/raising and the control/raising ambiguity}

The analysis of control and raising has played an important role in the development of linguistic theories. Recently, several radically different theories of control and raising have been advanced, reviving the discussion of control and raising (Hornstein 1999, 2003, Culicover \& Jackendoff 2001, Jackendoff \& Culicover 2003, Boecks \& Hornstein 2003, Landau 2003, Davies \& Dubinsky 2003, Polinsky \& Potsdam 2006). In this section, I briefly review three recent syntactic analyses of control and raising within the Minimalist Program (MP) framework: (i) the case-driven analysis, (ii) the movement-driven analysis, and (iii) the Agree-based analysis. While there are important differences between the three theories of control and raising, in all three analyses, both control and raising verbs are assumed to be verbs that take a clausal complement. The differences between control and raising verbs, therefore, boil down to differences in their lexical specifications, namely, selectional restrictions imposed on their complements and/or subjects. Thus, according to these theories of control and raising, the control/raising ambiguity with aspectual verbs would have to be lexical, as in the lexical ambiguity hypothesis. ${ }^{10}$

\subsection{The case-driven account (Martin 2001)}

Given the problematic status of PRO within the Government and Binding (GB) framework and $\mathrm{MP}^{11}$, Chomsky \& Lasnik (1993) propose a case-theoretical analysis of the distribution of PRO, according to which only non-finite T(ense) checks a special type of case called null case, which can only be found in PRO. Although this analysis accounts for the observation that the complement of a control verb is always non-finite ${ }^{12}$ and the embedded subject of a control complement is always phonologically null, Martin (2001) points out that such an analysis fails to distinguish control from raising. Thus, it wrongly predicts that (13a) should be grammatical while (13b) should be ungrammatical, contrary to fact.

10 Although I focus on the theories of control and raising within MP in this study, the same conclusion, that the control/raising ambiguity is lexical, also applies to any semantic theories of control/raising (i.e. Jackendoff \& Culicover 2003) and syntactic theories of control/raising within the lexical theories such as LFG (Bresnan 2001, Falk 2001) and HPSG (Pollard \& Sag 1994, Sag \& Wasow 1999).

11 See Hornstein (1999) and Martin (2001) for the theory-internal problems with PRO within GB as well as MP.

12 This appears to be the case with English, but may not be with other languages. See Landau (2004), for instance, for discussions of obligatory control with subjunctive complements. 
(13) a. $* \mathrm{John}_{\mathrm{i}}$ seems to Bill to $\mathrm{PRO}_{\mathrm{i}}$ have solved the problem.

b. Naomi believes her to have solved the problem.

As a refinement of Chomsky and Lasnik, Martin proposes a modified version of the null case analysis of control, according to which the difference between control and raising is due to a difference in the specification of the head of TP in the infinitival complement which control and raising verbs select. In Martin's proposal, control verbs select infinitival complement headed by $\mathrm{T}$ that is $[+$ tense, -finite], while raising verbs take infinitival complements headed by $\mathrm{T}$ that are [tense, -finite]. Only the $\mathrm{T}$ that is [+tense, -finite] has null case, the only case that can license PRO (14).

(14) John tried $\left[\mathrm{PRO}_{\mathrm{i}}\left[\mathrm{to}_{[+ \text {tense, -finite }]} \mathrm{t}_{\mathrm{i}}\right.\right.$ to be nice $]$

\section{null case}

On the other hand, the head of TP in the infinitival complement of a raising verb, $T$ [-tense, -finite], has no case to offer. Thus, it cannot license PRO or lexical DP as an embedded subject (14a). The only grammatical configuration with $\mathrm{T}$ [-tense, -finite] is one in which a lexical DP is raised to be the matrix subject and licensed by the matrix $\mathrm{T}(15 \mathrm{~b})$.

a. *John seemed $\left[\mathrm{PRO}_{\mathrm{i}}\left[\mathrm{to}_{[\text {-tense, -finite] }} \mathrm{t}_{\mathrm{i}}\right.\right.$ to be nice]

b. $\mathrm{John}_{\mathrm{i}}$ seemed [ $\mathrm{t}_{\mathrm{i}} \quad\left[\mathrm{to}_{\text {[-tense, -finite] }} \mathrm{t}_{\mathrm{i}}\right.$ to be nice] $\downarrow$ NOM

Under the null case theory of control proposed by Martin, therefore, the differences between control and raising verbs derive from the features of $\mathrm{T}$ within their complement. ${ }^{13}$ Therefore, when a verb is ambiguous between control and raising, as in the case of aspectual verbs, it can take either a TP that is [+ tense] or [-tense]. In other words, there are two aspectual verbs with the same meaning but two different sets of selectional restrictions. ${ }^{14}$ Therefore, the control/raising ambiguity is a lexical ambiguity under the null case theory of control (and raising).

13 Presumably, there is another important difference between control and raising verbs under the null case theory of control, i.e. that only control verbs have thematic subjects.

14 In fact, Martin assumes that seem/appear are such ambiguous verbs (fn. 42). When seem/appear take an agentive subject, thus they are control verbs. These verbs are eventive predicates which must (i) be in the past tense and (ii) take an eventive complement.

(i) a. *John seems to hit Bill (right now) (raising)

b. John seemed to hit Bill (right then). (control) 


\subsection{The movement-driven account (Hornstein 1999, 2003)}

In the movement theory of control (O'Neil 1995, Hornstein 1999, 2003), both control and raising are consequences of NP-movement. The difference between control and raising is whether the landing site of NP-movement is to an argument position (theta position) or non-argument position (non-theta position). One of the important consequences of this analysis is that PRO is no longer necessary to account for control. In Hornstein's $(1999,2003)$ analysis, thetaroles are analyzed as features that are provided by verbs and checked by DPs. Unlike the null case theory of control discussed above, an embedded subject is never case-licensed within the infinitival complement, whether the matrix verb is control or raising. In both control and raising, therefore, the embedded subject must move to the matrix subject position to be case-licensed. However, only in control, the moving DP checks the second theta-role on its way to its ultimate landing site, [Spec, TP], creating the control relation between the embedded subject and the matrix argument (16b).

(16) a. John tried to win.

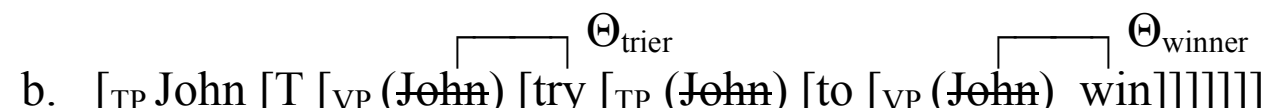
$\llcorner$ NOM

With a raising verb, the derivation is identical to (17) except that a raising verb does not provide the second argument role to the moving DP.

a. John seemed to be nice.

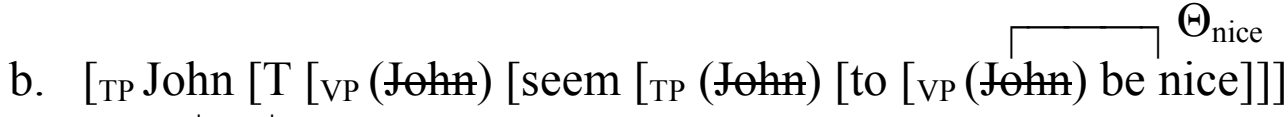
$\llcorner$ NOM

Under the movement analysis, control and raising verbs are explicitly claimed to have identical structure. The only difference between them is the selectional restrictions that they impose. Unlike the null case theory, which argues that control and raising verbs select different complements, under Hornstein's movement analysis of control, the only relevant selectional restrictions are imposed on subjects (external arguments). Nevertheless, some of the basic assumptions about control and raising are common to both the null case theory and the movement theory: (i) that control and raising verbs are verbs that take clausal complements, and (ii) that the differences between them derive from their differing lexical specifications, i.e. selectional restrictions.

\subsection{The agree-based account (Landau 1999, 2004)}

In contrast to the movement theory of control, which dispenses with PRO, PRO plays a crucial role in Landau's $(1999,2004)$ theory of control. However, unlike 
the null case theory, Landau's analysis does not rely on case to account for control. What creates the control relation between a matrix argument and an embedded subject in this account is Agree (Chomsky 2000, 2001).

According to Landau's analysis, control verbs select a CP complement with a distinct $\mathrm{C}$ head, which may carry both [Agr] and [T] features. The $\mathrm{C}$ head in turn selects an IP with distinct [T] features. The [T] feature on the head of IP can be selected or free, while selected tense can be further divided into anaphoric tense, which must be identical to the matrix tense, and dependent tense, which is dependent on the matrix tense but does not need to be identical to it. Moreover, CPs with both types of selected tense ((18b) and (18c)) are headed by C carrying the feature $[-\mathrm{T}]$ for anaphoric tense and $[+\mathrm{T}]$ for dependent tense, while a $\mathrm{CP}$ with free tense carries no $[\mathrm{T}]$ feature (18a).
a. $\quad\left[\mathrm{CP}\left[\mathrm{C}_{[\mathrm{Agr}]}\left[\mathrm{IP}\left[\mathrm{T}_{[\text {free }]}\right]\right]\right.\right.$
(C embedding IP with $\mathrm{T}$ that is free)
b. $\left[\mathrm{CP}\left[\mathrm{C}_{[\mathrm{Agr},-\mathrm{T}]}\left[\mathrm{IP}\left[\mathrm{T}_{\text {[anaphoric }]}\right]\right]\right.\right.$
(C embedding IP with anaphoric T)
c. $\left[\mathrm{CP}\left[\mathrm{C}_{[\mathrm{Agr},+\mathrm{T}]}\left[\mathrm{IP}\left[\mathrm{T}_{[\text {dependent }]}\right]\right]\right.\right.$
( $\mathrm{C}$ embedding IP with dependent $\mathrm{T}$ )

Finally, the selection of the right type of tense by the matrix verb is mediated by matching of feature values through C (Landau 2004:839).

$$
\begin{aligned}
& \mathrm{V} \ldots \ldots\left[{ }_{C \mathrm{P}} \mathrm{C}_{[ \pm \mathrm{T}]} \quad\left[\begin{array}{lll}
I P & \mathrm{I}_{[ \pm \mathrm{T}} & \mathrm{VP}
\end{array}\right]\right. \\
& \text { selection checking (of matching features) }
\end{aligned}
$$

Landau assumes that [Agr], which is essentially a bundle of $\varphi$-features, is purely morphological, as opposed to [T], which is semantic. Therefore, the head I of an IP, which lacks morphological instantiations of $\varphi$-features, has either a [-Agr] feature or lacks an [Agr] feature altogether, while indicative and subjunctive complements, with a morphological reflex of $\varphi$-features, have a [+Agr] feature. He further assumes that [+Agr] is parasitic on [+T] (ibid: 840 ).

On the other hand, DPs have a $[ \pm \mathrm{R}$ (eferential)] feature in this analysis. DPs that are capable of independent reference, such a lexical DPs and pro, are $[+\mathrm{R}]$, while DPs that are anaphoric, such as PRO, are [-R]. [+R] is assigned to I and $\mathrm{C}$ heads only when they are specified as $[+\mathrm{Agr}+\mathrm{T}]$, and any other combination results in $[-\mathrm{R}]$. When there is no [T] feature or [Agr] feature, $[\mathrm{R}]$ is not assigned.

Under the Agree-based analysis, there are two possible derivations for obligatory control. The first is exhaustive control, in which exhaustive referential identity is required between the matrix DP and PRO, as in (20a). The second is partial control, in which the controller is required to be included in, but not necessarily identical to, the referent of PRO (20b).

(20) a. *The chair ${ }_{[\text {singular] }}$ managed to $\mathrm{PRO}_{\text {[plural] }}$ meet at 6 .

b. The chair [singular] preferred to $\mathrm{PRO}_{[\text {[plural] }}$ meet at 6 . 
While the subject of both sentences in (20) is singular, the embedded verb meet requires a plural subject. The control verb in (20a), manage, does not tolerate such a disagreement, instantiating exhaustive control. The control verb in (20b), prefer, allows it, instantiating partial control. Since exhaustive control does not allow two different time references between the matrix and the embedded event, Landau assumes that complement of exhaustive control verbs is untensed or [-T], as in (18b). In contrast, the complement of a partial control verb is tensed or $[+\mathrm{T}]$, as in (18c), and as such compatible with two different time references.

Since aspectual verbs such as begin are classified as exhaustive control (Landau 2004: 835), I only discuss Landau's account of exhaustive control here. As can be seen below, a [-T] feature on the I head guarantees that the $[R]$ feature of $\mathrm{I}$ is $[-\mathrm{R}]$ (recall that $[+\mathrm{R}]$ is assigned to $\mathrm{I}$ and $\mathrm{C}$ heads only when they are specified as $[+\mathrm{Agr}+\mathrm{T}]$, and any other combinations result in $[-\mathrm{R}])$, making the Agree relation between PRO, which is [-R], and I possible (21a). C and I can also participate in an Agree relation, given that both are [-T] (21b). PRO, on the other hand is in an Agree relation with the matrix F(unctional head) which in turn is in an Agree relation with the matrix subject DP (21c).

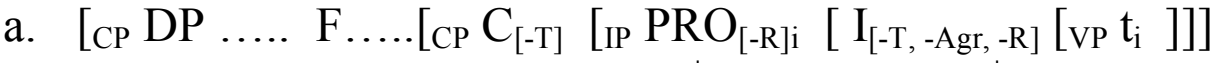

$$
\begin{aligned}
& \text { Agree }_{[-R]}-\longrightarrow \\
& \square \text { Agree }_{[-\mathrm{T}} \longrightarrow \\
& \text { b. } \quad\left[{ }_{\text {CP }} \mathrm{DP} \ldots . . \mathrm{F} \ldots . .\left[{ }_{\mathrm{CP}} \mathrm{C}_{[-\mathrm{T}]}\left[{ }_{\mathrm{IP}} \mathrm{PRO}_{[-\mathrm{R}] \mathrm{i}}\left[\mathrm{I}_{[-\mathrm{T},-\mathrm{Agr},-\mathrm{R}]}\left[\mathrm{vP} \mathrm{t}_{\mathrm{i}}\right]\right]\right]\right.\right. \\
& \left\llcorner\text { Agree }_{[-\mathrm{R}]} \_\right. \\
& \left\lceil\text {Agree }_{[-\mathrm{T} \Gamma} \longrightarrow\right. \\
& \text { c. }\left[{ }_{\mathrm{CP}} \mathrm{DP} \ldots \ldots . \mathrm{F} \ldots . .\left[\mathrm{CCP}_{[-\mathrm{T}]}\left[\mathrm{IIP} \mathrm{PRO}_{[-\mathrm{R}] \mathrm{i}}\left[\mathrm{I}_{[-\mathrm{T},-\mathrm{Agr},-\mathrm{R}]}\left[\mathrm{vP} \mathrm{t}_{\mathrm{i}}\right]\right]\right]\right.\right. \\
& \llcorner\text { Agree }\lrcorner\left\llcorner\text { Agree } _ { [ + \mathrm { Agr } ] } \downarrow \left\llcorner\text { Agree }_{[-\mathrm{T}]}-\right.\right.
\end{aligned}
$$

However, if a lexical DP or pro appears as the embedded subject, the [+R] feature of a lexical DP/pro prevents an Agree relation to hold between I and the lexical DP/pro. Thus, neither a lexical DP nor pro can appear as an embedded subject of an exhaustive control verb (ibid. 847).

$$
{ }_{\mathrm{CP}} \mathrm{DP} \ldots . . \mathrm{F} \ldots . .\left[\mathrm{CP}_{[-\mathrm{T}]} \mathrm{CIP}_{[\mathrm{I}}\left[\mathrm{I}_{[-\mathrm{T},-\mathrm{Agr},-\mathrm{R}]}\left[\mathrm{vP} \mathrm{DP} / \text { pro }_{[+\mathrm{R}]}\right]\right]\right]
$$

L *Agree

Although Landau (2004) discusses raising only briefly (Landau 2004:6.3), he does propose that a raising complement has no [R] feature. Landau assumes that this 'defectiveness', often associated with raising complements, is associated with the lack of [Agr]. Since lack of either a [T] or [Agr] feature means no [R] in this analysis, neither a lexical DP nor pro can engage in an Agree relation with a functional head in the complement to check off its $[+R]$ feature. Although 
Landau does not mention specifics of the derivation of Subject Raising, I assume that a lexical DP and pro must both move to the matrix domain, where I has a [+R] feature which supports the Agree relation. ${ }^{15}$ Thus, under Landau's Agree-based analysis, the derivation of a subject raising verb would look like $(23){ }^{16}$

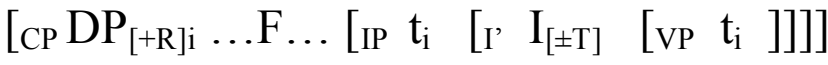

$$
\begin{aligned}
& \llcorner\text { Agree }\lrcorner{ }_{[+\mathrm{Agr},+\mathrm{R}]}
\end{aligned}
$$

As such, according to Laudau's Agree-based analysis of control and raising, aspectual verbs that are ambiguous between control and raising would have two different structures, (21) and (23). However, importantly, both (exhaustive) control verbs and raising verbs are verbs that take a clausal complement, and the differences between them are due to the structure of the complement they take, as in a CP embedding an IP with [-T] for the (exhaustive) control structure (21), and IP for the raising structure (23). Thus, Landau's Agree-based analysis of control (and raising) shares an assumption with two other analyses of control (and raising) that have already been examined: both control and raising verbs are lexical verbs that take a clausal complement. As such, these verbs are assumed to occupy the head of VP, and the control/raising distinction is a result of the imposition of different sets of selectional restrictions.

\subsection{Summary}

I have reviewed three recent analyses of control and raising, the case-driven analysis, the movement-driven analysis, and the Agree-based analysis. Although the differences between these theories of control and raising are significant, they all hold the same basic assumptions about control and raising verbs: whether a given verb is control or raising, its structural position is the head of VP. The differences between them control and raising follow from different selectional restrictions. Thus, under the analyses of control/raising examined so far, the control/raising ambiguity with aspectual verbs can only have one account: lexical ambiguity.

In fact, given the identical surface word order between sentences with control and raising verbs, ${ }^{17}$ this assumption seems to be the null hypothesis, unless there

15 Landau assumes that PRO cannot form the subject of a raising complement because such a structure would be ruled out by the $\Theta$-criterion (Landau 2004:fn.42).

16 Landau simply assumes that the raising complement lacks a CP projection (Landau 2004: 861).

17 This appears to be true for many languages, although there are some exceptions. For instance, in languages like Italian, Hebrew, and Indonesian, only control verbs optionally have a complement headed by a complementizer. See section 5 for the relevant data. 
is evidence that suggests otherwise. In the subsequent section, I present such evidence.

\section{The control/raising ambiguity is structural}

In this section, I present evidence which suggests that the control and raising instances of aspectual verbs occupy two different structural positions in a clause.

The evidence presented stems from four studies concerning aspectual verbs in languages from four distinct families, Wurmbrand (2001) for German, Fukuda (2006) for Japanese, Cinque (2003) for Romance languages, and Arregi \& Molina-Azaola (2004) for Basque. Although the exact positions in which aspectual verbs occur in each of the languages may differ slightly, there is a generalization to be made from the four sets of data reviewed in this study. When an aspectual verb is interpreted as raising, it occupies a position that is structurally higher than that of $v \mathrm{P}$, the projection where an external argument is introduced. When the same aspectual verb is interpreted as control, it occupies a position that is structurally lower than that of $v \mathrm{P}$.

Based on this generalization, I argue that the control/raising ambiguity for aspectual verbs derives from a difference in scope relations between an aspectual verb in these two different positions and an external argument in its base-generated position ([Spec, $v \mathrm{P}]$ ). When an aspectual verb occupies a position that is under the scope of an external argument, it is interpreted as a control verb. When it occupies a position that is higher than an external argument, it is interpreted as a raising verb. The analysis is illustrated as (24).

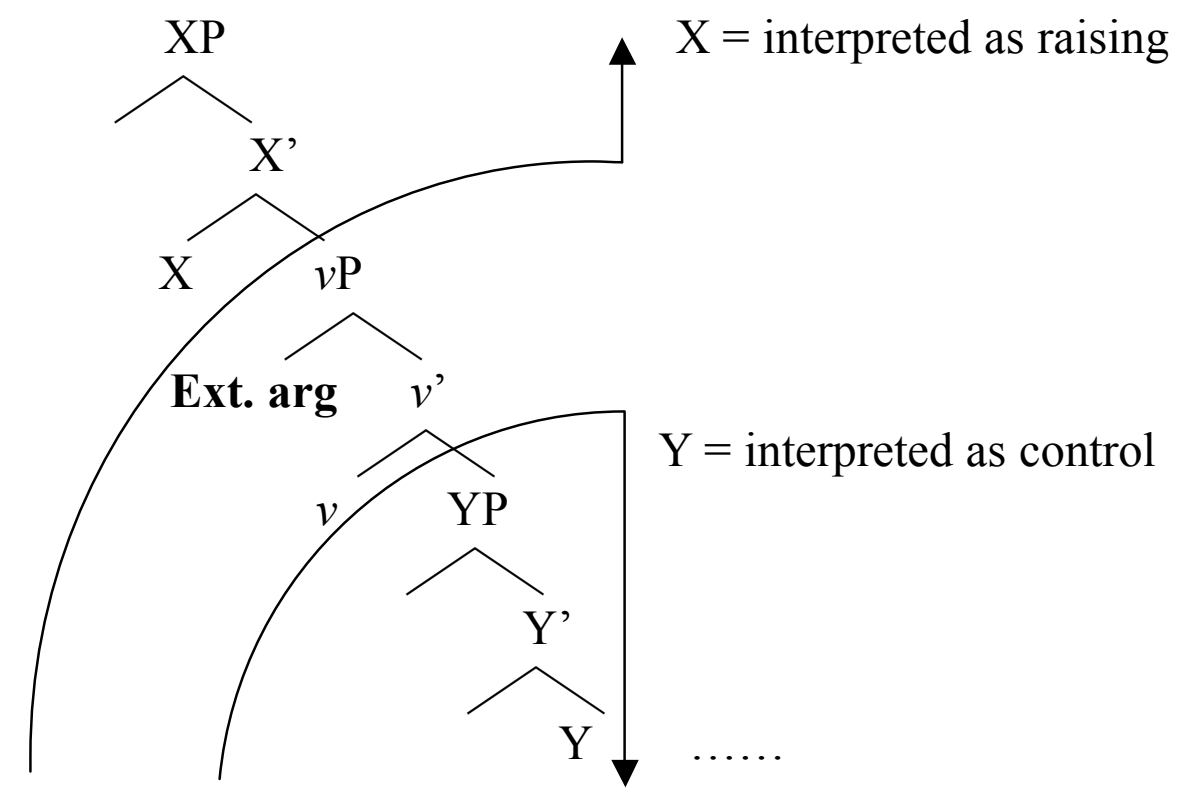




\subsection{German (Wurmbrand 2001)}

Wurmbrand (2001) argues that control and raising verbs in German occupy different positions in a clause. According to Wurmbrand, while German raising verbs occupy the position where auxiliary verbs are found, German control verbs are found as the head of VP (Wurmbrand 2001:206).

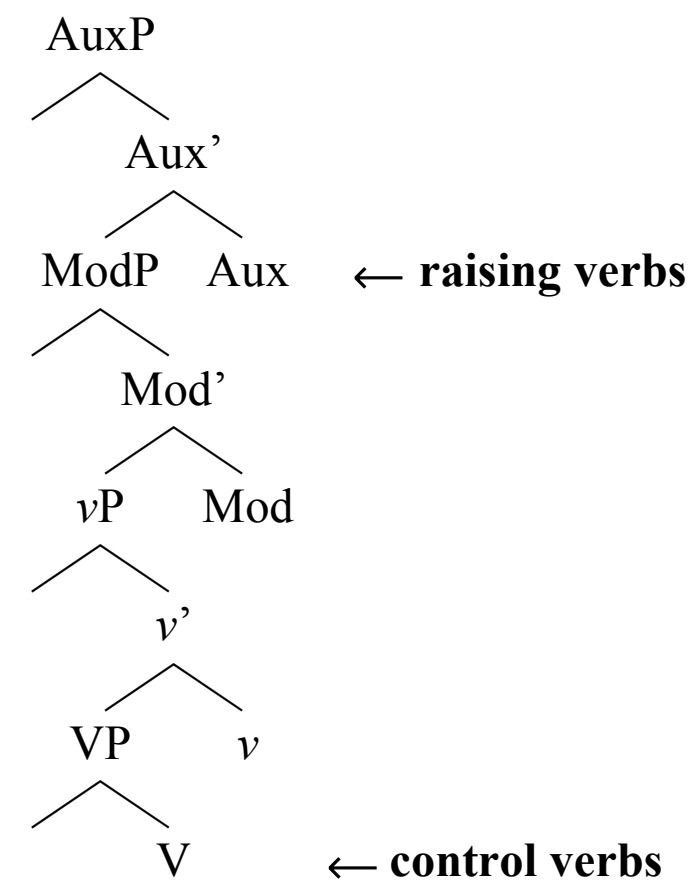

Under this analysis, aspectual verbs that are ambiguous between control and raising may appear in either of these two positions, while unambiguous control and raising verbs are restricted to occur as the head of VP and the head of AuxP, respectively.

In order to show differences in the structural position of control and raising verbs, Wurmbrand contrasts the distribution of unambiguous raising verbs, such as scheinen 'seem' and pflegen 'use to', and ambiguous verbs, such as versprechen 'promise', drohen 'threaten' and the aspectual verb beginnen 'begin'. First, Wurmbrand shows that the unambiguous raising verbs cannot be embedded under a modal, although they can embed a modal. ${ }^{18}$

a. * Morgen dürfte/muß er die Stadt zu verlassen scheinen. tomorrow might/must he the town to leave seem 'He will/might/must seem to be leaving the town tomorrow.'

b. Sie schien $\mathrm{zu}$ Hause arbeiten $\mathrm{zu}$ müssen/können. she seemed at home work to must/can 'She seemed to have to/be able to work at home.'

18 According to Wurmbrand, only deontic modals can be embedded under scheinen 'seem', which, under her analysis, occupies the position where auxiliary verbs and epistemic modals occupy. 
In contrast, ambiguous verbs can be embedded under a modal verb. However, when they are, they can only be interpreted as control verbs.

$$
\begin{aligned}
& \text { Er muß ein guter Vater } \mathrm{zu} \text { werden versprechen/drohen. } \\
& \mathrm{He} \text { must a good father to become promise/threaten } \\
& \text { 'He must promise/threaten to become a good father.' }
\end{aligned}
$$

Second, both the unambiguous raising verbs and the ambiguous verbs allow passive in the embedded clause ((28a) and (28b)). However, once an ambiguous verb is embedded under a modal, embedded passive becomes ungrammatical (28c).
a. ? Die Stadt begann zerstört zu werden. the town began destroy.PART to AUX.PASS
'The town began to get destroyed.'

b. Der Kaviar schien gegessen worden $\mathrm{zu}$ sein. the caviar seemed eat.PART AUX.PASS to be 'The caviar seemed to have been eaten.'
c. * Die Stadt muss/kann zerstört zu werden beginnen. the town must/can destroy.PART to AUX.PASS begin 'The town must/can/may begin to get destroyed.'

Third, while the unambiguous raising verbs do not passivize (29a), the ambiguous aspectual verb beginnen 'begin' can passivize, which can be an impersonal passive (29b) or a 'long passive', promotion of an embedded object to the matrix subject with the passive morpheme attached to the matrix verb $(29 \mathrm{c}) .{ }^{19}$
a. * Der Kaviar wurde zu essen gescheint/geschienen. the caviar AUX.PASS to eat seem.PART $a /$ seem.PART $_{b}$ 'It seemed that somebody ate the caviar.'
b. Es wurde begonnen den Wagen $\mathrm{zu}$ reparieren. it AUX.PASS begin.PART the. ACC car to repair 'They began to repair the car.' (impersonal passive)
c. Der Wagen wurde zu reparieren begonnen. the car AUX.PASS to repair begin.PART 'They began to repair the car.' (long passive)

Finally, an impersonal passive sentence with an ambiguous verb, as in (29b), can be embedded under a modal (30). However, in this particular environment, the ambiguous verb can only be interpreted as a control verb, as was the case with the 'disambiguated' instances of the ambiguous verbs, seen in (27) above.

19 The other two ambiguous verbs, versprechen 'promise' and drohen 'threaten' only allow impersonal passive. 
(30)

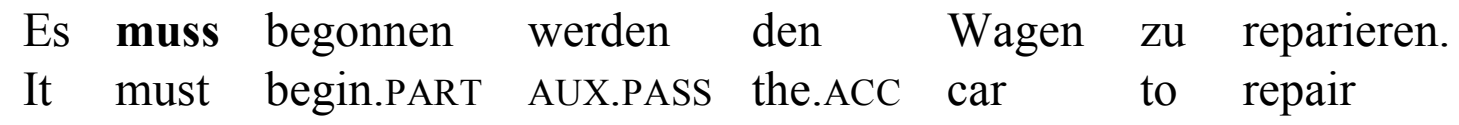

'They must begin to repair the car.'

Wurmbrand argues that all of the above observations show that control and raising verbs occupy two different structural positions, as illustrated in (25). The unambiguous raising verbs can embed a modal but cannot be embedded under a modal (26) because raising verbs occupy a position as high as or higher than where modals appear. When an ambiguous verb is embedded under a modal, as in (27), therefore, it can only be in the lower position, where it is interpreted as a control verb. Moreover, both the unambiguous raising verbs and the ambiguous verbs are expected to have embedded passive complement ((28a) and (28b)), since raising verbs occupy the position higher than $v \mathrm{P}$, where the passive morpheme is assumed to occupy. ${ }^{20}$ Yet once an ambiguous verb is embedded under a modal, as in (28c), it can only be in the lower position, where it is interpreted as a control verb. When an ambiguous verb is in the lower position, there is no $v \mathrm{P}$ projection below it. Thus, it follows that (28c) cannot allow an embedded passive. Moreover, the unambiguous raising verbs are above $v \mathrm{P}$, hence unable to passivize (29a). In contrast, the ambiguous verbs are below $v \mathrm{P}$; thus they are expected to passivize ((29b) and (29c)). Finally, since only an ambiguous verb in the lower position is expected to passivize, the 'passivized' ambiguous verbs are expected to embed under a modal as well (30).

On the other hand, if we were to maintain the assumption that control and raising verbs appear in the same position, i.e. the head of VP, the above observations would be problematic. One would have to assume, for instance, that these differences derive from differences in each verb's compatibility with modals and passives. However, such an approach would have to be quite complex, since, under such a scenario, the ambiguous verbs' compatibility with passive would have to change, depending on the presence/absence of a modal.

\subsection{Japanese (Fukuda 2006)}

Traditionally, Japanese aspectual verbs, such as hajime 'begin', tsuzuke 'continue', owar ' finish $_{1}$ ' and oe 'finish ${ }_{2}$ ', have been analyzed as control and raising verbs. Among these four aspectual verbs, owar 'finish' ${ }_{1}$ ' has been analyzed as an unambiguous raising verb, in contrast to oe 'finish ${ }_{2}$ ', which has been analyzed as an unambiguous control verb. The two other aspectual verbs,

20 Here I am assuming the $v \mathrm{P}$ analysis of passive (Kratzer 1994, 1996, Chomsky 1995), although Wurmbrand remains agnostic about the presence of $v \mathrm{P}$ in passive sentences (Wurmbrand 2000:fn 8). 
hajime 'begin' and tsuzuke 'continue', on the other hand, are analyzed as ambiguous. ${ }^{21}$

The analysis of $o e$ 'finish ${ }_{2}$ ' as a control verb has been motivated by sentences like (31) below, which suggest that only oe 'finish' ${ }_{2}$ ' selects its subject among the four aspectual verbs (Shibatani 1973:66).

$\begin{array}{llll}\text { Buranko-ga } & \text { yure } & \text {-hajime/tsuzuke/owar } / *^{*} \text { oe } & \text {-ta } \\ \text { Swing-NOM } & \text { swing } & \text {-begin//continue } / \text { finish }_{1} / \text { finish }_{2} & \text {-PERF } \\ \text { 'The swing began/continued/finished } & / \text { finished }_{2} \text { to swing/swinging.' }\end{array}$

On the other hand, the motivation for analyzing owar ' finish $_{1}$ ' as an unambiguous raising verb is more complicated, and it involves the aspectual verbs' differing behavior with respect to passive. Like the German ambiguous aspectual verb beginnen 'begin', three of the Japanese aspectual verbs, hajime 'begin', tsuzuke 'continue', and oe 'finish ${ }_{2}$ ' allow long passive.
a. Sono-shoosetsu $\mathrm{i}^{-} \mathrm{ga}\left[\begin{array}{lll}\mathrm{t}_{\mathrm{i}} & \mathrm{kaki} & \text { oe}\end{array}\right]$-rare-ta that-novel $\mathrm{i}_{\mathrm{i}}$-NOM $\quad\left[\mathrm{t}_{\mathrm{i}}\right.$ write finish $\left._{2}\right] \quad$-PASS-PERF 'That novel was finished to be written.'
b. Sono-shisutemu $\mathrm{i}_{\mathrm{i}}$-ga $\left[\mathrm{t}_{\mathrm{i}}\right.$ tsukai hajime $]$-rare-ta new-system ${ }_{\mathrm{i}}$-NOM $\quad\left[\mathrm{t}_{\mathrm{i}}\right.$ use begin $]$-PASS-PERF 'The system began to be recognized.'
c. Onaji-kyokasho ${ }_{\mathrm{i}}$-ga $\left[\mathrm{t}_{\mathrm{i}}\right.$ tsukai tsuzuke $]$-rare-ta same-textbook ${ }_{\mathrm{i}}$-NOM $\quad\left[\mathrm{t}_{\mathrm{i}}\right.$ use continue $]$-PASS-PERF 'The same text book continued to be used.'

While two of the three aspectual verbs that allow long passive, hajime 'begin' and tsuzuke 'continue', also allow an embedded passive ((33a) and (33b)), the embedded passive is ungrammatical with $o e$ ' finish $_{2}$ ' (33c) (Nishigauchi 1993).
a. Sono-chiryoho $\mathrm{i}_{\mathrm{i}}$-ga $\quad\left[\mathrm{t}_{\mathrm{i}}\right.$ mitome-rare $]$ that-treatment $\mathrm{i}_{\mathrm{i}} \mathrm{NOM} \quad\left[\mathrm{t}_{\mathrm{i}}\right.$ recognize-PASS $]$
hajime-ta 'That treatment began to be recognized.'
b. Onaji-kyokasho ${ }^{-}-g a \quad\left[t_{i}\right.$ tsukaw-are $]$ tsuzuke-ta same-textbook $_{\mathrm{i}}$-NOM $\quad\left[\mathrm{t}_{\mathrm{i}}\right.$ use-PASS $]$ continue-PERF 'The same text book continued to be used.'

21 In this discussion of Japanese aspectual verbs, I focus on four aspectual verbs, hajime 'begin', tsuzuke 'continue', owar 'finish', , and oe 'finish ${ }_{2}$ ', for a couple of reasons. First, they represent three of the basic aspectual distinctions: inception, continuation, and termination. Second, they have been discussed in several studies: (Shibatani 1973, 1978, Kuno 1987, Nishigauchi 1993, Kageyama 1993, 1999, Matsumoto 1996, Koizumi 1998, among others). 

c. * Sono-shoosestu-ga [ $\mathrm{t}_{\mathrm{i}}$ kak-are $]$ oe-ta that-novel-NOM $\quad\left[t_{i}\right.$ write-PASS $] \quad$ finish $_{2}$-PERF
'That novel finished being written.'

The fourth aspectual verb, owar ' finish $_{1}$ ', on the other hand, only allows an embedded passive (Shibatani 1978).

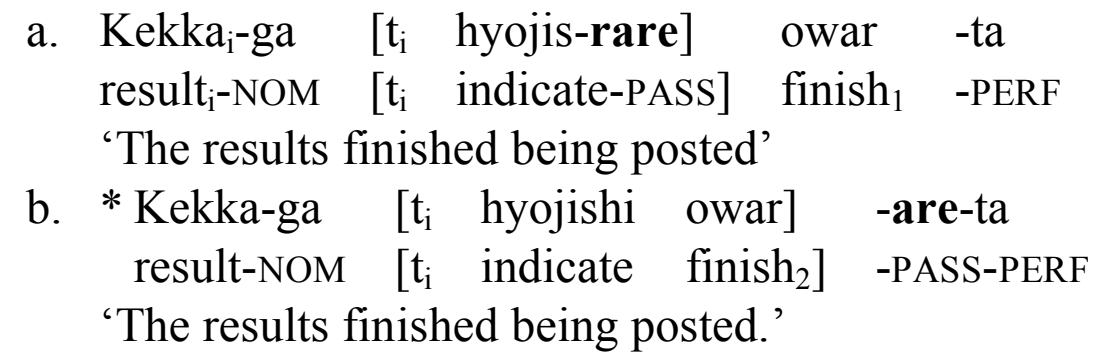

Thus, passivization patterns divide the four aspectual verbs into three groups: hajime 'begin' and tsuzuke 'continue' allow both the long and embedded passives, while oe 'finish' embedded passive, respectively.

Under traditional control/raising analyses of these aspectual verbs, these differences are accounted for by appealing directly to the definition of control and raising: while control verbs selects their external arguments, raising verbs do not. According to the control/raising analysis of the aspectual verbs, only if a given aspectual verb is a control verb, does it then have an external argument. Assuming that passive involves suppression of an external argument (Chomsky 1981), it follows that only control aspectual verbs would passivize. Therefore, the three aspectual verbs that passivize (i.e. allow the long passive), hajime 'begin', tsuzuke 'continue', and oe 'finish ${ }_{2}$ ', are control verbs at least in these instances, while the one that never passivizes, owar ' finish $_{1}$, is never a control verb and always a raising verb. Recall, however, that among the four aspectual verbs, only oe 'finish ${ }_{2}$ ' appears to impose selectional restrictions on its subject (30). The fact that both hajime 'begin' and tsuzuke 'continue' are compatible with an inanimate subject suggests that they can be raising verbs. Therefore, the selectional restrictions together with the passive facts led the previous studies to conclude that oe 'finish ${ }_{2}$ ' is the only unambiguous control verb, and owar 'finish ${ }_{1}$ ' is the only unambiguous raising verb, while hajime 'begin' and tsuzuke 'continue' are ambiguous.

However, the control/raising analysis outlined so far does not tell us why long passive is grammatical with the aspectual control verbs, since, under the PRO analysis of control, movement of an embedded object to the matrix subject position would incur a minimality violation (Rizzi 1991). In order to solve this problem, Kageyama $(1993,1999)$ proposes that the aspectual verbs subcategorize for either (i) a full complement with an embedded subject or (ii) a reduced complement without an embedded subject. Under this analysis, oe 'finish ${ }_{2}$ can 
only take a reduced complement. The combination of being a control verb and subcategorizing for a reduced complement accounts for the observations that oe ' finish $_{2}$ ' is compatible only with the long passive. If there is no embedded subject, then the long passive is unproblematic, while the embedded passive is impossible since there is no external argument for passive to suppress in the reduced complement. On the other hand, owar ' finish $_{1}$ ' is analyzed to take only a full complement. Thus, the embedded passive is expected to be grammatical. However, since it is a raising verb, the matrix passive (i.e. the long passive) is ungrammatical. Finally, the other two aspectual verbs, hajime 'begin' and tsuzuke 'continue', can be either control or raising and they can take either a full or reduced complement. Thus, they allow both the long and embedded passive.

Although the control/raising analysis with the full vs. reduced complement distinction proposed by Kageyama $(1993,1999)$ is quite successful, accounting for an impressive range of the data, it is problematic for two reasons. First, the control/raising distinction among aspectual verbs, which is crucial for the analysis, is not adequately motivated, as the typical diagnostics for control/ raising do not show the presumed control/raising distinction among Japanese aspectual verbs. Although Nishigauchi (1993) argues that differences in compatibility with idiomatic expressions motivate the control/raising distinction among the aspectual verbs, a closer examination of a wider range of data suggests that the pattern does not hold, as I have argued in Fukuda (2006). There are a handful of idiomatic expressions involving subjects, for example, that are compatible with hajime 'begin' and tsuzuke 'continue', but incompatible with owar 'finish', a presumed unambiguous raising verb.

$\begin{array}{lll}\text { a. Tonbi-ga } & \text { taka-o } & \text { um-u } \\ \text { kite-NOM } & \text { hawk-ACC } & \text { give.birth.to-IMP }\end{array}$

'A kite gives birth to a hawk.'

(A case of an ordinary parent producing a superior child.)

b. Tonbi-ga taka-o umi hajime/tsuzuke -ta kite-NOM hawk-ACC give.birth.to begin/continue -PERF 'A kite began/continue to give birth to hawks.'

c. Tonbi-ga taka-o umi *owar/*oe -ta kite-NOM hawk-ACC give.birth.to $*$ finish $_{1} / *^{*}$ finish $_{2}$-PERF 'A kite finish $\mathrm{H}_{1} / \mathrm{finish}_{2}$ giving birth to hawks.'

$$
\begin{aligned}
& \text { a. Rui-wa tomo-o yob -u } \\
& \text { kind-TOP friend-ACC call -IMP } \\
& \text { 'A kind calls for its friends.' } \approx \text { Birds of a feather flock together.) } \\
& \text { b. Rui-ga tomo-o yobi hajime/tsuzuke -ta } \\
& \text { kind-NOM friend-ACC call begin/continue -PERF } \\
& \text { 'A kind began/continued to call for its friends.' }
\end{aligned}
$$


c. Rui-ga tomo-o yobi *owar/*oe -ta kind-NOM friend-ACC call $*$ finish $_{1} / *$ finish $_{2} \quad$-PERF

'A kind finish ${ }_{1} /$ finish $_{2}$ calling for its friends.'

What these examples suggest is that the acceptability of idiomatic expressions with aspectual verbs is determined by their compatibility with certain aspectual specifications, i.e. completive aspect.

Another common diagnostic for the control/raising distinction is imperative formation, which has also been applied to Japanese aspectual verbs to argue for the control/raising distinction (Nishigauchi 1993). However, like idiomatic expressions, imperative formation also fails to motivate the control/raising distinction among Japanese aspectual verbs. As can seen in (37) below, a presumed raising aspectual verb owar 'finish' is just as compatible with imperative formation as a presumed control aspectual verb oe 'finish ${ }_{2}$ ' is (Shibatani 1973:78).
Asu-madeni yomi owar-e!/ oe-ro!
tomorrow-till read finish -IMP/ finish $_{2}$-IMP
'Finish reading (the book) by tomorrow!'

As it turns out, the diagnostic that has been used to motivate the control/raising analysis, the selectional restrictions on subjects, is not as a strong piece of evidence as has been assumed. As was shown earlier, oe 'finish' ${ }_{2}$ appears to be incompatible with an inanimate subject (31). However, as Nishigauchi (1993) points out, oe 'finish' also requires a particular type of an event as its complement.

a. Kodomo-ga aruki hajime/tsuzuke/owar/*oe -ta child-NOM walk begin/continue/finish $1 /$ finish $_{2} \quad$-PERF 'The child began/continued/finished $/$ finished $_{2}$ walking.'

b. Kodomo-tachi-ga sakamichi-o aruki oe-ta child-PL-NOM hill-ACC walk finish 2 -PERF 'The children finished walking (up) a hill.'

(38) shows that, regardless of the animacy of the subject, a sentence with oe 'finish ${ }_{2}$ ' is ungrammatical if its complement is an atelic event. Nishigauchi concludes from the contrast in (38) that oe 'finish ${ }_{2}$ ' requires an accomplishment event as its complement (Nishigauchi 1993:88). ${ }^{22,23}$ Nishigauchi's observation

22 The same observation was made for English finish by Dowty (1979).

23 Strictly speaking, a complement $o e$ ' finish $_{2}$ ' does not have to be an accomplishment. It only needs to compatible with being interpreted as an accomplishment. For instance, the VP in (i) by itself represents an activity, with a bare NP as its internal argument. However the VP gains an accomplishment interpretation with the presence of $o e$ ' finish $_{2}$ '. 
further casts doubt on the control/raising analysis of the aspectual verbs, as having an animate subject is not a sufficient condition for a sentence with oe ' finish $_{2}$ ' to be grammatical.

Our examination of data has revealed that none of the standard diagnostics for the control/raising distinction is able to motivate a contrast among the Japanese aspectual verbs. As an alternative analysis, I have elsewhere proposed that the aspectual verbs appear in two different positions in a clause, either above $v \mathrm{P}$, which I call high-aspect, or below $v \mathrm{P}$, which I call low-aspect (Fukuda 2006).

a. High-aspect

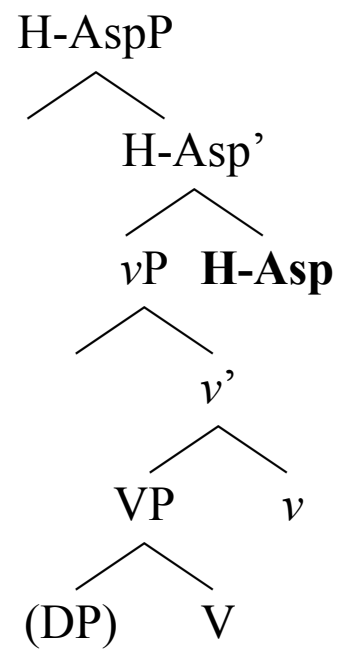

b. Low-aspect

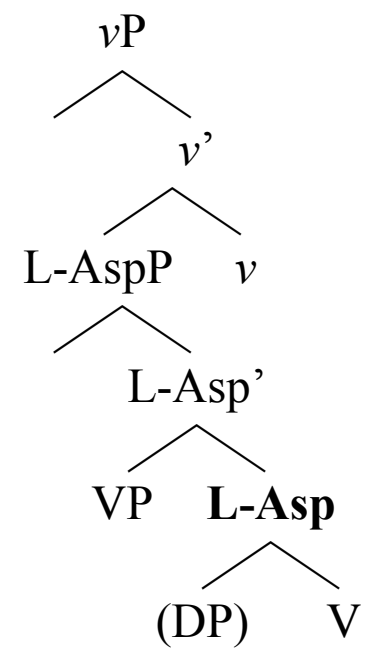

I have also argued that while some aspectual verbs are restricted to occur in only one of the two positions, others can only occur in either of the two positions. Specifically, while two of the aspectual verbs, hajime 'begin' and tsuzuk 'continue', can appear as either low- or high-aspect, oe 'finish ${ }_{2}$ ' can only appear as low-aspect and owar 'finish, 'can only appear as high-aspect.

Under this analysis, the passive facts presented earlier are consequences of the two positions for the aspectual verbs being higher and lower than $v$, where the passive morpheme is assumed to occupy. Since owar 'finish' appear as high-aspect, which is higher than $v$, its only option is the embedded passive (40a). In contrast, oe 'finish ${ }_{2}$ ' can only appear as low-aspect, which is lower than $v$. Thus, the long passive is the only option (40b).

\footnotetext{
(i) Ken-ga hon-o yomi oe -ta K-NOM book-ACC read finish 2 -PERF

'Ken finished reading the/a book(s).'
} 
(40)

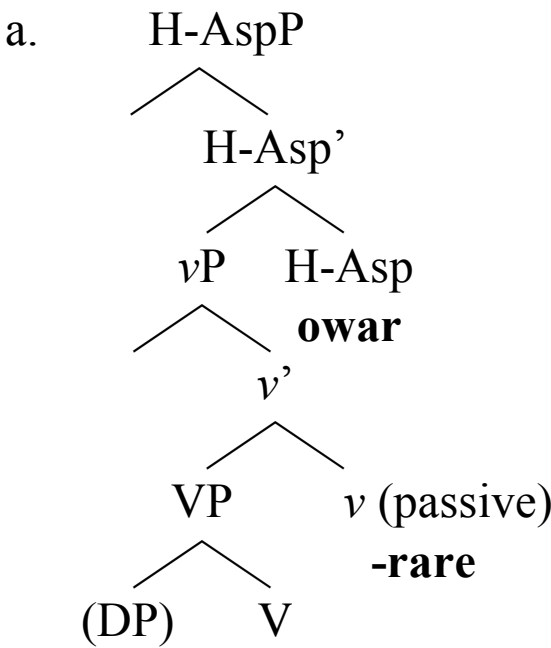

b.
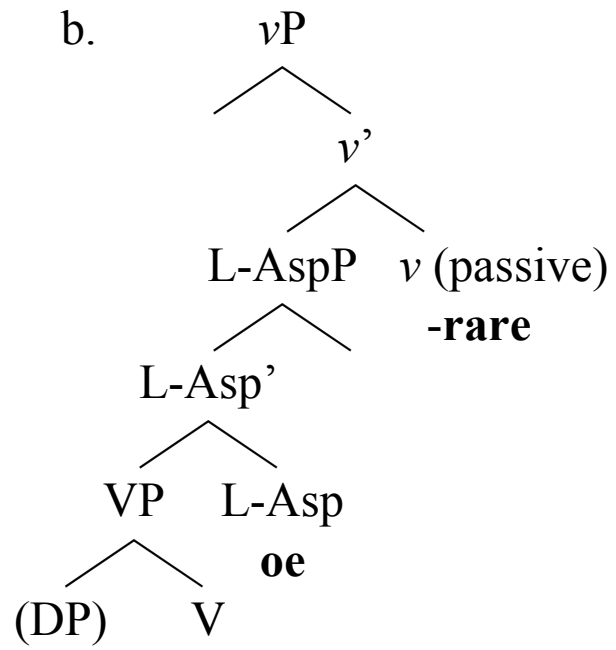

The two other aspectual verbs, hajime 'begin' and tsuzuk 'continue', on the other hand, can be realized as either low- or high-aspect, making them compatible with both the long and embedded passive.

Furthermore, the apparent differences among the aspectual verbs in the selectional restrictions of subjects can be analyzed as another consequence of the two structural positions for the aspectual verbs. When an aspectual verb appears as low-aspect, it is under the scope of an external argument. Thus, it is interpreted as control-like. In contrast, when an aspectual verb appears as highaspect, it takes scope over an entire $v \mathrm{P}$, and it is interpreted as raising-like. Under this account, oe 'finish 2 ' always generates the control-like interpretation, since it can only appear as low-aspect. On the other hand, owar 'finish' is always interpreted as a raising verb, since it can only appear as a high-aspect head. The other two verbs, hajime 'begin' and tsuzuke 'continue', can be interpreted as either control or raising, since they can appear in either of the two positions.

In sum, like the case of the control/raising ambiguity with German verbs, the control/raising ambiguity of Japanese aspectual verbs can also be analyzed to have a structural explanation. The control instances of the aspectual verbs occupy a position below an external argument, while the raising instances of the aspectual verbs occupy a position above an external argument.

However, there is at least one assumption in the analysis of Japanese aspectual verbs which needs to be further motivated. In the analysis that has been outlined above, it is crucial that oe 'finish' ${ }_{2}$ must occur in the lower position, while owar 'finish' ' must occur in the higher position, while other two aspectual verbs can occur in either of the two positions. As far as the Japanese data are concerned, it appears quite conveniently random. In the following section, I review evidence from Romance languages presented in Cinque (2003), which strongly suggests that aspectual verbs in Romance languages are also distributed between two positions, below and above vP. Crucially, Cinque 
suggests that the distribution of Romance aspectual verbs is based on the type of an event that they are predicated of, specifically, whether it is bounded or unbounded. I suggests that a similar approach can account for the distribution of Japanese aspectual verbs.

\subsection{Romance Languages (Cinque 2003)}

The analysis of Japanese aspectual verbs introduced in the previous section crucially relies on the assumption that some aspectual verbs only appear in a position lower than $v \mathrm{P}$ or only in a position higher than $v \mathrm{P}$, while others can appear in either of the two positions.

The data from Romance languages show that this pattern is not unique to Japanese aspectual verbs. Aissen \& Perlmutter (1983) note that long passive, one of the diagnostics that they use to identify clause-reduction (restructuring) triggering verbs in Spanish, can only be natural with a certain class of aspectual verbs. In other words, not all verbs that qualify as trigger verbs by other diagnostics, such as clitic climbing, allow long passive. Aissen \& Perlmutter characterize this class of aspectual verbs as ones that specify 'an end point of an action', such as terminar 'finish' and acabar (de) 'finish' (ibid: 392). The following (41) exemplifies the contrast:

a. Estas paredes están terminados de pintar.
these walls are finished to paint
'These walls are being finished to paint.'
b. * Estas paredes fueron tratadas de pintar.
these walls were tried, to paint
'These walls were tried to paint.'

Although Aissen \& Perlmutter speculate that this may be a language-peculiar restriction unique to Spanish, Cinque (2003) shows that a similar contrast is observed with other Romance languages, such as Italian, Portuguese, and Catalan. According to Cinque, in Italian, the aspectual verbs such as begin, continue, and finish allow long passive, while other restructuring verbs such as want, try and modals do not. In Portuguese, finish, begin, and send allow long passive, but not other aspectual verbs, such as continue, or any other restructuring verbs. Likewise, in Catalan, begin and finish allow long passive, but not other aspectual verbs (Cinque 2003:50-54). Given the data from four Romance languages, Cinque claims that the fact that 'finish' is always in the list of aspectual verbs that allow long passive is consistent with his theory of functional projection (Cinque 1999) which places the completive aspect projects 
lower than Voice, where passive morpheme occupies. ${ }^{24}$ However, the fact that begin, which denotes inception, also allows long passive in all four Romance languages is unexpected, since the inceptive aspect projects higher than Voice in the languages that Cinque studied.

In order to account for the distribution of the Romance aspectual verbs with respect to long passive, Cinque suggests that aspectual verbs be distributed between two regions, below and above Voice, depending on whether they are predicated of an unbounded event or a bounded event. ${ }^{25}$ The former group of aspectual verbs is projected above the projection of Voice, while the latter group of aspectual verbs is projected below Voice. Thus, only the aspectual verbs that belong to the latter group allow long passive. Cinque presents the following contrast to support his proposal (Cinque 2003:56).
a. Furono iniziate a construire solo due case were started to build only two house
'Only two houses started to be built.'
b. *Furono iniziate a coustruire case were started to build house 'Houses started to be built.'

The aspectual verb initiare 'start' allows long passive with a quantified object, which makes an event of building bounded, but not with a bare DP object, which makes an event of building unbounded.

Cinque's distribution of Romance aspectual verbs into two positions is reminiscent of the distribution of Japanese aspectual verbs. Recall that with the Japanese aspectual verbs, the only aspectual verb that must occur in the lower position, oe 'finish ${ }_{2}$ ', is the one that requires an accomplishment event or a bounded event (38). On the other hand, the aspectual verb that must occur in the higher position, owar 'finish', also denotes completion, but of an unbounded event, i.e. activity. I suggest that a classification of aspectual verbs which is similar to what Cinque suggests for Romance languages would account for the distribution of Japanese aspectual verbs between the two positions. The aspectual verbs that are predicated of an unbounded event occur in the higher position ( owar 'finish ${ }_{1}$ '), while the aspectual verbs that are predicated of a bounded event occur in the lower position ( oe 'finish ${ }_{2}$ '). If a single aspectual verb serves both functions, it is expected to occupy both positions (hajime 'begin' and tsuzuke 'continue').

24 In Cinque's analysis, only aspectual verbs that are generated below Voice passivize, since they can rise to Voice and acquire the passive morphology. In contrast, ones that are generated above Voice cannot bear the passive morphology, since they cannot lower to do so (Cinque 2002:55).

25 Cinque credits the idea to Paola Binnincà (p.c.). 
In sum, the evidence from Japanese and from Romance languages suggests that aspectual verbs are distributed between these two positions based on their meaning. While the aspectual verbs that denote inception/continuation/termination of an unbounded event appear in the position higher than $v \mathrm{P}$, the aspectual verbs that denote inception/continuation/completion of a bounded event appear in the position lower than $v \mathrm{P}$. In the following section, I examine evidence from yet another language, Basque, which provides an argument for two structural positions for aspectual verbs from a very different mechanism: agreement.

\subsection{Basque (Arregi \& Molina-Azaola 2004)}

Basque offers support for the proposed analysis of aspectual verbs, for a very different reason from the evidence presented so far. Arregi \& Molina-Azaola (2004) discuss two aspectual verbs, hasi 'begin' and amaitu 'finish', which show different agreement patterns. While both aspectual verbs are analyzed as restructuring verbs, since the matrix auxiliary can agree with embedded arguments with both of these verbs ${ }^{26}$, only amaitu 'finish' allows the matrix auxiliary to agree with both the embedded dative and absolutive argument (43a). As can be seen in (43b) and (43c), hasi 'begin' allows the matrix auxiliary to agree only with the embedded dative argument.

a. Ber he.ERG [You.DAT babak

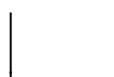

beans

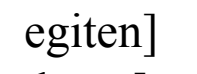

amaitu dautsuz

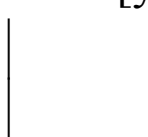

'He finished cooking the beans for you.'

b. Bera [zuri babak egiten] hasi jatzu he.ABS [you.DAT beans.ABS do.NF] began $\mathrm{AGR}_{\mathrm{D}} \mathrm{AGR}_{\mathrm{A}}$

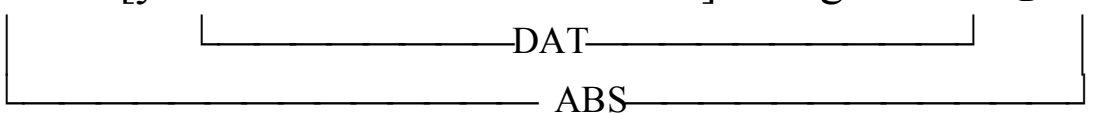

'He began cooking the beans for you.'

c.

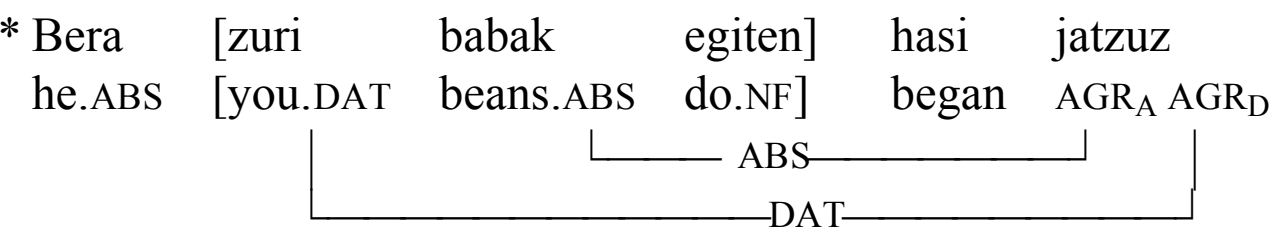

'He began cooking the beans for you.'

26 It is not clear whether these verbs are control or raising. From what I have found in the literature, however, these aspectual verbs appear to be closer, in their structural characteristics, to the verbs that are considered as control, than to the verbs that are considered as raising, as raising verbs in Basque generally require finite complements (Hualde \& de Urbina 2003:653-56). 
Arregi \& Molina-Azaola (henceforth A\&M) attempt to associate the difference in agreement patterns and the fact that these two aspectual verbs have different case on their subjects. As can be seen above, amaitu 'finish' has an ergative subject (43a), while hasi 'begin' has an absolutive subject (43b). Descriptively, therefore, it appears that the matrix auxiliary cannot agree with an embedded argument with a particular case, if it has already formed an agreement relation with a matrix argument of the same case. In (43c), the matrix auxiliary cannot form an agreement relation with the embedded absolutive argument, since it is already in an agreement relation with the matrix absolutive subject. Based on this observation, A\&M hypothesize that locality in agreement is relativized to case (A\&M 2004:108).

In order to account for the different agreement patterns of the two aspectual verbs, A\&M propose that these two aspectual verbs are functional heads that assign absolutive case, which occupy two different positions in a clause. Specifically, A\&M argue that while amaitu 'finish' occupies the position immediately below $v \mathrm{P}$, hasi 'begin' occupies the position immediately above $v \mathrm{P}$ (A\&M 2004:109).

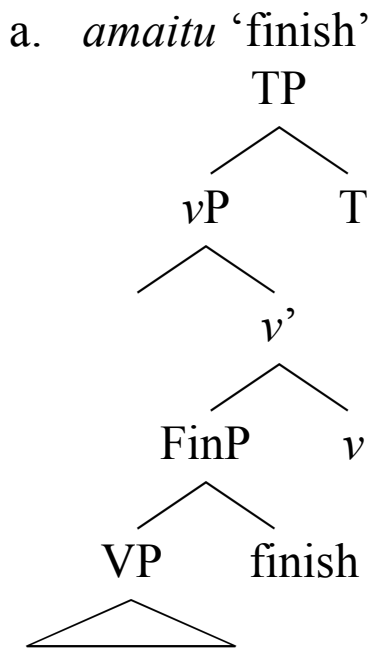

b. hasi 'begin'

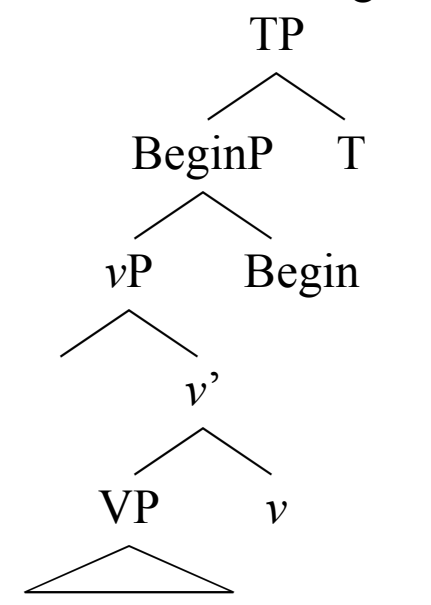

Their analysis accounts for the two agreement patterns as follows. One of the aspectual verbs, amaitu 'finish' provides absolutive case to the embedded verb's direct object, since it is closer to the direct object than $v$, the other functional head which potentially assigns absolutive case (45a). In contrast, with hasi 'begin', $v$ is closer to the direct object. Thus, it is $v$ that provides absolutive case to the direct object, and hasi 'begin' ends up providing its absolutive case to the subject. ${ }^{27}$ This accounts for the observation that only with hasi 'begin', is the subject marked with absolutive (45b).

27 In both configurations, A\&M assume that Applicative head is responsible for assigning dative case to the indirect object. 

a. [[ ${ }_{\mathrm{P}}$ Berak [fin [zuri babak Appl egiten] amaitu] $\left.v\right] \mathrm{T}$ [[he.ERG [ [you.DAT beans.ABS APPL do.NF] finish] $v$ ] T DAT-

'He finished cooking the beans for you.'

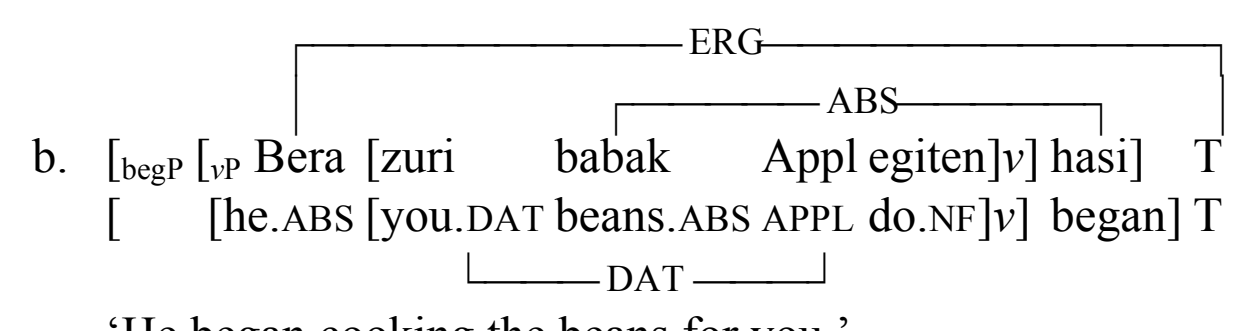

'He began cooking the beans for you.'

Assuming the relativized locality of agreement that they propose, this case assignment configuration accounts for the ungrammaticality of the long distance absolutive agreement with hasi 'begin' in (43c). With amaitu 'finish', the matrix $\mathrm{T}$ can agree with three arguments, the matrix ergative, the embedded dative, and the embedded absolutive, as seen in (43a), since there are no two arguments that bear the same case in this configuration. In contrast, with hasi 'begin', long distance agreement between the matrix $\mathrm{T}$ and the embedded absolutive argument is blocked by the matrix subject, which also bears absolutive case and is structurally higher than the embedded absolutive argument.

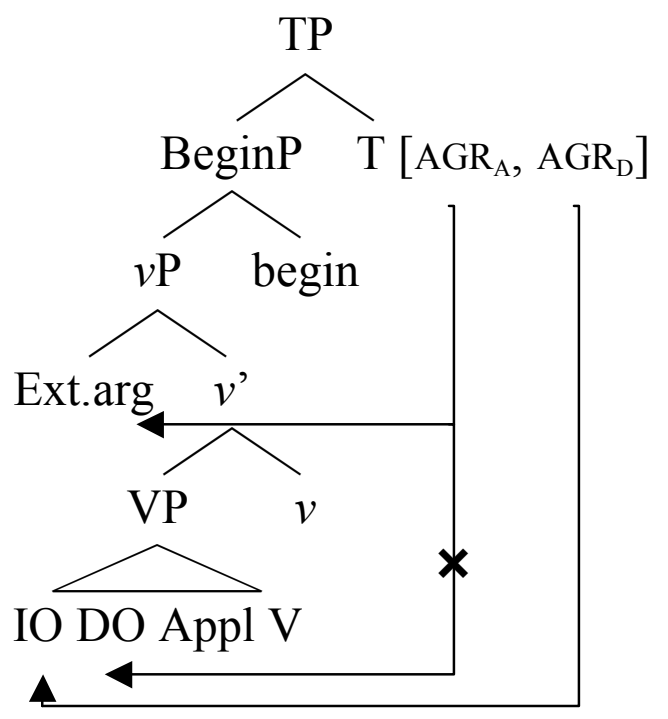

What is interesting about A\&M's analysis of Basque aspectual verbs for our purposes is that they reach a very similar conclusion to ours with Japanese aspectual verbs and Romance aspectual verbs about the syntactic positions of certain aspectual verbs. There are two positions for aspectual verbs, immediately below and above $v \mathrm{P}$, with 'finish' occupying the lower position and 'begin', the higher position. Importantly, their conclusion is reached based on a very 
different set of data concerning a very different mechanism of grammar than what we have examined, namely, agreement.

\subsection{Summary}

I have reviewed evidence from German, Japanese, Romance languages, and Basque, all of which suggest that aspectual verbs can occupy two different positions in a clause. This finding strongly suggests that the control/raising ambiguity observed with aspectual verbs cross-linguistically should be analyzed as a structural ambiguity.

In the spirit of the structural ambiguity hypothesis, I have proposed that the ambiguity derives from two positions of aspectual verbs and their structural height with respect to $\nu \mathrm{P}$, where an external argument is introduced. The aspectual verbs that appear below $v \mathrm{P}$ are under the scope of an external argument. Therefore, they are interpreted to be under control of the external argument. On the other hand, aspectual verbs that occur above $v \mathrm{P}$ take scope over an entire $v \mathrm{P}$ including the external argument. Therefore, they are interpreted as raising.

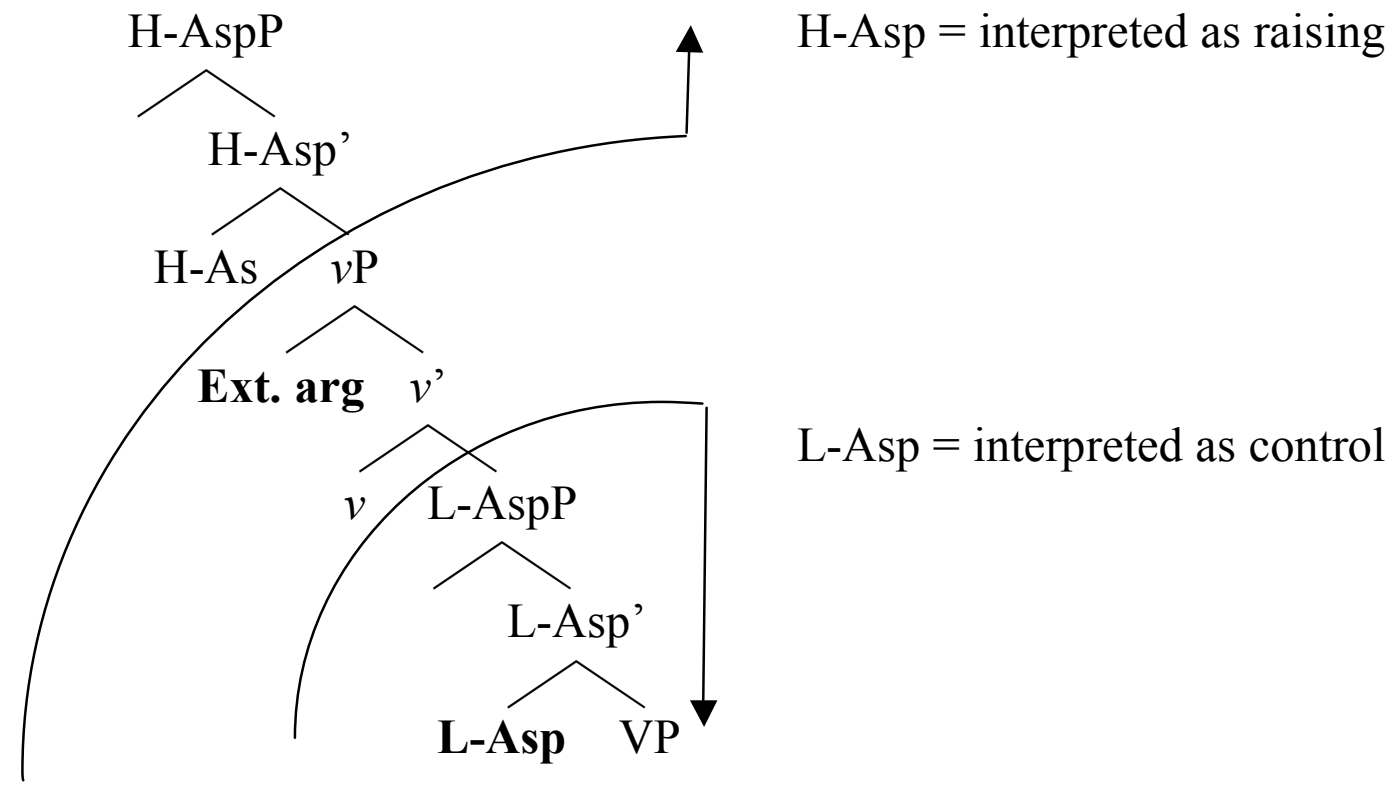

The evidence reviewed also suggests that aspectual verbs appear to be distributed between these two positions based on their meaning. In particular, while aspectual verbs that are predicated of an unbounded event appear in the higher position, the aspectual verbs that are predicated of a bounded event appear in the lower position.

In the rest of this paper, I extend the scope of this study and examine another type of verb that also shows the control/raising ambiguity: want-type verbs. In particular, I examine the want-type verbs in Indonesian discussed in Polinsky \& Potsdam (2006), which allow two distinctive interpretations under certain 
conditions. It is shown that the proposed analysis is able to offer a structural account for the two interpretations, based on Polinsky \& Potsdam's analysis of the semantics of these verbs, rendering unnecessary an assumption that these verbs are lexically ambiguous between control and raising.

\section{Want-type verbs in Indonesian}

In this final section, I examine data concerning the want-type verbs in Indonesian discussed by Polinsky \& Potsdam (2006). Polinsky \& Potsdam (henceforth $\mathrm{P} \& \mathrm{P}$ ) show that, when want-type verbs in Indonesian have a passive complement, they allow an unusual reading, in which the object of by-phrase is interpreted as the wanter, in addition to the expected reading, in which the subject is interpreted as the wanter. $\mathrm{P} \& \mathrm{P}$ argue that the want-verbs are raising verbs which can occupy the position that is otherwise occupied by an auxiliary verb, allowing the unusual interpretation. Although they assume that the control counterparts of the same verbs are responsible for the expected interpretation, I argue that we can maintain a single lexical entry for the want-verbs, following P\&P's analysis, and account for the expected reading, if we assume that the want-type verbs can appear two different positions, below or above $v \mathrm{P}$, just as aspectual verbs do.

\subsection{Two verbs ' $w a n t$ '?}

$\mathrm{P} \& \mathrm{P}$ show that two verbs that mean want in Indonesian, mau and ingin, show an interesting interpretational difference depending on whether their complement is active or passive. When the complement is active, it can only yield a control reading, in which the matrix subject that child is interpreted as the subject of the embedded predicate, kiss (48a). When the complement is passive, however, there are two interpretations available. One is the control reading just like the active case (48b-i), but the other is what P \& $\mathrm{P}$ call 'crossed interpretation', where the matrix subject is interpreted as the theme of the embedded verb while the passive agent is interpreted as the 'wanter' (48b-ii).

(48) a. anak itu mau/ingin men-cium ibu

child that want ACT-kiss mother

'That child wants to kiss the mother.'

b. anak itu mau/ingin di-cium oleh ibu

child that want PASs-kiss by mother

i) 'That child wants to be kissed by the mother.'

ii) 'The mother wants to kiss the child.'

Despite the puzzling reading (ii) with (48b), P\&P show that the pre-verbal DP anak itu 'that child' in (48b) has all the right characteristics of subjects in 
Indonesian, and the post-verbal 'by-phrase', oleh ibu 'by mother', has the characteristics consistent with a passive agent. Therefore, (48b) appears to have the syntactic structure of an ordinary embedded passive.

In order to account for the peculiar interpretation available for (48b), P \& P propose an analysis in which the want-type verbs in Indonesian are ambiguous between control and raising. They are control verbs in (48a), but raising verbs in (48b). P\&P present a number of arguments for claiming that the want-type verbs are different from the canonical control verbs, such as coba 'try'. Issues that are immediately relevant to our discussion are (i) that the want-type verbs with passive complement do not co-occur with auxiliaries (49) and (ii) that the wanttype verbs with passive complements cannot have a complementizer (50).
a. *Mereka sempat/bias/perlu/boleh mau di-tolong they have the opportunity/can/must/may want PASs-help
'Ali has a chance/can/must/may want to help them.'

b. Renta boleh (men)-coba musak

Renta may ACT-try enter

'Renta may try to enter.'

(50) a. Bagian kalimat ini mau (*untuk) di-tegaskan-nya section sentence this want (COMP) PASS-emphasize-3SG

'He wants to emphasize this part of the sentence.'

b. Rachman ingin (untuk) pergi

Rachman want (COMP) go

'Rachman wants to go.' (Vamarasi 1999:151)

The implication of (49) is rather clear given the earlier discussion of the ambiguous verbs in German: Just like the case with German raising verbs, the Indonesian want-type verbs' incompatibility with auxiliaries suggest that they are structurally as high as or higher than auxiliaries. In contrast, the position of the unambiguous control verb coba 'try' is lower than that of auxiliaries.

The implication of (50) has to do with a cross-linguistically attested pattern that, when a verb is ambiguous between control and raising, it is the control counterpart that is compatible with a complementizer, if a complementizer can occur at all (Kayne 1981, Landau 2003). Landau (2003) shows the following contrast from Hebrew (Landau 2003:488).
a. Rina xadla (me-) le' acben et Gil Rina stopped (COMP) to irritate ACC Gil 'Rina stopped irritating Gil.'
b. *Ha-muzika ha-ro'ešet xadla (*me-) le' acben et Gil the-music the-noisy stopped (*COMP) to irritate ACC Gil 'The loud music stopped irritating Gil.'


Landau notes that Kayne (1981) also shows a similar contrast with Italian verbs sembrare 'seem' and parere 'appear' with raising (52a) and dative control (52b) counterparts (Kayne 1981:352).

$$
\begin{aligned}
& \text { a. Gianni sembra/pare }(* \text { di) essere } \\
& \text { Gianni seems/appears (COMP) be } \\
& \text { 'Gianni appears/seems to have left.' }
\end{aligned}
$$
b. Mi sembra/pare di
aver capito
me seems/appears (COMP) have understand
'It seems/appears to me that I have understood.'

Based on these observations and others that also differentiate the want-type verbs from the canonical control verbs, ${ }^{28} \mathrm{P} \& \mathrm{P}$ propose that, when they allow the ambiguity, the want-types verbs are raising verbs, which occupy the position where an auxiliary verb occurs.

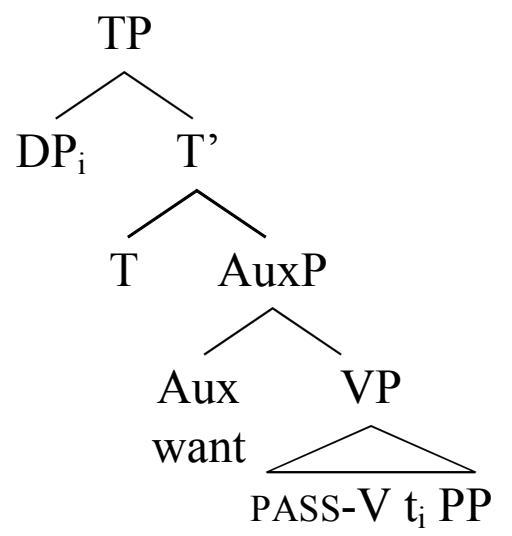

As for the unusual interpretation that these verbs allow, in which the object of the by-phrase is interpreted as the wanter (48b-ii), P\&P argue that it derives from the semantics of the want-verbs. They argue that the want-type verbs ascribe the wanter role to an agent, regardless of its syntactic position, as in the way that subject-oriented adverbs have been argued to ascribe a particular semantic property to an agent, even when an agent is not the subject, i.e. the object of a by-phrase, as in (54) below. ${ }^{29}$

(54) Madonna was willingly interviewed by Barbara.

(i) Madonna was the willing interviewee.

(ii) Barbara was the willing interviewer.

On the other hand, they assume that the expected reading, in which the surface subject is interpreted as the wanter ((48b-i)), obtains when the control want

28 According to P\&P, the want-type verbs do not (i) passivize, (ii) form an imperative, and (iii) embed under a control complement. They also do not allow (iv) independent temporal specification for their complements and (v) their complements to be fronted.

29 Cinque (2004) independently reaches a similar conclusion in his analysis of the restructuring verbs in Italian, which include the Italian counterpart of want. 
occupies the same position. Yet the question is whether we have to assume that there are control want-type verbs in Indonesian, which $\mathrm{P} \& \mathrm{P}$ assume to exist. In what follows, I argue that we do not have to assume that there are control counterparts of the want-type verbs in Indonesian, if we extend the proposed analysis of aspectual verbs to the case of the want-type verbs in Indonesian.

\subsection{A structural ambiguity analysis of the want-type verbs}

Two assumptions must be made in order to account for the availability of the two interpretations with the want-type verbs with a single lexical entry. First, I assume that the semantics of the want-type verbs proposed by P\&P must allow both the unusual reading and the expected reading. In fact, if the want-type verbs are indeed like subject-oriented adverbs in their semantics, as P\&P claim, then this must be the case, since subject-oriented adverbs do allow both the structural subject and the semantic agent to be ascribed the relevant property, as seen in (51i) and (51ii) above. Thus, we need only one lexical entry of the wanttype verbs to derive the two interpretations. Second, I assume that sentences with a want-type verb are always mono-clausal, and a want-type verb may occur either below or above $v \mathrm{P}$, following the proposed analysis of aspectual verbs.

Now, one interesting fact about the ambiguity with the Indonesian want-type verbs is that a passive complement seems to make the unusual interpretation available. The same verb is unambiguously interpreted to have the expected control reading, when it does not involve a passive complement. I argue that the two assumptions outlined above can give an account for this fact. Let us first consider the cases of active sentences with a want-type verb, in which a wanttype verb is below $v \mathrm{P}$, as in (52). ${ }^{30}$

30 Here, I tentatively assume that the position of want is below $v$ in (52). However, since want cannot be preceded by men(g)-, which has been analyzed to be the active voice marker, or $d i$, the presumed passive marker, one may also assume that want may occupy the position of $v$.

(i) * Saya meng-ingin orang ini

I ACT-want person this

'I want this person' (Vamarasi 1999: 147) 
$(55)$

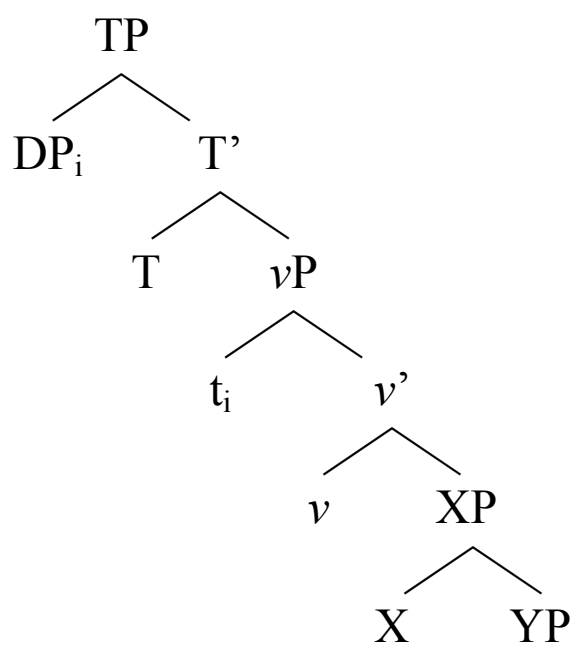

want

In this syntactic environment, the DP which ends up occupying [Spec, TP] is also the agent. Thus, only the subject can be ascribed the wanter role. However, with a passive complement, the want-type verb must be above $v \mathrm{P}$, if we assume that the passive prefix $d i$ - in Indonesian occupies the head of $v$, as in (56).

(56)

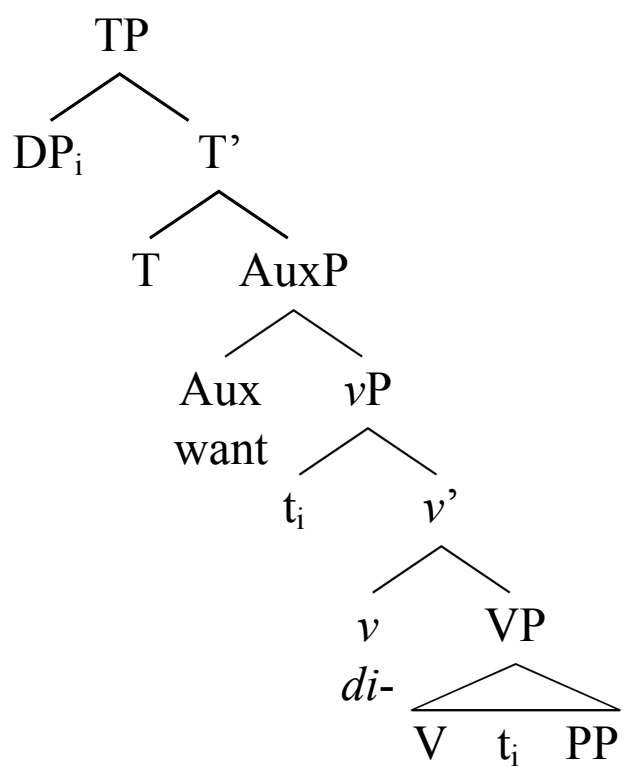

Notice that in (56), the external argument is base-generated below the want-type verb. In this base-generated configuration, the wanter role can be ascribed to the object of the by-phrase in the manner which $\mathrm{P} \& \mathrm{P}$ outline, creating the unusual interpretation. On the other hand, once the external argument moves up and occupies [Spec, TP], the subject position is filled, and the expected reading, in which the subject is the wanter, obtains. Thus, under the proposed structural ambiguity analysis, the two interpretations are made available via reconstruction. Importantly, under this analysis, we do not have to assume that the want-type verbs are also control verbs. 


\section{Conclusion}

In this study, I have argued that the control/raising ambiguity with aspectual verbs should be analyzed as a structural ambiguity, rather than a lexical ambiguity. I presented evidence from studies of aspectual verbs in four languages from four distinct families, German (Wurmbrand 2001), Japanese (Fukuda 2006), Romance languages (Cinque 2003), and Basque (Arregi \& Molina-Azaola 2004), all of which shows that aspectual verbs occur two different positions in a clause. Our evidence also shows that the crucial projection is $v \mathrm{P}$, where an external argument is introduced in a clause. When an aspectual verb occupies a position above $v \mathrm{P}$, it takes scope over an external argument and thus is interpreted as raising-like. When the same aspectual verb appears in a position below $v \mathrm{P}$, it is under the scope of an external argument and thus is interpreted as control-like. I have also extended the proposed analysis to the case of want-type verbs in Indonesian. I have argued that the proposed analysis accounts for the two interpretations available with the want-type verbs, without assuming that these verbs are lexically ambiguous between control and raising.

Our findings strongly suggest that the control/raising analysis may not be the best analysis for aspectual verbs. Rather, they should be analyzed to have their own places in the phrase structure, just like tense is assumed to have. As such, the proposed analysis shares its insight with studies that argue syntactic projections of aspect, such as Travis (1991), Borer (1994), Ramchand (1997), as well as Cinque $(1999,2003,2004)$. Moreover, the extension of the proposed analysis to account for the case of want-type verbs in Indonesian suggests that a structural account, such as one outlined in this study, may be suitable to other classes of verbs which have also been analyzed to be ambiguous between control and raising. ${ }^{31}$ In fact, one may wonder, given the findings presented in this study, if there is a true instance of lexical ambiguity between control and raising.

31 Once again, I leave the question of exactly where want-type verbs can occupy for future research. Relevant discussions can be found in the recent literature on restructuring verbs, as there have been debates over whether restructuring verbs are always functional (Cinque 2004) or can also be lexical (Wurmbrand 2004). 


\section{Abbreviations}

\begin{tabular}{ll|ll} 
ABS & absolutive & ERG & ergative \\
ACC & accusative & IMP & imperative \\
ACT & active & NF & nonfinite \\
$\mathrm{AGR}_{\mathrm{A}}$ & absolutive agreement & NOM & nominative \\
$\mathrm{AGR}_{\mathrm{D}}$ & dative agreement & PART & participle \\
$\mathrm{AGR}_{\mathrm{E}}$ & ergative agreement & PASS & passive \\
APPL & applicative & PERF & perfective \\
AUX & auxiliary & PL & plural \\
COMP & complementizer & SG & singular \\
DAT & dative & &
\end{tabular}

\section{References}

Aissen, J. \& D. Perlmutter. (1983). Clause reduction in Spanish. In: D. Perlmutter (ed.), Studies in Relational Grammar 1. Chicago: The University of Chicago Press, 360-403.

Alexiadou, A. \& E. Anagnostopoulou. (1999). Raising without infinitive and the nature of agreement. WCCFL 18, 14-26.

Arregi, K. \& G. Molina-Azaola. (2004). Restructuring in Basque and the theory of agreement. WCCFL 23, 101-114.

Borer, H. (1994). The projection of arguments. In: E. Benedicto \& J. Runner (eds.), Functional projections: university of Massachusetts occasional papers 17, 19-48.

Boecks, C. \& N. Hornstein. (2003). Reply to "Control Is Not Movement". Linguistic Inquiry $34,269-280$.

Bresnan, J. (2001). Lexical-Functional Syntax. Oxford: Blackwell.

Burzio, L. (1986). Italian Syntax. Dordrecht: Reidel.

Butler, J. (2003). A minimalist treatment of modality. Lingua 113, 967-96.

Chomsky, N. (1995). The Minimalist Program. Cambridge, Mass: MIT Press.

Chomsky, N. (2000). Minimalist inquiries: the framework. In: R. Martin, D. Michaels, J. Uriagereka (eds.), Step by Step: Essays on Minimalist Syntax in Honor of Howard Lasnik. Cambridge, Mass: MIT Press, 89-155..

Chomsky N. (2001). Derivation by phrase. In: M. Kenstowicz (ed.), Ken Hale: Life in Language. Cambridge, Mass: MIT Press, 1-52..

Chomsky, N. \& H. Lasnik. (1993). The Theory of Principle and Parameters. In: J. Jacobs, A. von Stechow, \& W. Sternfeld (eds.), Syntax: an international handbook of contemporary research. Berlin: Walter de Gruyter, 506-69.

Cinque, G. (1999). Adverbs and Functional Heads: a cross-linguistic perspective. Oxford: Oxford University Press.

Cinque, G. (2003). The interaction of passive, causative, and 'restructuring' in Romance. In: C. Tortora (ed.), The Syntax of Italian Dialects. Oxford: Oxford University Press.

Cinque, G. (2004). "Restructuring" and functional structure. In: A. Belletti (ed.), Structures and Beyond. The Cartography of Syntactic Structures, vol. 3. Oxford: Oxford University Press, 132-191. 
Culicover, P. \& R, Jackendoff. (2001). Control is not movement. Linguistic Inquiry 32, 493512.

Davies, W. D. \& S. Dubinsky. (2003). Raising (and Control). state-of-article. Glow International 7.

Den Dikken, M., R. Larson \& P. Ludlow. (1996). Internal 'transitive' verbs and concealed complement clauses. Rivista di Linguistica 8.2., 331-348.

Dowty, D. (1979). Word Meaning and Montague Grammar. London: Reidel

Falk, Y. N. (2001). Lexical-Functional Grammar: an Introduction to Parallel ConstraintBased Syntax. Stanford: CSLI.

Fukuda, S. (2006). The syntax of Japanese aspectual verbs. A paper presented at $3^{\text {rd }}$ Workshop on Altaic in Formal Linguistics.

Hornstein, N. (1999). Movement and control. Linguistic Inquiry 30, 69-96.

Hornstein, N. (2003). On control. In R. Hendrick (ed.), Minimalism Syntax. Oxford: Blackwell, 6-81.

Hualde, J. I. \& J. O. de Urbina. (2003). A Grammar of Basque. Berlin: Mouton de Gruyter.

Jackendoff, R. \& P. Culicover. (2003). The semantic basis of control in English. Language 79, 517-556.

Kageyama, T. (1993). Bumpo to gokeisei [Grammar and word formation], Tokyo: Hitsuji shoboo.

Kageyama, T. (1999). Word formation. In N. Tsujimura (ed.), The Handbook of Japanese Linguistics. Oxford: Blackwell, 297-325.

Kayne, R. S. (1980). On certain differences between French and English. Linguistic Inquiry 12, 349-72.

Koizumi, M. (1998). Invisible agree in Japanese. The Linguistic Review 15, 1-39.

Kratzer, A. (1994). On external arguments. In E. Benedicto \& J. Runner (eds.), Functional Projections: University of Massachusetts Occasional Papers 17, 103-130.

Kratzer, A. (1996). Severing the external argument from the verb. In J. Rooryck and L. Zaring (eds.), Phrase Structure and the Lexicon, Dordrecht: Kluwer.

Kuno, S. (1987). Honorific marking in Japanese and the word formation hypothesis of causatives and passives. Studies in Language 11.1, 99-128.

Lamiroy, B. (1987). The complementation of aspectual verbs in French. Language 63, 27898.

Landau, I. (2000). Elements of Control: Structure and Meaning in Infinitival Constructions. Dordrecht: Kluwer.

Landau, I. (2003). Movement out of control. Linguistic Inquiry 34, 471-498.

Landau. I. (2004). The scale of finiteness and the calculus of control. Natural Language and Linguistic Theory 22, 811-77.

Martin, R. (2001). Null case and the distribution of PRO. Linguistic Inquiry 32, 141-166.

Matsumoto, Y. (1996). Complex predicates in Japanese: a syntactic and semantic study of the notion 'word', Tokyo and Stanford: Kuroshio and CSLI

Moore, J. (1996). Reduced Constructions in Spanish. New York: Garland.

Newmeyer, F. J. (1975). English Aspectual Verbs. Paris: Mouton.

Nishigauchi, T. (1993). Long distance passive. In N. Hasegawa (ed.), Japanese Syntax in Comparative Grammar. Tokyo: Kuroshio, 79-114.

O'Neil, J. (1995). Out of control. NELS 25, 361-71. 
Perlmutter, D. (1968). Deep and Surface Structure Constraints in Syntax. PhD. Dissertation. MIT.

Perlmutter, D. (1970). The two verbs begin. In Jacobs \& P. Rosenbaum (eds.), Readings in English Transformational Grammar. Walthem, Mass: Blaisdell Publishing Company, 107-19.

Polinsky, M. \& E. Potsdam. (2006). The syntax and semantics of wanting in Indonesian. A paper presented at $10^{\text {th }}$ International Symposia on Malay/Indonesian Linguistics.

Polinsky, M. \& E. Potsdam. (2006). Expending the scope of control and raising. Syntax 9.2, 171-192.

Pollard, C. \& I. A. Sag (1994). Head-driven Phrase Structure Grammar. Chicago: The University of Chicago Press.

Pylkäanen, L. \& B. McElree. (to appear). The syntax-semantics interface: On-line composition of sentence meaning. In: M. Traxler \& M.A. Gensbacher (eds.), Handbook of Psycholinguistics. New York: Elsevier.

Ramchand, G. C. (1997). Aspect and predication: the semantics of argument Structure. Oxford: Clarendon Press.

Rizzi, L. (1982). A Restructuring Rule. Issues in Italian Syntax. Dordrecht: Foris.

Rizzi, L. (1991). Relativized Minimality. Cambridge, Mass.: MIT Press.

Rochette, A. (1999). The selection properties of aspectual verbs. In Johnson, K. \& I. Roberts (eds.), Beyond Principles and Parameters: essays in memory of Osvaldo Jaeggli. Dordrecht: Kluwer.

Ruwet, N. (1991). Syntax and Human Experience. Chicago: The University of Chicago Press.

Sag, I. A. \& T. Wasow. (1999). Syntactic Theory: a Formal Introduction. Stanford: CSLI.

Schroten, J. (1986). Ergativity, raising, and restructuring in the syntax of Spanish aspectual verbs. Linguisticae Investigationes 2, 439-465.

Shibatani, M. (1973). Where morphology and syntax clash: a case in Japanese aspectual verbs. Gengo Kenkyu 64, 65-96.

Shibatani, M. (1978). Nihongo No Gunseki, Tokyo:Taishukan.

Travis, L. (1991). Derived objects, inner aspect, and the structure of VP. A paper presented at NELS 21.

Vamarasi, M. K. (1999). Grammatical Relations in Bahama Indonesia. Canberra: Pacific Linguistics.

Wurmbrand, S. (1999). Modal verbs must be raising verbs. WCCFL 18, 599-612.

Wurmbrand, S. (2001). Infinitives: Restructuring and Clause Structure. Berlin: Mouton de Gruyter.

Wurmbrand, S. (2004). Two types of restructuring - Lexical vs. functional. Lingua 114, 9911014. 


\title{
Object control in Korean: Obligatory vs. non-obligatory control
}

\author{
Maria Polinsky
}

Harvard University

\section{Introduction*}

Object control is a dependency between the object of a matrix clause and the subject of the embedded clause, where the referential properties of the overt controller determine the referential properties of the silent controllee (represented as a gap below), as in (1).

(1) Kim persuaded $\mathrm{Pat}_{i} \quad\left[{ }_{\ldots} i\right.$ to run this race $]$ controller controllee

The degree of referential dependency between the controller and controllee varies from cases where the missing subject of the embedded clause has to be identified with the overt controller in the matrix clause, as in (1), to cases where there can be more than one unique controller, as in (2) and (3), and even further to cases where any controller would do (4):

(2) $\mathrm{Kim}_{\mathrm{i}}$ asked Pat $\mathrm{j}_{\mathrm{j}} \quad\left[{ }_{\ldots}{ }_{i+j}\right.$ to meet in the lobby $]$

(3) $\mathrm{Kim}_{\mathrm{i}}$ asked Pat $\mathrm{j}_{\mathrm{j}} \quad$ [if it was time [ _ _ $i, j, k$ to believe in himself/herself/ themselves/oneself]

(4) $\mathrm{Kim}_{\mathrm{i}}$ wondered [how __ _arb to exonerate oneself]

Different theories of control account for the range of possibilities available in the identification of the antecedent, from unique to arbitrary, by either positing different silent elements in infinitival structures, or by dividing control predicates into different lexical classes. Under the former approach, it is customary to distinguish between obligatory control (OC), as in (1) and nonobligatory control (NOC), as in (4), with various intermediary cases (Chomsky 1981, Koster 1984, Hornstein 2000, 2003, among many others). Each subtype is associated with a different type of empty category: in OC complements it is either PRO or trace of movement, in NOC, it is a null pronominal (pro). Under

* This project was supported in part by NSF grant BCS-0131946. I am grateful to HyonSook Choe, Shin Fukuda, Norbert Hornstein, Peter Jenks, Hakyung Jung, Shin-Sook Kim, Robert Kluender, Nayoung Kwon, Sun-Hee Lee, Phil Monahan, Eric Potsdam, Peter Sells, Barbara Stiebels, Mieko Ueno, and audiences at the JK conference 15, University of Maryland, and Zentrum für allgemeine Sprachwissenschaft in Berlin for helpful discussions of this paper. All errors are my responsibility. 
the latter approach, control predicates can be divided into those that force unique control (as in (1)) versus those that allow a wider range of controllers as in (2) through (4) (Jackendoff \& Culicover 2003). Regardless of a specific account, the difference between $\mathrm{OC}$ and NOC is connected to the difference in complement types and predicate types, with an underlying assumption that the meaning of the matrix predicate should determine the type of control.

In this paper, I examine two object control constructions in Korean which differ only in the surface word order: in one of the constructions, the control complement follows the controller, but in the other, precedes it. I argue that the contrast between these constructions cannot be attributed to scrambling. The difference between these constructions can only be captured if one of them is analyzed as OC, and the other as instantiating NOC. Section 2 presents the relevant constructions and their earlier analyses available in the literature; section 3 presents a detailed discussion of differences between the two object control constructions. My proposal for analyzing these constructions is presented in section 4. Section 5 introduces two outstanding questions related to the proposed structures: the status of scrambling in Korean and the analysis of the inverse control construction. Conclusions and general discussion follow in section 6 .

\section{Object control in Korean}

Object control in Korean involves one of a number of matrix control verbs shown in (5), and a complement clause headed by the complementizer -tolok (see Kim 1978, 1984 for evidence that it is actually a complementizer).

$$
\begin{aligned}
& \text { seltukhata 'persuade', kwonyuhata 'suggest, recommend', kangyohata } \\
& \text { 'force', kwuenhata 'recommend', myenglyenghata 'order', pwuthakhata } \\
& \text { 'ask (as a favor)', yokwuhata 'ask, request', congyonghata } \\
& \text { 'recommend/encourage', cisihata 'order', thailuta 'implore', } \\
& \text { pwuchwukita 'encourage', yochenghata 'entreat' }
\end{aligned}
$$

The construction is illustrated in (6), with the missing argument represented atheoretically as a gap:

$\begin{array}{llll}\text { Chelswu-nun } & \text { Yenghi } \mathrm{i}_{-}-\mathrm{lul} \quad\left[\mathrm{L}_{\mathrm{i}} \quad \begin{array}{l}\text { tomangka-tolok }] \\ \text { run.away-COMP }\end{array}\right. & \begin{array}{l}\text { seltukhayssta } \\ \text { persuaded }\end{array} \\ \text { Chelswu-TOP } & \text { Yenghi-ACC } & \\ \text { 'Chelswu persuaded Yenghi to run away.' }[A C C 1] & \end{array}$

This construction, which I will refer to as ACC1, alternates with the ACC2 construction, illustrated in (7), where the complement clause precedes the accusative DP. 


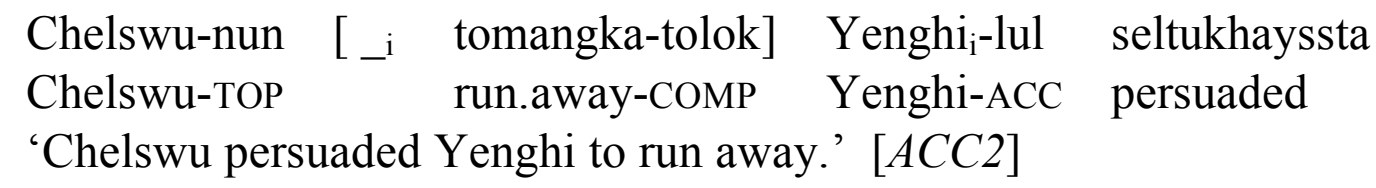

Korean also has an inverse (backward) control construction where the overt controller appears in the embedded clause, and the matrix clause has a silent element, whose surface position is not clear:
a. Chelswu-nun
[Yenghi $\mathrm{i}_{\mathrm{i}}-\mathrm{ka}$
tomangka-tolok]
seltukhayssta
Chelswu-TOP
Yenghi-NOM
persuaded
$\begin{array}{llll}\text { b. Chelswu-nun } & \text { [Yenghi }{ }_{i}-\mathrm{ka} & \text { tomangka-tolok }{ }_{2} \mathrm{i} & \text { seltukhayssta } \\ \text { Chelswu-TOP } & \text { Yenghi-NOM } & \text { run.away-COMP } & \text { persuaded }\end{array}$ 'Chelswu persuaded Yenghi to run away.' [NOM]

This construction, which has received significant attention in the literature (Monahan 2003, 2005, Cormack \& Smith 2004, Choe 2006), will play only a minor role in the discussion here; I will return to it in section 5.2. In addition, Korean has an object control construction with the controller in the dative, rather than accusative case. I will not discuss it in this paper; for an overview of that construction, see Gamerschlag (this volume).

I assume as given, following the analysis in Monahan (2003) and Cormack \& Smith (2002) that both ACC1 and ACC2 are biclausal and that they show evidence of control. The two structures have previously been analyzed as either syntactic control or semantic control. Under both analyses that have been proposed in the literature, $\mathrm{ACC} 1$ and $\mathrm{ACC} 2$ are viewed as derivationally related.

Under the syntactic analysis, which treats control as raising into a thetaposition, the matrix and embedded DP form an A-chain. In both accusative constructions (ACC1, ACC2), the tail of the chain is deleted, instantiating obligatory forward control. (An analysis in terms of PRO could also be pursued, but since recent syntactic work on these Korean constructions has relied on a movement approach, this is what is represented here.)

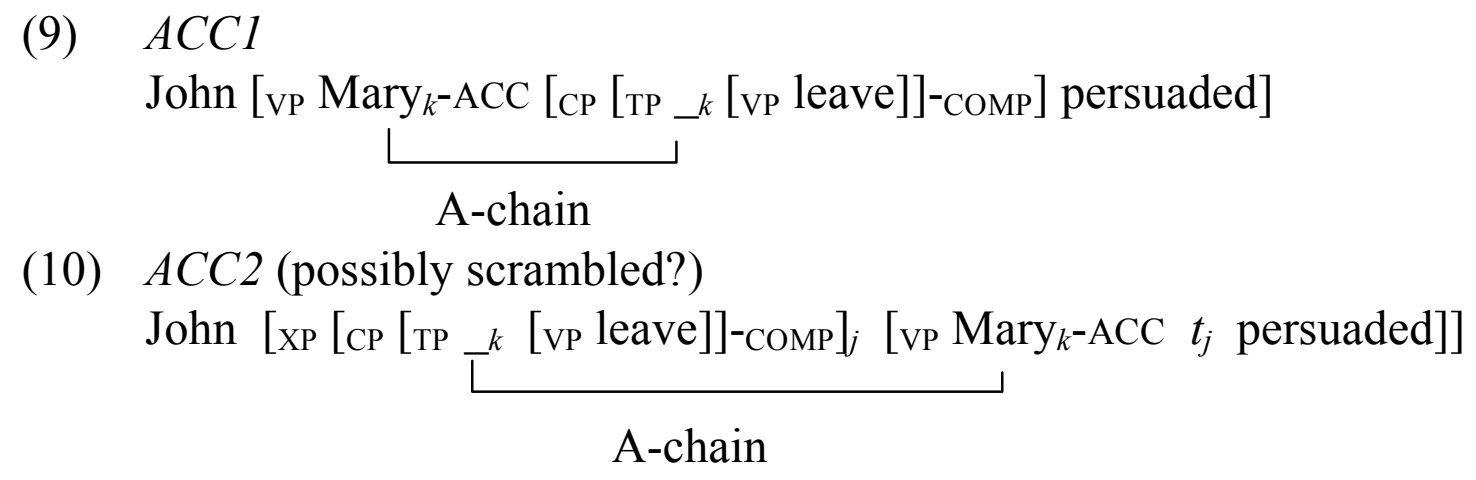

The semantic analysis of control relies on the fact that Korean has extensive subject pro-drop. This analysis assumes that the silent element in all three control constructions is a null pronominal. Then the overt DP is analyzed as 
being co-indexed with a null pronominal, via a meaning postulate (Agent-toAgent). In those instances where coindexation is impossible, the null pronominal is interpreted non-referentially (Cormack \& Smith 2002, 2004; Choe 2006).

According to this analysis, ACC1 is the basic structure, with the accusative DP in the specifier of VP, and the control complement adjoined to V' as shown in (11). The accusative DP c-commands the nominative DP (expressed by a null pronominal) in the embedded clause. The control interpretation is achieved by the meaning postulate which links the agent of the embedded proposition and the persuadee of the matrix (Cormack \& Smith 2004):

(11) John [vp [Mary $\left.{ }_{\mathrm{i}}-\mathrm{ACC}\right]\left[\mathrm{v}^{\prime}\right.$ [ст [тр pro $_{\mathrm{i}}$ leave]-COMP] persuaded]

Korean has object pro-drop, so the object of the matrix clause can be expressed by a null pronominal; the resulting structure, where the null pronominal in the object position is coindexed with the embedded subject, leads to a binding violation:

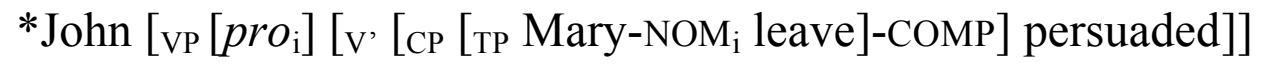

The apparent violation of Condition $\mathrm{C}$ in (12) seems to be remedied by local scrambling (within the verb phrase). Under such scrambling, the control complement appears in the specifier of VP, and the matrix DP adjoins to V':

(13) John [ ${ }_{\mathrm{vP}}\left[{ }_{\mathrm{CP}}\left[\mathrm{TTP}_{\mathrm{i}} \mathrm{DP}_{\mathrm{i}} \text { leave }\right]-\mathrm{COMP}\right]_{\mathrm{k}}\left[\mathrm{vp}_{\mathrm{p}}\left[\mathrm{DP}_{\mathrm{i}}-\mathrm{ACC}\right]\left[\mathrm{v}, \mathrm{t}_{\mathrm{k}}\right.\right.$ persuaded $\left.]\right]$

In this structure, either of the coindexed DPs (the matrix object or the embedded subject) can be expressed by a null pronominal:

(14) John [Vp [Cе [TP pro $_{\mathrm{i}}$ leave $\left.]-\mathrm{COMP}\right]\left[\mathrm{V},\left[\mathrm{DP} \mathrm{i}_{\mathrm{i}}-\mathrm{ACC}\right]\right.$ persuaded $\left.]\right]$

The control interpretation is achieved by the meaning postulate; when a referential antecedent of the null pronoun is not available, pro is interpreted arbitrarily (Choe 2006). To summarize, the existing approaches consider ACC1 and $\mathrm{ACC} 2$ derivationally related, with the assumption that $\mathrm{ACC} 1$ instantiates the base-generated structure, and ACC2 is derived via scrambling. Under the syntactic approach, both constructions are OC, while under the semantic approach both are NOC, thus:

\begin{tabular}{|l|c|c|}
\hline & Syntactic approach & Semantic approach \\
\hline ACC1 & OC & NOC \\
\hline ACC2 & OC & NOC \\
\hline
\end{tabular}

In the next section, I will revisit the relationship between the two constructions arguing that they are not related derivationally, and that they instantiate different types of control. The differences between ACC1 and ACC2 follow without additional stipulations, and the overall contrast between the two constructions 
becomes more reminiscent of the contrasts between obligatory and nonobligatory control in familiar languages.

\section{Differences between ACC1 and ACC 2}

On closer scrutiny, it turns out that the two control constructions, which seem to diverge only in word order, actually differ more profoundly in structural and interpretive properties.

First, ACC1 does not allow an arbitrary antecedent, ${ }^{1}$ whereas ACC2 does:

a. Chelswu-nun emeni-lul [ $\mathrm{ku}$ cha-lul phal-tolok] seltukhayssta Chelswu-TOP mother-ACC that car-ACC sell-COMP persuaded [ACC1]

(i) 'Chelswu persuaded mother to sell the car.'

?/*(ii) 'Chelswu persuaded mother that someone should sell the car.'

b. Chelswu-nun [_ ku cha-lul phal-tolok] emeni-lul seltukhayssta Chelswu-TOP that car- ACC sell-COMP mother-ACC persuaded [ACC2]

(i) 'Chelswu persuaded mother to sell the car.'

(ii) 'Chelswu persuaded mother that someone should sell the car.'

Second, as (16) shows, ACC1 does not allow a non-c-commanding antecedent, whereas ACC2 does (see also Choe 2006, ex. (35)):

(16) a. Chelswu-nun Yenghi-uy emeni-lul [_ ku cha-lul phal-tolok] Chelswu-TOP Yenghi-GEN mother-ACC that car-ACC sell-COMP seltukhayssta persuaded $[A C C 1]$

(i) 'Chelswu persuaded Yenghi's mother to sell the car.'

?/*(ii) 'Chelswu persuaded Yenghi's mother that someone should sell the car.'

*(iii) 'Chelswu persuaded Yenghi's mother that Yenghi should sell the car.'

b. Chelswu-nun [_ ku cha-lul phal-tolok] Yenghi-uy emeni-lul Chelswu-TOP that car- ACC sell-COMP Yenghi-GEN mother-ACC seltukhayssta persuaded $[A C C 2]$

(i) 'Chelswu persuaded Yenghi's mother to sell the car.'

(ii) 'Chelswu persuaded Y.'s mother that someone should sell the car.'

(iii) 'Chelswu persuaded Y.'s mother that Yenghi should sell the car.'

1 As the symbols $* /$ ? on (ii) in (15a) indicate, there is some variation in judgments here. I will return to this issue in section 5 below. 
Next, the two constructions differ as to whether the silent subject in the tolokclause can alternate with an overt pronoun: such an alternation is impossible in ACC1 but is fine in ACC2 (see also Cormack \& Smith 2004, Choe 2006):
a. *Chelswu-nun Yenghi-lul [ku-ka ttena-tolok] seltukhayssta Chelswu-TOP Yenghi-ACC s/he-NOM leave-COMP persuaded [ACC1]
'Chelswu persuaded Yenghi to leave.'
b. Chelswu-nun [ku-ka ttena-tolok] Yenghi-lul seltukhayssta
Chelswu-TOP s/he-NOM leave-COMP Yenghi-ACC persuaded [ACC2]
'Chelswu persuaded Yenghi to leave.'
'Chelswu persuaded Yenghi that someone should leave.'

These differences between $\mathrm{ACC} 1$ and $\mathrm{ACC} 2$ suggest that when it comes to the uniqueness of the antecedent for the missing subject of the tolok-clause, the two constructions have different restrictions. In $\mathrm{ACC} 1$, the requirement seems to be quite stringent: not only does the antecedent of the silent subject have to be unique but it also c-commands the gap. In ACC2, the interpretation of the silent controllee is not limited to the unique controller that follows the tolok-clause. To summarize our results so far, ACC1 and ACC2 differ along the lines of the wellknown differences between obligatory control and non-obligatory control, namely:
properties of OC versus NOC
a. allows arbitary reading (no antecedent)
b. allows a non-c-commanding antecedent
c. paraphrasable with a pronoun

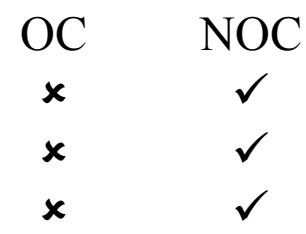

The characteristics of ACC1 correspond to those of OC, while ACC2 matches several criterial properties of NOC. Thus, ACC1 is obligatory control and ACC2 is not.

In addition to the difference in the range of available antecedents and the interpretations that follow from this difference, ACC1 and ACC2 also differ with respect to the interpretation of the controlled event as implicative (ACC1) or not (ACC2). In other words, the use of ACC1 implies that the event described by the embedded clause has to happen (without presupposing it), whereas with $\mathrm{ACC} 2$, the speaker is not committed to the truth of the proposition expressed by the embedded clause. The evidence for this interpretive contrast comes from the fact that ACC1 is infelicitous with the continuation that cancels the event expressed in the embedded clause; for ACC2, such a continuation does not lead to a contradiction: 
(19) a. Chelswu-ka Yenghi-lul hakkyo-lul ttena-tolok seltukhayssta. Chelswu-NOM Yenghi-ACC school-ACC leave-COMP persuaded \#Kulenta pro/Yenghi-nun hakkyo-lul ttena-ci Anh-ass-ta but pro/Yenghi-TOP school-ACC leave-INF NEG-PAST-DECL [ACC1]

'Chelswu persuaded Yenghi ${ }_{\mathrm{k}}$ to quit school, \#but even so $\mathrm{she}_{\mathrm{k}} /$ Yenghi did not.' (contradiction)

b. Chelswu-ka hakkyo-lul ttena-tolok Yenghi-lul seltukhayssta. Chelswu-NOM school-ACC leave-COMP Yenghi-ACC persuaded Kulenta pro/Yenghi-nun hakkyo-lul ttena-ci anh-ass-ta But pro/Yenghi-TOP school-ACC leave-NEG NEG-PAST-DECL [ACC2]

'Chelswu persuaded Yenghi ${ }_{\mathrm{k}}$ to quit school, but even so $\mathrm{she}_{\mathrm{k}} /$ Yenghi did not.' (no contradiction)

The contrast between $\mathrm{ACC} 1$ and $\mathrm{ACC} 2$ is reminiscent of the contrast between implicative and non-implicative control in English, for example, as in (20), which corresponds to the Korean ACC1, and (21), whose interpretation corresponds to that of $\mathrm{ACC} 2 .^{2}$ In English, the difference in implicativeness correlates with the use of the infinitival vs. finite complement (cf. Jackendoff \& Culicover 2003), whereas in Korean it seems to be simply linked to difference in surface word order. ${ }^{3}$

(20) John persuaded Mary to buy a BMW, ??/*but even so she didn't.

(21) John persuaded Mary that she should buy a BMW but even so she didn't.

All said it seems that the difference between ACC1 and ACC2 goes deeper than just a simple difference in scrambling. While scrambling may affect c-command relations (Saito 2003, Tsoulas 2004, Ko 2005, Choe 2006) ${ }^{4}$ and brings about some differences in topic interpretation or aboutness (Choi 2001), it is not known to have profound consequences for the interpretation of the null element in a control complement or to cause differences in implicativeness. Thus it seems possible that both constructions are independent and base-generated rather than one being derived from the other.

A possible counter-argument against such an approach comes from the differences between ACC1 and ACC2 with respect to extraction. In ACC1, the

2 I would like to thank Ray Jackendoff for a helpful discussion of this contrast in English.

3 It is striking that both English and Korean show a correlation between non-obligatory control and non-implicative interpretation. Intuitively, such a correlation does not seem accidental, but more work is needed to motivate it.

4 In Korean, scrambling has been shown to have an effect on condition A binding (Choi 2001) but not on condition C binding (Johnston \& Park 2001). 
tolok-clause is transparent and can be extracted out of the complement clause in (22b), but in ACC2, the extraction out of that clause is marginal at best (23b).

(22) a. Chelswu-ka Yenghi-lul [ku chayk-ul ilk-tolok] seltukhayssta. Chelswu-NOM Yenghi-ACC this book-ACC read-COMP persuaded 'Chelswu persuaded Yenghi to read this book.' [ACC1]

b. ku chayk-ul $\mathrm{i}_{\mathrm{i}}$, Chelswu-ka Yenghi-lul [ $\mathrm{t}_{\mathrm{i}}$ ilk-tolok] seltukhayssta this book-ACC Chelswu-NOM Yenghi-ACC read-COMP persuaded 'This book, Chelswu persuaded Yenghi to read.'

(23) a. Chelswu-ka [ku chayk-ul ilk-tolok] Yenghi-lul seltukhayssta. Chelswu-NOM this book-ACC read-COMP Yenghi-ACC persuaded 'Chelswu persuaded Yenghi to read this book.' [ACC2]

b. ??/* $\mathrm{ku}$ chayk-ul $\mathrm{i}_{\mathrm{i}}$ Chelswu-ka [ $\mathrm{t}_{\mathrm{i}}$ ilk-tolok $]$ Yenghi-lul this book-ACC Chelswu-NOM read-COMP Yenghi-ACC seltukhayssta persuaded 'This book, Chelswu persuaded Yenghi to read.'

This difference between ACC1 and ACC2 (22b) and (23b) seems consistent with the idea that ACC2 is derived from ACC1 by scrambling. Scrambling creates an island for further extraction (Saito 2003, Ko 2005, and many others), which should account for (23b). However, the ungrammaticality of (23b) can be accounted for independent of scrambling, under the structure which will be proposed in the next section. So at least for now, I suggest maintaining the idea that $\mathrm{ACC} 1$ and $\mathrm{ACC} 2$ are not related derivationally and instantiate different flavors of control.

\section{Structure of ACC1 and ACC2}

\section{1. $\mathrm{ACC1}$}

We have established that the structure in ACC1 instantiates obligatory control. The matrix verb (for example, 'persuade') takes two complements, the accusative DP (controller) and the complement clause (-tolok). These two internal arguments (the name of the persuadee and the embedded complement) are in the specifier and complement positions in the VP, which means that the accusative DP c-commands the complement clause, thus (English words are used to illustrate the Korean structure; only the necessary structural pieces are shown):

Chelswu-NOM [vP Yenghi $\mathrm{i}_{\mathrm{i}} \mathrm{ACC}\left[\mathrm{v},\left[\mathrm{CP}\left[\mathrm{TP} \_\mathrm{i}\right.\right.\right.$ leave $\left.] \mathrm{C}^{\circ}\right]$ [v persuade $\left.]\right]$ 
The missing subject in the embedded clause can be interpreted in two possible ways: as containing a special null category, PRO, or as involving a thematic chain in which the tail is deleted, thus:

$\begin{array}{lllll}\text { Chelswu-ka } & \text { Yenghi-lul } & \text { [PRO } & \text { ttena-tolok }] & \text { seltukhayssta } \\ \text { Chelswu-NOM } & \text { Yenghi-ACC } & \text { leave-COMP } & \text { persuaded }\end{array}$

a. Chelswu-ka Yenghi-lul [Yenghi ka ttena-tolok] seltukhayssta Chelswu-NOM Yenghi-ACC leave-COMP persuaded

b. Chelswu-NOM [vpYenghi-ACC [ст [тP Yenghi-NOM [vp go]] C] persuade]

To outline the movement analysis, as in (26), the DP Yenghi is merged in the embedded spec, $\mathrm{T}^{\circ}$. There, it satisfies the thematic requirements of the embedded verb leave and the $\varphi$-features of embedded $\mathrm{T}^{\circ}$. It then merges into matrix object position, satisfying the thematic requirements of the matrix verb, which assigns it accusative case. The head of the chain formed by the matrix object and the subject of the embedded clause is pronounced, while the other copy is deleted.

For general details of the movement analysis of control, see Hornstein (2003), Monahan (2005). For the discussion of factors that may determine the spell-out of the tail rather than head of the movement chain, see Polinsky \& Potsdam (2006), Potsdam (2006). Lastly, for comparison of the PRO-based and movement analysis, see Landau (2003, 2004, 2006), Hornstein \& Boeckx (2004), Boeckx \& Hornstein (2006), Polinsky \& Potsdam (2006).

\section{2. $\mathrm{ACC} 2$}

Recall that the ACC2 construction instantiates non-obligatory control, which means that the missing subject inside the embedded clause is a null pronominal. The null pronominal can alternate with an overt one (see (17b) above). Crucially, the subject of the tolok-clause is not c-commanded by the accusative controller in the matrix clause, and the dependency between the accusative controller and the silent controllee is referential, rather than syntactic. The two expressions are thus related by simple co-indexation. They do not have to have identical denotations, which is shown by examples such as (27) and (28), where the referent of the embedded subject and the referent of the matrix object are simply associated pragmatically.
cokyo-ka [haksayng-tul-i te umak swuep-ul tut-tolok] teacher's aide-NOM student-PL-NOM more music lesson-ACC take-COMP hakpwumo-tul-ul seltukhayssta

parent-PL-ACC persuaded [ACC2]

'The teacher's aide persuaded the parents of the students that their children should take more music lessons.' 


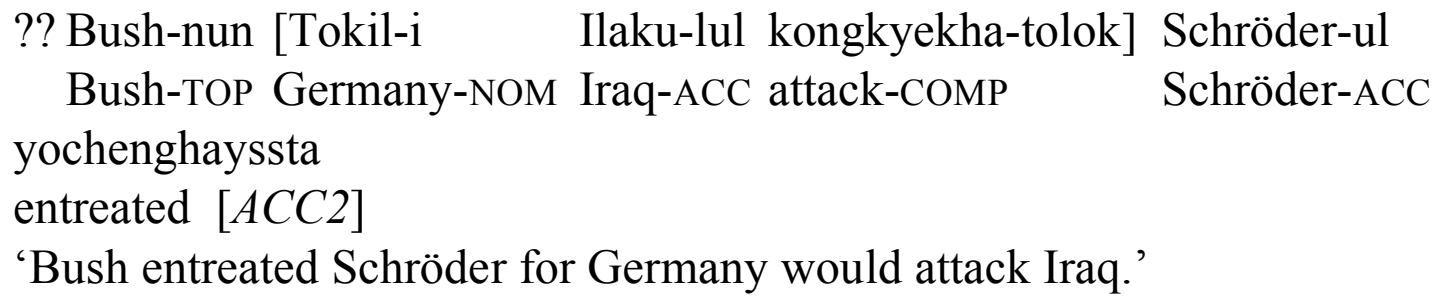

Recall also that even such pragmatic association is not required, and in the absence of other cues, an arbitrary reading of the null pronominal is equally possible (cf. (15b) above).

Since there is no c-command between the controller and controllee, variable binding should be impossible. While reflexive data are unclear (thus raising more general questions about the nature of anaphors in Korean), indefinite expressions (29) and negative polarity items (30) in ACC2 confirm this prediction and do not participate in co-indexation (see also Choe 2006, ex. (26), (36), and (40)):
Chelswu-ka
$\left[\right.$ pro $_{\mathrm{i}}$ ttena-tolok]
nwukwu $\mathrm{k}-1 \mathrm{ul}$
seltukhayss-nayo?
Chelswu-NOM
leave-COMP who-ACC
persuaded-INTERR

'Whom ${ }_{\mathrm{k}}$ did Chelswu persuade that someone $\mathrm{i}_{\mathrm{i}}$ should leave?'
(30) Chelswu-ka $\left[\right.$ pro $_{i}$ ttena-tolok $]$ amwuto $_{k}$ seltukha-ci anh-ass-ta Chelswu-NOM leave-COMP anyone persuade-INF NEG-PAST-DEC 'Chelswu did not persuade anyone $\mathrm{k}_{\mathrm{k}}$ that someone $\mathrm{i}_{\mathrm{i}}$ should leave.'

This is in contrast to the variable binding freely available in ACC1. Compare (29) with (31); in (29), the variable binding interpretation is not allowed, whereas in (31) it is available, which follows from the c-command relation between the matrix object and the embedded subject:
(31) Chelswu-ka nwukwu $\mathrm{i}_{\mathrm{i}}-\mathrm{lul} \quad \mathrm{L}_{\mathrm{i}}$ ttena-tolok] seltukhayss-nayo? Chelswu-NOM who-ACC leave-COMP persuaded-INTERR 'Whom did Chelswu persuade to leave?'

Similarly, compare (30) with (32), in which variable binding is available as it is allowed structurally:
Chelswu-ka
amwuto $_{i}\left[{ }_{i}\right.$ ttena-tolok]
seltukha-ci
anh-ass-ta
Chelswu-NOM leave-COMP
'Chelswu did not persuade anyone to leave.'

All these data further support the difference between ACC1 and ACC2 and confirm the pronominal nature of the empty element in ACC2.

Assuming that there is no c-command between the accusative controller and tolok-clause, what is the structural position of that clause?

To answer this question, let's start with the argument structure of 'persuade' and other verbs listed in (5) above. They all appear to be standard three-place 
predicates, which take an agent, a theme (persuadee), and a propositional object, corresponding to the intended event. In the standard control structure (ACC1), this propositional object is expressed by the tolok-clause. For ACC2, I propose that this object is an implicit argument, semantically bound by the overt tolokclause, which appears in the adjunct position in the verb phrase. The verb thus still has a propositional object as its internal argument, remaining a three-place predicate, but there is an additional adjunct higher in the verb phrase filled with the tolok-clause. The proposed structure of ACC2 is as follows:

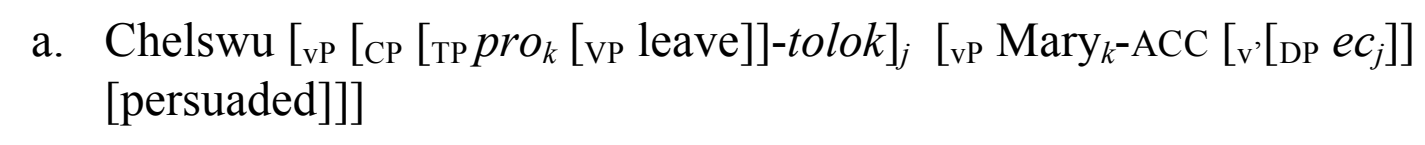

b.

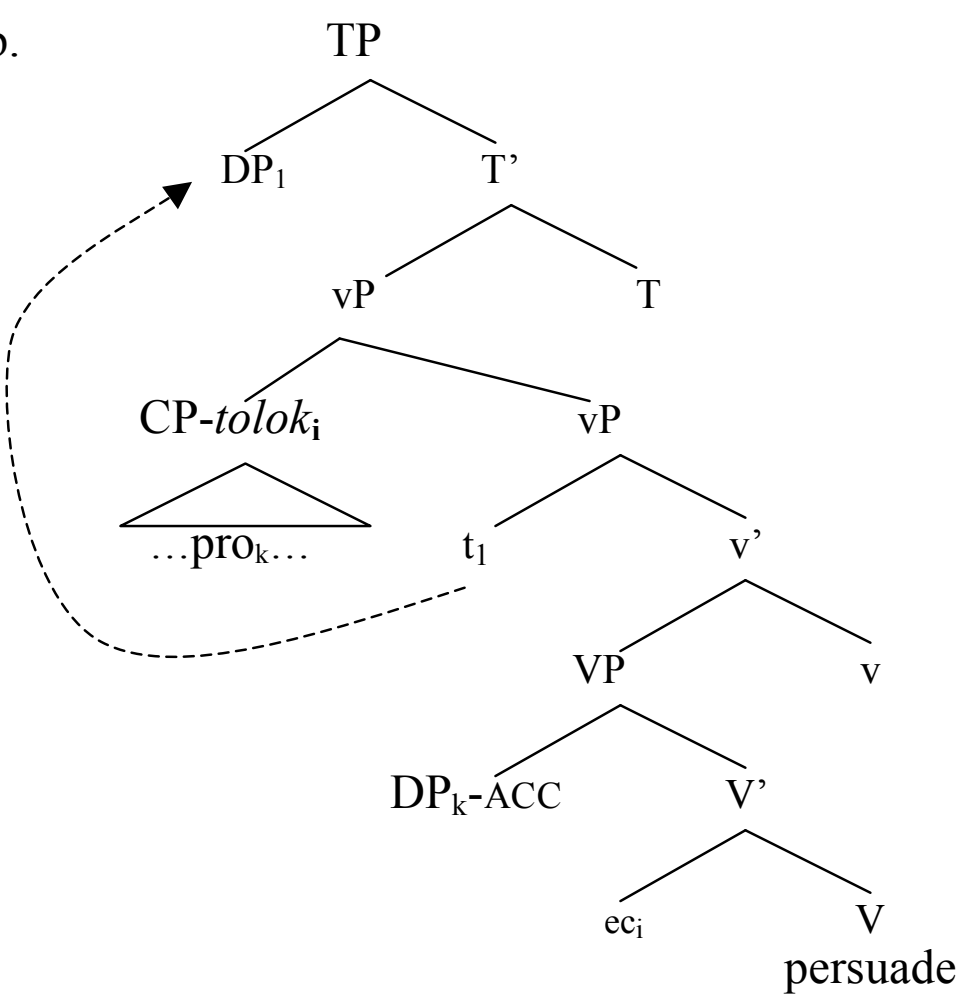

The evidence for this structure involves several analytical components. First, evidence for the implicit argument position is desirable. Second, we need to demonstrate that the tolok-clause is indeed an adjunct, situated at the left periphery of the verb phrase.

Starting with the implicit argument, one could expect that such an argument could alternate with an overt object, for example with some abstract noun ('idea', 'proposal') or a pronoun, something like the anticipatory it in English. However, due to the pervasive nature of Korean object pro-drop (about $50 \%$ of objects are null, cf. Kim 2000), even referential arguments are often awkward when overtly expressed, let alone abstract, propositional entities. Note that even in English, where there is no pro-drop, anticipatory it in the position of a propositional object is rather awkward: 
... so well convinced him of $i t$ that he has become quite anxious to have you apply for the chair

(jhmas.oxfordjournals.org/cgi/reprint/XXIV/1/44.pdf)

Although a pronominal or an abstract DP seems impossible, the implicit argument position can be filled with a clausal complement, co-occuring with the higher tolok-clause: ${ }^{5}$

(35) a. Chelswu-nun $\left[\right.$ pro $_{i}$ Yenghi-lul manna-tolok $]$ Minswu $_{i}-1 u l$ Chelwsu-TOP Yenghi-ACC Meet-COMP Minswu-ACC

[_i Seoul-lo ka-key] seltukhayssta

Seoul-to go-COMP persuaded

'Chelswu persuaded Minswu to go to Seoul to meet Yenghi.'

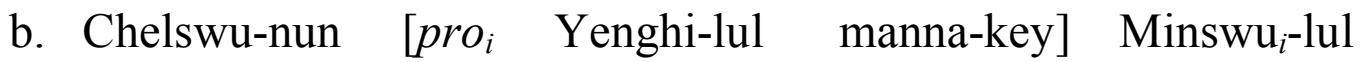

Chelwsu-TOP Yenghi-ACC meet-COMP Minswu-ACC

[_i $\quad$ Seoul-lo ka-tolok] seltukhayssta

Seoul-to go-COMP persuaded

'Chelswu persuaded Minswu to go to Seoul to meet Yenghi.'

Speakers prefer for the two embedded clauses to have to have different complementizers, as in (35), but the following example, with both clauses headed by tolok is acceptable to some (the variation in judgments seems to hold across speakers; individual speakers are consistent in either accepting or rejecting double -tolok sentences):

$$
\begin{aligned}
& \% \text { Chelswu-nun }\left[\mathrm{pro}_{\mathrm{i}}\right. \text { amwu kekceng-epsi sal swuiss-tolok] } \\
& \text { Chelwsu-TOP any worry-without live be.able-COMP } \\
& \text { Minswu }_{\mathrm{i}}-\text { lul [_i Seoul-ul ttena-tolok] seltukhayssta } \\
& \text { Minswu-ACC Seoul-ACC go-COMP persuaded } \\
& \text { 'Chelswu persuaded Minswu to leave Seoul so that he (Minswu) would } \\
& \text { live without worry.' }
\end{aligned}
$$

Turning now to the position of the tolok-clause in ACC2, evidence that it is at the left edge of the verb phrase comes from adverbial placement. Korean has several adverbials that are ambiguous between high and low adverbs (Sohn 2001; Ko 2005). For example, the adverbial palo has the meaning 'directly; true, indeed' as an IP-adverb, and the meaning 'immediately' as a VP-adverb (Sohn 2001:212). Consider the following sentence, where palo is placed to the left of the tolok-clause and where it can only have the VP-adverb interpretation:

5 I am leaving open the question about the category of the empty element in the second control clause. 
Chelswu-ka palo [onil__ _i hakkyo-lul ttena-tolok] Yenghi-lul Chelwsu-NOM ADV tomorrow school-ACC leave-COMP Yenghi-ACC selthuhaessta

persuaded

'Chelswu immediately persuaded Yenghi to quit school tomorrow.'

NOT: 'Chelswu indeed/truly persuaded Yenghi to quit school tomorrow.'

The VP-adverb interpretation of the adverbial which precedes the tolok-clause indicates that this clause is inside the verb phrase, adjoined to the vP.

The argument in support of the adjunct status of the preposed tolok-clause in ACC2 comes from extraction restrictions. ${ }^{6}$ If the preposed tolok-clause is an adjunct, it should be an island for extractions. Empirical facts show that it is. Recall that scrambling or topicalization out of the tolok-clause in ACC2 was ungrammatical:

$$
\begin{aligned}
& ? ? /{ }^{*} \mathrm{ku} \quad \text { chayk-ul } \mathrm{i}_{\mathrm{i}}, \quad \text { Chelswu-ka } \quad\left[\mathrm{t}_{\mathrm{i}} \text { ilk-tolok }\right] \text { Yenghi-lul } \\
& \text { this book-ACC Chelswu-NOM read-COMP Yenghi-ACC } \\
& \text { seltukhayssta } \\
& \text { persuaded } \\
& \text { 'This book, Chelswu persuaded Yenghi to read.' (=(23b)) }
\end{aligned}
$$

If the analysis proposed here is on the right track, then the islandhood of tolokclauses in ACC2 follows from their adjunct status, not from scrambling. At this point, one could imagine that the two explanations are equally valid; however, there is additional evidence suggesting that the adjunct island explanation is the correct one.

This evidence comes from constraints on scrambling over an already scrambled element. In Korean, scrambling over a scrambled constituent is ungrammatical, which is illustrated by the following examples. In (39b), the word 'book' has been scrambled out of the embedded clause, which is grammatical, but scrambling of the remnant embedded clause over 'book' is ungrammatical $(39 \mathrm{c}):^{7}$

6 Assuming the optionality of adjuncts, one can also expect the tolok-clause to be omitted, with the verb taking only one overt object, as in (i). Of course, in such a case it is hard to tell if this surface structure reflects ACC1 or ACC2.

(i) Chelswu-nun Minswu-lul ec seltukhayssta

Chelswu-TOP Minswu-ACC Persuaded

'Chelswu convinced Minswu (of something).'

7 I am grateful to Shin-Sook Kim for calling my attention to this paradigm in scrambling. 
a. Chelswu-ka [Yenghi-ka ku chayk-ul ilkessta-ko]

Chelswu-NOM Yenghi-NOM that book-ACC read-that sayngkakha-n-ta

think-PRES-DEC

'Chelswu thinks that Yenghi read that book.'

b. $\mathrm{ku}$ chayk-ul $\mathrm{i}_{\mathrm{i}}$ Chelswu-ka [Yenghi-ka $t_{\mathrm{i}}$ ilkessta-ko]

that book-ACC Chelswu-NOM Yenghi-NOM read-that

sayngkakha-n-ta

think-PRES-DEC

'That book, Chelswu thinks that Yenghi read.'

c. * [Yenghi-ka $t_{\mathrm{i}}$ ilkessta-ko $]_{\mathrm{k}} \quad \mathrm{ku}$ chayk-ul $\mathrm{i}_{\mathrm{i}}$ Chelswu-ka $t_{\mathrm{k}}$ Yenghi-NOM read-that that book-ACC Chelswu-NOM sayngkakha-n-ta

think-PRES-DEC

('That Yenghi read it, that book, Chelswu thinks.')

The paradigm in (39) allows us to establish the baseline generalization: scrambling over a scrambled constituent in Korean is ungrammatical. If the tolokclause in ACC2 is in its surface position due to scrambling, then scrambling over it should also be ungrammatical. However, this prediction is not borne out: in (40b), a prepositional phrase is scrambled over the tolok-clause, but the sentence remains grammatical.
a. Chelswu-nun
$\left[\right.$ pro $_{i}$
hakkyo-ey
ka-tolok]
Yenghi-lul $1_{i}$
Chelswu-TOP school-to
go-COMP
Yenghi-ACC
[PP kunyecasin ${ }_{\mathrm{i}}$-uy yuik-ul
wihay] seltukhayssta
herself-GEN
benefit-ACC for
persuaded

'Chelswu persuaded Yenghi to go to school for her own benefit.'

(Monahan 2005, ex. (39))

b. Chelswu-nun [PP kunyecasin ${ }_{i}$-uy yuik-ul wihay $]_{j}$

Chelswu-TOP herself-GEN benefit-ACC for

$\left[\right.$ pro $_{i}$ hakkyo-ey ka-tolok] Yenghi-lul ${ }_{\mathrm{i}} t_{\mathrm{j}}$ seltukhayssta

school-to go-COMP Yenghi-ACC persuaded

'Chelswu, for her own benefit, persuaded Yenghi to go to school.'

Equally grammatical is (41b), where the low adverbial mwulyeyhakey 'in a rude manner' is scrambled over the tolok-clause: ${ }^{8}$

8 Adverbs such as 'rudely' are ambiguous between high and low adverbials (Ko 2005). However, Ko (2005: 59-60) proposes a useful diagnostic for disambiguating the two readings in Korean: when an adverb such as 'rudely' appears between the subject and the floated quantifier it is interpreted as a high adverb, but when it follows the quantifier as in (41b) it is interpreted low. Thus in (41b) the adverb starts out in the vP and scrambles out. 
$(41)$

$\begin{array}{lllll}\text { a. haksayng-tul-i } & \text { sey-myeng } & \text { ecey } & \text { [maykcwu-lul } \\ \text { student-PL-NOM } & \text { 3-CL } & \text { yesterday beer-ACC } \\ \text { masi-tolok] } & \mathrm{ku} & \text { ai-lul } & \text { mwulyeyhakey } & \text { cisihayssta } \\ \text { drink-COMP that } & \text { child-ACC } & \text { rudely } & \text { ordered }\end{array}$

'Yesterday three students rudely ordered the child to drink beer.'

b. haksayng-tul-i sey-myeng mwulyeyhakeyi ecey student-PL-NOM 3-CL rudely yesterday

[maykcwu-lul masi-tolok] $\mathrm{ku}$ ai-lul ti beer-ACC drink-COMP that child-ACC ordered

'Yesterday three students rudely ordered the child to drink beer.'

The comparison between (39) on the one hand and (40) or (41) on the other is not ideal, because the examples in (39) involve cross-clausal scrambling, whereas (40) and (41) involve clause-internal scrambling. Therefore I would like to offer this evidence as suggestive but not definitive.

Additional arguments in favor of the adjunct analysis come from processing (Kwon \& Polinsky 2006). In general, scrambling is known to incur an additional processing cost; this has been amply demonstrated for scrambled sentences in Japanese (Mazuka et al. 2002; Ueno \& Kluender 2003; Miyamoto and Takahashi 2002), and for scrambling in Korean (Kwon et al. 2007). However, the two structures discussed here do not differ in terms of reading time (Kwon \& Polinsky 2006), and in fact, the reading time for ACC2 is even slightly faster, as shown in the reading time graph below:

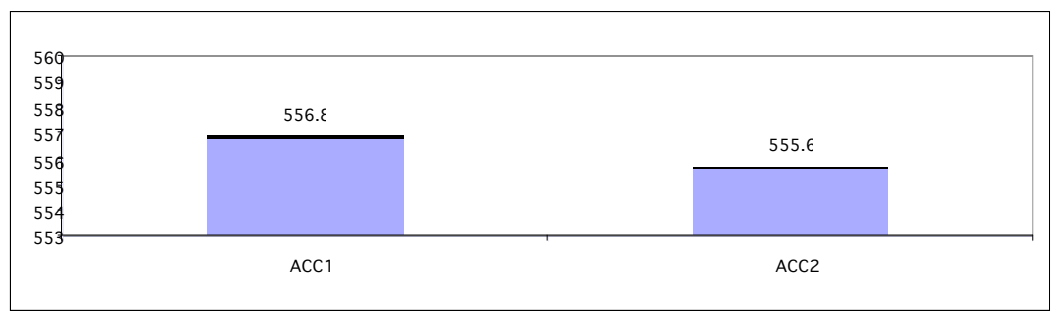

Figure 1 Reading time results (Kwon \& Polinsky 2006)

If scrambling were implicated in ACC2, we would expect it to cause some slowdown in reading, which does not happen. The processing profile shown in Figure 1 is yet another indication that ACC2 is not due to scrambling.

In sum, the evidence for structural differences between ACC1 and ACC2 is quite strong. The controller-controllee relationship in ACC2 is determined on semantic or pragmatic, rather than syntactic, grounds. The referential dependency in ACC2 accounts for the fact that the null pronominal in the tolok-clause can alternate with an overt pronoun (42), and an overt DP whose referent is only relationally associated with the referent of the persuadee, as in (43): 
(42) Chelswu-nun [kunye-ka ttena-tolok] Yenghi-lul seltukhayssta Chelswu-TOP she-NOM leave-COMP Yenghi-ACC persuaded 'Chelswu persuaded Yenghi to leave.' $(=(17 b))$ [3SG coindexed with Yenghi]

cokyo-ka [haksayng-tul-i te umak swuep-ul tut-tolok] teacher's aide-NOM student-PL-NOM more music lesson-ACC take-COMP hakpwumo-tul-ul seltukhayssta parent-PL-ACC persuaded 'The teacher's aide persuaded the students' parents that their children should take more music lessons.' [children coindexed with parents]

\section{Outstanding questions}

\subsection{Where is scrambling?}

Assuming that the two object control constructions in Korean are not derivationally related and are in fact quite different, they may both still be structurally ambiguous, due to scrambling. Scrambling of two internal arguments is possible in Korean (Park \& Whitman 2003, Maling \& Kim 1992, Sells 2005, Baek \& Lee 2004, and others), so it is feasible that each of the surface constructions, ACC1 and ACC2, actually masks two possibilities, thus (using English words with Korean word order):

a. ACC1, direct order

Chelwsu Yenghi $\mathrm{i}_{\mathrm{i}}$-ACC $\left[\mathrm{PRO} / \mathrm{t}_{\mathrm{i}}\right.$ go-COMP $]$ persuaded

b. ACC1, scrambled

Chelwsu $\left[\mathrm{PRO} / \mathrm{t}_{\mathrm{i}} \text { go-COMP }\right]_{\mathrm{k}}$ Yenghi $\mathrm{i}_{\mathrm{i}}$-ACC $\mathrm{t}_{\mathrm{k}}$ persuaded

a. ACC2, direct order

Chelwsu $\left[\text { pro }_{\mathrm{i}} \text { go-COMP }\right]_{\mathrm{j}}$ Yenghi $\mathrm{i}_{\mathrm{i}}-\mathrm{ACC} \mathrm{ec}_{\mathrm{j}}$ persuaded

b. ACC2, scrambled

Chelwsu Yenghi ${ }_{i}$-ACC $\left[\right.$ pro $_{\mathrm{i}}$ go-COMP] $\mathrm{t}_{\mathrm{i}} e c_{\mathrm{j}}$ persuaded

If the two constructions are structurally ambiguous, then ACC1 could actually mask ACC2 (cf. (44b)), and ACC2 could conceal ACC1 (cf. (45b)).

The structure in $(44 \mathrm{~b})$ is untenable on several theory-internal and empirical grounds. Under a PRO-based analysis of control, it is ruled out because of the disruption of c-command between PRO and its antecedent. Adopting a controlas-movement analysis, Monahan (2005) and Kwon \& Polinsky (2006) argue against the scrambling analysis of ACC1, such as that shown in (44b). The main arguments have to do with variable binding (see above) and quantifier float (Monahan 2005). In addition, under a movement analysis of control, the derivation of (44b) involves scrambling (remnant movement) over a moved constitu- 
ent: first the controller has to move, and then the rest of the tolok-clause moves over it to the left. We have seen that such movement is impossible in Korean (see (39c) above), which suggests that ACC1 does not undergo scrambling. Thus, the derivation in (46a) is impossible. However, sentences with the surface order as in (46a) are grammatical, which suggests that they have a different structure, the one shown in (46b).
a. * Chelswu-nun Chelswu-TOP $\left[\begin{array}{lllll}t_{\mathrm{i}} & \text { ka-tolok } \\ \mathrm{k}_{\mathrm{k}} & \begin{array}{l}\text { Yenghi-lul } \\ \text { go-COMP }\end{array} & t_{\mathrm{k}} & \begin{array}{l}\text { seltukhayssta } \\ \text { Yenghi-ACC }\end{array} & \text { persuaded }\end{array}\right.$
b. Chelswu-nun $\left[\text { pro }_{i} \text { ka-tolok }\right]_{\mathrm{k}}$ Yenghi-lul $\mathrm{i}_{\mathrm{i}} \mathrm{ec}_{\mathrm{k}}$ seltukhayssta 'Chelswu persuaded Yenghi to go.'

That (46a) is untenable meshes well with some additional empirical observations: ACC1 is normally judged as unambiguous, and only some speakers show mild ambiguity, reflected in the judgments in (15a) above - note the graded judgments on (ii) there. The next step in understanding such graded judgments should involve a psycholinguistically designed judgment of a larger number of ACC1 examples to evaluate off-line judgments; such a judgment task is currently under development.

Let us now turn to ACC2 and the scrambled representation in (45b). The main argument against this representation comes from island effects. If a subset of ACC 1 constructions were due to scrambling, the tolok-clause in those scrambled structures should remain an island for extractions, so we should expect something like (47a) to be ungrammatical because it would have the structure in (47b) and would involve scrambling out of an adjunct island as well as scrambling over a scrambled constituent ('Yenghi'):
a. ku chayk-ul ${ }_{i}$, Chelswu-ka Yenghi-lul [ $\mathrm{t}_{\mathrm{i}}$ ilk-tolok $]$ this book-ACC Chelswu-NOM Yenghi-ACC read-COMP seltukhayssta
persuaded
'This book, Chelswu persuaded Yenghi to read.' $(=(22 b))$

b. this book $\mathrm{k}_{\mathrm{i}}$ Chelswu-NOM Yenghi $\mathrm{k}_{\mathrm{k}}$-ACC $\left[\text { CP }_{\mathrm{i}} \mathrm{t}_{\mathrm{i}} \text { read-COMP }\right]_{\mathrm{j}} \mathrm{t}_{\mathrm{k}} \quad e c_{\mathrm{j}}$ persuaded

However, (47a) is well-formed, which argues against the structural ambiguity in ACC2 offered in (45).

Taken as a whole, these results cast further doubt on derivational accounts of scrambling. On a more general level, many arguments in favor of scrambling can be shown to be empirically flawed or inconclusive (Fanselow 2001). Theoretically, the concept of A-scrambling conflicts with a number of accepted minimalist assumptions, and base-generation of alternative orders may be a bet- 
ter solution (Fanselow 2001). The data presented here add further empirical support to such a proposal.

\subsection{Status of the nominative construction}

Throughout this paper, I have avoided the discussion of the nominative or inverse control construction, in which the overt controller in the tolok-clause is coindexed with a silent controllee in the matrix clause (for evidence in support of the silent controllee, see Monahan 2003, Cormack \& Smith 2004, Choe 2006):

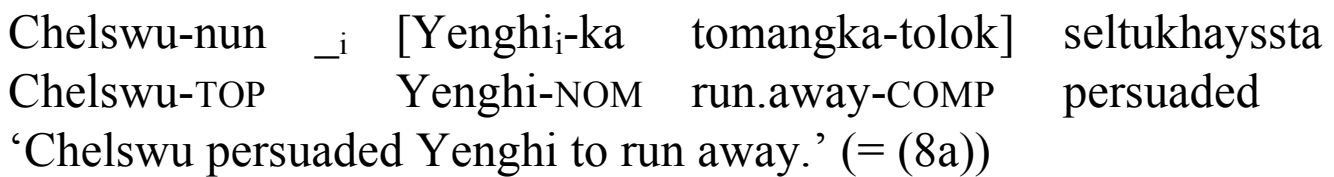

This construction is compatible with both ACC1 and ACC2. If it is related to obligatory control (ACC1), then it should be analyzed as backward control, with the controller and controller related by movement, as proposed in Monahan (2005) and Kwon \& Polinsky (2006). ${ }^{9}$ The difference between this construction and ACC1 then has to do with pronunciation of the tail versus the head of the movement chain.

Because Korean has extensive subject pro-drop, the construction illustrated in (48) is also compatible with non-obligatory control, hence, it could be a variant of ACC2. Under the NOC analysis, the only difference between this construction and $\mathrm{ACC} 2$ lies in the position of the null pronominal. If the null pronominal is in the subject position of the tolok-clause, the result is ACC2, if it is in the object position of the matrix clause, the result is NOM:
a. Chelswu-nun $\left[\mathrm{vp}_{\mathrm{P}}\left[\mathrm{pro}_{\mathrm{i}} \text { tomangka-tolok }\right]_{\mathrm{k}} \quad \mathrm{VvP}_{\mathrm{v}}\right.$ Yenghi $\mathrm{i}_{\mathrm{i}}-\mathrm{lul}$ Chelswu-TOP run.away-COMP Yenghi-ACC
[v, $e c_{\mathrm{k}} \quad$ seltukhayssta] $]$ persuaded
[ACC2]

b. Chelswu-nun ${ }_{\mathrm{vp}} \quad\left[\text { Yenghi }_{\mathrm{i}}-\mathrm{ka} \text { tomangka-tolok }\right]_{\mathrm{k}} \quad$ [vp $_{\text {pro }}$ Chelswu-TOP Yenghi-NOM run.away-COMP

[v, $e c_{\mathrm{k}} \quad$ seltukhayssta]] persuaded [NOM]

'Chelswu persuaded Yenghi to run away.'

Speakers seem to vary with respect to the uniqueness of the antecedent in the controller-controllee relationship in NOM. While preliminary data seem to favor the OC interpretation of NOM, hence the control-as-movement analysis, there is

9 See Polinsky \& Potsdam $(2002,2006)$ and Monahan (2003) for arguments as to why PRO-based analysis of backward control is untenable. 
also serious variation in judgments (see especially Choe 2006), which needs to be investigated further.

\section{Conclusions}

In this paper, I have examined two Korean object control constructions with the complementizer -tolok: where the overt accusative controller in the matrix clause either precedes or follows the embedded clause (ACC1, ACC2). I have argued that these two constructions differ in more than just surface word order of the internal objects. ACC1 instantiates obligatory control (OC) and can be accounted for under either a PRO-based analysis or a movement analysis (which is preferable for independent reasons not discussed in this paper). ACC2 shows non-obligatory control (NOC), and is best accounted for under an analysis which posits a null pronominal inside the control clause, coindexed with an overt accusative DP in the matrix clause. The controller-controllee relationship in ACC2 is based on a referential, rather than a syntactic, dependency. The differentiation of the two constructions as obligatory $v s$. non-obligatory control is supported by structural considerations as well as some processing evidence.

It is intriguing that the difference between OC and NOC in Korean object control is manifested as a word order difference. In more familiar languages, such a difference is typically associated with the difference in the type of control complement - for example, the difference between an infinitival clause and a finite clause in English (Jackendoff \& Culicover 2003), or the difference in lexical predicates. The availability of surface word order as the sole surface feature differentiating $\mathrm{OC}$ and NOC indicates that the range of morphosyntactic options available for expressing this contrast is broader than we think. It would be informative to understand what in general is possible within that range and what other features of a given language correlate with the use of a particular morphosyntactic option separating OC and NOC.

The differential analysis of the two control constructions proposed here brings together insights from work on semantic control in Korean (Cormack \& Smith 2002, 2004; Choe 2006) and syntactic analysis proposed by Monahan $(2003,2005)$. The semantic analysis correctly captures the non-obligatory control cases (ACC2), while the syntactic analysis is more appropriate for obligatory control because it does not need additional stipulations to handle active/passive synonymy (Monahan 2005, Kwon \& Polinsky 2006) or variable binding. 


\section{References}

Baek, J. Y.-K. \& J.-M. Lee (2004). Double object constructions in Korean: Asymmetry between theme and goal. Ohak Yon'gu/Language Research 40, 669-679.

Boeckx, C. \& N. Hornstein (2006). The virtues of control as movement. Syntax 9, 118-130.

Choe, H.-S. (2006). On (backward) object control in Korean. Harvard Studies on Korean Linguistics XI. Kyunggi: Hanshin Pub, 373-386.

Choi, H.-W. (2001). Binding and discourse prominence: Reconstruction in "focus" scrambling. In G. Legendre, J. Grimshaw \& S. Vikner (eds.), Optimality-Theoretic Syntax. Cambridge, Mass.: MIT Press, 143-169.

Chomsky, N. (1981). Lectures on government and binding. Dordrecht: Foris.

Cormack, A. \& N. Smith (2002). Compositionality, copy theory, and control. University College of London Working Papers in Linguistics 14, 355-373.

Cormack, A. \& N. Smith (2004). Backward control in Korean and Japanese. University College of London Working Papers in Linguistics 16, 57-83.

Fanselow, G. (2001). Features, $\theta$-roles, and free constituent order. Linguistic Inquiry 32, 405437.

Gamerschlag, T. (this volume). Semantic and structural aspects of complement control in Korean.

Hornstein, N. (2000). Move! A minimalist theory of construal. Oxford: Blackwell.

Hornstein, N. (2003). On control. In R Hendrick (ed.), Minimalist Syntax. Oxford: Blackwell, 6-81.

Hornstein, N. \& C. Boeckx (2004). Movement under control. Linguistic Inquiry 35, 431-452.

Jackendoff, R. \& P. Culicover (2003). The semantic basis of Control in English. Language 79, 517-556.

Johnston, J. \& I. Park (2001). Some problems with a lowering account of scrambling. Linguistic Inquiry 32, 727-732.

Kim, Y.-J. (2000). Subject/object drop in the acquisition of Korean: A cross-linguistic comparison. Journal of East Asian Linguistics 9, 325-351.

Kim, N.-K. (1978). Tolok sentential complements in Korean. In Papers in Korean Linguistics: Proceedings of the Symposium on Korean Linguistics. Columbia: Hornbeam Press, 137-147.

Kim, N.-K. (1984). The grammar of Korean complementation. Honolulu: Center for Korean Studies, University of Hawaii.

Ko, H. (2005). Syntactic edges and linearization. Ph.D. Diss., MIT.

Koster, J. (1984). On binding and control. Linguistic Inquiry 15. 417-459.

Kwon, N. \& M. Polinsky (2006). Object control in Korean: Structure and processing. JKL 15.

Kwon, N., M. Polinsky \& R. Kluender (2007). Processing of empty categories in Korean. MS.

Landau, I. (2003). Movement out of control. Linguistic Inquiry 34, 471-498.

Landau, I. (2004). The scale of finiteness and the calculus of control. Natural Language and Linguistic Theory 22, 811-877.

Landau, I. (2006). Severing the distribution of PRO from case. Syntax 9, 153-170.

Maling, J. \& S. Kim (1992). Case assignment in the inalienable possession construction in Korean. Journal of East Asian Linguistics 1, 37-68. 
Mazuka, R., K. Itoh \& T. Kondo (2002). Cost of scrambling in Japanese sentence processing. In M. Nakayama (ed.), Sentence processing in East Asian languages. Stanford: CSLI, 131-166.

Miyamoto, E. T. \& S. Takahashi (2002). Sources of difficulty in processing scrambling in Japanese. In M. Nakayama (ed.), Sentence processing in East Asian languages. Stanford: CSLI, 167-188.

Monahan, P. (2003). Backward object control in Korean. WCCFL 22, 356-369.

Monahan, P. (2005). Backward object control in Korean. Ms. University of Maryland.

Park, S-D. \& J. Whitman (2003). Direct movement passives in Korean and Japanese. In W. McClure (ed.) Japanese/Korean Lingustics 11. Stanford: CSLI, 307-321.

Polinsky, M. \& E. Potsdam (2002). Backward control. Linguistic Inquiry 33, 245-282.

Polinsky, M. \& E. Potsdam (2006). Expanding the scope of control and raising. Syntax 9, 171-192.

Potsdam, E. (2006). Backward object control in Malagasy: Against an empty category analysis. WCCFL 25, 328-336.

Saito, M. (2003). A derivational approach to the interpretation of scrambling chains. Lingua $113,481-515$.

Sells, P. (2005). Comments on object shift and cyclic linearization. Theoretical Linguistics 31, 185-198.

Sohn, H.-M. (2001). The Korean language. Cambridge Cambridge University Press

Tsoulas, G. (2004). On a binding-theoretic argument for base generation of long distance scrambling. York Papers in Linguistics, Series 2, 1, 223-236.

Ueno, M. \& R. Kluender (2003). Event-related brain indices of Japanese scrambling. Brain and Language 86, 243-271. 